\title{
O MERCADO DE REPOSIÇÃO DA PECUÁRIA BOVINA DE CORTE NO ESTADO DE SÃO PAULO
}

\author{
MARCOS MINORU HASEGAWA \\ Engenheiro Agrônomo
}

Orientador: Prof. Dr. GERALDO SANT'ANA DE CAMARGO BARROS

Dissertação apresentada à Escola Superior de Agricultura "Luiz de Queiroz", da Universidade de São Paulo, para a obtenção do título de Mestre em Agronomia, Área de Concentração: Economia Agrária.

PIRACICABA

Estado de São Paulo - Brasil

Dezembro - 1995 
Dados Internacionais de Catalogação na Publicação (CIP)

\section{DIVISÃo DE BIBLIOTECA E DOCUMENTAÇÃO - Campus “Luiz de Queiroz”iuSP}

Hasegawa, Marcos Minoru

O mercado de reposição da pecuária bovina de corte no Estado de São Paulo / Marcos Minoru Hasegawa. - - Piracicaba, 1995.

142p. : il.

Dissertação (Mestrado) - - Escola Superior de Agricultura Luiz de Queiroz, 1995.

Bibliografia.

1. Pecuária de corte - Aspecto econômico - São Paulo (Estado) I. Título

CDD 338.176213 


\title{
O MERCADO DE REPOSIÇÃO DA PECUÁRIA BOVINA DE CORTE NO ESTADO DE SÃO PAULO
}

\author{
MARCOS MINORU HASEGAWA
}

Aprovado em: 02.04.1996

Comissão Julgadora:

Prof. Dr. Geraldo Sant'Ana de Camargo Barros

ESALQ/USP

Prof. Dr. Joaquim Bento de Souza Ferreira Filho

ESALQ/USP

Prof. Dr. Danilo Rolim Dias de Aguiar

UFV

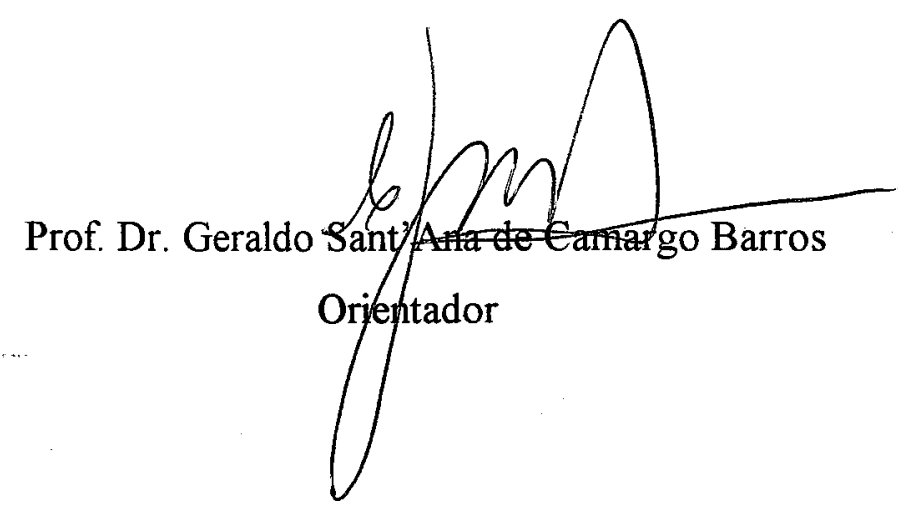


Dedico

a todos que trabalham com agricultura e

dela necessitam para sobreviver. 


\section{AGRADECIMENTOS}

Ao Departamento de Economia e Sociologia Rural da Escola Superior de Agricultura "Luiz de Queiroz" - USP pela minha formação em Economia Agrária.

Ao Prof. Dr. Geraldo Sant'Ana de Camargo Barros pela orientação, apoio e amizade.

Ao Centro de Pesquisas em Economia Agrícola da Fundação de Estudos Agrários "Luiz de Queiroz" pelo apoio que recebi durante todo o período de desenvolvimento do projeto de minha dissertação.

Às empresas leiloeiras Programa Leilões de Araçatuba e Bauru, Repique Leilões de Araçatuba, Tairana Leilões de Presidente Prudente e a Trajano Leilões cujas colaborações foram valiosíssimas nas partes desta pesquisa que tratam sobre os leilões.

Ao Prof.Dr. Rodolfo Hoffmann pelos meus conhecimentos em Econometria e pelas dicas sobre as ferramentas para o trabalho com séries temporais.

Aos colegas Maurício Vaz Lobo Bittencourt e Mirian Rumenos Piedade Bacchi pelo apoio recíproco e pelas intermináveis discussões sobre os ferramentais econométricos utilizados nesta pesquisa.

Ao Prof. Dr. Pedro Walls Pereira do IME-USP pelas dicas sobre o procedimento de Johansen e ao Pesquisador Hedibert Freitas Lopes do IPEA pelo fornecimento dos "softwares" usados para a realização do Procedimento de Johansen, bem como dicas, também, a respeito do procedimento de Johansen.

A todos os amigos que fiz ao longo do curso de Mestrado que são tão importante quanto os conhecimentos adquiridos em Economia Agrária.

A todos que direta ou indiretamente contribuiram para a realização desta pesquisa. 


\section{SUMÁRIO}

página

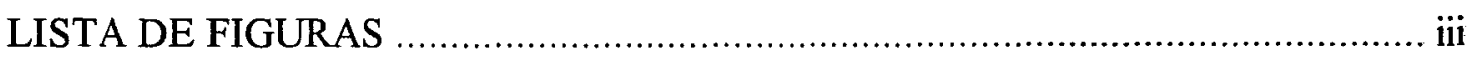

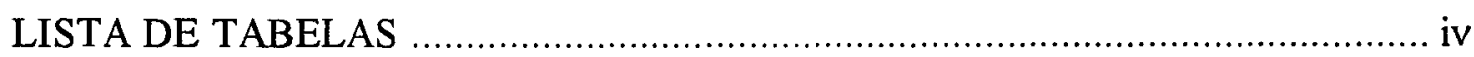

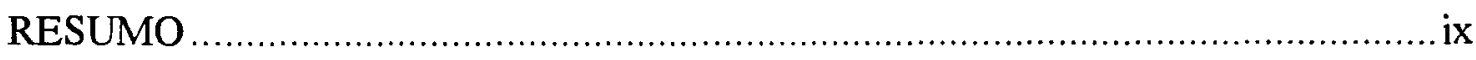

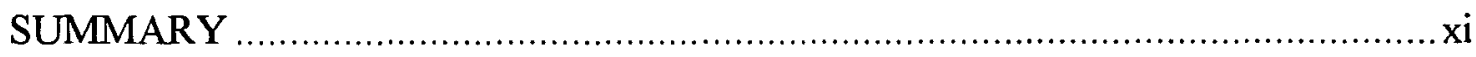

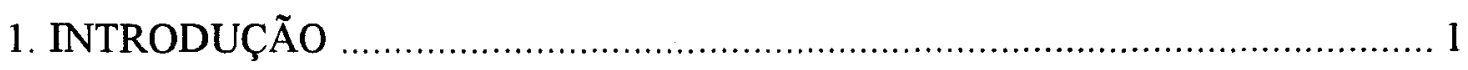

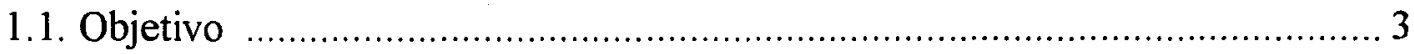

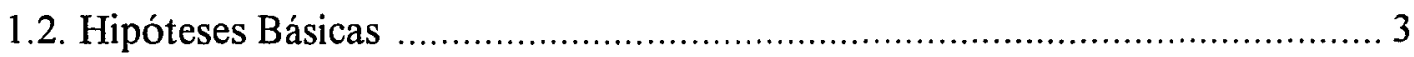

2. ALGUNS ASPECTOS DA PECUÁRIA BOVINA DE CORTE …..................... 5

2.1. A importância econômica da bovinocultura de corte ....................................... 5

2.2. A pecuária bovina de corte no estado de São Paulo ...................................... 8

2.3. Característica do processo produtivo ....................................................... 11

2.3.1. As etapas ou fases do processo produtivo ........................................... 11

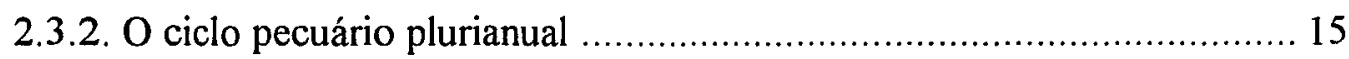

2.3.3. A popularização do leilão de gado geral ............................................. 19

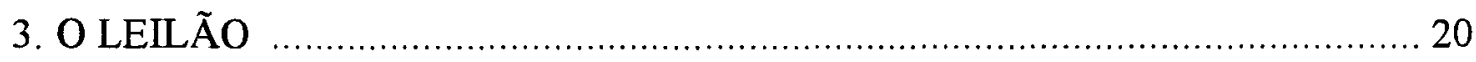

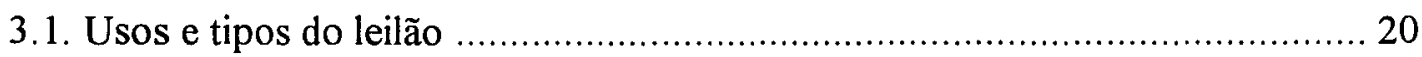

3.2. A origem do leilão de gado bovino no Brasil ........................................... 23

3.3. Caracterização do leilão de gado geral no Brasil ......................................... 25

3.4. Alguns aspectos teóricos relevantes para o leilão de gado bovino ................. 28

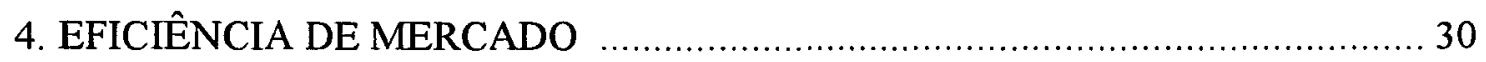

4.1. Arbitragem e eficiência de mercado ………................................................. 30

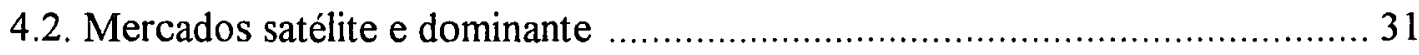

4.3. A questão da transmissão da informação preço ........................................... 32

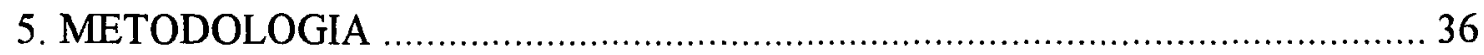




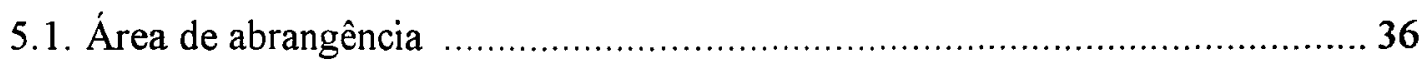

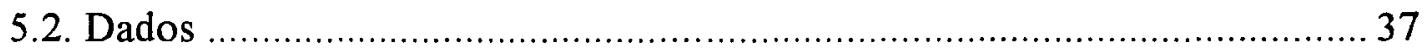

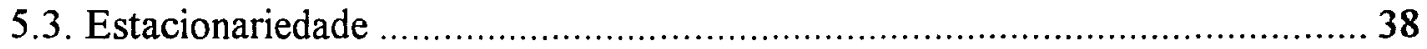

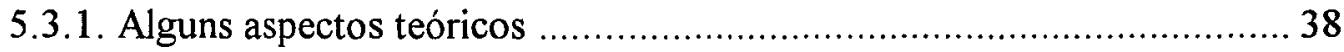

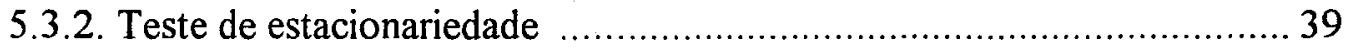

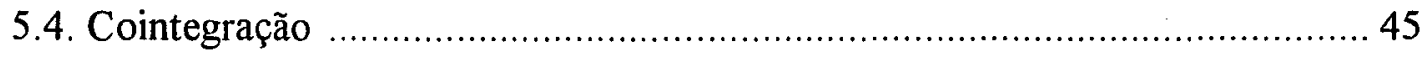

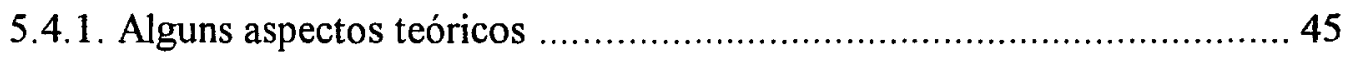

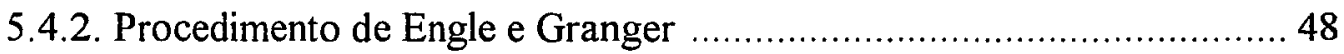

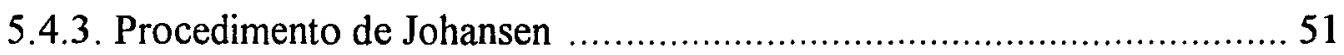

5.5. Modelo Autorregressivo Vetorial (VAR) ………..................................... 57

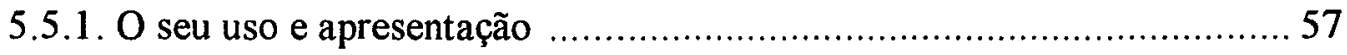

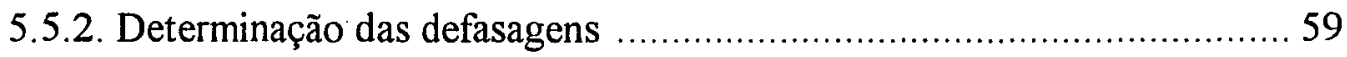

5.5.3. A função de resposta-impulso e a decomposição da variância .............. 62

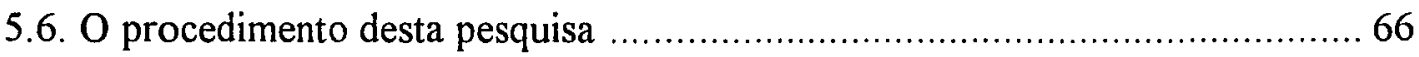

5.6.1. Sequência de trabalho para estimação do modelo VAR ……………..... 66

5.6.2. Alguns detalhes sobre a obtenção dos resultados ............................... 68

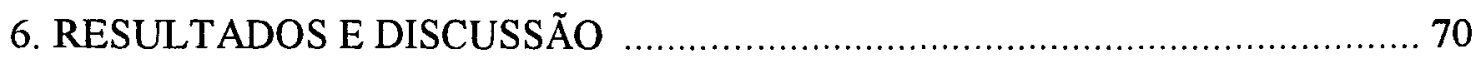

6.1. Categorias da Pecuária de Corte em São Paulo ……................................. 70

6.1.1. Alguns aspectos dos preços relativos ……..................................... 70

6.1.2. Teste de Integração e Cointegração ……………............................. 76

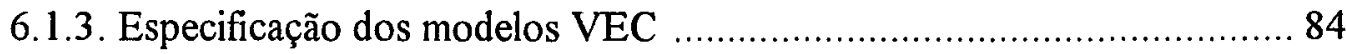

6.1.4. Análise dos resultados: junho de 1970 a junho de 1982 .................... 89

6.1.5. Análise dos resultados: junho de 1982 a maio de 1994 ...................... 98

6.1.6. Decomposição da variância no ciclo pecuário................................... 106

6.1.7. Comparação entre os períodos analisados ....................................... 111 


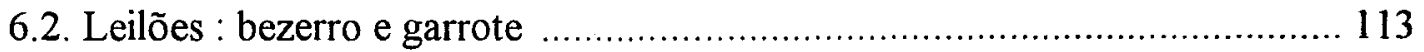

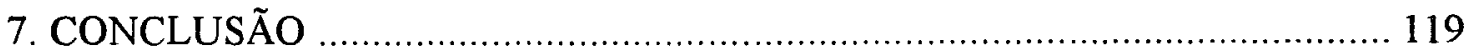

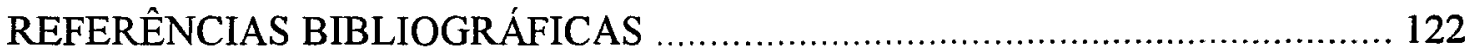

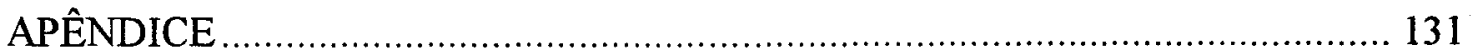

\section{LISTA DE FIGURAS}

$\mathrm{n}^{\circ}$

página

6.1.1 Preços do boi gordo e da vaca gorda em cruzeiros por arroba no estado de São Paulo para o período de junho de 1970 a maio de 1994

6.1.2 Preços do boi magro, garrote e bezerro em cruzeiros por unidade no estado de São Paulo para o período de junho de 1970 a maio de 1994

6.1.3 Relação de preços entre boi gordo e bezerro para o estado de São Paulo.

6.1.4 Relação de preços entre boi gordo e vaca gorda no estado de São Paulo.

6.1.5 Relação de preços entre boi gordo e boi magro no estado de São Paulo.

6.1.6 Relação de preços entre boi magro e garrote no estado de São Paulo .

6.1.7 Relação de preços entre boi magro e bezerro no estado de São Paulo.

6.1.8 Relação de preços entre garrote e bezerro no estado de São Paulo .....

6.1.9 Resposta aos impulsos quando há inovação na variável boi gordo no modelo VEC para o período de junho de 1970 a junho de 1982

6.1.10 Resposta aos impulsos quando há inovação na variável bezerro no modelo VEC para o período de junho de 1970 a junho de 1982 
6.1.11 Resposta aos impulsos quando há inovação na variável vaca gorda no modelo VEC para o período de junho de 1970 a junho de 1982 ......... 95

6.1.12 Respostas aos impulsos quando há inovação na variável garrote no modelo VEC para o período de junho de 1970 a junho de $1982 \ldots \ldots \ldots . \quad 96$

6.1.13 Respostas aos impulsos quando há inovação na variável boi magro no modelo VEC para o período de junho de 1970 a junho de $1982 \ldots \ldots \ldots .$.

6.1.14 Respostas aos impulsos quando há inovação na variável boi gordo no modelo VEC para o período de junho de 1982 a maio de 1994

6.1.15 Respostas aos impulsos quando há inovação na variável bezerro no modelo VEC para o período de junho de 1982 a maio de 1994

6.1.16 Respostas aos impulsos quando há inovação na variável vaca gorda no modelo VEC para o período de junho de 1982 a maio de 1994

6.1.17 Resposta aos impulsos quando há inovação na variável garrote no modelo VEC para o período de junho de 1982 a maio de 1994

6.1.18 Resposta aos impulsos quando há inovação na variável boi magro no modelo VEC para o período de junho de 1982 a maio de 1994

\section{LISTA DE TABELAS}

$\mathrm{n}^{\circ}$

página

2.1.1 Valores desagregados da produção animal e vegetal e suas respectivas percentagens no Brasil em 1985

2.1.2 Valores dos bovinos comprados e vendidos, desagregados de acordo com a finalidade do rebanho no Brasil em 1985 
2.1.3 Efetivo da pecuária bovina de acordo com a finalidade do rebanho no Brasil em 1985

2.1.4 Efetivo de bovinos nas grandes regiões e seus respectivos valores percentuais no Brasil em 1985

2.1.5 Efetivo de bovinos nas unidades federativas de maior relevância para a pecuária bovina de corte e seus respectivos valores percentuais no Brasil em 1985

2.2.1 Efetivo da pecuária bovina de acordo com a finalidade do rebanho no estado de São Paulo em 1985

2.2.2 Valores dos bovinos comprados e vendidos, desagregados de acordo com a finalidade do rebanho no estado de São Paulo em 1985

2.2.3 Efetivo da pecuária bovina de acordo com as mesorregiões e microrregiões no estado de São Paulo em 1985

2.3.1 Número de rebanhos de acordo com a finalidade dentro da pecuária bovina de corte no Brasil e no estado de São Paulo em 1985

6.1.1 Algumas relações de troca entre as categorias da pecuária bovina de corte para os períodos de junho de 1970 a junho de 1982, junho de 1982 a maio de 1994 e janeiro de 1990 a maio de 1994.

6.1.2 Teste Dickey-Fuller Expandido (ADF) e suas respectivas defasagens para determinação da ordem de integração das séries estudadas.

6.1.3 Relação das ordens definidas pelos critérios de Akaike (AIC), HannanQuinn (HQ) e Schwarz (SC) para cada combinação possivel do modelo nos períodos definidos na metodologia 
6.1.4 Teste traço e lâmbda máximo para o caso da não existência de tendência linear para cada período, considerando a inclusão e a não inclusão das variáveis binárias

6.1.5 Teste traço e lâmbada máximo para o caso da existência de tendência linear para cada periodo, considerando a inclusão e a não inclusão das variáveis binárias

6.1.6 Relações de cointegração relevantes para os casos de inclusão e não inclusão das variáveis binárias no modelo, em cada período, pressupondo a não existência da tendência linear.

6.1.7 Relações de cointegração relevantes para os casos de inclusão e não inclusão das variáveis binárias no modelo em cada período pressupondo a existência da tendência linear

6.1.8 Teste de razão de verossimilhança para verificação da importância da constante e das variáveis binárias no modelo a ser especificado para cada período

6.1.9 Decomposição da variância para a variável bezerro no modelo VEC para o período de junho de 1970 a junho de 1982

6.1.10 Decomposição da variância para a variável boi gordo no modelo VEC para o período de junho de 1970 a junho de 1982

6.1.11 Decomposição da variância para a variável boi magro no modelo VEC para o período de junho de 1970 a junho de 1982

6.1.12 Decomposição da variância para a variável garrote no modelo VEC para o período de junho de 1970 a junho de 1982

6.1.13 Decomposição da variância para a variável vaca gorda no modelo VEC para o período de junho de 1970 à junho de 1982 
vii.

6.1.14 Decomposição da variância para a variável bezerro no modelo VEC para o período de junho de 1982 a maio de 1994

101

6.1.15 Decomposição da variância para a variável boi gordo no modelo VEC para o período de junho de 1982 a maio de 1994.

6.1.16 Decomposição da variância para a variável boi magro no modelo VEC para o período de junho de 1982 a maio de 1994

103

6.1.17 Decomposição da variância para a variável garrote no modelo VEC para o período de junho de 1982 a maio de 1994 .

104

6.1.18 Decomposição da variância para a variável vaca gorda no modelo VEC para o período de junho de 1982 a maio de 1994

6.1.19 Decomposição da variância para a variável bezerro no modelo VEC para o período de junho de 1970 a novembro de 1973

6.1.20 Decomposição da variância para a variável boi gordo no modelo VEC para o período de junho de 1970 a novembro de 1973

6.1.21 Decomposição da variância para a variável boi magro no modelo VEC para o período de junho de 1970 a novembro de 1973

6.1.22 Decomposição da variância para a variável garrote no modelo VEC para o período de junho de 1970 a novembro de 1973

6.1.23 Decomposição da variância para a variável vaca gorda no modelo VEC para o período de junho de 1970 a novembro de 1973

6.1.24 Decomposição da variância para a variável bezerro no modelo VEC para o período de novembro de 1973 a junho de 1977.

6.1.25 Decomposição da variância para a variável boi gordo no modelo VEC para o período de novembro de 1973 a junho de 1977. 
viii.

6.1.26 Decomposição da variância para a variável boi magro no modelo VEC para o período de novembro de 1973 a junho de 1977

6.1.27 Decomposição da variância para a variável garrote no modelo VEC para o período de novembro de 1973 a junho de 1977

6.1.28 Decomposição da variância para a variável vaca gorda no modelo VEC para o período de novembro de 1973 a junho de 1977

6.2.1 Média, desvio padrão e número de observações dos preços semanais, em dólar por unidade, dos leilões por categoria, raça, sexo em Araçatuba de maio de 1991 a dezembro de 1993.

6.2.2 Média, desvio padrão e número de observações dos preços semanais, em dólar por unidade, dos leilões por categoria, raça e sexo em Bauru de maio de 1991 a dezembro de 1993.

6.2.3 Média, desvio padrão e número de observações dos preços semanais, em dólar por unidade, dos leilões por categoria, raça e sexo em Presidente Prudente de maio de 1991 a dezembro de 1993.

6.2.4 Teste " $F "$ da contribuição de cada variável e o coeficiente de determinação parcial, considerando todas as combinações quanto a variável dependente 


\section{O MERCADO de REPOSIÇÃo dA PECUÁRIA dE CORTE NO ESTAdo dE SÃo PAULO}

Autor: Marcos Minoru Hasegawa

Orientador: Prof. Dr. Geraldo Sant'Ana de Camargo Barros

\section{RESUMO}

O objeto de estudo desta pesquisa foi a formação de preços no mercado de animais de reposição da pecuária bovina de corte do estado de São Paulo. Estudou-se a eficiência do mercado de reposição e do mercado do boi gordo por meio da determinação do sentido, da intensidade e da duração da transmissão de preço entre as diferentes categorias. Complementarmente, foi analisada a importância do leilão na formação de preços no mercado de reposição, assim como as relações que existem entre as categorias comercializadas através desse canal de comercialização nas principais regiões do estado de São Paulo.

Para o estudo do mercado de reposição da pecuária de corte no estado de São de Paulo foi usado o modelo do vetor de correção de erros (VEC) que é basicamente o modelo auto-regressivo vetorial em diferença com vetores de correção dos erros. Este modelo foi usado para o mercado de reposição como um todo e por isso utilizou-se as séries de preços das categorias boi gordo, bezerro, vaca gorda, garrote e boi magro entre junho de 1970 e maio de 1994. Para a obtenção do modelo definitivo, foi testado através 
do procedimento de Johansen se as variáveis são cointegradas e se a constante e as variáveis binárias são relevantes para o modelo estimado. A ordem de integração de cada série foi verificada através do teste Dickey-Fuller Expandido (ADF). No caso dos leilóes, foram usadas apenas regressões lineares múltiplas para a determinação da contribuição de cada variável na explicação das demais. As séries de preços dos leilões foram analisadas mediante estatística descritiva.

Os resultados obtidos permitem concluir que as séries de preços dos mercados da pecuária de corte são cointegradas, o que equivale a dizer que os mercados da pecuária de corte são significativamente eficientes no conjunto. Os mercados de boi gordo e de bezerro são as fontes de variação dos preços para os demais, porque é melhor estruturado, possuem maior quantidade de informação e maior volume de comercialização. Analisando ambos os períodos, junho de 1970 a junho de 1982, e junho de 1982 a maio de 1994, pôde-se notar que o ciclo pecuário plurianual influenciou a relação entre os mercados da pecuária de corte. Além disso, o fluxo de informações entre os mercados aumentou do primeiro para o segundo período. No ciclo pecuário plurianual, o padrão do fluxo de informações entre os mercados muda. $\mathrm{Na}$ fase ascendente do ciclo, o segmento boi gordo domina os demais mercados como fonte da variação dos preços, enquanto que na fase descendente, as outras categorias passam a influenciar muito mais os outros mercados. Em relação aos leilões de Araçatuba, Bauru e Presidente Prudente não existe relação dominante-satélite. 


\title{
THE REPLACEMENT MARKET OF SLAUGHTER CATTLE IN SÃO PAULO STATE
}

\author{
Author: Marcos Minoru Hasegawa \\ Adviser: Prof. Dr. Geraldo Sant'Ana de Camargo Barros
}

\section{SUMMARY}

The object of study in this research was the price formation in replacement market for slaughter cattle of State of São Paulo. The efficiency of replacement market and fat cattle market was analysed by determining of direction, intensity and duration of price transmission between different animal categories.

In the study of replacement market of slaughter cattle in the State of São Paulo the vector error correction model (VEC), that is, the vector autoregression model in difference with error correction vectors, was used for several time series running from june'70 to may'94. The Johansen procedure was used to verify whether the variables are cointegrated and whether the constant and dummies variables are or not important in the estimated model.The integration order of each serie was verified by Dickey-Fuller augmented test (ADF). In the auction's study, multiple linear regressions were estimated to determine the contribution of each variable in other variables'explanation.

The price series of the slaughter cattle markets are cointegrated or, in others words, these markets are jointly efficient. The fat cattle market and the calf market are 
the main source of price variation affecting other categories because both are better structured, have better information and deal large volumes. The flow of information between markets increased from first period to second period, what is verified by response-impulse analysis. In both periods, june'70 to june' 82 and june' 82 to may'94, the pluriannual cattle cycle influenced the relationship between slaughter cattle markets. In the increasing phase of price cycle, the fat cattle dominates other categories as source of price variation, while in the decreasing phase, the other categories influence more intensively other markets. There is not dominant-sattelite relationships between Araçatuba, Bauru and Presidente Prudente auctions. 


\section{INTRODUÇÃO}

O processo produtivo da pecuária bovina de corte no estado de São Paulo tem sofrido algumas mudanças quanto às técnicas de manejo, tais como o confinamento e o cruzamento industrial, assim como na distribuição espacial das fases de cria, recria e engorda. De acordo com IGREJA (1987), houve um aumento das fases de cria e recria devido à erradicação do café nas regiões do oeste paulista que liberou área para a pastagem. Além disso, também houve um aumento da fase de engorda em áreas tipicamente agrícolas.

Outro fato importante é a crescente utilização do leilão para a comercialização dos animais de reposição da pecuária bovina de corte. Apesar de apenas uma parcela do volume comercializado passar pelos leilões, o leilão tem sido importante referencial para as negociações no mercado convencional ${ }^{1}$. MACHADO FILHO (1994) destaca que o leilão evoluiu muito, principalmente quando este serviço se popularizou no estado de São Paulo, e atualmente passa por um processo de amadurecimento no que diz respeito à relação entre as leiloeiras e os seus clientes. Apesar de o autor enfocar o ponto de vista do "marketing", ou seja, do leilão de animais de raça, aponta a necessidade de estudos com o intuito de analisar profundamente as conseqüências dos leilões na estrutura do sistema de comercialização de animais, comparando-se, por exemplo, a evolução das vendas realizadas em leilões com as feitas diretamente nas propriedades.

\footnotetext{
${ }^{1}$ Considera-se mercado convencional a parte do mercado de reposição que não passa pelo leilão, ou seja, entre compradores e vendedores individuais, diretamente ou através de intermediários.
} 
Sabe-se ainda que os mercados das categorias de reposição, assim como os mercados de boi gordo e de vaca, são bastante relacionados entre si através dos preços. Tal fato é verificado pelas análises realizadas por TOLEDO \& SANTIAGO (1984) e MASCOLO (1979). Ou seja, um impacto no mercado do boi gordo, por exemplo, afeta direta e/ou indiretamente as demais categorias em maior ou menor intensidade.

Considerando os fatos acima citados, torna-se interessante saber como ocorrem as relações de preços entre o mercado de reposição e o mercado do boi gordo, assim como as relações entre as regiões de predomínio pecuário. Outro aspecto importante e interessante de ser conhecido é a eficiência dos mercados separados espacialmente e dos leilões em relação ao mercado convencional. Será que a formação de preços nos leilões é mais eficiente ${ }^{2}$ que no mercado convencional? Existem vários trabalhos estrangeiros que estudam a questão da eficiência no processo da formação de preços através de análise dinâmica. BAILEY \& BRORSEN (1985), VAN TASSELL \& BESSLER (1988) e SCHROEDER \& GOODWIN (1990) associam a maior ou menor eficiência ao volume comercializado e à distância entre os mercados. BUCCOLA (1985) analisa a eficiência na formação de preços em mercados centralizado e não-centralizado e sugere que mercados centralizados são mais eficientes. KOONTZ et alii (1990) utilizam-se do conceito de mercados dominante e satélite para explicar as relações entre o mercados futuro e físico do boi gordo associado à questão da eficiência de mercado no processo de formação do preço de equilibrio. GOODWIN \& SCHROEDER (1991) avaliam as relações espaciais nos mercados regionais usando o teste de cointegração. WILLIAMS \& BEWLEY (1993) analisam a transmissão da informação de preços assim como a existência de oportunidades de arbitragem entre os leilões da região de Queensland na Austrália.

\footnotetext{
$2 \mathrm{O}$ conceito de eficiência que envolve questões relacionadas a oportunidades de lucro anormal, acesso a informações e a velocidade de ajustamento, será discutido no capítulo 4 .
} 


\subsection{Objetivo}

O principal objetivo desta pesquisa é estudar a formação de preços no mercado de animais de reposição da pecuária bovina de corte do estado de São Paulo.

Os objetivos específicos são:

- estudar a eficiência do mercado das diferentes categorias de reposição e do mercado do boi gordo mediante a determinação do sentido, da intensidade e da duração da transmissão de preço entre as diferentes categorias;

- analisar a importância do leilão na formação de preços no mercado de reposição, assim como as relações que existem entre as categorias comercializadas através desse canal de comercialização nas principais regiões do estado de São Paulo.

\subsection{Hipóteses Básicas}

a) O preço do boi gordo deve influenciar as cotações das categorias do mercado de reposição por ser formado em mercado de maior concentração;

b) Os mercados das categorias de reposição assim como o mercado do boi gordo devem ser eficientes ${ }^{3}$. Como as categorias são fases ou etapas do processo produtivo que leva ao boi gordo, espera-se que as fortes relações entre as categorias façam os preços nestes mercados variarem aproximadamente juntos;

c) Os sentidos das transmissões de preço entre as diferentes categorias podem mudar de padrão quando se passa da fase ascendente para a fase descendente do ciclo

\footnotetext{
${ }^{3}$ Vide nota de rodapé anterior.
} 
pecuário plurianual e vice-versa. Esta hipótese toma como base os trabalhos sobre a pecuária bovina de corte que destacam o abate das matrizes como a principal causa do ciclo plurianual. Isto equivale a dizer que o sentido do fluxo das informações sobre os preços seria do boi gordo para as demais categorias na fase ascendente do ciclo e das categorias do mercado de reposição para o boi gordo na fase descendente.

d) Não existem mercados regionais dominantes e satélites entre as três praças de leilões pesquisadas. A prática de arbitragem, comprando em um mercado regional e vendendo em outro, conduz a uma diferença de preços que corresponde ao custo de transporte. Esta hipótese está associada a análise dos leilões nas regiões definidas no capítulo 5. A fundamentação desta hipótese está no grande fluxo de informações que existe entre as três regiões, decorrente da disponibilidade e da facilidade dos meios de comunicação. Esta disponibilidade dos meios de comunicação permitem que os agentes de comercialização tenham o acesso as informações dos mercados de outras regiões quase em tempo real. 


\section{ALGUNS ASPECTOS DA PECUÁRIA BOVINA DE CORTE}

\subsection{A importância econômica da bovinocultura de corte}

A produção animal foi responsável por $31,80 \%$ do valor total da produção agropecuária brasileira em 1985, sendo que só os animais de grande porte foram responsáveis por $21,22 \%$ (tabela 2.1.1). Neste mesmo ano, o valor comercializado (vendido) de bovinos correspondeu a quase metade do valor da produção animal (tabelas 2.1.1 e 2.1.2). Os números, portanto, indicam que a pecuária bovina tem um peso significativo no setor agrícola brasileiro.

Dentro da pecuária bovina, a pecuária de corte representa $73,95 \%$ do total do efetivo de bovinos do país (tabela 2.1.3) e o valor dos bovinos vendidos para corte corresponde a $90,69 \%$ do valor total vendido (tabela2.1.2).

As regiões Centro-Oeste e Sudeste detêm mais da metade do rebanho bovino brasileiro (tabela 2.1.4). Os estados mais importantes são Minas Gerais, Mato Grosso do Sul, Goiás, Rio Grande do Sul e São Paulo. Os efetivos destes estados juntos equivale, também, a mais da metade do efetivo total de bovinos (tabela 2.1.5). 
Tabela 2.1.1 -Valores desagregados da produção animal e vegetal e suas respectivas percentagens no valor da produção agropecuária do Brasil em 1985

\begin{tabular}{lrr}
\hline \multicolumn{1}{c}{ valor da produção } & mil cruzados & \multicolumn{1}{c}{$\%$} \\
\hline Produção Animal & & \\
Animais de grande porte & 41.736 .857 & 21,22 \\
Animais de médio porte & 8.006 .817 & 4,07 \\
Aves e pequenos animais & 12.814 .301 & 6,51 \\
Sub-total & 62.557 .976 & 31,80 \\
Produção Vegetal & & \\
Lavouras & & \\
permanentes & 42.766 .514 & 21,74 \\
temporárias & 79.740 .406 & 40,54 \\
Horticultura e Floricultura & 2.759 .004 & 1,40 \\
Silvicultura & 4.568 .563 & 2,32 \\
Extração Vegetal & 4.313 .073 & 2,19 \\
Sub-total & 134.147 .562 & 68,20 \\
Valor total da produção agrícola & 196.705 .538 & \\
\hline
\end{tabular}

Fonte: Censo Agropecuário de 1985.

Tabela 2.1.2 - Valores dos bovinos comprados e vendidos, desagregados de acordo com a finalidade do rebanho no Brasil em 1985

\begin{tabular}{lrrrr}
\hline \multirow{2}{*}{ Finalidade } & \multicolumn{2}{c}{ Comprados } & \multicolumn{2}{c}{ Vendidos } \\
\cline { 2 - 5 } & \multicolumn{1}{c}{ valor $(1)$} & \multicolumn{1}{c}{$\%$} & \multicolumn{1}{c}{ valor $(1)$} & \multicolumn{1}{c}{$\%$} \\
\hline Corte & 10.793 .561 & 84,71 & 25.033 .216 & 90,69 \\
Cria & 2.027 .793 & 15,91 & 5.048 .114 & 18,29 \\
Recria & 1.603 .323 & 12,58 & 2.713 .944 & 9,83 \\
Engorda & 3.746 .474 & 29,40 & 7.261 .215 & 26,31 \\
Cria e Recria & 1.146 .279 & 9,00 & 3.711 .769 & 13,45 \\
Cria e Engorda & 375.226 & 2,94 & 1.054 .186 & 3,82 \\
Recria e Engorda & 850.830 & 6,68 & 1.720 .048 & 6,23 \\
Cria, Recria e Engorda & 1.043 .634 & 8,19 & 3.523 .937 & 12,77 \\
& & & & \\
Leite & 1.380 .229 & 10,83 & 957.962 & 3,47 \\
Corte e Leite & 404.621 & 3,18 & 1.214 .788 & 4,40 \\
Animais de trabalho e ignorada & 163.694 & 1,28 & 397.960 & 1,44 \\
Total & 12.742 .107 & & 27.603 .927 & \\
\hline
\end{tabular}

(1) - valor em mil cruzados

Fonte: Censo Agropecuário de 1985. 
Tabela 2.1.3 - Efetivo da pecuária bovina de acordo com a finalidade do rebanho no Brasil em 1985

\begin{tabular}{lrr}
\hline & & Efetivo \\
\cline { 2 - 3 } Finalidade & unidades & $\%$ \\
\hline Corte & 94.689 .528 & 73,95 \\
& & \\
Cria & 22.375 .255 & 17,47 \\
Recria & 9.916 .425 & 7,74 \\
Engorda & 16.278 .161 & 12,71 \\
Cria e Recria & 19.949 .609 & 18,58 \\
Cria e Engorda & 4.284 .154 & 3,35 \\
Recria e Engorda & 5.041 .467 & 3,94 \\
Cria, Recria e Engorda & 16.844 .457 & 13,16 \\
& & \\
Leite & 25.972 .763 & 20,28 \\
Corte e Leite & 6.929 .885 & 5,41 \\
Animais de trabalho e ignorada & 449.581 & 0,35 \\
Total & 128.041 .757 & \\
\hline
\end{tabular}

Fonte: Censo Agropecuário de 1985.

Tabela 2.1.4 - Efetivo de bovinos nas grandes regiões e seus respectivos valores percentuais no Brasil em 1985

\begin{tabular}{lrc}
\hline & \multicolumn{2}{c}{ Total do Efetivo } \\
\cline { 2 - 3 } Regiões & unidades & $\%$ \\
\hline Centro-Oeste & 36.116 .293 & 28,21 \\
Sudeste & 35.741 .876 & 27,91 \\
Sul & 24.826 .784 & 19,39 \\
Nordeste & 22.391 .193 & 17,49 \\
Norte & 8.965 .609 & 7,00 \\
Brasil & 128.041 .757 & \\
\hline
\end{tabular}

Fonte: Censo Agropecuário de 1985.

Tabela 2.1.5 - Efetivo de bovinos nas unidades federativas de maior relevância para a pecuária bovina de corte e seus respectivos valores percentuais no Brasil em 1985

\begin{tabular}{lrc}
\hline Unidades Federativas & \multicolumn{2}{c}{ Total do Efetivo } \\
\cline { 2 - 3 } & 19.983 .506 & $\%$ \\
\hline Minas Gerais & 15.017 .906 & 5,61 \\
Mato Grosso do Sul & 14.476 .565 & 11,73 \\
Goiás & 13.509 .324 & 11,31 \\
Rio Grande do Sul & 12.210 .369 & 10,55 \\
São Paulo & 9.315 .074 & 9,54 \\
Bahia & 8.574 .564 & 7,28 \\
Paraná & 6.545 .956 & 6,70 \\
Mato Grosso & 99.633 .564 & 5,11 \\
Sub-Total & 28.408 .493 & 77,81 \\
Outros Estados & & 22,19 \\
& 128.041 .757 & \\
Brasil & & \\
\hline
\end{tabular}

Fonte: Censo Agropecuário de 1985. 


\subsection{A pecuária bovina de corte no estado de São Paulo}

A região Sudeste possui $27,91 \%$ do total do efetivo de bovinos no Brasil (tabela 2.1.4), sendo que só o estado de São Paulo possui $9,54 \%$ ou 12.210 .369 unidades (tabela 2.1.5). Dentro da pecuária bovina paulista, o efetivo da pecuária de corte representa $67,93 \%$ do total e o valor dos bovinos vendidos para corte corresponde a $90,24 \%$ do valor total vendido no estado (tabelas 2.2 .1 e 2.2.2). Como verifica IGREJA(1987), as regiões de predomínio pecuário são Presidente Prudente, Araçatuba e São José do Rio Preto.

As regiões de Presidente Prudente e Araçatuba, que se localizam na região oeste do estado de São Paulo, são conhecidas como importantes praças do boi gordo. $\mathrm{Na}$ região de São José do Rio Preto a pecuária bovina se destaca como atividade predominante apesar do avanço das culturas da laranja e da cana-de-açucar. Barretos, na região de Ribeirão Preto (tabela 2.2.3), perdeu a importância que tinha como praça de comercialização de boi gordo. Atualmente, as culturas da cana-de-açucar e laranja são as atividades predominantes nesta região.

Entre as regiões tipicamente agrícolas que se destacam na pecuária bovina de corte colocam-se Bauru e Marília (IGREJA, 1987). 
Tabela 2.2.1 - Efetivo da pecuária bovina de acordo com a finalidade do rebanho no estado de São Paulo em 1985

\begin{tabular}{lrr}
\hline & & Efetivo \\
\cline { 2 - 3 } Finalidade & unidades & \multicolumn{1}{c}{$\%$} \\
\hline Corte & 8.294 .184 & $\mathbf{6 7 , 9 3}$ \\
Cria & 1.947 .013 & 15,95 \\
Recria & 996.652 & $\mathbf{8 , 1 6}$ \\
Engorda & 2.222 .798 & $\mathbf{1 8 , 2 0}$ \\
Cria e Recria & 1.221 .449 & 10,00 \\
Cria e Engorda & 434.425 & 3,56 \\
Recria e Engorda & 508.466 & 4,16 \\
Cria, Recria e Engorda & 963.381 & 7,89 \\
& & \\
Leite & 3.320 .320 & 27,19 \\
Corte e Leite & 592.394 & 4,85 \\
Animais de trabalho e ignorada & 3.471 & 0,03 \\
Total & 12.210 .369 & 100,00 \\
\hline
\end{tabular}

Fonte: Censo Agropecuário de 1985.

Tabela 2.2.2 - Valores dos bovinos comprados e vendidos, desagregados de acordo com a finalidade do rebanho no estado de São Paulo em 1985

\begin{tabular}{lcrrr}
\hline Finalidade & \multicolumn{2}{c}{ Comprados } & \multicolumn{2}{c}{ Vendidos } \\
\cline { 2 - 5 } & valor (1) & \multicolumn{1}{c}{$\%$} & valor (1) & \multicolumn{1}{c}{$\%$} \\
\hline Corte & 1.499 .818 & 85,29 & 3.089 .427 & 90,24 \\
& & & & \\
Cria & 239.737 & 13,63 & 559.619 & 16,35 \\
Recria & 217.448 & 12,36 & 330.720 & 9,66 \\
Engorda & 703.693 & 40,01 & 1.289 .434 & 37,66 \\
Cria e Recria & 92.048 & 5,23 & 305.531 & 8,92 \\
Cria e Engorda & 52.391 & 2,98 & 136.427 & 3,99 \\
Recria e Engorda & 102.841 & 5,85 & 208.994 & 6,10 \\
Cria, Recria e Engorda & 91.656 & 5,21 & 258.700 & 7,56 \\
& & & & \\
Leite & 201.099 & 11,44 & 153.535 & 4,48 \\
Corte e Leite & 47.045 & 2,68 & 139.091 & 4,06 \\
Animais de trabalho e ignorada & 10.618 & 0,60 & 41.418 & 1,21 \\
Total & 1.758 .580 & 100,00 & 3.423 .473 & 100,00 \\
\hline
\end{tabular}

(1) - valor em mil cruzados

Fonte: Censo Agropecuário de 1985. 
Tabela 2.2.3 - Efetivo da pecuária bovina de acordo com as mesorregiões e microrregiões no estado de São Paulo em 1985

\begin{tabular}{lrr}
\hline & & Efetivo \\
\cline { 2 - 3 } Mesorregiões e Microrregiões & unidades & \multicolumn{1}{c}{$\%$} \\
\hline Sudoeste Paulista & 6.601 .388 & 54,06 \\
Alta Sorocabana de P. Prudente & 1.557 .007 & 12,75 \\
Alta Noroeste de Araçatuba & 1.034 .896 & 8,48 \\
Bauru & 861.232 & 7,05 \\
Nova Alta Paulista & 561.514 & 4,60 \\
Alta Paulista (Região de Marilia) & 532.404 & 4,36 \\
Outras & 2.054 .335 & 16,82 \\
& & \\
Alta e Média Araraquarense & 2.255 .432 & 18,47 \\
Alta Araraquarense Fernandópolis & 603.622 & 4,94 \\
São José do Rio Preto & 412.226 & 3,38 \\
Divisor São José Dourados-Tietê & 336.991 & 2,76 \\
Outras & 1.225 .861 & 7,39 \\
& & \\
Campinas e Ribeirão Preto & 1.794 .866 & 14,70 \\
Araraquara & 364.118 & 2,98 \\
Barretos & 204.887 & 1,68 \\
Outras & 1.225 .861 & 10,04 \\
Outras Mesorregiões & & 12,77 \\
Total & 1.558 .683 & 100,00 \\
\hline Font: Censo Agropecuá & \\
\hline
\end{tabular}

Fonte: Censo Agropecuário de 1985.

\subsection{Características do processo produtivo}

Há certas peculiaridades da pecuária bovina que são importantes para se entender o comportamento do mercado de reposição de animais, assim como do mercado de animais para abate. Este compreende, basicamente, boi gordo, vaca de descarte e matriz. Uma breve caracterização destas peculiaridades é feita a seguir. 


\subsubsection{As etapas ou fases do processo produtivo}

\section{Cria}

A fase de cria, segundo ZIMMER (1993) visa a produção de bezerros' ${ }^{1}$, ou seja, envolve a reprodução.

O período do nascimento à desmama constitui a fase mais importante da vida do animal em relação ao crescimento, pois o bezerro de corte consegue, em sete meses, atingir cerca de 25 a $35 \%$ do seu peso final de abate, enquanto que, para completar o restante do seu desenvolvimento, deverá precisar de mais trinta a quarenta meses, em média (PEIXOTO, 1993).

A etapa de cria destaca-se pelo grau elevado de atomização (OLIVEIRA, 1991) e grande mobilização de estoques de terras e rebanho em relação a seu produto final, o bezerro (DIAS, 1972). De acordo com OLIVEIRA (1991), o ciclo de produção é longo, variando de dois a três anos e o nível tecnológico é baixo, o que explica, em grande parte, o baixo índice de natalidade e o elevado índice de mortalidade.

Os criadores, através da produção de bezerros, são responsáveis pela manutenção da taxa de crescimento do rebanho e pela determinação da oferta de animais para reposição.

\section{Recria}

A fase de recria, segundo ZIMMER (1993), envolve a fase de desmama dos seis a oito meses até o início da reprodução das fêmeas e o início da terminação nos machos.

\footnotetext{
${ }^{1}$ Bezerro é a denominação para os bovinos cuja idade está entre zero e seis a oito meses quando são desmamados, ou melhor, separados da mãe (ZIMMER, 1993 p.246). De acordo com os técnicos da Coordenadoria de Assistência Técnica Integral (CATI), 84,46\% dos estabelecimentos agropecuários paulistas realizam a desmama entre os sete e dez meses de idade (CATI, 1985).
} 
De acordo com os técnicos da Coordenadoria de Assitência Técnica Integral (CATI), metade das fazendas de cria e de cria-recria, castra os machos para comercialização e a totalidade das empresas de engorda e de cria-recria-engorda castra os bovinos machos. Além disso, $82 \%$ dos animais são castrados antes dos vinte meses de idade e $50 \%$ na época de desmama, ou seja, até os doze meses (CATI, 1985). Os produtos finais desta fase do processo produtivo são a novilha e o novilho².

A etapa de recria caracteriza-se por apresentar baixo nível de organização e mobilização de estoques de terras e rebanho ajustados e proporcionais aos seus produtos finais, o novilho e a novilha. O ciclo de produção é de um ano e meio aproximadamente. O nível tecnológico é baixo o que afeta marginalmente os recriadores por trabalharem, geralmente, apenas com animais do sexo masculino e em idade de maior resistência a doenças e subnutrição. Isto equivale a dizer que não há problemas de natalidade e o índice de mortalidade é menor. Este segmento tem, ainda, a função de aglutinar o rebanho pulverizado entre os criadores, facilitando sua comercialização aos invernistas, bem como manter o bezerro adquirido até tornar-se novilho (OLIVEIRA, 1991).

\section{Engorda}

Segundo ZIMMER (1993), a engorda ou terminação é a fase que visa a obtenção de bons ganhos de peso por animal, para que se tenha bom e rápido acabamento para o abate. Esta fase envolve novilhos, bois adultos e fêmeas de descarte.

$\mathrm{Na}$ região centro-oeste e parte da região sudeste, os melhores preços têm ocorrido no período da seca (geralmente, nos meses de setembro e outubro) que corresponde ao período da entressafra da pecuária bovina de corte. Parte dos pecuaristas

\footnotetext{
${ }^{2} \mathrm{O}$ novilho é, também, chamado de garrote que difere do boi magro por ainda não ser castrado.
} 
que trabalha com a fase de engorda (chamados de invernistas) abate os seus animais na entressafra via manutenção do peso corpóreo, através do manejo da pastagem e do controle da sua lotação de animais. Uma outra forma de abater os animais na entressafra é o uso do confinamento. A sua desvantagem é o fato do lucro ou prejuizo depender do nível de preço do boi gordo na entressafra, pois, de acordo com TOLEDO \& SANTIAGO (1984), nem sempre os preços conseguidos na entressafra têm proporcionado lucro positivo aos confinadores. Ou seja, existe um risco significativo associado ao preço do boi gordo na técnica do confinamento.

De acordo com OLIVEIRA (1991), na fase de engorda o lucro é fundamentado na grande liquidez do capital e no ganho de peso de animais, ou seja, é a etapa que melhor remunera o capital. A fase de engorda possui um razoável grau de organização e é a mais tecnificada do processo produtivo.

\section{A verticalização}

O quarto ator ou grupo do processo produtivo é representado por aqueles que verticalizam total ou parcialmente as três fases ou etapas do processo. Trata-se de um grupo bastante reduzido de produtores, uma vez que as condições presentes dificilmente convergem para esta integração. Fatores associados a terra, como a localização, qualidade e preço, concorrem favoravelmente para a especialização em apenas uma das etapas do processo produtivo. Também atuam no mesmo sentido os condicionamentos culturais e outros de natureza econômica, gerados pela necessidade de realização de fluxo mensal de receita para giro e/ou manutenção do proprietário. Um exemplo disto é o enorme contigente de pequenos "criadores" que, concomitantemente, realizam a função típica de reprodução da pecuária bovina e da produção leiteira mesmo através da 
exploração de rebanhos com baixa aptidão genética e com insatisfatórias condições de manejo e nutrição. Ao realizar a produção de leite, estes obtém o rendimento mensal. E ao realizar a reprodução da pecuária através da venda de bezerros, os pequenos "criadores" obtém o rendimento anual (OLIVEIRA, 1991).

\section{Distribuição geográfica das etapas do processo produtivo}

MARQUES \& AGUIAR (1993) destacam, ainda, que a distribuição geográfica das etapas ou fases do processo produtivo da pecuária bovina de corte segue um padrão ditado pelos custos de transporte e pelo valor das terras. Em geral, as atividades de cria e recria são feitas em áreas mais afastadas dos centros consumidores, enquanto a engorda é realizada mais próxima desses centros. É comum no Brasil produtores que têm propriedades na região Centro-Oeste (região de terras mais baratas e afastadas dos principais centros consumidores) e na região sudeste (onde as terras são mais caras e próximas dos centros de consumo), realizando cria e recria na primeira região e engorda na segunda. Portanto, o reduzido número do quarto ator que verticaliza parcial ou totalmente as etapas do processo produtivo está relacionado com a distribuição geográfica destas etapas.

De acordo com IGREJA (1987), no estado de São Paulo o rebanho nas fases de cria e a recria teve um crescimento em relação ao rebanho na fase de engorda. Além disso, houve uma diminuição da área de pastagem do estado, especificamente nas regiões tipicamente agrícolas. Mas, mesmo assim, as regiões de Presidente Prudente, Araçatuba e São José do Rio Preto continuam sendo as mais importantes nesta atividade. De acordo com este mesmo autor, a erradicação do café no final da década de sessenta 
nas regiões do oeste paulista, entre as quais as citadas anteriormente e as regiões de Bauru e Marília, liberou áreas que foram convertidas em pastagem.

\subsubsection{O ciclo pecuário plurianual}

\section{O caráter biológico do processo produtivo}

O ciclo pecuário plurianual se constitui numa das características mais marcantes da bovinocultura de corte. Além das variações sazonais ou estacionais de preços e quantidade que ocorrem ao longo de um ano agrícola de forma esperada entre os períodos "das águas" e "da seca", existem movimentos cíclicos nos preços com período de aproximadamente seis anos (IGREJA, 1987).

A pecuária bovina de corte, assim como todas as atividades agrícolas, tem um caráter biológico no seu processo produtivo que a diferencia das outras atividades, como as industriais e as comerciais. Desta forma, qualquer mudança no processo produtivo ocorrerá, efetivamente, decorrido um certo período de tempo. Esta característica revelase no período de seis a sete anos que é necessário para o nascimento de uma matriz até o abate da sua primeira cria (HADDAD, 1993; MARQUES \& AGUIAR, 1993; SUMA AGRÍCOLA, 1987). Este caráter biológico na atividade agropecuária também mostra-se através do caráter ineslástico da oferta da maioria dos seus produtos (MARQUES \& AGUIAR, 1993). 


\section{A composição da oferta e o desequilíbrio entre os grupos}

MASCOLO (1979), MULLER (1987) e OLIVEIRA (1991) destacam que a estrutura da oferta e a dinâmica das relações entre os quatros grupos do processo produtivo são importantes para compreender o ciclo pecuário plurianual. A oferta de carne bovina é composta pelo abate de boi gordo e de vacas, sendo que o abate destas envolve tanto matrizes como vacas de descarte. Mas a oferta originária do abate de matrizes é a principal componente da variação cíclica, pois a oferta proveniente do abate de boi gordo e animais de descarte não compromete a oferta futura.

Entre os grupos do processo produtivo, verifica-se a existência de um desbalanceamento do poder de barganha entre as atividades de cria, recria e engorda, associado ao nível de concentração que se reflete no processo de formação de preço da carne bovina (OLIVEIRA, 1991). A fase de cria tem um número de rebanho 4,1 vezes maior que a etapa de engorda no Brasil todo, sendo que no estado de São Paulo esta relação é de 2,58 (tabela 2.3.1). Ou seja, a fase de engorda é bem mais concentrada que as outras fases do processo produtivo e suas combinações.

Tabela 2.3.1 - Número de rebanhos de acordo com a finalidade dentro da pecuária bovina de corte no Brasil e no estado de São Paulo em 1985

\begin{tabular}{lcrrr}
\hline & \multicolumn{2}{c}{ Brasil } & \multicolumn{2}{c}{ São Paulo } \\
\cline { 2 - 5 } Finalidade & $\mathrm{n}^{\mathrm{o}}$ & $\%$ & $\mathrm{n}^{\mathrm{0}}$ & $\%$ \\
\hline & & & & \\
cria & 584.422 & 45,49 & 28.836 & 43,04 \\
recria & 231.598 & 18,03 & 12.974 & 19,36 \\
engorda & 142.465 & 11,09 & 11.194 & 16,71 \\
cria e recria & 193.346 & 15,05 & 7.530 & 11,24 \\
cria e engorda & 36.274 & 2,82 & 1.917 & 2,86 \\
recria e engorda & 23.943 & 1,86 & 1.691 & 2,52 \\
cria, recria e engorda & 72.676 & 5,66 & 2.863 & 4,27 \\
Total & & & & \\
\hline
\end{tabular}

Fonte: Censo Agropecuário de 1985. 


\section{O ciclo propriamente dito}

O ciclo pecuário plurianual é descrito por vários autores, entre os quais DIAS (1972), MULLER (1987), IGREJA (1987), KASSOUF (1988), OLIVEIRA (1991), MARQUES \& AGUIAR (1993) e HADDAD (1993). OLIVEIRA (1991) relaciona o ciclo pecuário com a elasticidade-preço negativa da oferta de animais para abate. A elasticidade-preço da oferta de animais para abate no curto-prazo é negativa devido a uma maior retenção de vacas ante uma variação do preço da carne. Tal fato foi constatado por LATTIMORE (1974) para o Brasil, por PLOUVIER MONTEMURRO (1979) para o Uruguai e por Yver $(1971)^{3}$ citado por PLOUVIER MONTEMURRO (1979) para a Argentina.

O ciclo pecuário é basicamente composto por duas fases nos quais o preço do boi gordo tem comportamentos opostos, ou seja, uma fase de queda continua do preço do boi gordo e a outra de aumento contínuo do mesmo. Na fase descendente do ciclo cria-se uma expectativa pessimista em relação a queda do preço do boi gordo por todas as etapas do processo produtivo. A etapa de cria do processo, diferentemente das outras duas etapas, é a que mais sente o efeito da queda do preço do boi gordo por ser a responsável pela reposição de animais. Para diminuir o prejuízo, o criador abate as suas matrizes $^{4}$ que deixam de produzir os bezerros e bezerras que iriam repor os animais do rebanho bovino de corte. $\mathrm{O}$ abate das matrizes provoca a diminuição da oferta dos animais de reposição e o aumento da oferta de animais para abate que diminui ainda mais o preço do boi gordo. No momento que a oferta de boi gordo diminui devido a menor

\footnotetext{
${ }^{3}$ YVER, R.E. The investment behavior and the supply response of the cattle industry in Argentina. Chicago, 1971. (Ph.D. - University of Chicago)

${ }^{4}$ Embora não exista diferenciação de preços para o consumidor final, o boi gordo e a vaca gorda têm valorações diferentes na venda para o abate. $O$ preço da vaca gorda parece ter comportamento muito semelhante ao do boi gordo que pode ser explicado pela mesma finalidade, ou seja, produção de carne.
} 
disponibilidade de animais de reposição, ocorre a reversão da expectativa em relação ao preço do boi gordo por todas as etapas do processo produtivo. Com isso inicia-se a fase ascendente do ciclo pecuário. Nesta fase, o criador inicia a retenção das suas matrizes para suprir a falta de animais de reposição do rebanho bovino, diminuindo a oferta de animais para abate que aumenta ainda mais o preço da carne para o consumidor final. Nesta fase os criadores geralmente conseguem recuperar o prejuízo da fase descendente do ciclo. $\mathrm{O}$ ciclo fecha com a reversão das expectativas em relação ao preço do boi gordo que ocorre com aumento da oferta de animais para abate, decorrente do aumento da oferta de animais de reposição do rebanho bovino. Com a reversão das expectativas, inicia-se uma fase descendente de um novo ciclo.

Desta forma, a ocorrência do ciclo pecuário plurianual se deve ao fato da vaca ser considerado simultaneamente como bem de capital assim como bem de consumo (LATTIMORE,1974; PLOUVIER MONTEMURRO,1979). Ou seja, a fêmea serve tanto para gerar bezerros, repondo os animais do rebanho, como para o abate.

PLOUVIER MONTEMURRO (1979), destaca que a baixa resposta da oferta de vacas pelos criadores à uma variação do preço do animal para abate é devido a esta dupla finalidade que as fêmeas possuem e ao ciclo de produção mais longo da fase de cria em relação a fase de engorda, associado a especialização das fases do processo produtivo. Tal aspecto parece também ser válido para a pecuária bovina brasileira, pois a pecuária bovina de corte uruguaia é muito parecida com a pecuária bovina de corte brasileira.

Como o ciclo pecuário plurianual é tido como prejudicial tanto para o criador como para o consumidor final, muitos autores sugerem algumas medidas com a finalidade de diminuir a amplitude e a duração do ciclo. HADDAD (1993), por exemplo, sugere como principais medidas anticíclicas: a) programas que visem estimular a precocidade dos animais pois quanto maior a precocidade menor será a duração do ciclo pecuário; b) 
programas de incentivo à retenção de matrizes, procurando evitar o abate descontrolado de ventres e, em conseqüência, a futura escassez de boi gordo.

\subsubsection{A popularização do leilão de gado geral}

Nestes últimos cinco anos, o leilão ganhou espaço como canal de comercialização entre as fases ou segmentos do processo produtivo da pecuária bovina de corte. O leilão, como canal de comercialização, pode ser muito interessante do ponto de vista do criador, pois aumentaria o poder de barganha do grupo ou segmento menos organizado no mercado de animais de reposição. De acordo com o clássico modelo de análise da organização industrial que pode ser visto em SCHERER (1970), ao alterar a estrutura do mercado novas condutas são adotadas pelas empresas e o desempenho do mercado também se altera. Ou seja, ao reunir em um local determinado mercadorias e seus potenciais compradores, quebrar-se-ia o poder de oligopsônio, pois seria possível ofertar a um maior número de compradores simultaneamente, aumentando a concorrência. Além disso, os participantes estariam melhor informados sobre os preços. Os criadores vendedores, representados pelo leiloeiro, teriam a possibilidade de, assim, extrair uma parte do excedente do consumidor (ou, melhor, do comprador) recebendo preços mais altos que aqueles recebidos na negociação individual no próprio estabelecimento. Apesar de não haver estudo sobre leilões na pecuária bovina de corte brasileira dedicado a estas questões, este canal de comercialização parece ter um grande potencial para melhorar a distribuição de renda no setor e tornar a oferta de animais de reposição mais elástica à variação do preço, além de diminuir a margem de comercialização das etapas mais organizadas do processo produtivo. 


\section{0 LEILÃO}

\subsection{Usos e tipos do leilão}

O esquema e a conduta dos leilões como instituição têm ocupado a atenção de várias pessoas há milhares de anos. O relato mais antigo de um leilão foi feito pelo historiador grego Herodotus que descreveu a venda de mulheres para esposa na Babilônia, por volta do ano 500 a.C. Durante os últimos anos do império romano, o leilão do produto proveniente dos saques era comum. $\mathrm{Na}$ China, os pertences pessoais de monges budistas falecidos eram vendidos em leilão desde o século sete (MILGROM \& WEBER, 1982).

Atualmente, vários tipos de mercadorias são vendidas através do leilão, entre os quais: trabalho de arte, livros, antiguidades, produção agrícola, direito de exploração mineral, papéis do tesouro nacional, etc.(Cassady, $1967^{1}$ citado por McAFEE \& McMILLAN, 1987). Na produção agrícola tem-se, como exemplo, o tabaco no Canadá, peixe em Israel, flores na Holanda e no Brasil e animais da pecuária em vários países como Estados Unidos, Argentina, Uruguai e Brasil.

O leilão é uma instituição de mercado com um conjunto explícito de regras que determina a alocação de recursos e preços com base nos lances provenientes dos participantes do mercado. Apesar do leilão ser normalmente conhecido como uma venda

\footnotetext{
${ }^{1}$ CASSADY Jr., R. Auctions and auctioneering. Berkeley: University of California Press, 1967.
} 
pública na qual artigos são vendidos para a pessoa que faz o maior lance, o termo leilão é usado tanto para venda como para compra, sendo que no caso da compra o critério de escolha é o menor lance. Cassady (1967) citado por McAFEE \& McMILLAN (1987), argumenta que um dos motivos de se usar os leilões em lugar de fixar um preço, por exemplo, é o fato de alguns produtos não terem um valor padrão, ou seja, pelo fato de não se saber o preço do artigo ou mercadoria.

Vários trabalhos fazem uma descrição dos tipos de leilão existentes, entre os quais LOOMES (1989), McAFEE \& McMILLAN (1987) e MILGROM \& WEBER (1982). Há quatro tipos básicos usados quando um único item ou mercadoria é comprado ou vendido: o leilão inglês, também chamado de leilão oral, leilão aberto, ou leilão de lances ascendentes; o leilão holandês, também chamado de leilão de lances descendentes; o leilão de lance fechado do primeiro preço; e o leilão de lance fechado do segundo preço, também chamado de leilão de Vickrey² .

O leilão inglês é a forma de leilão mais comum usada para venda de mercadorias. Neste tipo de leilão, o preço é sucessivamente aumentado até que apenas um lance permaneça. Isto pode ser feito através de um leiloeiro que obtém os lances dos compradores e anuncia ao público o maior lance corrente, ou através dos lances feitos oralmente entre os compradores sem a atuação do leiloeiro, ou através de lances submetidos eletronicamente com o registro do melhor lance corrente. A característica essencial do leilão inglês é o conhecimento de cada um dos compradores, a qualquer momento do leilão, do melhor lance corrente. Antiguidades e trabalhos de arte são geralmente vendidos através do leilão inglês. No Brasil, o uso do leilão inglês é muito

\footnotetext{
2 VICKREY (1961), além de estabelecer a equivalência entre o leilão inglês e o leilão do lance fechado do segundo preço e leilão holandês e o leilão de lance fechado do primeiro preço, é um marco na pesquisa sobre a teoria do leilão.
} 
comum na venda dos animais de reposição, de elite e reprodutores da pecuária, principalmente a bovina de corte.

O leilão holandês é o inverso do leilão inglês. O leiloeiro dá um preço inicial alto $\mathrm{e}$ então o diminui sucessivamente até que um comprador aceite o preço corrente. De acordo com McAFEE \& McMILLAN (1987), o leilão holandês é usado para venda de flores na Holanda, peixe em Israel, e tabaco no Canadá. No Brasil, o leilão holandês é usado na comercialização de flores pela Cooperativa Agro-pecuária Holambra.

No caso do leilão de lance fechado do primeiro preço, cada comprador potencial faz um lance fechado e a mercadoria é adquirida pelo comprador que faz o lance mais alto. A diferença básica entre o leilão inglês e este tipo de leilão é que, no leilão inglês, os compradores são capazes de observar os lances dos seus rivais e, desta forma, revisar os seus próprios lances. No caso do leilão de lance fechado cada comprador pode propor somente um lance. Este tipo de leilão é usado pelo governo americano para leiloar os direitos de exploração mineral nas suas terras assim como para contratos de aquisição (McAFEE \& McMILLAN, 1987).

No caso do leilão de lance fechado do segundo preço, os compradores fazem os lances fechados sendo que o lance mais alto define o comprador que fica com a mercadoria e o segundo maior lance define o valor a ser pago. Apesar deste tipo de leilão ter propriedades teóricas úteis, raramente é utilizado na prática.

Há inumeras variações destes quatro tipos de leilões que são utilizadas na prática. Em alguns casos, por exemplo, os vendedores impõe um preço de reserva para descartar todos os lances que são muito baixos (Cassady, 1967 citado por McAFEE \& McMILLAN, 1987). No leilão inglês, o leiloeiro pode indicar um incremento mínimo 
aceitável para a elevação dos lances ( Yamey, $1972^{3}$ citado por McAFEE \& McMILLAN, 1987).

\subsection{A origem do leilão de gado bovino no Brasil ${ }^{4}$}

Ao contrário do que geralmente se pensa, a origem do leilão de gado geral no Brasil está associada aos criadores gaúchos e não aos leilões de obras de artes e antiguidades. O leilão de gado foi introduzido no Rio Grande do Sul na década de quarenta pelos uruguaios que vinham prestar o serviço aos criadores gaúchos. No Uruguai e Argentina o leilão tem mais de um século de história como processo de comercialização do gado. De acordo com SILVA ${ }^{5}$, o leiloeiro, atuava em cima de seu próprio cavalo, nas encruzilhadas da região fronteiriça entre Brasil e Uruguai ${ }^{6}$. A partir da década de sessenta, os leilões passaram a ser feitos nas propriedades, inicialmente na região de Bagé (RS) e depois nas demais. Desta forma, o início dos anos sessenta é considerado o marco inicial dos leilões de gado no Brasil como prestação de serviço. A efetiva popularização do leilão no Rio Grande do Sul ocorreu a partir de 1970 através da implantação da feira de terneiro pelo governo estadual.

A partir do exemplo do Rio Grande do Sul, o leilão de gado para criação, associado a feira de bezerro, foi introduzido no Paraná e em Minas Gerais na década de setenta. A Empresa de Assistência Técnica e Extensão Rural (EMATER) assim como a Secretaria da Agricultura destes dois estados tiveram um papel muito importante na

3 YAMEY, B. S. Why L $\$ 2,300,000$ for a Velasquez? An Auction Bidding Rule. Journal of Political Economy, 80(6): 1323-1327, nov./dez. 1972.

${ }^{4}$ Esta seção foi elaborada com base nas comunicações pessoais do vice-presidente do Sindicato Nacional das Empresas Leiloeiras e diretor da Trajano Leilões, Oswaldo Silva , do leiloeiro da Tairana Leilões, Omar Fayad e do técnico da Fundação de Estudos Agrários Luiz de Queiróz, Sérgio De Zen.

${ }^{5}$ SILVA, Osvaldo. (Trajano Leilões - Rua Firmino Vieira de Matos, 1070 - CEP:79825-050 Dourados MS.) Comunicação Pessoal. 1994.

${ }^{6}$ De acordo com SILVA, Eudócio Correa foi o leiloeiro pioneiro na região fronteiriça entre Brasil e Uruguai. 
divulgação e popularização do leilão como forma de comercialização do gado. Por isso, o leilão teve um grande impulso no pais depois da sua introdução nestes dois estados.

No sul do Paraná, onde o frio é um fator limitante à criação, o leilão representou uma forma prática e dinâmica de se vender os seus animais para os criadores do norte do Paraná que possuem condições climáticas mais favoráveis, segundo $\mathrm{FAYAD}^{7}$. A região de Guarapuava se destacava no comércio de gado através dos leilões. Apesar do estado de Santa Catarina estar ao lado do Rio Grande do Sul, o uso do leilão na comercialização do gado no estado catarinense foi introduzido depois da introdução no Paraná.

Em Minas Gerais, o leilão de gado, também associado à feira de bezerros, foi introduzido em 1979, inicialmente nas regiões de Montes Claros e Governador Valadares, norte de Minas Gerais, segundo FAYAD. O uso do leilão foi sucesso consagrado em todo estado mineiro, pois teria tornado a comercialização mais eficiente, sobretudo nas regiões onde o rebanho bovino é, na sua maioria, pulverizado entre os pequenos e numerosos criadores. Atualmente destacam-se os leilões realizados no triângulo mineiro, especificamente na região de Uberaba. As empresas leiloeiras mais representativas desta região comercializam, em média, seis mil cabeças por semana, de acordo com ZEN ${ }^{8}$.

No estado de São Paulo, o leilão começou a ser efetivamente utilizado para a comercialização de animais para reposição a partir do começo da década de oitenta. Até então, as poucas empresas leiloeiras paulistas surgiram da associação da iniciativa dos paulistas e da experiência dos gaúchos. No início da década de setenta foram fundadas a Programa Leilões e a Remate, hoje tradicionais empresas leiloeiras. Atualmente, a Remate trabalha quase exclusivamente com animais de raça e a Programa com animais de

\footnotetext{
${ }^{7}$ FAYAD, Omar. (Tairana Leilões - Rod. Raposo Tavares, Km563 Distrito Industrial - Presidente Prudente - SP) Comunicação Pessoal, 1994.

${ }^{8}$ ZEN, Sérgio De. (Centro de Pesquisas em Economia Agrícola - Av. Carlos Botelho, 987 - CEP:13416145 Piracicaba-SP) Comunicação Pessoal, 1994.
} 
reposição. Estas duas empresas, por exemplo, tiveram a ajuda da experiência do leiloeiro gaúcho Trajano Silva que contribuiu grandemente para a divulgação e popularização do leilão na região sudeste e centro-oeste do Brasil. Até o final da década de setenta, existiam apenas quatro empresas leiloeiras no estado de São Paulo: Lance, Trajano Leilões, Remate e Programa Leilões. Atualmente existem mais de sessenta empresas leiloeiras no estado de São Paulo assim como no estado do Mato Grosso do Sul.

No Mato Grosso do Sul, como observa ZEN, especificamente em Campo Grande, ocorrem leilões diários que atraem compradores até de outros estados como os de São Paulo. Em cada um destes leilões são comercializados cerca de mil cabeças.

Segundo SILVA, hoje o leilão é um canal de comercialização comum e utilizado em quase todos os estados brasileiros, entre os quais Mato Grosso do Sul, Pará, Goiás, Tocantins, Mato Grosso e alguns estados da região nordeste. Tal fato pode ser observado pelo grande crescimento do número de empresas leiloeiras nos últimos dez anos. Em Minas Gerais, por exemplo, existiam apenas três empresas leiloeiras em 1983 e agora existem mais de duzentas. Para organizar a atividade das empresas e dos leiloeiros, foram criados recentemente o Sindicato Nacional das Empresas Leiloeiras (SINAL) e 0 Sindicato Nacional dos Leiloeiros Rurais (SNLR). Mas, mesmo assim, de $10 \%$ a $20 \%$ dos bovinos comercializados passam pelos leilões.

\subsection{Caracterização do leilão de gado geral no Brasil}

Como o objeto do presente estudo é o mercado de reposição da pecuária bovina de corte no Brasil, o leilão relevante é o de gado geral, ou seja, é o leilão que está associado ao mercado de reposição. Há várias características do leilão de gado geral que podem variar de uma empresa leiloeira para outra. 
Para serem leiloados, os animais devem estar agrupados de acordo com a categoria, idade, raça e prazo de pagamento em lotes homogêneos, cujo tamanho pode ser variável. O local de realização do leilão, além de fácil acesso, deve permitir o exame detalhado dos lotes antes do início do evento. Toda informação a respeito da mercadoria deve estar disponivel a todos os compradores sem discriminação. Com este intuito, as empresas ainda costumam distribuir listas com a relação dos lotes com suas respectivas características. Uma característica importante, principalmente em um país com elevada inflação, é o prazo de pagamento. As empresas leiloeiras em geral fixam o prazo, não permitindo a sua alteração durante a realização do leilão.

Outras manobras questionáveis em um leilão são a defesa e o repasse. A defesa, como o próprio nome diz, são os lances efetuados pelos próprios vendedores com a intenção de elevar artificialmente o preço do seu lote. A defesa é a forma do vendedor recusar o lance corrente que esteja muito abaixo do valor esperado do seu lote de animais. O repasse é o retorno à pista do lote já leiloado anteriormente, cujo comprador tenta, de forma especulativa, revender os animais. $O$ repasse geralmente está associado à defesa e a forma usada para evitá-los é a cobrança sem discriminação da comissão da empresa leiloeira. A comissão ou taxa de serviço varia de $1,5 \%$ a $4 \%$ ad valorem cobradas de ambas as partes. Mas, algumas empresas leiloeiras acabam não cobrando a taxa do vendedor quando o lote é defendido.

Aparentemente, nos últimos anos, o grande aumento do número de empresas leiloeiras tem tornado o mercado deste tipo de serviço mais competitivo ${ }^{9}$. Isto explica a reduzida comissão ou taxa de serviço cobrada e o fornecimento de transporte por algumas empresas que tentam garantir a sua clientela face a concorrência.

\footnotetext{
${ }^{9}$ A situação no qual existe competição entre empresas leiloeiras é denominada de leilão duplo pela teoria do leilão. Para mais detalhes sobre o leilão duplo (ou "double auction" em inglês) ver McAFEE \& MCMILLAN (1987).
} 
Os lotes são leiloados seqüencialmente e os compradores podem, ainda, obter informações adicionais durante a realização do leilão observando a evolução dos lances dos outros compradores. Os lances têm incrementos que variam de uma empresa para outra, mas que são fixas durante a realização do leilão. Geralmente usa-se incrementos iniciais maiores e os finais menores de modo a atingir o preço de equilíbrio mais rápido. É usual o leiloeiro pedir aos compradores o lance inicial, também chamado de preço de reserva pela teoria do leilão, que elimina os lances muito baixos. No Brasil, o lance é o preço que o comprador potencial está disposto a pagar por animal do lote leiloado ${ }^{10}$.

Logo que o martelo é batido, o nome do comprador do lote corrente é anunciado ao público e o mesmo passa a ser o único responsável pela mercadoria, retirada depois do acerto do pagamento.

A empresa leiloeira assim como os próprios compradores participantes devem honrar os seus compromissos, para que se mantenha a credibilidade de ambas as partes. Pois, se o leilão não se realiza dentro das regras pré-estabelecidas de forma clara e imparcial, os participantes não têm motivos para continuar participando do evento. Da mesma forma, o comprador que não paga devidamente pelo lote arrematado não consegue participar dos leilões seguintes.

Com o uso do leilão, os recriadores e invernistas não precisam mais sair a procura de bezerro e boi magro nas propriedades dos criadores com a incerteza de realizar as suas aquisições para prosseguirem as suas atividades. Por outro lado, os criadores se vêem livres do trabalho de reunir o rebanho cada vez que um comprador chega na propriedade para examinar a mercadoria. O leilão ainda oferece ao comprador quantidade e a possibilidade de escolha do padrão da mercadoria. Além disso, facilita o alcance de um preço que represente a avaliação de inúmeros ofertantes e demandantes. Por estas

\footnotetext{
${ }^{10}$ No leilão americano o lance é o preço que o comprador está disposto a pagar por peso do lote leiloado que pode ser, por exemplo, dólares por cem quilogramas.
} 
vantagens e as outras citadas na seção 2.3.3., o leilão dinamiza o processo produtivo da pecuária bovina de corte.

\subsection{Alguns aspectos teóricos relevantes para o leilão de gado bovino}

Ao mesmo tempo que o comprador potencial tenta aumentar a diferença entre a sua valoração da mercadoria leiloada e o preço a ser pago, o vendedor, na pessoa do leiloeiro, tenta diminuir esta diferença de modo a maximizar os seus ganhos na transação. De acordo com HARRIS \& RAVIV (1981), a competição entre os compradores diminui os seus ganhos, pois o leiloeiro, através do poder de monopólio, consegue extrair parte do excedente do consumidor, ou melhor, do comprador.

Diferenças entre as valorações dos compradores potenciais podem aumentar por causa das preferências individuais e/ou do valor objetivo simples da mercadoria leiloada. Estas duas causas definem dois modelos em situações extremas em relação a assimetria de informação e o comportamento do comprador face à incerteza. Em um extremo há o modelo dos valores-privados-independentes, no qual cada comprador não tem dúvida sobre a sua valoração e desconhece a valoração exata dos outros compradores. Por outro lado, cada comprador, assim como o vendedor, percebe as valorações delineadas pelas distribuições de probabilidade de cada comprador. Portanto, diferenças entre as avaliações dos compradores potenciais refletem as diferenças correntes em suas preferências. Em outro extremo há o modelo do valor-comum, no qual a mercadoria leiloada tem um valor objetivo simples e ninguém sabe o seu valor real. Os compradores, talvez tendo acesso a informações diferentes, têm diferentes pressuposições sobre quanto a mercadoria realmente vale. Se $V$ é o valor real não observado, então os valores percebidos pelos compradores $v_{i}, i=1, \ldots, n$, são delineados independentemente de 
alguma distribuição de probabilidade $H\left(v_{i} \mid V\right)$. Todos os agentes conhecem a distribuição $H$. Ou seja, no modelo do valor-comum, o comprador provavelmente mudaria a sua valoração se o conhecimento da valoração de outros compradores fornecesse informação útil sobre o valor real da mercadoria. No modelo dos valoresprivados-independentes, o conhecimento da valoração de outros compradores não causa qualquer mudança na valoração de qualquer comprador, apesar de haver a possibilidade de, por razões estratégicas, mudar seu lance. Em situações de leilão no mundo real, parece haver aspectos de ambos os modelos simultaneamente (McAFEE \& McMILLAN, 1987).

Um modelo geral que permite correlações entre as valorações dos compradores potenciais e inclui como casos especiais o modelo dos valores-privados-independentes e o modelo do valor-comum foi desenvolvido por MILGROM \& WEBER (1982). Este modelo é o que melhor se adequa ao esquema do leilão de gado geral brasileiro, pois, como foi descrito na seção 3.3., os compradores têm a possibilidade de observar a evolução dos lances dos outros compradores e assim modificar tanto a sua valoração como os seus lances. Além disso, os compradores potenciais participam do leilão visando o mercado final para a sua mercadoria. Por exemplo, o invernista adquire lotes de boi magro para revendê-los como boi gordo para o abate, assim como o recriador adquire lotes de bezerros para revendê-los como bois magros para o invernista ${ }^{11}$.

11 Para maiores detalhes, ver MILGROM \& WEBER (1982). 


\section{EFICIÊNCIA DE MERCADO}

\subsection{Arbitragem e eficiência de mercado}

Considerando mercados espacialmente separados para uma mesma mercadoria, a arbitragem é a possibilidade de vender de um mercado para outro com uma diferença positiva no preço maior que o custo de transporte. Desta forma, a arbitragem faz com que a diferença de preços entre mercados seja apenas o custo de transporte. Mas o ajuste dos preços dos mercados espacialmente separados pode não acontecer simultaneamente quando ocorre uma flutuação na demanda e/ou oferta entre os diferentes locais. Tal situação reflete a não eficiência quanto a utilização da informação.

O conceito de eficiência, segundo BAILEY \& BRORSEN (1985), tem diferentes significados para os economistas. PANTON (1980), por exemplo, define como mercado eficiente aquele no qual um especulador seria incapaz de obter um lucro acima do "normal". Fama (1970)1 citado por BAILEY \& BRORSEN (1985), define como mercado eficiente aquele que reflete integralmente toda informação disponível. Se certos mercados influenciam sistematicamente outros nos ajustamentos de preços decorrentes de nova informação, estes podem ser mais eficientes no reflexo a novas informações que os mercados defasados, ou melhor, influenciados. BAILEY \& BRORSEN (1985) também consideram eficiente os mercados que refletem toda informação em um curto período de

\footnotetext{
${ }^{1}$ FAMA, E.F. Efficient capital markets: a review of theory and empirical work. Journal of Finance, 25: $383-423,1970$.
} 
tempo. Adicionalmente, WILLIAMS \& BEWLEY (1993) destaca que a velocidade de ajustamento pode prover uma indicação da integração dos mercados e ainda ajudar na definição dos mercados relevantes.

\subsection{Mercados Satélite e Dominante}

Em um sistema perfeitamente integrado, todos os mercados assimilam a nova informação no mesmo ponto do tempo e os preços se ajustam simultaneamente. Se os mercados não são perfeitamente integrados, um mercado pode ser mais capaz de registrar os impactos da nova informação. Em tais mercados, a introdução de uma nova informação pode resultar em diferenças de preços entre mercados maiores que o custo dos serviços de comercialização para intervalos de tempos curtos (KOONTZ et alii, 1990).

Em mercados imperfeitamente integrados o ajustamento entre preços num mercado A e em outro mercado B pode ser caracterizado em um dos dois caminhos descritos a seguir: a) o ajustamento pode ser simétrico, isto é, preços no mercado A movem-se para a mesma direção que os preços no mercado B tão rapidamente como aqueles em $B$ movem-se para a mesma direção dos preços em $A ; b)$ o ajustamento pode ser unilateral, isto é, preços no mercado B usualmente ajustam-se aos preços em A, com um tempo de atraso determinado pela velocidade das comunicações. $O$ caso $b$ é chamado de relação de mercado dominante-satélite. Nesta exposição, o mercado A é o dominante e o mercado B é o satélite (GARBADE \& SILBER, 1979).

De acordo com SCHROEDER \& GOODWIN (1990), se a relação dominantesatélite existe, os mercados satélites podem responder menos eficientemente a novas informações. Alternativamente, alguns mercados podem ser fontes de significativo 
montante de novas informações, enquanto que outros mercados podem ter atividade insuficiente para gerar informações novas em quantidade. Ou seja, como destaca WILLIAMS \& BEWLEY (1993), os mercados dominantes, por terem usualmente maiores volumes de comercialização, provêm as informações requeridas.

\subsection{A questão da transmissão da informação preço}

Segundo WILLIAMS \& BEWLEY (1993), os preços refletem a informação sobre demanda e oferta não somente nos mercados nos quais são identificados mas também nos outros mercados espacialmente relacionados da mesma mercadoria. A transmissão desta informação entre mercados afeta a natureza da relação entre preços em mercados diferentes. Há dois aspectos relacionados à transmissão da informação preço: a primeira é a velocidade com a qual a nova informação preço é transmitida e absorvida por outros mercados e o segundo é a direção na qual os preços ajustam-se em relação à informação.

BARROS (1990) também discute a questão da não uniformidade no acesso à informação entre as partes envolvidas na comercialização de produtos agrícolas. Tanto o produtor agrícola, devido à sua pequena escala de operação e à não-especialização de atividades, como as unidades varejistas, também não-especializadas, estão em aparente desvantagem em relação ao segmento atacadista, que tende a especializar-se no comércio de um pequeno grupo de produtos agrícolas, sobre cujo mercado deve deter volume maior e melhor de informações. Além disso, trabalhando com maior escala no comércio de um produto, o atacadista geralmente pode exercer o papel de líder nas variações de preços. 
GARBADE \& SILBER (1979) e KOONTZ et alii (1990) enfocam suas análises de mercados dominante-satélite na direção na qual os preços se ajustam. Estes autores examinam a assimetria aparente nos fluxos de informação e portanto nos movimentos dos preços.

Sob o ponto de vista da transmissão de preço, torna-se interessante estudar as relações que as regiões de predomínio pecuário guardam entre si e verificar se as regiões tipicamente agrícolas que se destacam na pecuária de corte são influenciadas pelas regiões de predomínio pecuário. Entre os estudos realizados que analisam as relações entre mercados espacialmente separados tem-se os vários já citados anteriormente. BAILEY \& BRORSEN (1985) e SCHROEDER \& GOODWIN (1990) estudaram a dinâmica dos preços da pecuária de corte em várias regiões dos Estados Unidos, analisando a velocidade de ajustamento dos preços a novas informações e a relação dominante-satélite. KOONTZ et alii (1990) investigaram as relações existentes entre os mercados físico e futuro da pecuária de corte utilizando o conceito de mercados dominante e satélite e a definição de causalidade de Granger. WILLIAMS \& BEWLEY (1993) estudaram a possibilidade da prática de arbitragem entre leilões espacialmente separados na região de Queensland na Austrália através da análise da transmissão de preço. Neste mesmo trabalho, a análise da inovação é utilizada para examinar variações das respostas a mudanças nos preços destes mercados.

Uma análise das relações que ocorrem através da informação preço entre as diferentes categorias de uma mesma região é justificável pois, como foi verificado por TOLEDO \& SANTIAGO (1984), as categorias bezerro, garrote e boi magro acompanham, de forma bem próxima, as variações dos preços do boi gordo. Além disso, pode-se verificar as relações que estas categorias, inclusive a de boi gordo, apresentam no fenômeno ciclo pecuário plurianual. Vários trabalhos têm estudado as relações via 
preço entre as diferentes categorias. SPREEN \& SHONKWILER (1981) estudaram a relação causal que existe entre os custos da pecuária de corte, preços do boi gordo $\mathrm{e}$ preços do boi magro. VAN TASSELL \& BESSLER (1988) utilizaram o modelo de autoregressão vetorial (VAR) para investigar as relações dinâmicas existentes entre os mercados de animais de raça e de animais para fins comerciais. SANTANA \& BRANDT (1991) analisaram as relações entre preços de boi gordo, novilho e bezerro no mercado do estado de Minas Gerais utilizando o modelo de correção de erro de Engle e Granger.

No mercado de reposição, o leilão tem sido importante fonte de informação para os agentes de comercialização e os próprios pecuaristas, o que revela a influência deste sobre o mercado convencional. Os leilões, à semelhança das bolsas de valores e mercadorias, têm funcionado como bolsas regionais informais de animais de reposição. BUCCOLA (1985) fez um estudo comparativo entre mercados centralizados e nãocentralizados e sugere que os mercados centralizados são mais eficientes na formação de preços que os não centralizados. Thonsen $(1951)^{2}$ citado por MACHADO FILHO (1994), ressaltou que o leilão, além de servir como forma de determinar as condições de oferta e demanda em determinada área eliminando iniqüidades estabelecidas na barganha direta entre comprador e vendedor, é fonte de informação de mercado.

Os meios de comunicação convencionais como a televisão, o rádio, a revista e o jornal melhoraram muito o fluxo de informações dos mercados agrícolas nos últimos tempos. Além dos meios de comunicação convencionais, existem as empresas que vendem as informações sobre os mercados agrícolas e os orgãos e instituições do governo que coletam e divulgam dados de preços dos mercados agrícolas como o Instituto de Economia Agrícola da Secretaria de Agricultura do Estado de São Paulo que

2 THONSEN, F.L. Agricultural marketing. New York, McGraw-Hill, 1951. p.109. 
também têm contribuído para o aumento do fluxo das informações. Atualmente,parece ser muito dificil a existência de arbitragem entre dois mercados de um mesmo produto. 


\section{METODOLOGIA}

\section{1. Área de abrangência}

O estudo sobre os leilões ficará restrito às regiões mais importantes para a pecuária bovina de corte do Estado de São Paulo. De acordo com algumas pesquisas, como IGREJA (1987), e comunicação pessoal de pesquisadores do Instituto de Economia Agrícola e do Centro de Pesquisas em Economia Agrícola da Fundação de Estudos Agrários "Luiz de Queiroz" que trabalham com a pecuária bovina de corte, estas regiões seriam Araçatuba, Presidente Prudente e Bauru. Conforme foi dito, a região de Barretos perdeu a importância que tinha para a pecuária bovina de corte paulista. Por isso esta região não será considerada neste estudo. Além disso, tanto a região de Marília como a de São José do Rio Preto não entrarão no estudo pelo fato de seus dados de preços médios obtidos em leilões não estarem disponíveis. É evidente que o presente trabalho ficaria muito mais interessante se fossem incluidos os estados do Mato Grosso do Sul, Minas Gerais, Goiás, Mato Grosso e Paraná. Mas a principal limitação para isto é a indisponibilidade de dados homogêneos e de bom padrão nestes estados, tanto no mercado convencional como nos leilões.

Quanto ao mercado convencional do boi gordo, vaca gorda, boi magro, garrote e bezerro, a abrangência será o Estado de São Paulo como um todo. 


\subsection{Dados}

Neste trabalho serão utilizadas as séries de preços mensais de bezerro, boi magro, boi gordo, garrote e vaca gorda para estudar as relações existentes entre as categorias; e os preços médios de bezerro e novilhos (garrote) obtidos nos leilões nas diferentes regiões para verificar a importância de cada região nas respectivas categorias.

Os preços mensais foram obtidos junto ao Centro de Pesquisas em Economia Agrícola da Fundação de Estudos Agrários "Luiz de Queiroz" - CEPEA/FEALQ. Os preços médios obtidos nos leilões foram fornecidos pelas seguintes empresas leiloeiras: Programa Leilões de Araçatuba, Repique Leilões de Araçatuba, Programa Leilões de Bauru e Tairana Leilões de Presidente Prudente. Não poder-se-á contar com os dados de leilão de São José do Rio Preto porque a filial da Programa desta cidade encerrou as suas atividades. Esta empresa tinha a série de dados mais longa e homogênea das empresas leiloeiras da região.

Para deflacionar os preços mensais, será utilizado o Índice Geral de Preços da Fundação Getúlio Vargas, disponibilidade interna, e para os preços diários, a cotação do dólar oficial diário para venda (livre).

Para fins da análise, as séries do CEPEA/FEALQ serão divididas em vários períodos. O primeiro período seria de junho de 1970 a junho de 1982 que corresponde a parte da série no qual o ciclo pecuário é bem marcante e possui dois ciclos completos de "vale a vale". O segundo período vai de junho de 1982 a maio de 1994 que corresponde a parte da série no qual o ciclo pecuário praticamente deixa de existir. Adicionalmente, os períodos de junho de 1970 a novembro de 1973 e novembro de 1973 a junho de 1977 
são definidos para a análise da mudança de comportamento dos preços durante o ciclo pecuário nas fases ascendente e descendente, respectivamente.

\subsection{Estacionariedade}

\subsubsection{Alguns aspectos teóricos}

\section{Estacionariedade}

Uma das suposições mais freqüentes que se faz a respeito de uma série temporal é a de que ela é estacionária. Entretanto, muitas séries econômicas apresentam tendências, sendo o caso mais simples aquele em que a série flutua ao redor de uma reta com inclinação positiva ou negativa (tendência linear). Há a forma de não estacionariedade explosiva, como o crescimento de uma colônia de bactérias, e a forma de não estacionariedade homogênea. Neste caso, a série pode ser estacionária, flutuando ao redor de um nível por certo tempo, depois mudar de nível e flutuar ao redor de um novo nível e assim por diante. Ou então, mudar de inclinação, ou ambas as coisas. (BOX \& JENKINS, 1976 e MORETTIN \& TOLOI, 1986, p.6).

Como a maioria dos procedimentos de análise estatística de séries temporais e de regressão supõe que estas sejam estacionárias, é necessário transformar os dados originais, se estes não formam uma série estacionária. A transformação mais comum consiste em tomar diferenças sucessivas da série original, até se obter uma série estacionária. Em situações normais, é suficiente tomar uma ou duas diferenças para que a série se torne estacionária (MORETTIN \& TOLOI, 1986, p.7). A notação geral para indicar série em diferença(s) é: 


$$
\Delta^{n} Z(t)=\Delta\left[\Delta^{n-1} Z(t)\right]
$$

Nos modelos autorregressivos vetoriais a não-estacionariedade das séries pode ocasionar a não convergência das respostas aos choques ao longo do tempo o que equivale a dizer que o modelo não tem um ponto de equilíbrio (HAKKIO \& MORRIS, 1984).

Mas quando a série é diferenciada, perdem-se as informações de longo-prazo, sendo este aspecto o principal foco das críticas ao procedimento. Este problema pode ser contornado com a utilização do vetor de correção de erros relacionado à idéia de cointegração introduzida inicialmente por GRANGER (1981) e desenvolvida por ENGLE \& GRANGER (1987).

Recentemente têm surgido muitos trabalhos sobre cointegração, a maioria deles com variáveis macroeconômicas. Para se fazer o teste de cointegração deve-se inicialmente determinar se as variáveis em questão são estacionárias ou não, ou seja, a ordem de integração $I(d)$. Se não forem, deve-se determinar o número de diferenças necessárias para que as séries tornem-se estacionárias (uma abordagem mais detalhada sobre cointegração, teste de cointegração e modelo de correção de erros será feita nas seções seguintes). Percebe-se, desta forma, a relevância da questão da estacionariedade das séries econômicas estudadas.

\subsubsection{Teste de estacionariedade}

Para verificar a ordem de integração de uma série, DICKEY \& FULLER (1979, 1981) propuseram a verificação da existência de raiz unitária. BOX \& JENKINS (1976, 
p.53) mostram, de forma bem clara, a relação que há entre a ordem de integração e a raiz unitária. Assume-se que a série é gerada por um processo autorregressivo de ordem $p$ $(\operatorname{AR}(p))$,

$$
\Phi(B) \widetilde{z}_{t}=a_{t}
$$

onde,

B é o operador de defasagem;

$\tilde{z}_{t}$ é a variável $z_{t}$ menos a média;

$a_{t}$ é o erro aleatório.

Modificando-se (5.3.1) para

$$
\widetilde{z_{t}}=\Phi^{-1}(B) a_{t}
$$

com

$$
\Phi(B)=\left(1-G_{1} B\right)\left(1-G_{2} B\right) \ldots\left(1-G_{p} B\right)
$$

e expandindo em frações parciais,

$$
\widetilde{z}_{t}=\Phi^{-1}(B) a_{t}=\sum_{i=1}^{p} \frac{K_{i}}{\left(1-G_{i} B\right)} a_{t}
$$

Desta forma, se $\Psi(B)=\Phi^{-1}(B)$, as séries devem ser convergentes para $|B|>1$, então temos $\left|G_{i}\right|<$, onde $i=1,2, \ldots, p$. Equivalentemente, a raiz de $\Phi(B)=0$ deve estar fora do círculo unitário. As raízes da equação $\Phi(B)=0$ podem ser referidas como os zeros do polinômio $\Phi(B)$. Portanto, a condição de estacionariedade pode ser expressa dizendo que os zeros de $\Phi(B)$ ou as raízes devem estar fora do círculo unitário. Um argumento semelhante pode ser aplicado quando os zeros (ou raízes) de $\Phi(B)$ não são todos distintos. A equação $\Phi(B)=0$ é chamada a equação característica para o processo. 
A condição de estacionariedade é de que as raizes do polinômio $\Phi(B)=0$ devem estar fora do círculo unitário. Assim, os testes da raiz unitária consistem, de uma forma suscinta, em testar sequencialmente a presença de raiz sobre o círculo unitário depois de cada diferença realizada na série até que se torne estacionária, ou melhor, não exista mais raízes que estejam sobre o círculo unitário. A seguir são descritos os testes Dickey Fuller (DF) e Dickey Fuller Expandido (ADF), tendo como base DICKEY \& FULLER(1979), DICKEY \& FULLER(1981), DOLADO et al. (1990), e BACCHI (1994).

\section{Teste Dickey Fuller (DF)}

De acordo com DICKEY \& FULLER $(1979,1981)$, o teste DF é geralmente usado para testar se um processo AR(1) puro (com "drift" ou não) tem ou não uma raiz unitária. Considerando que a série temporal $y_{t}$ obedece o seguinte processo gerador de dados:

$$
y_{t}=\beta_{0}+\beta_{1} t+\rho y_{t-1}+\varepsilon_{t}
$$

onde,

$y_{t}$ é a variável em nivel;

$y_{t-1}$ é a variável defasada de um período;

$\mathrm{t}$ é a variável tempo;

$\beta_{0}, \beta_{1}$ e $\rho$ são os parâmetros da equação;

$\varepsilon_{t}$ é o resíduo com distribuição Normal.

O parâmetro $\beta_{0}$ é uma constante, podendo ser zero sem perda de generalidade. DICKEY \& FULLER (1979) colocam o problema na forma do teste da hipótese da nulidade 
$H_{0}: \rho=1$ contra a hipótese alternativa $H_{1}: \rho<1$, ou seja, não-estacionariedade versus estacionariedade em torno de uma tendência determinística, sugerindo a estimação de mínimos quadrados ordinários de uma versão reparametrizada da equação (5.3.2):

$$
\Delta y_{t}=\beta_{0}+\beta_{1} t+\gamma y_{t-1}+\varepsilon_{t}
$$

onde, $H_{0}: \rho=1$ é equivalente a $H_{0}: \gamma=0$ (desde que $\gamma=\rho-$ ). 0 teste é implementado através do teste $t$ usual do coeficiente estimado $\hat{\gamma}$, chamado de $\tau_{\tau}$. Esta estatística $\tau_{\tau}$ em vez de ter uma distribuição $t$, tem uma distribuição que é função do movimento browniano. Por este fato, deve-se utilizar a distribuição assintótica tabulada por FULLER (1976, p.373) para obter os valores críticos.

Há outras estatísticas que podem ser obtidas omitindo alguns parâmetros da equação (5.3.3) ou testando grupo de parâmetros. Omitindo-se o parâmetro $\beta_{1}$, ou seja, retirando-se a variável $t$ da equação (5.3.3), o teste $t$ calculado sobre o coeficiente $\hat{\gamma}$ é chamado de $\tau_{\mu}$. Quando se retira tanto a variável $t$ como a constante da equação (5.3.2), a estatística obtida é chamada de $\tau$. DICKEY \& FULLER (1981) propuseram, considerando a mesma equação (5.3.3), a estatística $F$ para hipótese da nulidade $H_{0}: \beta_{0}=\beta_{1}=\gamma=0$, denominada de $\Phi_{2}$, e a estatística $F$ para a hipótese da nulidade $H_{0}: \beta_{1}=\gamma=0$, denominada de $\Phi_{3}$. Como estas estatísticas não tem uma distribuição $F$ usual, deve-se ultilizar os valores críticos tabulados por DICKEY \& FULLER (1981, p.1083).

\section{Teste Dickey Fuller Expandido (ADF)}

No caso do teste DF considera-se o processo gerador de valores como uma $\operatorname{AR}(1)$ puro. Se, em vez disso, o processo gerador de valores é um processo $\operatorname{AR}(p)$ : 


$$
z_{t}=\beta_{0}+\beta_{1} t+\sum_{i=1}^{p} \Phi_{i} z_{t-i}+\varepsilon_{t}
$$

onde a equação característica da série temporal (como foi visto no ínicio desta seção) é $\Phi(B)=0$ e $G_{i}$,para $i=1,2, \ldots, p$, são as raizes características do processo. DICKEY \& FULLER $(1979,1981)$ consideram o problema de testar as hipóteses da nulidade $H_{0}: G_{i}=1$ e $\left|G_{i}\right|<$, para $i=2, \ldots, p$, sugerindo a estimação pelos mínimos quadrados ordinários do modelo de regressão:

$$
\Delta z_{t}=\beta_{0}+\beta_{1} t+\gamma_{1} z_{t-1}+\sum_{i=1}^{p-1} \gamma_{2 i} \Delta z_{t-i}+\varepsilon_{t}
$$

reparametrizado de 5.3.4, onde $p$, de acordo com DOLADO et al. (1990) é grande o suficiente para garantir que o resíduo $\varepsilon_{t}$ seja ruído branco. Para auxiliar na determinação do número de defasagens, utiliza-se o teste $\mathrm{Q}$, cujos valores críticos possuem uma distribuição qui-quadrada. $O$ teste consiste em testar o coeficiente estimado $\hat{\gamma}_{1}$ através do cálculo do teste $t$ e é chamado de teste Dickey Fuller Expandido. Os valores críticos são os mesmos tabulados por DICKEY \& FULLER (1976, p.373), uma vez que estas estatísticas não possuem a distribuição $t$. Como é descrito por BACCHI (1994), definido o nível de probabilidade ( $1 \%, 5 \%$ ou $10 \%$ ), se o valor calculado for negativo e maior, em módulo, que o valor crítico, rejeita-se a hipótese nula (a da raiz unitária), e indica-se que a série é estacionária, ou seja, $I(0)$. Caso a hipótese de raiz unitária não seja rejeitada, conclui-se que a série é integrada de uma ordem maior que zero e prossegue-se com o teste do modelo:

$$
\Delta^{2} y_{t}=\beta_{0}+\beta_{1} t+\gamma_{1} \Delta y_{t-1}+\sum_{i=1}^{p-1} \gamma_{2 i} \Delta^{2} y_{t-i}+\varepsilon_{t}
$$


A rejeição da hipótese da nulidade neste modelo indica que a série é integrada de ordem um. Se a hipótese da nulidade não é rejeitada, conclui-se que a ordem de integração é superior a um e deve-se prosseguir o teste para verificar se a série é integrada de ordem dois e assim por diante. Generalizando, para se testar a hipótese da nulidade de que a série é integrada de ordem $n+1$ contra a hipótese alternativa de que a ordem de integração é $n$, usamos o seguinte modelo geral,

$$
\Delta^{n+1} y_{t}=\beta_{0}+\beta_{1} t+\gamma_{1} \Delta^{n} y_{t-1}+\sum_{i=1}^{p-1} \gamma_{2 i} \Delta^{n+1} y_{t-i}+\varepsilon_{t}
$$

onde,

$\Delta^{n+1} y_{t}$ é a variável testada em diferença $n+1$ vezes;

$t$ é a variável tempo para captar tendência;

$\Delta^{n} y_{t-1}$ é a variável defasada de um período em diferença $\mathrm{n}$ vezes ;

$\Delta^{n+1} y_{t-i}$ é a variável em diferença $n+1$ vezes defasada de um período $i$,

$\beta_{0}, \beta_{1}, \gamma_{1}$ e $\gamma_{2}$ são os parâmetros da equação a serem estimados;

$\varepsilon_{t}$ é o resíduo da equação que deve ter distribuição Normal.

Apesar de existirem vários testes que verificam se uma série é ou não estacionária, entre os quais o teste Phillips \& Perron (PP), o mais utilizado é o de Dickey-Fuller Expandido (ADF). O teste Phillips \& Perron relaxa a pressuposição de que o erro do modelo estimado para o teste seja ruído branco, mas, como foi constatado por BACCHI (1994), o seus resultados diferem dos resultados obtidos com o teste ADF. A maioria dos trabalhos que determinam a ordem de integração de suas séries utilizam o teste ADF, entre os quais, BACCHI (1994), WILLIAMS \& BEWLEY (1993), SARKER (1993) e LIMA et al. (1993). Esta pesquisa também utilizará o teste ADF para testar a estacionariedade. 
45.

\subsection{Cointegração}

\subsubsection{Alguns aspectos teóricos ${ }^{1}$}

A teoria da co-integração foi introduzida inicialmente por GRANGER (1981) e desenvolvida em seguida por ENGLE \& GRANGER (1987). Antes de definir o que é co-integração, alguns conceitos devem ser conhecidos.

De acordo com a definição de ENGLE \& GRANGER (1987), uma série $y_{t}$ sem componente determinístico, com representação ARMA, estacionária e invertível após $d$ diferenças é integrada de ordem $d$ e denotada como $y_{t} \sim I(d)$. Ou seja, esta série $y_{t}$ precisa ser diferenciada $d$ vezes para tornar-se estacionária. Desta forma uma série integrada de ordem zero é estacionária em nivel, enquanto que uma outra integrada de ordem um precisaria de uma diferença para ser estacionária. Uma série com ruído branco e outra com passeio aleatório são, respectivamente, exemplos de séries $I(0)$ e $I(1)$.

Existem algumas diferenças básicas entre séries $I(0)$ e $I(1)$. A série integrada de ordem zero possui as seguintes características: possue variância finita que não depende do tempo; tem uma memória limitada do seu comportamento passado, ou seja, efeitos de uma particular inovação aleatória são apenas transitórios; tende a flutuar em torno da média que pode incluir uma tendência determinística e; tem autocorrelação nos resíduos que declinam rapidamente com o aumento das defasagens. No caso da série integrada de ordem um: a variância depende do tempo e tende ao infinito quando o tempo tende ao infinito; o processo tem uma memória infinitamente longa, ou seja, uma inovação afetará

\footnotetext{
${ }^{1}$ Para maiores detalhes sobre a teoria da co-integração, veja GRANGER (1981), GRANGER (1986), HENDRY (1986), ENGLE \& GRANGER (1987), DOLADO et al. (1990) e LÜTKEPOHL (1991, p.346).
} 
permanentemente o processo; a variação é muito grande em relação a média e; as autocorrelações tendem a um para todos os intervalos de tempo (GRANGER, 1986).

Relações estáveis de equilibrio de longo prazo podem existir entre inúmeras variaveis econômicas tais como renda familiar e gastos ou preços de uma mesma mercadoria em diferentes mercados. Suponha que o vetor de variáveis de interesse $y_{t}=\left(y_{1 t}, \ldots, y_{k t}\right)^{\prime}$ tenha uma relação de longo prazo $c y_{t}=c_{1} y_{1 t}+\ldots+c_{k} y_{k t}=0$, onde $c=\left(c_{1}, \ldots, c_{k}\right)$. Em algum período particular essa situação pode não se verificar exatamente e ter-se $c y_{t}=z_{t}$, onde $z_{t}$ é uma variável estocástica representando os desvios do equilibrio. Se existir realmente um equilíbrio no longo prazo, é plausível assumir que as variáveis do vetor $y_{t}$ movem-se juntas e que $z_{t}$ é estacionária. Tal fato, entretanto, não exclui a possibilidade de que as variáveis do vetor $y_{t}$ variem extensivamente como um grupo. Desta forma, não se exclui que cada variável seja integrada, ainda que exista uma combinação linear das variáveis que é estacionária. Variáveis integradas com estas propriedades são chamadas co-integradas (LÜTKEPOHL, 1991, p.351).

De acordo com a definição de ENGLE \& GRANGER (1987), os componentes do vetor $y_{t}$ são ditos co-integrados de ordem $d$, $b$, denotado como $y_{t} \sim C I(d, b)$, se: 1$)$ todos os seus componentes são $I(d) ; 2)$ existe um vetor $c \neq 0$ tal que $z_{t}=c^{\prime} y_{t} \sim I(d-b), b>0$, ou seja, existe uma combinação linear entre os componentes do vetor. $\mathrm{O}$ vetor $c$ é chamado de vetor de co-integração. Especificamente no caso em que $d=b=1$, co-integração significa que todos os componentes de $y_{t}$ são $I(1)$ e, assim, o erro de equilibrio (ou a combinação linear desses componentes) é $I(0)$, o que é interessante do ponto de vista econométrico.

DOLADO et al. (1990) explicam que o conceito de co-integração tenta mimetizar a existência de um equilíbrio de longo prazo para o qual um sistema econômico converge 
ao longo do tempo. Se, em geral, a teoria econômica sugere a seguinte relação entre duas variáveis $y_{t}$ e $x_{t}$, por exemplo,

$$
y_{t}=\alpha+\beta x_{t}+z_{t}
$$

então $z_{t}$ pode ser interpretado como um erro de equilíbrio, ou seja, a distância que o sistema é separado do equilibrio de longo prazo em qualquer ponto do tempo. Se $y_{t}$ e $x_{t}$ são co-integradas $C I(1,1)$ então deve existir uma representação do modelo de correção de erro $(\mathrm{MCE})^{2}$,

$$
\Delta y_{t}=\theta_{0}+\theta_{1} z_{t-1}+\theta_{2} \Delta x_{t}+\varepsilon_{t}
$$

onde $\varepsilon_{t}$ é uma sequência de erros aleatórios independentes e identicamente distribuídos com média zero e variância constante ( ou seja, $\varepsilon_{t} \sim i i d\left(0, \sigma_{\varepsilon}^{2}\right)$ ). Note que o termo $z_{t-1}$ na equação 5.4.1 representa a extensão do desequilíbrio entre níveis de $y$ e $x$ dentro do período previsto. O MCE retrata que mudanças em $y_{t}$ não dependem somente das mudanças em $x_{t}$ mas também da extensão do desiquilíbrio entre os níveis de $y$ e $x$. A formulação do modelo de correção de erros é muito atraente pelo fato de combinar flexibilidade na especificação dinâmica com desejáveis propriedades de longo prazo, o que poderia ser visto como uma captura da dinâmica do sistema concomitantemente a incorporação do equilíbrio sugerido pela teoria econômica.

GRANGER (1986) destaca que se $y_{t}$ e $x_{t}$ são $I(1)$ e cointegradas, deve existir causalidade no sentido de Granger em no mínimo uma direção, de forma que uma variável pode ajudar na previsão de outra.

Quando se trabalha com duas variáveis, é possível testar a existência de cointegração entre as variáveis relevantes na pesquisa e estimar o modelo de correção de erros através da estimação pelo método dos mínimos quadrados ordinários. Neste caso só existiria uma única relação de equilíbrio, ou seja, um único vetor de co-integração e o

\footnotetext{
2 Para maiores detalhes, veja o artigo de ENGLE \& GRANGER (1987).
} 
48.

procedimento usado para esta situação é o de Engle e Granger. Já no caso em que se tem mais de duas variáveis, pode existir mais de um vetor de co-integração o que impossibilita a utilização do procedimento de Engle e Granger. Para esta situação, o procedimento usual é o de Johansen para o qual as variáveis cointegradas são geradas por um processo autorregressivo vetorial. Ou seja, o processo gerador das variáveis cointegradas é um $\operatorname{VAR}(p)$ restrito, cuja restrição é o vetor de correção de erros. A desvantagem do procedimento de Johansen é a complexidade dos cálculos para se testar a co-integração entre as variáveis, e estimar o vetor de correção de erros. Nas seções seguintes são descritos, rapidamente, ambos os procedimentos, sendo que nesta pesquisa será utilizado o procedimento de Johansen devido ao número de variáveis envolvidas.

\subsubsection{Procedimento de Engle e Granger}

Este procedimento é também denominado de estimação em duas etapas e encontra-se bem detalhado em GRANGER (1986), ENGLE \& GRANGER (1987) e DOLADO et al. (1990). PORTUGAL (1992), de forma clara e suscinta, explica que, na primeira etapa, o vetor de co-integração, contendo os coeficientes de longo prazo, é estimado através de uma regressão estática em nível . Na segunda etapa, o termo de correção de erros, ou melhor, os resíduos obtidos na primeira etapa, é usado numa equação de diferenças para se obter os coeficientes de impacto (ou "loading matrix"). Ou seja, na primeira etapa, usando as séries integradas de ordem um, são extraídas todas as informações de longo prazo ignorando as considerações sobre dinâmica. A estrutura dinâmica é incorporada apenas na segunda etapa, quando as variáveis aparecem na forma 
de diferenças, enquanto que as restrições em nível são incorporadas através do termo de correção de erros.

\section{Teste de cointegração}

Antes de se fazer o teste de cointegração é necessário verificar a ordem de integração das séries envolvidas no estudo. Como foi exposto na seção anterior, a determinação da ordem de integração pode ser feita pelo teste da raiz unitária expandida (ADF). Se o teste ADF acusar que as séries são integradas de ordem um, isto é, $I(1)$, pode-se, então, verificar a existência de cointegração, que também é feita com o teste Dickey-Fuller expandido ${ }^{3}$. Para se realizar o teste de co-integração entre duas variáveis $y_{t}$ e $x_{t}$, deve-se, inicialmente, estimar a regressão de cointegração pelo método dos mínimos quadrados ordinários e obter os resíduos que são utilizados para testar a cointegração. O modelo a ser estimado é:

$$
y_{t}=\alpha+\beta x_{t}+z_{t}
$$

onde $\alpha$ é a constante do modelo $z_{t}$ é o resíduo a ser testado. Obtidos os resíduos, estimase, também por mínimos quadrados ordinários, o seguinte modelo

$$
\Delta z_{t}=\gamma_{1} z_{t-1}+\sum_{i=1}^{p} \gamma_{2 i} \Delta z_{t-i}+\varepsilon_{t}
$$

onde o coeficiente a ser testado é $\gamma_{1}$ e $p$ é suficientemente grande para que os erros sejam aproximadamente ruído branco, o que pode ser verificado através do teste $Q$. Os valores críticos deste teste de cointegração, também denominado de teste CRADF, encontram-se tabulados em ENGLE \& YOO (1987). A hipótese da nulidade neste teste é $H_{0}: x_{t}, y_{t}$ não

\footnotetext{
${ }^{3} \mathrm{O}$ teste Durbin-Watson também pode ser utilizado para testar co-integração entre duas variáveis, mas como observa ENGLE \& GRANGER (1987), os valores críticos obtidos com o teste ADF são mais estáveis que o teste $\mathrm{DW}$ cujos valores críticos, a semelhança do $\mathrm{ADF}$, também, não tem uma distribuição usual .
} 
são cointegrados que é equivalente a $H_{0}: z_{t} \sim I(1)$ contra a hipótese alternativa $H_{a}: z_{t} \sim I(0)$, ou ainda, a hipótese nula $H_{0}: \gamma_{1}=0$ contra $H_{a}: \gamma_{1} \neq 0$.

\section{Estimação do Modelo de Correção de Erros}

Se o resíduo $z_{t}$ é integrado de ordem zero, este deve ser incluído no modelo de correção de erros que pode ser estimado pelo método dos mínimos quadrados ordinários, pois todas as variáveis são integradas de ordem zero. Considerando, por exemplo, a equação 5.4.2, se as variáveis $y_{t}$ e $x_{t}$ são integradas de ordem um e existe uma combinação linear entre ambas que é integrada de ordem zero, o modelo de correção de erros seria:

$$
\Delta y_{t}=\phi_{0}+\phi_{1} z_{t-1}+\phi_{2} \Delta x_{t}+\varepsilon_{t}
$$

onde todas as variáveis são integradas de ordem zero, $\varepsilon_{t} \sim i i d\left(0, \sigma_{\varepsilon}^{2}\right)$ e $z_{t-1}$ é a correção dos desvios das variáveis em relação ao equilíbrio no longo prazo. Ou seja, todas as informações de longo prazo captadas através do resíduo obtidas na primeira etapa são incorporadas na segunda que considera a estrutura dinâmica.

Stock (1987) citado por PORTUGAL (1992) mostra que os coeficientes obtidos na primeira etapa são "superconsistentes", convergindo mais rapidamente para o parâmetro populacional. Este resultado permite considerar o vetor de correção de erros, estimado na primeira etapa, como verdadeiro vetor ao realizar a segunda etapa. Por isso, justifica-se a omissão da dinâmica na primeira etapa e a incorporação das restrições entre equações através do termo de correção de erros somente na segunda etapa. 


\subsubsection{Procedimento de Johansen}

O procedimento de Johansen foi proposto por JOHANSEN (1988) e aplicado para estudar a demanda de moeda da Finlândia e Dinamarca por JOHANSEN \& JUSELIUS (1990). Vários trabalhos foram realizados a partir daí, entre os quais estudos envolvendo produtos àgrícolas como SARKER (1993) e WILLIAMS \& BEWLEY (1993).

Num contexto multivariado pode haver mais de um vetor de co-integração, ou seja, pode-se ter a existência de $n-1$ vetores linearmente independentes. $O$ procedimento de Johansen possibilita a determinação dos vetores relevantes se estes existirem. Como destaca HAMILTON(1994), a abordagem de Phillips \& Ouliaris testa apenas a existência ou não de relações de cointegração sendo que o procedimento de Johansen, além de determinar o número de relações existentes, possibilita obtê-los. Há duas limitações básicas deste procedimento: considera-se apenas os casos em que as séries são $I(1)$ e a discussão limita-se aos processos autorregressivos vetoriais de ordem finita. A apresentação do procedimento é feita a seguir.

\section{a)Estimação}

De acordo com JOHANSEN $(1988,1991)$ e JOHANSEN e JUSELIUS (1990) o procedimento começa com uma representação autorregressiva vetorial não restrita de ordem $p$ do vetor de variáveis $X_{t}$ tal que:

$$
X_{t}=c+\Theta_{1} X_{t-1}+\Theta_{2} X_{t-2}+\ldots+\Theta_{p} X_{t-p}+\Phi D_{t}+e_{t}
$$


onde

$X_{t}$ - é um vetor de $n$ variáveis $I(1)$;

$D_{t}$ - variáveis binárias para captar o efeito da sazonalidade;

$\Theta_{i}$ - matriz de coeficientes de dimensão $(n \times n)$;

$\mu$ - vetor de termos constantes de dimensão $(n \times 1)$ e;

$e_{t}$ - vetor de resíduos com com distribuição normal.

A equação (5.4.3) pode ser reparametrizada como:

$$
\Delta X_{t}=\mu+\Gamma_{1} \Delta X_{t-1}+\Gamma_{2} \Delta X_{t-2}+\ldots+\Gamma_{p-1} \Delta X_{t-p+1}-\Pi X_{t-p}+\Phi D_{t}+e_{t}
$$

onde

$$
\begin{aligned}
\Gamma_{i} & =-I+\Theta_{1}+\Theta_{2}+\ldots \Theta_{i}, \mathrm{e} \\
-\Pi & =I-\Theta_{1}-\Theta_{2}-\ldots-\Theta_{p} \quad \forall i=1,2, \ldots, p-1 .
\end{aligned}
$$

É interessante notar que este modelo reparametrizado é um tradicional VAR em primeira diferença com exceção do termo $\Pi X_{t-p}$. A matriz de coeficientes de $X_{t-p}, \Pi$, contém informações sobre as relações de longo prazo entre as variáveis. Se $\Pi$ tem um um posto completo, então, $X_{t}$ é um processo estacionário. Neste caso, um modelo VAR em nível é apropriado. Se $\Pi$ tem um posto igual a zero, então $\Pi$ é uma matriz nula e $X_{t}$ é um processo integrado e somente neste caso um tradicional modelo VAR em primeira diferença é apropriado.( LÜTKEPOHL, 1991). Se, entretanto, o posto da matriz П está entre zero e $n$, existe cointegração e $\Pi$ pode ser representada como um produto de duas matrizes $\alpha$ e $\beta$ de dimensão $(n \times r)$, tal que $\Pi=\alpha \beta^{\prime}$. Os vetores de $\beta$ são os vetores de 
cointegração e os de $\alpha$ são os pesos ou vetores de impacto. Desta forma, $\beta^{\prime} X_{t}$ é estacionária. Quando o posto é igual a um, o equilíbrio de longo prazo é único.

A determinação do número de defasagens a ser usado no modelo autoregressivo vetorial restrito far-se-á através dos critérios de informação de Akaike, de Hannan-Quinn e de Schwarz.

A estimação por máxima verossimilhança de $\Pi$ consiste na estimação de dois conjuntos de regressões: um conjunto gera os resíduos $R_{0 t}$ através das regressões de $\Delta X_{t}$ contra $\Delta X_{t-1}, \ldots, \Delta X_{t-p+1}$, e outro conjunto que gera $R_{p t}$ através das regressões de $X_{t-p}$ contra $\Delta X_{t-1}, \ldots, \Delta X_{t-p+1}$. A função de verossimilhança concentrada em termos de produto das matrizes de momentos dos resíduos podem ser expressos como:

$$
L(\beta)=|\hat{\Omega}(\beta)|^{-T / 2}=\left|S_{00}-S_{0 p} \beta\left(\beta^{\prime} S_{p p} \beta\right)^{-1} \beta^{\prime} S_{p 0}\right|^{-T / 2}
$$

onde $S_{00}, S_{0 p}, S_{p 0}$ e $S_{p p}$ são matrizes de momentos provenientes dos resíduos definidos como:

$$
S_{i j}=T^{-1} \sum_{i=1}^{T} R_{i t} R_{j t}^{\prime} \forall i, j=0, p
$$

Através da equação (5.4.5) que a maximização da função concentrada de verossimilhança é equivalente a minimização de $|\hat{\Omega}(\beta)|$. A minimização equivale a resolver a seguinte equação característica:

$$
\left|\lambda I-C^{-1} S_{p 0} S_{00}^{-1} S_{0 p} C^{\prime-1}\right|=0
$$


onde $C$ é uma matriz de dimensão $(n \times n)$ tal que $S_{p p}=C C^{\prime}$. O vetor de autovalores ou raizes características é dado através de $\lambda$ enquanto os correspondentes autovetores ou vetores característicos podem ser derivados como $v_{i}=C^{\prime-1} e_{i}$, onde os $e_{i}$ são os autovetores provenientes da equação (5.4.6). As estimativas de $\alpha$ e $\Omega$ podem ser obtidos usando-se os valores estimados de $\beta^{1}$.

\section{b)Teste de co-integração}

O teste de co-integração consiste em testar a hipótese da nulidade de que existem vetores co-integrados usando dois testes de razão de verossimilhança chamados teste do traço e o teste do máximo autovalor $\left(\lambda_{\text {max }}\right)$. Se $H_{1}$ :é um caso especial de $H_{2}:$ para $r=n$, então a estatística traço é definida como:

$$
-2 \ln \left(Q ; H_{1} \mid H_{2}\right)=-T \sum_{i=r+1}^{n} \ln \left(1-\hat{\lambda}_{i}\right)
$$

Similarmente, a estatística do máximo autovalor para testar $H_{1}(r)$ em $H_{2}(r+1)$ pode ser definido como:

$$
-2 \ln (Q ; r \mid r+1)=-T \ln \left(1-\hat{\lambda}_{r+1}\right)
$$

$O$ teste $\lambda_{\max }$, portanto, é simplesmente a diferença entre sucessivas estatísticas traço.

As distribuições assintóticas destes testes de razão de verossimilhança não seguem a distribuição qui-quadrada padrão. Estas distribuições representam as versões

${ }^{1}$ Como coloca JOHANSEN \& JUSELIUS $(1990, \mathrm{p} .177) \hat{\beta}=\left(v_{1}, \ldots v_{p}\right)$. 
multivariadas da distribuição de Dickey-Fuller. Os valores críticos para estes testes são gerados através de simulações e foram tabulados por JOHANSEN \& JUSELIUS (1990, p.208-209).

\section{c) Testando outras hipóteses}

É importante verificar, como destaca West(1988)² citado por JOHANSEN \& JUSELIUS(1990), se o modelo a ser usado terá ou não tendência linear, pois a distribuições assintóticas das estatísticas dos testes e estimadores dependem de qual pressuposição é mantida. A hipótese da nulidade da ausência de tendência linear no modelo é equivalente a $H_{0}: \mu=\alpha \beta_{0}^{\prime}$. Quando $H_{0}$ é verdadeiro, temos que:

$$
\alpha \beta^{\prime} X_{t-p}+\mu=\alpha \beta^{\prime} X_{t-p}+\alpha \beta_{0}^{\prime}=\alpha \beta^{*} X_{t-p}^{*}
$$

onde $\beta^{*}=\left(\beta, \beta_{0}\right)$ e $X_{t-p}^{*}=\left(X_{t-p}, 1\right)$. Os autovalores e autovetores podem ser obtidos através do procedimento normal. O teste estatístico pode ser obtido utilizando as raízes características relevantes e as matrizes $\mathbf{S}_{\mathbf{0 0}}$ de cada modelo para serem utilizadas na seguinte fórmula:

$$
-2\left(Q_{r}^{*}-Q_{r}\right)=-\left[T \ln \left|S_{00}\right|+T \sum_{i=1}^{r} \ln \left(1-\lambda_{i}\right)-T \ln \left|S_{00}^{*}\right|-T \sum_{i=1}^{r *} \ln \left(1-\lambda_{i}^{*}\right)\right]
$$

onde,

Té o número de observações;

${ }^{2}$ WEST. K. Asymptotic normality when regressors have a unit root. Econometrica 56:1397-1417, 1988. 
$Q_{t}$ e $Q^{*}{ }_{t}$ são as funções de máxima verossimilhança para os modelos irrestrito e restrito respectivamente;

$\mathbf{S}_{\mathbf{0 0}}$ e $\mathbf{S}^{*}{ }_{00}$ são as matrizes provenientes das somatórias dos quadrados dos vetores dos resíduos $\mathbf{R}_{\mathbf{0 t}}$ e $\mathbf{R}^{*}{ }_{\mathbf{o t}}$ respectivamente e divididos por $T$;

$\lambda_{i} \mathrm{e} \lambda_{i}^{*}$ são as i-ésimas raizes características dos modelos sem tendência e com tendência;

$r$ e $r^{*}$ são os números de raizes características relevantes para os modelos irrestrito $\mathrm{e}$ restrito respectivamente.

Esta estatística tem uma distribuição qui-quadrada com $n-r$ graus de liberdade. No caso de número diferentes de raízes relevantes nos modelos testados, convencionou-se usar o que proporciona o menor grau de liberdade.

A importância das variáveis binárias podem ser testadas da mesma forma que a tendência linear. Obtém-se as matrizes $\mathbf{S}_{\mathbf{0 0}}$ e $\mathbf{S}^{*} \mathbf{0 0}$ e as raízes características $\lambda_{i} \mathrm{e} \lambda_{i}^{*}$ através da estimação dos modelos VAR restrito com binária e sem binárias, respectivamente, que são utilizados na fórmula (5.4.9).

Os cálculos para a estimação e testes podem ser realizados através da rotina CATS efetuada no pacote econométrico RATS. Maiores detalhes sobre o procedimento de Johansen podem ser conseguidos em JOHANSEN (1988, 1991), JOHANSEN \& JUSELIUS (1990) LÜTKEPOHL (1991), WILLIAMS \& BEWLEY (1993) e HAMILTON(1994). 


\subsection{Modelo Autorregressivo Vetorial (VAR)}

\subsubsection{O seu uso e apresentação}

Os modelos autorregressivos vetoriais (VAR) são modelos ateóricos que utilizam somente das propriedades das séries temporais observadas para serem estimados. Pelo fato de serem não-teóricos os modelos de séries temporais vetoriais podem ser estimados sem imposição de restrições prévias que são necessárias para identificar e estimar modelos econométricos estruturais. Entretanto, o modelo VAR não pode ser usado para se fazer inferências sobre a estrutura de uma economia, mas podem ser usados para estimar parâmetros de interesse para formuladores de políticas, entre os quais os coeficientes tanto da representação autorregressiva como da média móvel (HAKKIO \& MORRIS, 1984) pois estes permitem obter, respectivamente, a decomposição da variância e as funções de resposta ao impulso.

Através do modelo VAR, portanto, pode-se fazer a decomposição da variância das respostas ao impulso, permitindo-se, assim, a determinação do sentido do fluxo de informações sobre os preços entre os leilões nas suas respectivas regiões, por exemplo, bem como o comportamento dos preços nestes leilões ao longo do tempo, dado o choque em uma das variáveis preços.

Apesar dos modelos VAR serem mais comumente utilizados nos estudos das relações que existem entre as variáveis macroeconômicas, inúmeros trabalhos de pesquisa na economia agrícola utilizam-se deste modelo para explicar a relação dinâmica que os preços de vários produtos agrícolas, por exemplo, guardam entre si, entre os quais os já citados anteriormente, GUIMARÃES (1990) e BLISKA (1989). A seguir é apresentado o modelo VAR baseado na exposição de GUIMARÃES (1990). 
Seja $X_{t}$ um processo estocástico ${ }^{1}$ estacionário com $n$ componentes. Pelo teorema de representação de Wold, todo processo estocástico não-determinístico pode ser expresso através de uma representação de médias móveis:

$$
\begin{aligned}
& X_{t}=A_{0} e_{t}+A_{1} e_{t-1}+A_{2} e_{t-2}+\ldots \\
& X_{t}=\left(A_{0} L^{0}+A_{1} L^{1}+A_{2} L^{2}+\ldots\right) e_{t} \\
& X_{t}=A(L) e_{t}
\end{aligned}
$$

onde $X_{t}$ é um vetor de $n$ séries temporais, $A_{j}$ são matrizes $(n \times n)$ de parâmetros, $A_{0}=I_{n}$ e $A(L)$ um polinômio matricial infinito em $L$ ( $L$ é o operador de defasagem) ${ }^{2}$.

$\mathrm{O}$ vetor de inovações, $e_{t}$, é um processo estocástico com média zero $\left(\mathrm{E}\left[e_{t}\right]=0\right)$, matriz de variâncias e covariâncias finitas $(\Sigma)$, o que equivale a $\mathrm{E}\left[e_{t} e_{t}^{\prime}\right]=\Sigma$, e não autocorrelacionado $\left(\mathrm{E}\left[e_{t} e_{t+k}^{\prime}\right]=0\right)$ para $k=0$; ou seja, $e_{t}$ é um ruído branco. Observe que $e_{t}$ é o erro de previsão de um período definido por

$$
e_{t}=X_{t}-\mathrm{E}\left[X_{t} / X_{t-1}, X_{t-2}, \ldots\right]
$$

Os erros de previsão de $k$ periodos são definidos por

$$
e_{t-k}=X_{t-k}-\mathrm{E}\left[X_{t-k} / X_{t}, X_{t-1}, \ldots\right], \quad \text { para } k=1,2, \ldots
$$

Quando todas as raizes do polinômio $A(L)$ forem superiores à unidade (em módulo), o processo $X_{t}$ admite uma representação autorregressiva ${ }^{3}$. Ou seja,

$$
\begin{aligned}
B_{0} X_{t}-B_{1} X_{t-1}-B_{2} X_{t-2}-\ldots & =e_{t} \\
\left(B_{0} L^{0}-B_{1} L^{1}-B_{2} L^{2}-\ldots\right) X_{t} & =e_{t} \\
B(L) x_{t} & =e_{t}
\end{aligned}
$$

onde $B_{j}$ são matrizes $(n \times n)$ de parâmetros; $B_{0}=I_{n}$ e $B(L)$ um polinômio matricial infinito em $L$. Os polinômios $A(L)$ e $B(L)$ satisfazem a relação $A(L) B(L)=I$. A

\footnotetext{
${ }^{1}$ Uma definição clara de processo estocástico pode ser encontrada em MORETIN \& TOLOI (1986, p.16).

${ }^{2} \mathrm{~L}$ é o operador de defasagem sendo que:

$L^{0} X_{t}=X_{t} ; L^{1} X_{t}=X_{t-1} ; L^{2} X_{t}=X_{t-2} ;$ etc.

${ }^{3}$ Ver BOX \& JENKINS (1976) para as condições de invertibilidade.
} 
representação autorregressiva é usada para a determinação da causalidade no sentido de Granger e para a obtenção da matriz de variância e covariância dos resíduos necessária para a decomposição da variância. Mas para isto é necessário determinar a ordem do processo, ou seja, determinar o número de defasagens a serem consideradas no modelo de modo que o processo possa ser representado. Note que (5.5.3) contém um número infinito de parâmetros. Determinada a ordem $p$, teriamos, de acordo com a notação de JUDGE (1988, p.753), um processo autorregressivo vetorial de ordem $p$ [VAR( $(p)]$ para um sistema de $n$ variáveis $X_{i}=\left(x_{1}, x_{2}, \ldots x_{n t}\right)^{\prime}$ definido como

$$
X_{t}=c+\Theta_{1} X_{t-1}+\Theta_{2} X_{t-2}+\ldots+\Theta_{p} X_{t-p}+e_{t}
$$

Neste sistema de $n$ equações $c=\left(c_{1}, c_{2}, \ldots c_{n}\right)^{\prime}$ é um vetor constante de dimensão $n$, a matriz de coeficientes

$$
\Theta_{i}=\left[\begin{array}{ccc}
\theta_{11, i} & \cdots & \theta_{1 n, i} \\
\vdots & \ddots & \vdots \\
\theta_{n 1, i} & \cdots & \theta_{n n, i}
\end{array}\right]
$$

de dimensão $(n \times n)$ e $e_{\mathrm{t}}=\left(e_{1 t}, e_{2 t}, \ldots e_{n t}\right)^{\prime}$ o vetor de resíduos. Na seção seguinte são discutidas algumas formas de se determinar o número de defasagens.

\subsubsection{Determinação das defasagens}

Modelos mais parcimoniosamente parametrizados, como destaca JUDGE et al. (1988, p. 761), podem prover previsões mais acuradas e são consequentemente preferidos para propósitos de previsões. Nos modelos VAR puros, restrições de parâmetros podem, algumas vezes, ajudar no aumento da eficiência da estimação e previsão. Mesmo se, em uma particular situação, um processo VAR puro é um modelo adequado para o processo gerador de uma série temporal multipla, a ordem do processo 
será geralmente desconhecida. Este tem sido estimado através dos dados assim como os coeficientes do processo. No caso univariado, a escolha adequada da ordem de um processo autorregressivo é baseada nas autocorrelações parciais. Para processos vetoriais, as autocorrelações parciais são matrizes e a escolha da ordem do modelo através da inspeção visual destas matrizes requer uma certa experiência. Certamente, testes formais poderiam ser usados para decidir sobre as suas significâncias. Uma abordagem alternativa é usar um critério designado para ajudar na escolha da ordem do VAR. Um teste tradicional para a determinação da ordem é a razão de verossimilhança que é um teste sequencial que permite verificar se entre duas ordens o aumento do poder explicativo é significativo ou não. Há outros testes ou críterios de informação que fornecem um valor para a ordem testada e por isso permitem a comparação direta entre as ordens testadas. Por serem mais práticos, os críterios de informação serão utilizados nesta pesquisa.

O critério de informação é baseado na minimização de uma função-objetivo. Especifica-se um limite superior $n$ para a ordem da autorregressão e a função-objetivo é avaliada para todas as ordens da autorregressão $\operatorname{com} j=0,1, \ldots, p$. Então o $\hat{p}$ estimado é escolhido de forma que a função-objetivo assume seu mínimo para uma $\operatorname{AR}(\hat{p})$.

Três critérios usados para os modelos de defasagens distribuídas, os critérios de Akaike (AIC), Hannan-Quinn (HQ) e Schwarz (SC), podem ser generalizados para a escolha da ordem do VAR (JUDGE et al., 1988, p.761 e LÜTKEPOHL,1993, p.128). Dentro do contexto estes critérios são definidos como seguem:

$$
\begin{aligned}
& \operatorname{AIC}(p)=\ln \operatorname{det}\left(\hat{\Sigma}_{p}\right)+\frac{2 n^{2} p}{T} \\
& H Q(p)=\ln \operatorname{det}\left(\hat{\Sigma}_{p}\right)+\frac{2 n^{2} p \ln \ln T}{T}
\end{aligned}
$$




$$
\operatorname{SC}(p)=\ln \operatorname{det}\left(\hat{\Sigma}_{p}\right)+\frac{n^{2} p \ln T}{T}
$$

onde $n$ é o número de variáveis no sistema, $T$ é o tamanho da amostra, e $\hat{\Sigma}_{p}$ é uma estimativa da matriz $\Sigma_{e}$ de covariância dos resíduos obtidos com um modelo de autorregressão vetorial de ordem $p(\operatorname{VAR}(p))$. Os elementos de $\hat{\Sigma}_{p}$ são computados como:

$$
\tilde{\sigma}_{i j}=\frac{\left(\mathrm{y}^{i}-X \hat{\theta}_{i}\right)^{\prime}\left(\mathrm{y}^{j}-X \hat{\theta}_{j}\right)}{T}
$$

onde,

T é o total de observações da amostra;

$\mathbf{y}^{i}, \mathbf{y}^{j}$ são os vetores das variáveis dependentes observadas; $X \hat{\theta}_{i}$ e $X \hat{\theta}_{j}$ são os vetores com os valores estimados da variáveis dependentes e;

$i$ e $j$ identificam a posição dos elementos $\tilde{\sigma}_{i j}$ na matriz $\hat{\Sigma}_{p}$, e as equações relacionadas do sistema.

A ordem $p$ é escolhida desde que o critério AIC, HQ ou SC seja minimizado. Ou seja, os modelos com ordem $p=0,1, \ldots, P$ são estimados com $P$ pré-especificado no limite superior para a ordem da autorregressão vetorial. Então, as matrizes $\hat{\Sigma}_{p}$. para $p=$ $0,1, \ldots, P$ e os correspondentes valores $\operatorname{AIC}(p), \mathrm{HQ}(p)$ ou $\mathrm{SC}(p)$ são computados. O valor $p(\mathrm{AIC})$ é a ordem que minimiza $\operatorname{AIC}(p)$ para $p=0,1, \ldots, P, p(\mathrm{HQ})$ a ordem que minimiza $\mathrm{HQ}(p)$ e $p(\mathrm{SC})$ e a ordem que minimiza $\mathrm{SC}(p)$. Neste procedimento o tamanho da amostra $T$ (número total de observações) é mantido fixo. 


\subsubsection{A função de resposta ao impulso e a decomposição da variância}

Com a ordem $p$ determinada e (5.5.3) estimada, pode-se estudar os choques ou inovações no processo $X_{t}$. assim como a decomposição da variância. A apresentação sobre a função de resposta ao impulso e a decomposição da variância é baseada em GUIMARÃES (1990), cuja exposição é clara e didática, sendo que maiores detalhes podem ser encontrados em HAKKIO \& MORRIS (1984), BRANDÃO (1985) e JUDGE et al. $(1988$, p. 771$)$.

Considerando a representação de médias móveis (5.5.1) com duas variáveis para facilidade do entendimento,

$$
\left[\begin{array}{l}
x_{1 t} \\
x_{2 t}
\end{array}\right]=\left[\begin{array}{ll}
1 & 0 \\
0 & 1
\end{array}\right]\left[\begin{array}{l}
e_{1 t} \\
e_{2 t}
\end{array}\right]+\left[\begin{array}{ll}
a_{11}^{1} & a_{12}^{1} \\
a_{21}^{1} & a_{22}^{1}
\end{array}\right]\left[\begin{array}{l}
e_{1, t-1} \\
e_{2, t-1}
\end{array}\right]+\left[\begin{array}{ll}
a_{11}^{2} & a_{12}^{2} \\
a_{21}^{2} & a_{22}^{2}
\end{array}\right]\left[\begin{array}{l}
e_{1, t-2} \\
e_{2, t-2}
\end{array}\right]+\ldots
$$

a $i$-ésima coluna de $A_{k}$ mede o efeito de um choque (inovação) unitário no $i$-ésimo componente do vetor de inovações no período $(t-k)$ sobre $X$ no período $t$. A primeira coluna de $A_{1}$ mede as respostas de $X_{t}$ a um dado choque unitário no primeiro componente do vetor de inovações no período $t-1 \operatorname{com}\left(e_{1, t-1}=1\right)$ e com $e_{2, t-1}=0$.

Obtendo-se os coeficientes da representação de médias móveis, é possível descrever o comportamento dinâmico dos componentes do sistema dada uma variação em qualquer um deles. Mas os choques em $e_{1 t}, e_{2 t}, \ldots, e_{n t}$ podem ocorrer simultaneamente com uma probabilidade não nula, portanto, a matriz de variâncias e covariâncias de $e_{t}$ ( $\Sigma$ e) não é necessariamente diagonal. Desta forma, um choque em $e_{1, t-j}$ pode ser acompanhado por alterações contemporâneas nos demais $e_{i, t-j}$ inviabilizando a previsão de respostas a choque em uma das séries consideradas sobre as demais. Por isso, deve-se diagonalizar a matriz de variâncias e covariâncias $\Sigma_{e}$. Existe várias formas de se diagonalizar uma matriz sendo que a mais usual para o processo VAR é a decomposição de Cholesky. 
Como $\Sigma_{e}$ é uma matriz $(n \times n)$ positva definida, então existe uma matriz $C$ nãosingular e triangular inferior de característica $n$, de forma que $\Sigma_{e}=C C^{\prime}$ e que

$$
\left(C^{-1}\right) \Sigma\left(C^{,-1}\right)=I
$$

Pode-se definir $\eta_{t}=C^{-1} e_{t}$ de modo que pré-multiplicando (5.5.3) por $C^{-1}$ obtém-se

$$
\begin{aligned}
C^{-1} B_{0} X_{t}-C^{-1} B_{1} X_{t-1}-C^{-1} B_{2} X_{t-2}-\ldots & =C^{-1} e_{t} \\
C^{-1} B(L) X_{t} & =\eta_{t}
\end{aligned}
$$

onde $\eta_{t}$ é ruído branco. $O$ procedimento garante que a matriz de variância e covariância das inovações transformadas é uma matriz identidade:

$$
\mathrm{E}\left[\eta_{t} \eta_{t}^{\prime}\right]=\mathrm{E}\left[C^{-1} e_{t} e_{t}^{\prime}\left(C^{\prime}\right)^{-1}\right]=\left[C^{-1} \Sigma\left(C^{\prime}\right)^{-1}\right]=I
$$

Qualquer correlação contemporânea entre as séries de resíduos é eliminada pela diagonalização (HAKKIO \& MORRIS, 1984, p.12; JUDGE et al. 1988, p.772). Podemos da mesma forma obter a representação de médias móveis

$$
X_{t}=A(L) C \eta_{t}
$$

Considerando o exemplo de duas variáveis novamente, as matrizes $C$ e $C^{-1}$ seriam

$$
C=\left[\begin{array}{cc}
c_{11} & 0 \\
c_{21} & c_{22}
\end{array}\right] \quad C^{-1}=\left[\begin{array}{cc}
\frac{1}{c_{11}} & 0 \\
\frac{-c_{21}}{c_{11} c_{22}} & \frac{1}{c_{22}}
\end{array}\right]
$$

Expandindo a representação de médias móveis com duas variáveis tem-se

$$
\left[\begin{array}{l}
x_{1 t} \\
x_{2 t}
\end{array}\right]=\left[\begin{array}{ll}
1 & 0 \\
0 & 1
\end{array}\right]\left[\begin{array}{cc}
c_{11} & 0 \\
c_{21} & c_{22}
\end{array}\right]\left[\begin{array}{c}
\frac{e_{1, t}}{c_{11}} \\
\frac{e_{2, t}}{c_{22}}-\frac{c_{21} e_{1, t}}{c_{11} c_{22}}
\end{array}\right]+\left[\begin{array}{ll}
a_{11}^{1} & a_{12}^{1} \\
a_{21}^{1} & a_{22}^{1}
\end{array}\right]\left[\begin{array}{cc}
c_{11} & 0 \\
c_{21} & c_{22}
\end{array}\right]\left[\begin{array}{c}
\frac{e_{1, t-1}}{c_{11}} \\
\frac{e_{2, t-1}}{c_{22}}-\frac{c_{21} e_{1, t-1}}{c_{11} c_{22}}
\end{array}\right]+\ldots,
$$

a partir do qual pode-se observar dois fatos importantes: inovações na primeira variável $e_{1 t}$ afetam contemporaneamente as variáveis posteriores, mas a primeira variável não é afetada contemporaneamente por inovações em nenhuma das demais. Assim, a primeira irá impactar da segunda em diante, a segunda irá impactar a partir da terceira, etc. mas não serão afetadas por nenhuma delas. A ordem pela qual as variáveis são posicionadas 
no sistema afeta os resultados, a menos que a covariância contemporânea entre os resíduos seja relativamente pequena (BRANDÃO, 1985, p.43). A própria matriz $C$ depende da ordem em que as variáveis são ordenadas no sistema (HAKKIO \& MORRIS, 1984, p.13).

Os coeficientes $A_{j} C$ medem as respostas do sistema dado um choque unitário em $\eta_{i, t-j}$. Para o exemplo anterior, uma variação de uma unidade em $X_{1}$ no instante $t$, equivale a considerar $\eta_{1, t}=1$ e $\eta_{2, t}=0$. Desta forma, as respostas do sistema são fornecidas pelos coeficientes $A_{j} C$ :

$$
X_{1, t}=c_{11} \text { e } X_{2, t}=c_{21}
$$

Inversamente, um choque tal que $\eta_{1, t}=0$ e $\eta_{2, t}=1$, resulta:

$$
X_{1, t}=0 \text { e } X_{2, t}=c_{22}
$$

Os demais coeficientes $A_{j} C$ medem as respostas de $X_{t}$ ao longo do tempo ( $k$ períodos à frente).

Passa-se, então, a apresentação da decomposição da variância dos erros de previsão de $k$ períodos. A partir de (5.5.2) temos que

$$
e_{t}=X_{t}-\mathrm{E}\left[X_{t} / X_{t-1}, X_{t-2}, \ldots\right]
$$

e que

$$
\mathrm{E}\left[e_{t} e_{t}^{\prime}\right]=C C^{\prime}
$$

Considerando o exemplo de duas variáveis, temos a seguinte composição da matriz $C C^{\prime}$

$$
C C^{\prime}=\left[\begin{array}{cc}
c_{11}^{2} & c_{11} c_{21} \\
c_{11} c_{21} & \left(c_{21}^{2}+c_{22}^{2}\right)
\end{array}\right] .
$$

Os elementos da diagonal principal são somas de quadrados. Verifica-se que $100 \%$ da variância do erro de previsão de um período em $X_{1, t}$ se deve a inovação em $X_{1, t}$ e que $\left[\frac{c_{21}^{2}}{c_{21}^{2}+c_{22}^{2}}\right] \times 100 \%$ da variância do erro de previsão em $X_{2, t}$ se deve à inovação em $X_{1, t}$. 


$$
X_{t+k}=A_{0} C \eta_{t+k}+A_{1} C \eta_{t+k-1}+\ldots+A_{k-1} C \eta_{t-1}+A_{k} C \eta_{t}+A_{k+1} C \eta_{t-1}+\ldots
$$

e por isso

$$
X_{t+k}-\mathrm{E}\left[X_{t+k} / X_{t}, X_{t-1}, \ldots\right]=\sum_{j=0}^{k-1} A_{j} C \eta_{t+k-j}
$$

A matriz de variância e covariância é

$$
\sum_{j=0}^{k-1} A_{j} \Sigma A_{j}^{\prime}=\sum_{j=0}^{k-1}\left(A_{j} C\right)\left(A_{j} C\right)^{\prime}
$$

A diagonal principal de cada uma das matrizes desta soma é uma soma de quadrados, e por isso pode-se atribuir à variância em cada uma das inovações, a parcela que se deve à própria inovação e as parcelas devidas às demais. No entanto este procedimento também está sujeito a ressalvas no que se refere à ordenação das variáveis.

Através da decomposição da variância e da obtenção das funções de respostas ao impulso, pode-se verificar o sentido predominante do fluxo de informações entre dois mercados; a análise das respostas ao impulso permitem conhecer, ao longo do tempo, o comportamento dos preços de todas as categorias dada uma inovação ou choque no preço do bezerro na região de Presidente Prudente, por exemplo e; a decomposição da variância nos permite observar, ao longo do tempo, o quanto o preço do boi gordo, por exemplo, pode ser mais ou menos importante na variação do preço do bezerro. 


\subsection{O procedimento desta pesquisa}

Como existem falhas ao longo das séries de preços de leilão, ou seja, as séries não são contínuas, o ferramental econométrico proposto será utilizado apenas para as séries de preços das categorias da pecuária bovina de corte para o estado de São Paulo. Para análise das relações de preços dos leilões serão utilizados a média, o desvio padrão e a regressão múltipla sem defasagens. Desta forma, pretende-se verificar os níveis médios de preços, assim como suas variabilidades e suas relações entre as categorias e entre as regiões onde ocorrem os leilões. Através da regressão multipla, pretende-se determinar a contribuição de cada variável nas três regiões consideradas. $\mathrm{O}$ procedimento para $\mathrm{O}$ cálculo da significância estatística da contribuição de cada variável em relação as demais e as correlações parciais, foi retirado de HOFFMANN \& VIEIRA (1987, p.135-141).

\subsubsection{Sequência de trabalho para estimação do modelo VAR}

Inicialmente, as séries de preços são testadas através do teste ADF para a verificação da ordem de integração. Para a determinação do número de defasagens a serem utilizadas no teste $\mathrm{ADF}$, será usado o teste $\mathrm{Q}$. Outros critérios para a determinação das defasagens como os critérios de AIC e SC e a significância do teste $t$ dos coeficientes do próprio teste $\mathrm{ADF}$ foram usados preliminarmente para fins comparativos com o teste Q e proporcionaram resultados não coerentes, com uma variabilidade grande. Será utilizada a estatística $\tau_{\tau}$. somente, pois, como pôde ser notado nos trabalhos que utilizaram estes testes, incluindo constante e tendência parece impor um maior rigor ao teste. Tratando-se de variáveis econômicas, espera-se que sejam integradas de ordem um, 
pois a observação no instante $t$ geralmente tem incorporada informação dos períodos anteriores que é constatada através da autocorrelação nos resíduos.

Se a ordem de integração das séries de preços é igual a um, passa-se ao teste de cointegração de Johansen. O procedimento de Johansen pressupõe que as séries sejam integradas de ordem um e que o vetor de resíduos seja normalmente distribuído. Para estimar o modelo VAR restrito é necessário determinar a sua ordem que nesta pesquisa é feita através dos critérios AIC, HQ e SC. Ao realizar o teste de cointegração, obtém-se o vetor de correção de erros, ou melhor dizendo, o vetor das relações de equilíbrio de longo-prazo relevantes. Como alertam ENGLE \& GRANGER (1987), LÜTKEPOHL (1991), PORTUGAL (1992) e outros trabalhos, é importante frisar que a existência da cointegração entre as variáveis no estudo condiciona a incorporação do vetor de correção de erros e por isso o modelo VAR não restrito ficaria mal especificado em nível e em diferenças. Assim sendo, realiza-se o teste de cointegração de Johansen para cada período definido para análise e obtêm-se os seus respectivos vetores de correção de erros.

Tendo a mão o vetor de resíduos relevantes e o posto da matriz $\Pi 0<\mathrm{rk}(\Pi)<\mathrm{k}$, pode-se estimar o modelo de correção de erros (VEC) que no caso desta pesquisa seria um modelo $\operatorname{VAR}(p)$ em diferenças com o vetor de correção erros incorporado. Se o posto da matriz $\operatorname{rk}(\Pi)=k$, estima-se o modelo $\operatorname{VAR}(p)$ para o vetor $X_{t}$ das variáveis e se $\operatorname{rk}(\Pi)=0$, estima-se o modelo $\operatorname{VAR}(p-1)$ em diferenças para o vetor $X_{t}$ das variáveis.

Em seguida, testa-se, através do teste de razão de verossimilhança, a importância da constante e das binárias no modelo VAR restrito para cada período.

Obtido o modelo de correção de erros, pode-se efetuar a obtenção das respostas ao impulso e a decomposição da variância, cujos resultados são interpretados utilizando a estratégia apresentada a seguir. 


\subsubsection{Alguns detalhes sobre a obtenção dos resultados}

Nesta pesquisa são consideradas duas análises com enfoques diferentes.

Na primeira análise, consideram-se as categorias da pecuária bovina de corte do estado de São Paulo. Neste caso os preços mensais do boi gordo, bezerro, garrote, boi magro e vaca gorda refletem o comportamento destas variáveis no estado num período de vinte e três anos. No processo de estimação das autorregressões vetoriais são considerados conjuntos de variáveis na sua forma logarítmica e em diferença, se assim for o caso.

Quanto a ordenação é necessário considerar algumas pressuposições que são baseadas na descrição das peculiaridades da pecuária bovina de corte. Entre os mercados da pecuária bovina de corte, o mercado do boi gordo tem o maior volume de comercialização e é o mais concentrado. Desta forma, pressupõem-se que o mercado do boi gordo seja o mais eficiente devido ao maior fluxo de informações. Partindo desta pressuposição, o preço do boi gordo passa ser considerado nesta pesquisa a variável que influencia as demais, ou seja, ela é exógena em relação às demais pelo fato de ser a que possui maior conteúdo em termos de informação. O bezerro, como um dos insumos do processo produtivo da pecuária bovina de corte, parece ser, também, uma importante fonte de informação, principalmente com o advento dos leilões e da tendência de especialização das etapas de cria, recria e engorda que têm sido constatado nos últimos dez anos. Adicionalmente, observa-se, na prática, que o mercado da vaca gorda está fortemente associado ao do boi gordo da mesma forma que o mercado do garrote está fortemente associado ao mercado do bezerro. No que diz respeito ao mercado do boi magro, observa-se um comportamento intermediário que se deve, provavelmente, a 
69.

influência recebida tanto do boi gordo como do bezerro e do garrote. Assim sendo, a ordenação das variáveis preço definida para o modelo VEC é: boi gordo, bezerro, vaca gorda, garrote e boi magro.

Se o modelo estimado for em diferença, as respostas das variáveis às inovações não devem ser interpretadas como elasticidades. Assim, as respostas das variáveis às inovações devem ser interpretadas em termos de variação da mudança de preços, ou seja, taxa de crescimento dos preços, e não em termos de variação percentual dos preços apenas.

Quanto à verificação da mudança no sentido da transmissão de preço quando se passa da fase ascendente para a fase descendente do ciclo pecuário plurianual, esta é feita através da decomposição da variância, obtida da estimação do modelo nos respectivos períodos.

Na segunda análise são consideradas, de forma mais restrita, as regiões de maior relevância assim como os preços médios de bezerro e garrote dos leilões. As séries de preços são semanais cobrindo um periodo de tempo menor, ou seja, três anos. $O$ enfoque é, portanto, sobre as relações entre preços de bezerro e garrote nas diferentes regiões. 


\section{RESULTADOS E DISCUSSÃO}

\subsection{Categorias da pecuária de corte}

\subsubsection{Alguns aspectos dos preços relativos}

As séries foram analisadas na sua forma original antes de aplicar qualquer tipo de ferramental econométrico. Os preços deflacionados das cinco categorias foram colocados graficamente nas figuras 6.1 .1 e 6.1.2. O ciclo pecuário plurianual é bem evidente de junho de 1970 a junho de 1982. Após este período, o comportamento dos preços não caracteriza mais os ciclos pecuários, como pode-se observar pelas figuras citadas anteriormente. Com este fato justifica-se a divisão da série em dois períodos para o estudo. Além disso, nota-se, também, que nos últimos dez anos as oscilações estão cada vez menores. Pela semelhança no comportamento dos preços, praticamente não existe motivos para as séries não cointegrarem, o que será verificado na seção seguinte. Para obtenção dos preços relativos do boi gordo e da vaca gorda, considerou-se 16,5 e 10 arrobas de peso médio para o boi gordo e a vaca gorda, respectivamente. 


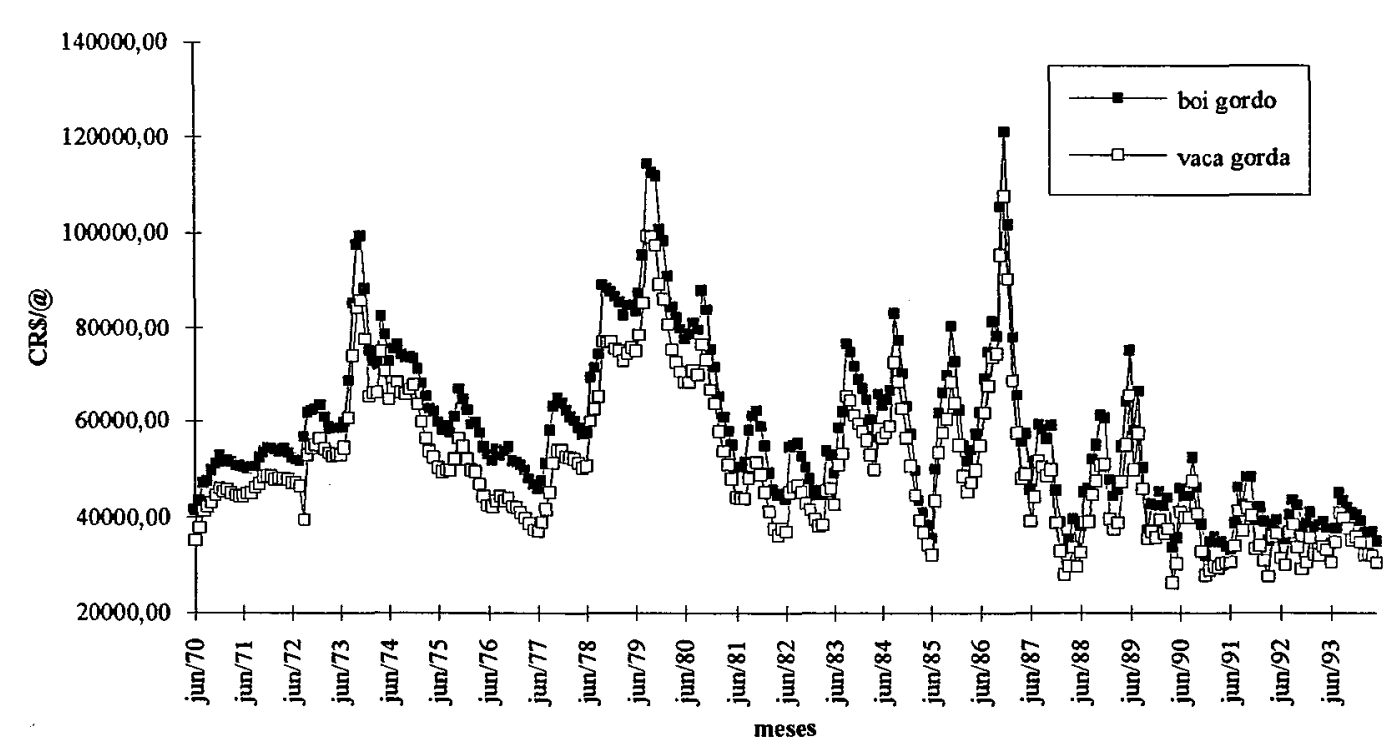

Figura 6.1.1 - Preços do boi gordo e da vaca gorda em cruzeiros por arroba no estado de São Paulo para o período de junho de 1970 a maio de 1994 (base monetária: maio de 1994).

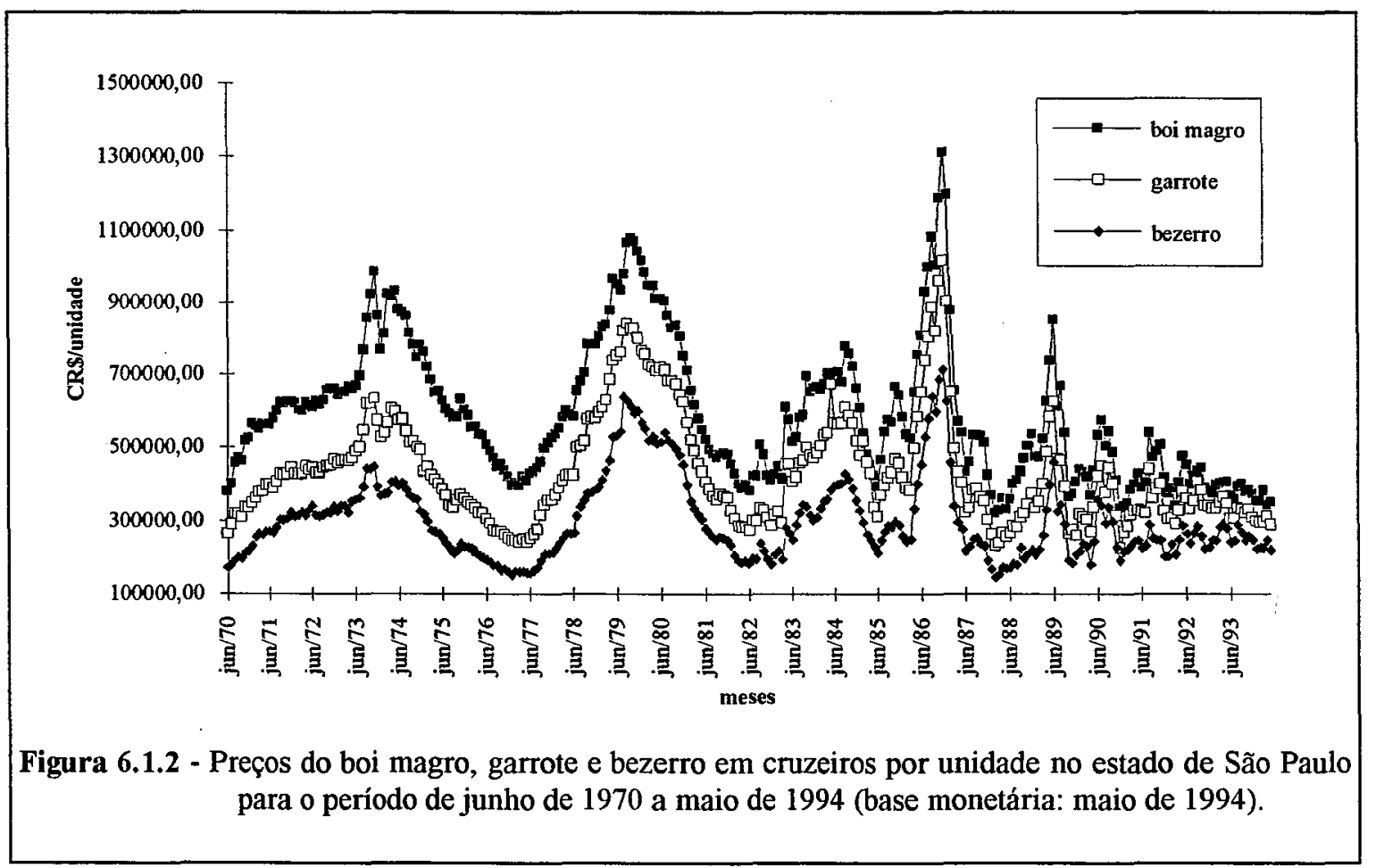


Através das relações de preços apresentadas nas figuras 6.1.3, 6.1.4, 6.1.5 e 6.1 .6 e de algumas médias das relações de trocas apresentadas na tabela 6.1.1 percebe-se uma pequena tendência de queda do preço do boi gordo em relação ao do bezerro, principalmente nos últimos anos das séries. Foi notado, também, que a relação entre as categorias de mesma finalidade, como vaca e boi gordo, ou contíguas, como bezerro e garrote, parece não ter qualquer tipo de tendência o que indica comportamentos semelhantes das suas respectivas séries. Pelas figuras 6.1 .5 e 6.1.6, também foi constatado uma leve tendência de aumento do preço do bezerro em relação aos preços do boi magro e do garrote. Ainda pela tabela 6.1.1 nota-se como as médias revelam a queda das relações boi gordo/bezerro, boi magro/bezerro e boi magro/garrote e a estabilidade das relações boi gordo/vaca gorda, boi gordo/boi magro e garrote/bezerro. Percebe-se, então, que o pecuarista responsável pela fase de engorda e recria está pagando relativamente mais pelo bezerro, garrote e boi magro, principalmente nos últimos cinco anos, como se observa na tabela 6.1.1.

No periodo em que o ciclo pecuário é mais evidente, as relações de preços são aparentemente inversas. Ou seja, o período correspondente à fase ascendente do ciclo pecuário, corresponde à uma fase descendente nos preços relativos (figuras 6.1.3, 6.1.5, $6.1 .6,6.1 .7$ e 6.1 .8$)$.

Tabela 6.1.1- Algumas relações de troca entre as categorias da pecuária bovina de corte para os períodos de junho de 1970 a junho de 1982, junho de 1982 a maio de 1994 e janeiro de 1990 a maio de 1994

\begin{tabular}{lccc}
\hline \multicolumn{1}{c}{ relação de troca ${ }^{1}$} & junho/70-junho/82 & junho/82-maio/94 & janeiro/90-maio/94 \\
\hline boi gordo / boi magro & 1,66 & 1,64 & 1,59 \\
boi magro / garrote & 1,45 & 1,30 & 1,23 \\
garrote / bezerro & 1,47 & 1,45 & 1,36 \\
boi gordo / bezerro & 3,59 & 3,11 & 2,66 \\
boi gordo / vaca gorda & 1,16 & 1,15 & 1,16 \\
boi magro / bezerro & 2,15 & 1,88 & 1,67 \\
\hline
\end{tabular}

1 - como os preços do boi gordo e da vaca gorda são cruzeiros por arroba $(15 \mathrm{Kg})$, utilizou-se os pesos médios de 16,5 arrobas para o boi gordo e 10 arrobas para a vaca gorda

Fonte: resultados da pesquisa. 


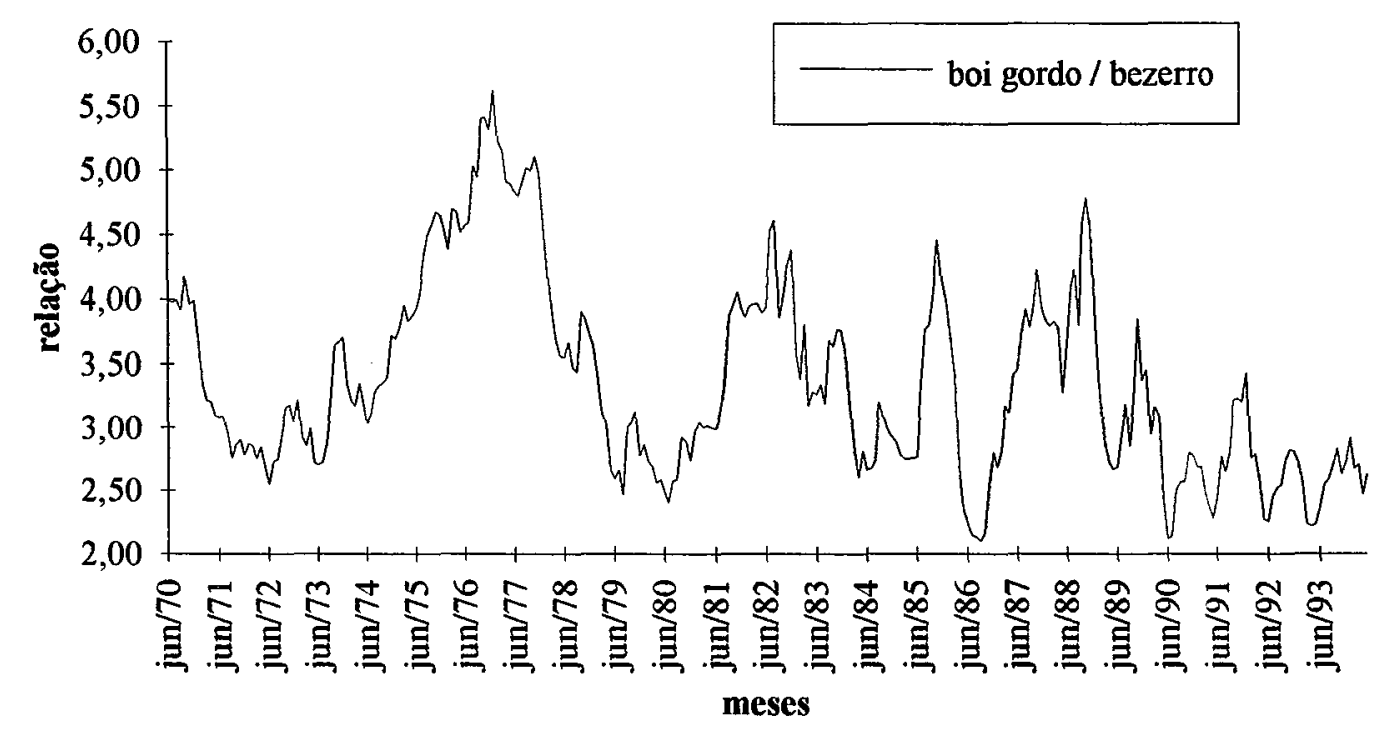

Figura 6.1.3 - Relação de preços entre boi gordo e bezerro para o estado de São Paulo.

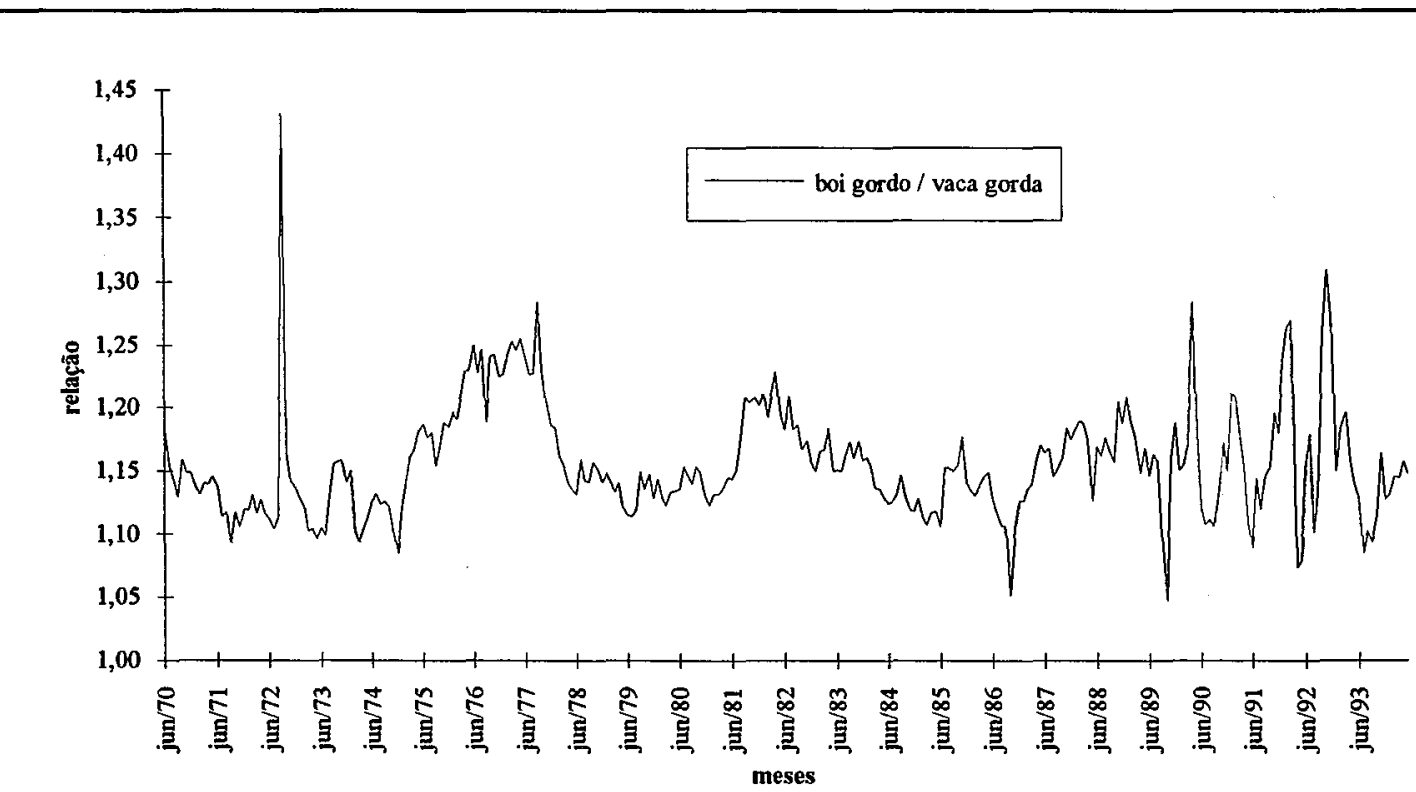

Figura 6.1.4 - Relação de preços entre boi gordo e vaca gorda no estado de São Paulo. 


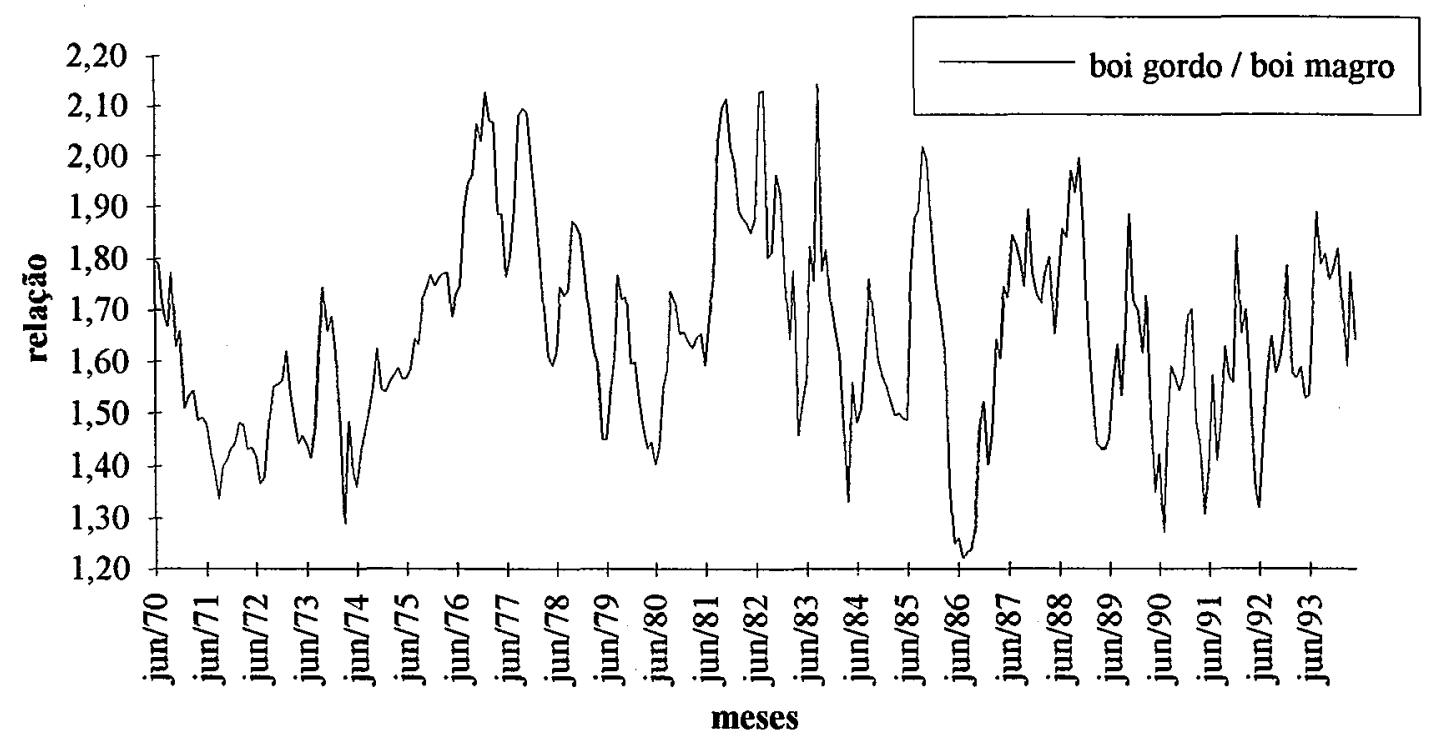

Figura 6.1.5 - Relação de preços entre boi gordo e boi magro no estado de São Paulo.

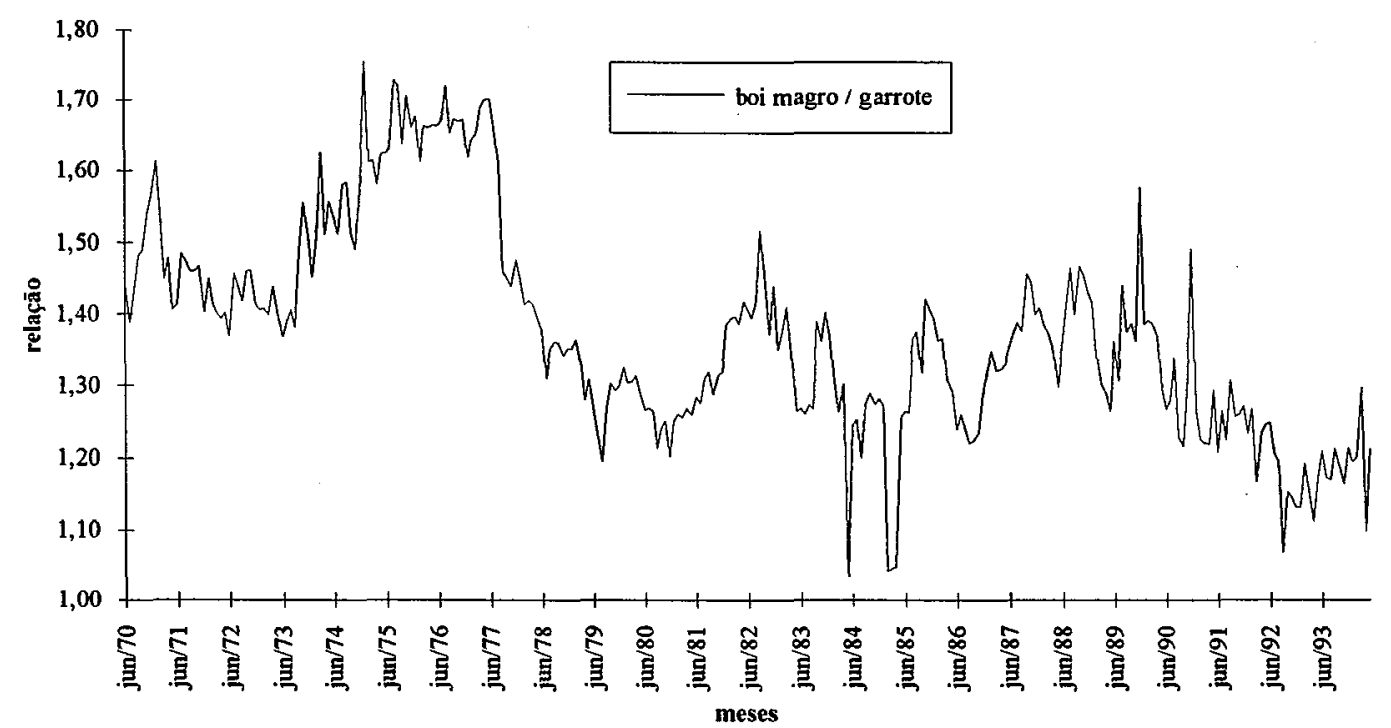

Figura 6.1.6 - Relação de preços entre boi magro e garrote no estado de São Paulo. 


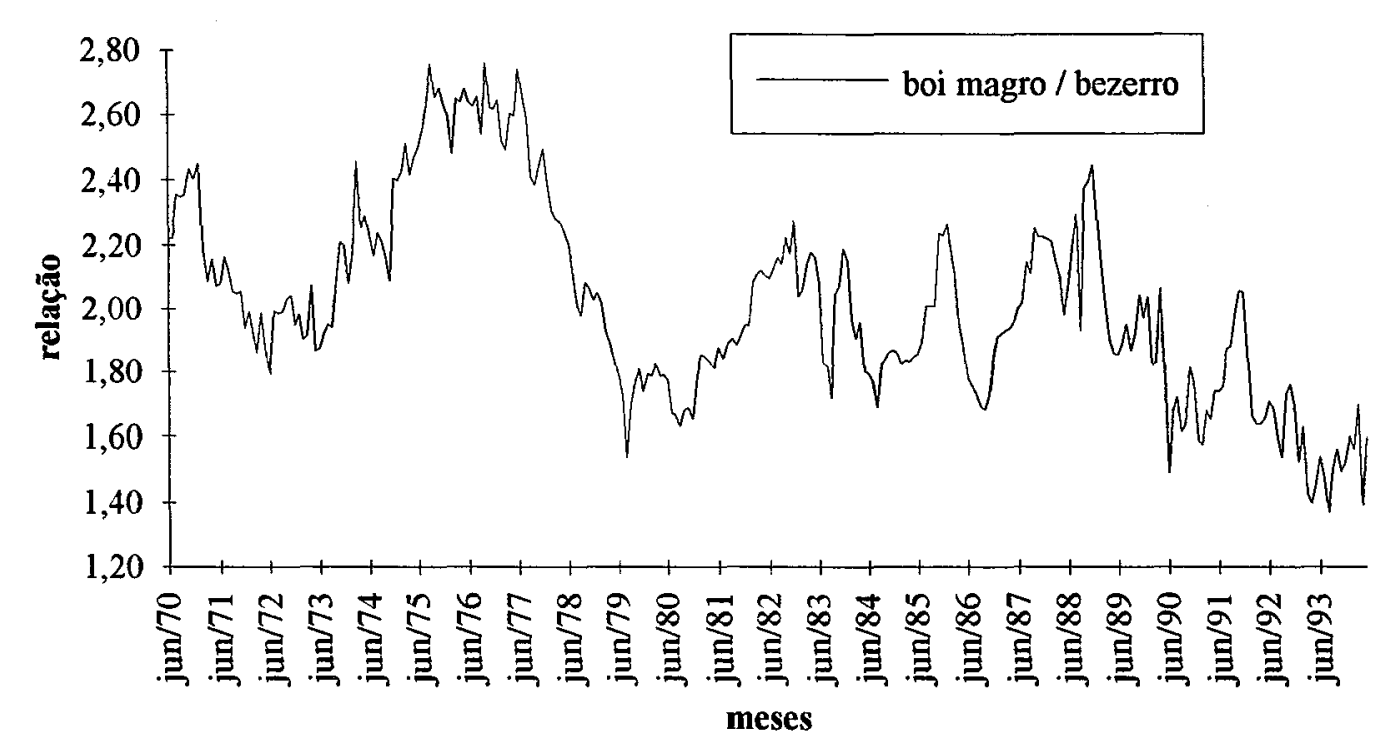

Figura 6.1.7 - Relação de preços entre boi magro e bezerro no estado de São Paulo.

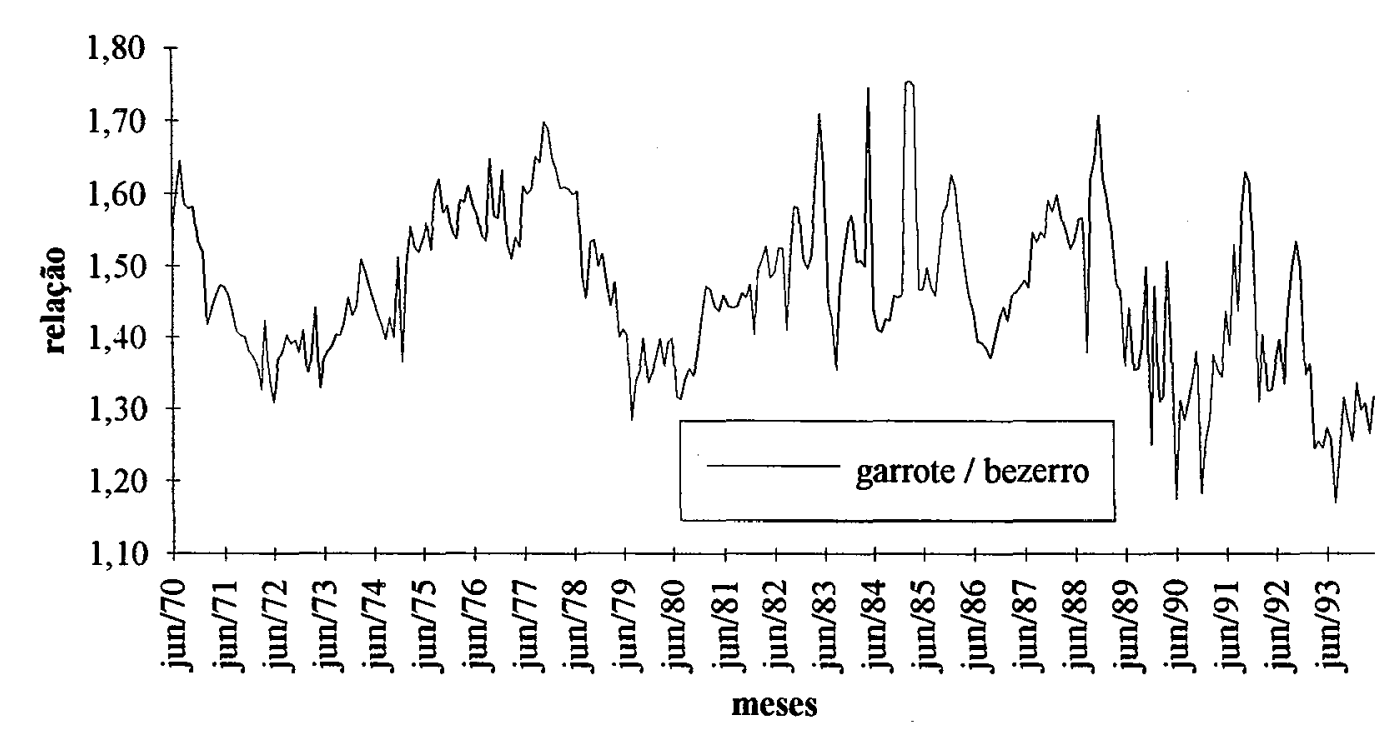

Figura 6.1.8 - Relação de preços entre garrote e bezerro no estado de São Paulo. 


\subsubsection{Teste de integração e cointegração}

\section{a) teste ADF}

Para a determinação da ordem de integração das séries mensais da pecuária de bovina de corte, foi utilizado o teste Dickey-Fuller Expandido (ADF) considerando-se a tendência, ou seja, a estatística $\tau_{\tau}$ ao nível de $5 \%$ de significância. $O$ nível de significância adotado para o teste Q que determina o número de defasagens do teste $\mathrm{ADF}$ foi de $90 \%$. Ou seja, as defasagens foram incluidas na regressão do teste $\mathrm{ADF}$ até que o nível de significância do teste $Q$ fosse igual ou superior a noventa por cento, o que pode ser considerado suficiente para os erros serem ruídos brancos, ou seja, não autocorrelacionados. Os resultados da estatística $\tau_{\tau}$ encontram-se na tabela 6.1 .2 a seguir.

Tabela 6.1.2 - Teste Dickey-Fuller Expandido (ADF) e suas respectivas defasagens ${ }^{1}$ para a determinação da ordem de integração das séries estudadas

\begin{tabular}{lcccc}
\hline & teste ADF & defasagens & teste ADF & defasagens \\
& $\mathrm{I}(\mathbf{1})$ & & $\mathrm{I}(2)$ & \\
\hline bezerro & $-3,055$ & 25 & $-3,774$ & 26 \\
garrote & $-2,938$ & 20 & $-4,556$ & 20 \\
boi magro & $-3,081$ & 27 & $-3,825$ & 29 \\
boi gordo & $-2,829$ & 20 & $-4,854$ & 22 \\
vaca gorda & $-2,741$ & 23 & $-4,917$ & 24 \\
\hline
\end{tabular}

1 - As defasagens foram determinadas pelo teste $Q$ sendo que o nível de significância adotado como critério foi igual ou superior a $90 \%$

obs.: O nível de significância adotado para o teste ADF foi $5 \%$

Fonte:resultados da pesquisa.

De acordo com os valores críticos tabulados por FULLER (1976, p.373) a $5 \%$ de significância (apêndice), não se rejeita a hipótese da nulidade de que cada uma das séries não é estacionária. As séries sendo integradas de ordem um, foram, então, testadas para saber se seriam integradas de ordem dois. Pela estatística $\tau_{\tau}$, rejeita-se a hipótese da 
nulidade de que cada uma das séries é integrada de ordem dois ao nível de $5 \%$ de significância.

Sendo todas as séries integradas de ordem um, pode-se testar a cointegração entre estas variáveis, o que equivale a verificar e testar combinações lineares destas variáveis que são integradas de ordem zero. $\mathrm{O}$ procedimento de Johansen foi utilizado para verificar a cointegração ou não dessas séries.

\section{b) Procedimento de Johansen}

Para testar cointegração pelo procedimento de Johansen, foi, inicialmente, determinada a ordem do modelo autorregressivo vetorial (VAR) restrito. A determinação da ordem foi feita através dos critérios de informação de Akaike (AIC), Hannan-Quinn (HQ) e Schwarz (SC). O teste de cointegração, assim como a determinação dos vetores de correção de erros, foram realizados para todos os períodos definidos no capítulo 5, considerando todas as possibilidades quanto à inclusão ou não da constante e das binárias. Isto foi necessário para testar a importância da constante e das

variáveis binárias no modelo de correção de erros (VEC). As ordens para todas as combinações em cada um dos períodos estão na tabela 6.1.3. 
Tabela 6.1.3 - Relação das ordens definidas pelos critérios de Akaike (AIC), Hannan-Quinn (HQ) e Schwarz (SC) para cada combinação possível do modelo nos períodos definidos na metodologia

\begin{tabular}{llll}
\hline & \multicolumn{3}{c}{ ordem do VAR } \\
\cline { 2 - 4 } período e combinação & AIC & HQ & SC \\
\hline com constante e com binárias & 3 & 2 & 2 \\
junho/70 a junho/82 & 2 & 2 & 2 \\
junho/82 a maio/94 & 4 & 4 & 4 \\
junho/70 a novembro/73 & 4 & 4 & 4 \\
novembro/73 a junho/77 & & 2 & 2 \\
com constante e sem binárias & 2 & 2 & 2 \\
junho/70 a junho/82 & 2 & 6 & 6 \\
junho/82 a maio/94 & 6 & 6 & 6 \\
junho/70 a novembro/73 & 6 & 2 & 2 \\
novembro/73 a junho/77 & & 2 & 2 \\
sem constante e com binárias & 3 & 4 & 4 \\
junho/70 a junho/82 & 2 & 4 & 2 \\
junho/82 a maio/94 & 4 & & 2 \\
junho/70 a novembro/73 & 4 & 2 & 6 \\
novembro/73 a junho/77 & & 2 & 6 \\
sem constante e sem binárias & 2 & 6 & \\
junho/70 a junho/82 & 2 & 6 & \\
junho/82 a maio/94 & 6 & & \\
junho/70 a novembro/73 & 6 & & \\
novembro/73 a junho/77 & & &
\end{tabular}

Fonte: resultados da pesquisa.

Pelas ordens obtidas, verifica-se que o critério de Akaike, em algumas das combinações, indicou uma defasagem a mais que os outros critérios, confirmando LÜTKEPOHL(1993), que diz que o critério de Akaike tende a superestimar a ordem do VAR. A ordem do VAR restrito é definida nesta pesquisa pelo critério de Schwarz (SC) e pelo critério de Hannan-Quinn (HQ) que indicam defasagem igual a dois. De acordo com LUTKEPOHL (1993), o critério de Schwarz (SC) é o mais parcimonioso dos três critérios.

É interessante destacar que o valor mínimo para a ordem do VAR é dois, pois, a ordem do VEC é igual a ordem do VAR restrito menos um. 
Para os períodos que correspondem, respectivamente, às fases ascendentes e descendentes do ciclo pecuário plurianual definido na metodologia, os critérios calculados foram prejudicados pelo número de observações disponiveis. Mas, para ordem igual a dois, é possível estimar o VAR restrito para as ambas as fases do ciclo pecuário e ainda ter uma folga em termos de graus de liberdade. Assim sendo, os modelos VAR restritos são estimados com ordem igual a dois.

Determinada a ordem, estima-se o VAR restrito para obter o teste do traço e o lâmbda máximo, assim como os coeficientes $\beta$ que fornecem os vetores de correção de erros.

Os resultados dos testes traço e lâmbda máximo são apresentados nas tabelas 6.1.4 e 6.1.5, respectivamente, para os casos da não existência de tendência linear e o da existência de tendência linear. Como pode-se verificar em alguns casos, o teste traço indicou um número de relações de cointegração diferente do teste lâmbda máximo. Nestes casos, considerou-se o maior para a obtenção da matriz beta. $\mathrm{O}$ nível de significância adotado para o teste de cointegração foi $95 \%$ para $n-r$ graus de liberdade. Os valores críticos usados estão tabulados em JOHANSEN \& JUSELIUS (1990, p.208209). Para o período no qual o ciclo pecuário é bem evidente, ou seja, de junho de 1970 a junho de 1982, verificou-se um número de vetores de cointegração menor em relação ao outro período no qual o ciclo pecuário já não é mais evidente, ou seja, de junho de 1982 a maio de 1994.

No período correspondente à fase ascendente do ciclo pecuário obteve-se um número de relações de cointegração menor que a fase descendente sendo que em alguns casos o teste traço indicou o posto matriz $\Pi$ igual a zero. Os coeficientes das relações de cointegração estão relacionados nas tabelas 6.1 .6 e 6.1.7, respectivamente para o caso da não existência de tendência linear e o caso da existência de tendência linear. 
Tabela 6.1.4 - Teste traço e lâmbda máximo para o caso da não existência de tendência linear para cada período, considerando a inclusão e a não inclusão das variáveis binárias

\begin{tabular}{|c|c|c|c|c|c|}
\hline & \multicolumn{5}{|c|}{ Ho } \\
\hline & $r<=4$ & $r<=3$ & $\mathrm{r}<=2$ & $r<=1$ & $\mathbf{r}<=0$ \\
\hline \multicolumn{6}{|l|}{ teste traço } \\
\hline valores críticos a $95 \%$ & 9,094 & 20,168 & 35,068 & 53,347 & 75,328 \\
\hline valores críticos a $99 \%$ & 12,740 & 24,988 & 40,198 & 60,054 & 82,969 \\
\hline \multicolumn{6}{|l|}{ valores calculados } \\
\hline \multicolumn{6}{|l|}{ sem constante e binárias } \\
\hline junho de 70 a junho de 82 & 1,711 & 5,969 & 17,000 & 48,579 & 89,528 \\
\hline junho de 82 a maio de 94 & 4,308 & 19,219 & 43,032 & 76,745 & 131,841 \\
\hline junho de 70 a novembro de 73 & 4,272 & 15,355 & 29,567 & 48,006 & 78,288 \\
\hline novembro de 73 a junho de 77 & 6,250 & 13,064 & 28,120 & 67,265 & 107,334 \\
\hline \multicolumn{6}{|l|}{ sem constante e com binárias } \\
\hline junho de 70 a junho de 82 & 1,765 & 6,292 & 11,784 & 36,470 & 79,958 \\
\hline junho de 82 a maio de 94 & 3,576 & 15,821 & 37,852 & 68,204 & 122,289 \\
\hline junho de 70 a novembro de 73 & 2,155 & 12,199 & 28,569 & 52,816 & 101,712 \\
\hline novembro de 73 a junho de 77 & 6,401 & 13,287 & 38,963 & 74,336 & 153,807 \\
\hline \multicolumn{6}{|l|}{ lâmbda máximo } \\
\hline valores críticos a $95 \%$ & 9,094 & 15,752 & 21,894 & 28,167 & 34,397 \\
\hline valores críticos a $99 \%$ & 12,740 & 19,834 & 26,409 & 33,121 & 39,672 \\
\hline \multicolumn{6}{|l|}{ valores calculados } \\
\hline \multicolumn{6}{|l|}{ sem constante e binárias } \\
\hline junho de 70 a junho de 82 & 1,711 & 4,259 & 11,031 & 31,579 & 40,949 \\
\hline junho de 82 a maio de 94 & 4,308 & 14,910 & 23,813 & 33,713 & 55,095 \\
\hline junho de 70 a novembro de 73 & 4,272 & 11,083 & 14,212 & 18,439 & 30,282 \\
\hline novembro de 73 a junho de 77 & 6,250 & 6,814 & 15,056 & 39,145 & 40,069 \\
\hline \multicolumn{6}{|l|}{ sem constante e com binárias } \\
\hline junho de 70 a junho de 82 & 1,765 & 4,527 & 5,492 & 24,687 & 43,488 \\
\hline junho de 82 a maio de 94 & 3,576 & 12,245 & 22,031 & 30,352 & 54,085 \\
\hline junho de 70 a novembro de 73 & 2,155 & 10,044 & 16,370 & 24,247 & 48,897 \\
\hline novembro de 73 a junho de 77 & 6,401 & 6,886 & 25,676 & 35,373 & 79,471 \\
\hline
\end{tabular}

Obs.: Os valores críticos foram obtidos de JOHANSEN \& JUSELIUS (1990 p.208-209)

Fonte: resultado da pesquisa. 
Tabela 6.1.5 - Teste traço e lâmbada máximo para o caso da existência de tendência linear para cada período. considerando a inclusão e a não inclusão das variáveis binárias

\begin{tabular}{|c|c|c|c|c|c|}
\hline & \multicolumn{5}{|c|}{ Ho } \\
\hline & $r<=4$ & $r<=3$ & $\mathrm{r}<=2$ & $\mathrm{r}<=1$ & $r<=0$ \\
\hline \multicolumn{6}{|l|}{ teste traço } \\
\hline valores críticos a $95 \%$ & 8,083 & 17,844 & 31,256 & 48,419 & 69,977 \\
\hline valores críticos a $99 \%$ & 11,576 & 21,962 & 37,291 & 55,551 & 77,911 \\
\hline \multicolumn{6}{|l|}{ valores calculados } \\
\hline \multicolumn{6}{|l|}{ com constante e binárias } \\
\hline junho de 70 a junho de 82 & 1,683 & 6,209 & 11,700 & 36,367 & 79,854 \\
\hline junho de 82 a maio de 94 & 3,106 & 15,298 & 37,321 & 67,656 & 121,696 \\
\hline junho de 70 a novembro de 73 & 0,625 & 10,663 & 26,058 & 50,016 & 91,998 \\
\hline novembro de 73 a junho de 77 & 0,036 & 6,682 & 32,314 & 67,605 & 146,037 \\
\hline \multicolumn{6}{|l|}{ com constante e sem binárias } \\
\hline junho de 70 a junho de 82 & 1,637 & 5,892 & 16,918 & 48,486 & 89,434 \\
\hline junho de 82 a maio de 94 & 4,059 & 18,909 & 42,720 & 76,432 & 131,463 \\
\hline junho de 70 a novembro de 73 & 1,469 & 12,461 & 26,348 & 44,680 & 70,297 \\
\hline novembro de 73 a junho de 77 & 0,056 & 6,423 & 21,326 & 60,212 & 100,258 \\
\hline \multicolumn{6}{|l|}{ lâmbda máximo } \\
\hline valores criticos a $95 \%$ & 8,083 & 14,595 & 21,279 & 27,341 & 33,262 \\
\hline valores críticos a $99 \%$ & 11,576 & 18,782 & 26,154 & 32,616 & 38,858 \\
\hline \multicolumn{6}{|l|}{ valores calculados } \\
\hline \multicolumn{6}{|l|}{ com constante e binárias } \\
\hline junho de 70 a junho de 82 & 1,683 & 4,525 & 5,491 & 24,667 & 43,487 \\
\hline junho de 82 a maio de 94 & 3,106 & 12,192 & 22,023 & 30,335 & 54,040 \\
\hline junho de 70 a novembro de 73 & 0,625 & 10,037 & 15,395 & 23,959 & 41,981 \\
\hline novembro de 73 a junho de 77 & 0,036 & 6,645 & 25,633 & 35,291 & 78,432 \\
\hline \multicolumn{6}{|l|}{ com constante e sem binárias } \\
\hline junho de 70 a junho de 82 & 1,637 & 4,255 & 11,025 & 31,568 & 40,948 \\
\hline junho de 82 a maio de 94 & 4,059 & 14,850 & 23,811 & 33,712 & 55,031 \\
\hline junho de 70 a novembro de 73 & 1,469 & 10,992 & 13,886 & 18,332 & 25,616 \\
\hline novembro de 73 a junho de 77 & 0,056 & 6,367 & 14,902 & 38,886 & 40,046 \\
\hline
\end{tabular}

Obs.: Os valores críticos foram obtidos de JOHANSEN \& JUSELIUS (1990 p.208-209)

Fonte: resultados da pesquisa. 
82.

Tabela 6.1.6 - Relações de cointegração relevantes para os casos de inclusão e não inclusão da variáveis binárias no modelo, em cada período, pressupondo a não existência da tendênci linear

\begin{tabular}{|c|c|c|c|c|c|c|c|}
\hline & $z_{i}^{1}$ & constante & bezerro & boi gordo & boi magro & garrote & $\begin{array}{l}\text { vaca } \\
\text { gorda }\end{array}$ \\
\hline \multicolumn{8}{|l|}{ sem constante e binárias } \\
\hline \multirow[t]{2}{*}{ junho/70 a junho/82 } & $\mathrm{z}_{1}$ & 48,165 & 7,013 & $-34,225$ & $-6,407$ & $-14,045$ & 46,737 \\
\hline & $\mathrm{z}_{2}$ & $-6,088$ & $-22,121$ & $-19,156$ & 0,343 & 28,869 & 10,735 \\
\hline \multirow[t]{3}{*}{ junho/82 a maio/94 } & $z_{1}$ & 20,737 & $-0,335$ & $-33,271$ & $-4,692$ & 0,849 & 36,908 \\
\hline & $\mathrm{z}_{2}$ & $-11,311$ & 6,367 & 17,860 & $-12,817$ & $-1,178$ & $-7,308$ \\
\hline & $\mathrm{z}_{3}$ & $-12,795$ & 10,292 & $-0,577$ & 15,465 & $-22,021$ & $-2,737$ \\
\hline junho/70 a novembro/73 & $\mathrm{z}_{1}$ & $-17,791$ & 2,859 & 19,585 & $-7,669$ & 11,456 & $-25,842$ \\
\hline \multirow[t]{2}{*}{ novembro/73 a junho/77 } & $\mathrm{z}_{1}$ & 167,724 & $-20,713$ & $-48,801$ & $-41,173$ & 63,108 & 33,679 \\
\hline & $\mathrm{z}_{2}$ & $-132,274$ & $-0,225$ & 65,747 & $-17,799$ & 16,186 & $-51,615$ \\
\hline \multicolumn{8}{|l|}{ sem constante e com binárias } \\
\hline junho/70 a junho/82 & $\mathrm{z}_{1}$ & 54,102 & 9,728 & $-36,240$ & $-7,218$ & $-18,198$ & 51,036 \\
\hline \multirow[t]{3}{*}{ junho/82 a maio/94 } & $\mathrm{z}_{1}$ & 26,801 & $-2,464$ & $-38,463$ & $-0,963$ & 0,951 & 39,384 \\
\hline & $\mathrm{z}_{2}$ & $-3,706$ & 3,979 & 10,923 & $-20,422$ & 6,291 & 2,152 \\
\hline & $\mathrm{z}_{3}$ & $-11,463$ & 12,047 & 2,371 & 9,377 & $-22,119$ & $-0,299$ \\
\hline junho/70 a novembro/73 & $\mathrm{z}_{\mathrm{I}}$ & 14,161 & 7,365 & $-11,744$ & 22,914 & $-40,908$ & 22,857 \\
\hline \multirow[t]{3}{*}{ novembro/73 a junho/77 } & $z_{1}$ & 239,793 & $-6,786$ & $-40,101$ & $-20,730$ & 58,706 & $-17,498$ \\
\hline & $z_{2}$ & $-58,903$ & $-9,750$ & 44,215 & $-40,050$ & $+5,748$ & $-33,273$ \\
\hline & $\mathrm{z}_{3}$ & 45,178 & $-41,013$ & $-76,634$ & $-28,576$ & 36,388 & 112,490 \\
\hline
\end{tabular}

1 - $\mathrm{i}$ relações de cointegração que equivale $\mathrm{a} Z=\mathrm{b}^{\prime} \mathrm{X}_{\mathrm{t}}$

Fonte: resultados da pesquisa. 
Tabela 6.1.7 - Relações de cointegração relevantes para os casos de inclusão e não inclusão das variáveis binárias no modelo, em cada periodo, pressupondo a existência de tendência linear

\begin{tabular}{|c|c|c|c|c|c|c|c|}
\hline & $z_{i}^{1}$ & constante & bezerro & boi gordo & boi magro & garrote & $\begin{array}{r}\text { vaca } \\
\text { gorda } \\
\end{array}$ \\
\hline $\begin{array}{c}\text { com constante e binárias } \\
\text { junho/70 a junho/82 }\end{array}$ & $\mathrm{z}_{1}$ & * & $-9,724$ & 36,243 & 7,218 & 18,193 & $-51,038$ \\
\hline junho/82 a maio/94 & $\begin{array}{l}z_{1} \\
z_{2} \\
z_{3}\end{array}$ & $\begin{array}{l}* \\
* \\
*\end{array}$ & $\begin{array}{r}-2,478 \\
3,953 \\
12,041\end{array}$ & $\begin{array}{r}-38,492 \\
10,862 \\
2,354\end{array}$ & $\begin{array}{r}-0,946 \\
-20,434 \\
9,352\end{array}$ & $\begin{array}{r}0,954 \\
6,319 \\
-22,113\end{array}$ & $\begin{array}{r}39,404 \\
2,221 \\
-0,253\end{array}$ \\
\hline junho/70 a novembro/73 & $\begin{array}{l}z_{1} \\
z_{2}\end{array}$ & * & $\begin{array}{l}-12,344 \\
-17,382\end{array}$ & $\begin{array}{r}12,800 \\
-18,104\end{array}$ & $\begin{array}{r}-24,713 \\
38,467\end{array}$ & $\begin{array}{r}51,583 \\
2,817\end{array}$ & $\begin{array}{r}-27,178 \\
-2,435\end{array}$ \\
\hline novembro/73 a junho/77 & $\begin{array}{l}z_{1} \\
z_{2} \\
z_{3}\end{array}$ & $\begin{array}{l}* \\
* \\
*\end{array}$ & $\begin{array}{r}6,867 \\
9,861 \\
41,072\end{array}$ & $\begin{array}{r}40,462 \\
-44,477 \\
77,492\end{array}$ & $\begin{array}{l}21,122 \\
39,979 \\
28,506\end{array}$ & $\begin{array}{l}-59,686 \\
-45,185 \\
-36,705\end{array}$ & $\begin{array}{r}18,026 \\
32,539 \\
-112,689\end{array}$ \\
\hline $\begin{array}{l}\text { com constante e sem binárias } \\
\text { junho/70 a junho/82 }\end{array}$ & $\begin{array}{l}z_{1} \\
z_{2}\end{array}$ & * & $\begin{array}{r}-7,015 \\
22,121\end{array}$ & $\begin{array}{l}34,224 \\
19,165\end{array}$ & $\begin{array}{r}6,407 \\
-0,342\end{array}$ & $\begin{array}{r}14,048 \\
-28,869\end{array}$ & $\begin{array}{l}-46,736 \\
-10,743\end{array}$ \\
\hline junho/82 a maio/94 & $\begin{array}{l}z_{1} \\
z_{2} \\
z_{3} \\
z_{4}\end{array}$ & $\begin{array}{l}* \\
* \\
* \\
*\end{array}$ & $\begin{array}{r}0,342 \\
6,371 \\
10,284 \\
-3,766\end{array}$ & $\begin{array}{l}33,294 \\
17,878 \\
-0,610 \\
-3,809\end{array}$ & $\begin{array}{r}4,696 \\
-12,815 \\
15,474 \\
3,663\end{array}$ & $\begin{array}{r}-0,853 \\
-1,180 \\
-22,026 \\
-4,166\end{array}$ & $\begin{array}{r}-36,938 \\
-7,329 \\
-2,703 \\
5,830\end{array}$ \\
\hline junho/70 a novembro/73 & $\mathrm{z}_{1}$ & $*$ & 4,125 & 24,156 & $-10,906$ & 12,910 & $-30,356$ \\
\hline novembro/73 a junho/77 & $\begin{array}{l}z_{1} \\
z_{2}\end{array}$ & * & $\begin{array}{r}20,714 \\
-1,471 \\
\end{array}$ & $\begin{array}{r}43,969 \\
-69,716 \\
\end{array}$ & $\begin{array}{l}42,372 \\
14,719\end{array}$ & $\begin{array}{l}-64,164 \\
-11,346 \\
\end{array}$ & $\begin{array}{r}-29,911 \\
54,445 \\
\end{array}$ \\
\hline
\end{tabular}

1 - i relações de cointegração que equivale a $Z=b^{\prime} X_{t}$

Fonte: resultados da pesquisa.

$\mathrm{O}$ aumento no número de relações de longo-prazo no período em que o ciclo pecuário não é bem evidente indica o aumento das forças que unem estes cinco mercados quanto à variação dos preços ao longo do tempo. O aumento relativo do preço do bezerro provavelmente poderia ser uma das consequências deste aumento no número de relações de longo-prazo. 


\subsubsection{Especificação dos modelos VEC}

\section{a) Modelo do vetor de correção de erros (VEC)}

No modelo do vetor de correção de erros pode-se incluir ou não a constante e as vạiáveis binárias. Para verificar qual modelo é adequado às variáveis cointegradas estudadas nesta pesquisa, as seguintes hipóteses foram testadas:

$$
\begin{array}{ll}
\mathrm{H}_{\mathrm{o}}: \mu=\alpha \beta_{\mathrm{o}} \text { contra } & \mathrm{H}_{\mathrm{a}}: \mu \neq \alpha \beta_{\mathrm{o}} \\
\mathrm{H}_{\mathrm{o}}: \Phi=0 \text { contra } \mathrm{H}_{\mathrm{a}}: \Phi \neq 0 .
\end{array}
$$

Os resultados obtidos a partir do teste definido pela fórmula (5.4.9) são apresentados a seguir na tabela 6.1.8. Testa-se todas as combinações possíveis do modelo a ser estimado para cada período.

Os resultados provenientes do teste de razão de verossimilhança são bem coerentes, principalmente quando se relaciona ao comportamento das séries analisadas no início da seção anterior. Tanto para o período de junho de 1970 a junho de 1982 como para o período de junho de 1982 a maio de 1994, os testes indicaram unanimente que a constante no modelo do vetor de correção de erros não é importante, permitindo-se, assim, a sua exclusão. Analisando as figuras 6.1 .1 e 6.1 .2 da seção anterior, percebe-se nitidamente que neste período não existe qualquer tipo de tendência. As variáveis binárias, ao contrário da constante, são importantes para o modelo, pois o modelo irrestrito diferiu significativamente do restrito. Portanto, ao nível de $5 \%$ de significância, não se rejeita a hipótese da nulidade de que não existe tendência linear em qualquer uma das séries cointegradas e rejeita-se a hipótese da nulidade de que as variáveis binárias não são importantes no modelo a ser estimado para o período. 
Tabela 6.1.8 - Teste de razão de verossimilhança para verificação da importância da constante e das variáveis binárias no modelo a ser especificado para cada periodo

\begin{tabular}{|c|c|c|c|}
\hline & $\begin{array}{c}\text { grau(s) de liber- } \\
\text { dade }^{2}\end{array}$ & $\begin{array}{c}\begin{array}{c}\text { Razão de verossi- } \\
\text { milhança }\end{array} \\
\end{array}$ & $\begin{array}{l}\text { nível de signifi- } \\
\text { cância }^{1} \\
\end{array}$ \\
\hline \multicolumn{4}{|l|}{ período junho/70 a junho/82 } \\
\hline $\begin{array}{l}\text { com binárias e } H_{0}: \mu=\alpha \beta_{o} \text { vs. } H_{a}: \mu \neq \alpha \beta_{o} \\
\text { sem binárias e } H_{0}: \mu=\alpha \beta_{0} \text { vs. } H_{a}: \mu \neq \alpha \beta_{o} \\
\text { com constante e } H_{o}: \Phi=0 \text { vs. } H_{a}: \Phi \neq 0 \\
\text { sem constante e } H_{0}: \Phi=0 \text { vs. } H_{a}: \Phi \neq 0\end{array}$ & $\begin{array}{l}4 \\
3 \\
4 \\
4\end{array}$ & $\begin{array}{r}0,143 \\
0,143 \\
120,349 \\
120,349\end{array}$ & $\begin{array}{l}0,998 \\
0,986 \\
0,000 \\
0,000\end{array}$ \\
\hline \multicolumn{4}{|l|}{ período de junho/82 a maio/94 } \\
\hline $\begin{array}{l}\text { com binárias e } H_{0}: \mu=\alpha \beta_{0} \text { vs. } H_{a}: \mu \neq \alpha \beta_{o} \\
\text { sem binárias e } H_{0}: \mu=\alpha \beta_{0} \text { vs. } H_{a}: \mu \neq \alpha \beta_{o} \\
\text { com constante e } H_{o}: \Phi=0 \text { vs. } H_{a}: \Phi \neq 0 \\
\text { sem constante e } H_{0}: \Phi=0 \text { vs. } H_{a}: \Phi \neq 0 \\
\text { período de junho/70 a novembro/73 }\end{array}$ & $\begin{array}{l}2 \\
1 \\
1 \\
2\end{array}$ & $\begin{array}{r}0,710 \\
0,387 \\
121,263 \\
120,940\end{array}$ & $\begin{array}{l}0,701 \\
0,534 \\
0,000 \\
0,000\end{array}$ \\
\hline $\begin{array}{l}\text { com binárias e } H_{o}: \mu=\alpha \beta_{o} \text { vs. } H_{a}: \mu \neq \alpha \beta_{o} \\
\text { sem binárias e } H_{o}: \mu=\alpha \beta_{0} \text { vs. } H_{a}: \mu \neq \alpha \beta_{o} \\
\text { com constante e } H_{o}: \Phi=0 \text { vs. } H_{a}: \Phi \neq 0 \\
\text { sem constante e } H_{0}: \Phi=0 \text { vs. } H_{a}: \Phi \neq 0 \\
\text { período de novembro/73 a junho/77 }\end{array}$ & $\begin{array}{l}3 \\
4 \\
3 \\
4\end{array}$ & $\begin{array}{r}10,149 \\
7,843 \\
122,889 \\
120,584\end{array}$ & $\begin{array}{l}0,017 \\
0,097 \\
0,000 \\
0,000\end{array}$ \\
\hline $\begin{array}{l}\text { com binárias e } H_{o}: \mu=\alpha \beta_{o} \text { vs. } H_{a}: \mu \neq \alpha \beta_{o} \\
\text { sem binárias e } H_{o}: \mu=\alpha \beta_{o} \text { vs. } H_{a}: \mu \neq \alpha \beta_{o} \\
\text { com constante e } H_{o}: \Phi=0 \text { vs. } H_{a}: \Phi \neq 0 \\
\text { sem constante e } H_{o}: \Phi=0 \text { vs. } H_{a}: \Phi \neq 0\end{array}$ & $\begin{array}{l}2 \\
3 \\
2 \\
2\end{array}$ & $\begin{array}{r}7,741 \\
7,051 \\
98,251 \\
117,041\end{array}$ & $\begin{array}{l}0,021 \\
0,070 \\
0,000 \\
0,000\end{array}$ \\
\hline $\begin{array}{l}1 \text { - Ao invés de comparar o valor calc } \\
\text { o valor da probabilidade obtido para } \\
\text { que no caso é } 5 \% \text {; } \\
2 \text { - graus de liberdade=número de var } \\
\text { Fonte: resultados da pesquisa. }\end{array}$ & $\begin{array}{l}\text { om o valor crí } \\
\text { calculado do } \\
\text { lúmero de veto }\end{array}$ & $\begin{array}{l}\text { um nivel de sig } \\
\text { com o nível de }\end{array}$ & $\begin{array}{l}\text { cância, compara- } \\
\text { nificância definic } \\
\text { levantes; }\end{array}$ \\
\hline
\end{tabular}

Para os períodos de junho de 1970 a novembro de 1973 e novembro de 1973 a junho de 1977, correspondentes às fases ascendente e descendente do ciclo pecuário plurianual, respectivamente, a constante foi significativamente importante ao nível de $10 \%$ de significância para o caso da não inclusão das variáveis binárias e 
significativamente importante ao nível de $5 \%$ para o caso da inclusão das variáveis binárias. Confirma-se, assim, a visível tendência em ambos os períodos (figuras $6.1 .1 \mathrm{e}$ 6.1.2). É interessante notar a diferença no valor dos testes quando se inclui as variáveis binárias, o que, de certa forma, reforça a sua importância no modelo. Desta forma, rejeita-se a hipótese da nulidade de que não existe tendência linear em qualquer uma das séries cointegradas ao nível de $10 \%$ significância para o caso da não inclusão das variáveis binárias e ao nível de $5 \%$ para o caso da inclusão das binárias. Também, rejeitase a hipótese da nulidade de que as variáveis binárias não são importantes no modelo ao nível de $1 \%$.

De acordo com os testes realizados nesta seção, os modelos corretamente especificados para cada um dos períodos a serem estudados são definidos a seguir.

Para os períodos de junho de 1970 a junho 1982 e junho de 1982 a maio de 1994 o modelo seria:

$$
\Delta X_{t}=\Psi_{1} \Delta X_{t-1}+\Omega Z_{t-1}+\Phi D_{t}+\varepsilon_{t}
$$

onde,

$\Delta X_{t}$ é o vetor das variáveis nas diferenças sem defasagens;

$\Delta X_{t-1}$ é o vetor das variáveis nas diferenças com uma defasagem definida pelos critérios;

$Z_{t-1}$ é o vetor de correção de erros obtido através da matriz $\beta$;

$D_{t}$ é o vetor das variáveis binárias;

$\Psi_{1}, \Omega$ e $\Phi$ são as matrizes dos coeficientes estimados e;

$\varepsilon_{t}$ é o vetor dos resíduos.

Para os períodos de junho de 1970 a novembro de 1973 e novembro de 1973 a junho de 1977, o modelo seria: 


$$
\Delta X_{t}=\zeta_{1} \Delta X_{t-1}+\varphi Z_{t-1}+\theta+\omega D_{t}+e_{t}
$$

onde,

$\Delta X_{t}$ é o vetor das variáveis nas diferenças sem defasagens;

$\Delta X_{t-1}$ é o vetor das variáveis nas diferenças com uma defasagem definida pelos critérios;

$Z_{t-1}$ é o vetor de correção de erros obtido através da matriz $\beta$;

$D_{t}$ é o vetor das variáveis binárias;

$\zeta_{1}, \varphi$ e $\omega$ são as matrizes dos coeficientes estimados;

$\theta$ é o vetor das constantes e;

$e_{t}$ é o vetor dos resíduos.

Neste modelo, a constante serve, na realidade, para captar a tendência linear ${ }^{1}$ presente nas séries cointegradas e por isso não deve ser considerada como um mero intercepto de uma regressão múltipla.

Um detalhe importante na estimação de um modelo VAR, seja este em nivel ou em diferença, sem ou com vetor de correção de erros, é a ordenação das variáveis. A ordenação das variáveis afeta diretamente a decomposição da variância e as respostaimpulsos, o que está relacionado à decomposição de Cholesky utilizada para a obtenção das mesmas (DOAN,1992). No teste de cointegração de Johansen, a ordem não afeta os resultados pelo fato de ser semelhante a um teste de razão de verossimilhança. Nesta pesquisa foi observado que, ao alterar a ordem das variáveis no modelo, os resultados obtidos, colocando o preço do boi gordo na primeira posição ou o preço do bezerro por exemplo, são diferentes. De acordo com a pressuposição do final do capítulo 5 , de que o mercado do boi gordo é a fonte de informação mais importante do processo produtivo seguido pelo mercado do bezerro, a ordenação do modelo é boi gordo, bezerro, vaca

\footnotetext{
${ }^{1}$ Uma explicação mais detalhada sobre a tendência linear e suas implicações é feita por HAMILTON (1994, capítulo 19).
} 
gorda, garrote e boi magro. A título de comparação, o modelo é, também, estimado com a inversão da posição entre o boi gordo e o bezerro e entre a vaca gorda e o garrote, cujos resultados são colocados nas tabelas A.2.11 a A.2.20 que estão no apêndice.

Assim sendo, são obtidas a decomposição da variância e as respostas a impulso para cada período. Através destes resultados, é analisada a dinâmica das inter-relações dos mercados da pecuária bovina de corte. 
89.

\subsubsection{Análise dos resultados : junho de 1970 a junho de 1982}

Definido o modelo do vetor de correção de erros, foram obtidas a decomposição da variância e as respostas a impulsos. Para o modelo VEC, as respostas a impulsos estão apresentadas graficamente nas figuras $6.1 .9,6.1 .10,6.1 .11,6.1 .12$ e 6.1 .13 , e a decomposição da variância nas tabelas 6.1.9, 6.1.10, 6.1.11, 6.1.12 e 6.1.13. Os valores usados para elaborar cada uma das figuras estão tabulados no apêndice.

Observando o comportamento das respostas a impulso, nota-se que, após o choque, as variáveis convergem rapidamente ao nível zero. De uma forma geral, o choque em um determinado mercado é sentido mais fortemente pelos mercados mais proximamente relacionados e mais fracamente naqueles que estão relativamente separados no processo produtivo. Como exemplo, temos a inovação na variável preço do boi gordo na figura 6.1.9. Neste caso, a resposta ao impulso que mais se aproxima do boi gordo em termos de impacto inicial é a da vaca gorda, enquanto que as outras categorias sofrem um impacto menor e aproximadamente no mesmo nível. $\mathrm{O}$ impacto nas categorias devido à inovação na categoria boi gordo persiste de 7 a 8 passos.

Para o preço do boi gordo, praticamente $82 \%$ da variação é devido ao próprio boi gordo. O preço do bezerro explica em torno de $12 \%$ e o do garrote $4,14 \%$ da variação do preço do boi gordo (tabela 6.1.9). Note que o preço do boi magro praticamente não afeta o mercado do boi gordo.

No caso do bezerro (figura 6.1.10), as respostas a impulsos do bezerro e do garrote são parecidos pelo fato de no processo produtivo fazerem parte de etapas contíguas. As respostas a impulsos das outras categorias crescem no primeiro passo sendo que o nível máximo de cada um está bem abaixo do nível inicial das variáveis bezerro e garrote. O restabelecimento do equilibrio após o choque no mercado do 
bezerro leva em torno de 8 meses. No primeiro passo, as respostas são crescentes para as categorias vaca gorda e boi magro, sendo que neste último é a menos crescente das duas.

$\mathrm{Na}$ decomposição da variância para o preço do bezerro (tabela 6.1.10), a maior parte da variação ao longo do tempo, em torno de $69 \%$, é devido ao próprio preço do bezerro. O preço do boi gordo é responsável por aproximadamente $23 \%$ da variação no mercado do bezerro enquanto que o preço do garrote é responsável por aproximadamente $7,5 \%$. O preço da vaca gorda e o preço do boi magro praticamente não explicam as variações ocorridas no mercado do bezerro.

A inovação na variável vaca gorda (figura 6.1.11) provoca um decréscimo nas respostas dos outros mercados, com exceção do bezerro, chegando a valores negativos. No caso do bezerro, a resposta a inovação no mercado da vaca gorda é pequena. $\mathrm{O}$ equilíbrio é restabelecido rapidamente após o choque na variável vaca gorda. Na tabela 6.1.11, a maior parte da variação do preço da vaca gorda é devido ao preço do boi gordo $(60 \%)$, sendo que apenas $24,11 \%$ é devido ao próprio preço da vaca gorda. $\mathrm{O}$ preço do bezerro é responsável por aproximadamente $13 \%$, o do garrote por aproximadamente $2,78 \%$. O preço do boi magro explica praticamente nada. É interessante notar que a decomposição da variância revela a grande influência que o mercado do boi gordo tem sobre o da vaca gorda.

$\mathrm{Na}$ figura 6.1.12, a inovação no mercado do garrote tem um maior efeito nos mercados do bezerro e do boi magro enquanto que nos mercados do boi gordo e da vaca gorda o efeito é menor. Observa-se que, no primeiro passo, as respostas a impulsos das variáveis são crescentes para as variáveis preços do boi gordo, do bezerro e da vaca gorda. Na tabela 6.1 .12 , o preço do bezerro é responsável por $44,9 \%$, o do boi gordo por $29 \%$ e o do próprio garrote por $25,4 \%$. Observa-se que o boi gordo é 
consideravelmente importante na variação do garrote confirmando a importância que o mercado tem como fonte de informação para os demais mercados da pecuária de corte.

O impacto da inovação no mercado do boi magro é pequeno nos demais mercados, como observa-se no gráfico 6.1.13. No que diz respeito à variação do preço boi magro, aproximadamente $31 \%$ da variação é explicada pela própria variável boi magro, $29 \%$ pelo preço do boi gordo, $24,5 \%$ pelo preço do bezerro e aproximadamente $12,3 \%$ pelo preço do garrote (tabela 6.1 .13 ). É interessante notar que o preço do boi magro é influenciado pelas outras categorias, em menor extensão pelo preço da vaca gorda.

Associando as respostas a impulso à decomposição da variância, é possível perceber que os mercados do boi gordo e do bezerro influenciam as demais. Retomando a idéia de mercados dominantes e satélites, os mercados do boi gordo e do bezerro seriam os mercados dominantes e os demais seriam os mercados satélites. Pois, o fluxo da informação, que no caso seria o preço, seria maior destes dois mercados para os outros. Tal evidência pode ser explicado pelo fato dos mercados do boi gordo e do bezerro serem muito melhores estruturados em comparação com os demais. Ao mercado do boi gordo estão associados o mercado da vaca gorda e o boi magro. Ao bezerro estão associados o mercado do garrote e do boi magro. Mas também existe o fluxo de informação entre os mercados de ambos os grupos.

$\mathrm{Na}$ prática, o mercado do boi gordo exerce forte influência sobre as demais categorias sendo que o bezerro, em menor intensidade, também exerce uma influência considerável. Quando se inverte as posições entre as variáveis preços do boi gordo e do bezerro no modelo, a variável preço do bezerro influencia as demais com maior intensidade que a variável preço do boi gordo no modelo definido na seção 6.1.3 (tabelas A.2.6 a A.2.20 do apêndice). Tal fato mostra que as variáveis preços do boi gordo e do 
bezerro são muito semelhantes em termos de conteúdo de informação. O pecuarista toma a sua decisão de venda do boi gordo baseado no mercado do boi gordo e também no mercado do bezerro. Pois, a venda do produto final é tão importante quanto a compra da matéria-prima para a sua produção, ou seja, a venda do boi gordo ou do boi magro é tão importante quanto a compra do bezerro ou do garrote que estará repondo este mesmo boi gordo.

Apesar de ter sido analisado todas as variáveis, os preços da vaca gorda e do boi magro pouco explicam o comportamento dos demais mercados. 


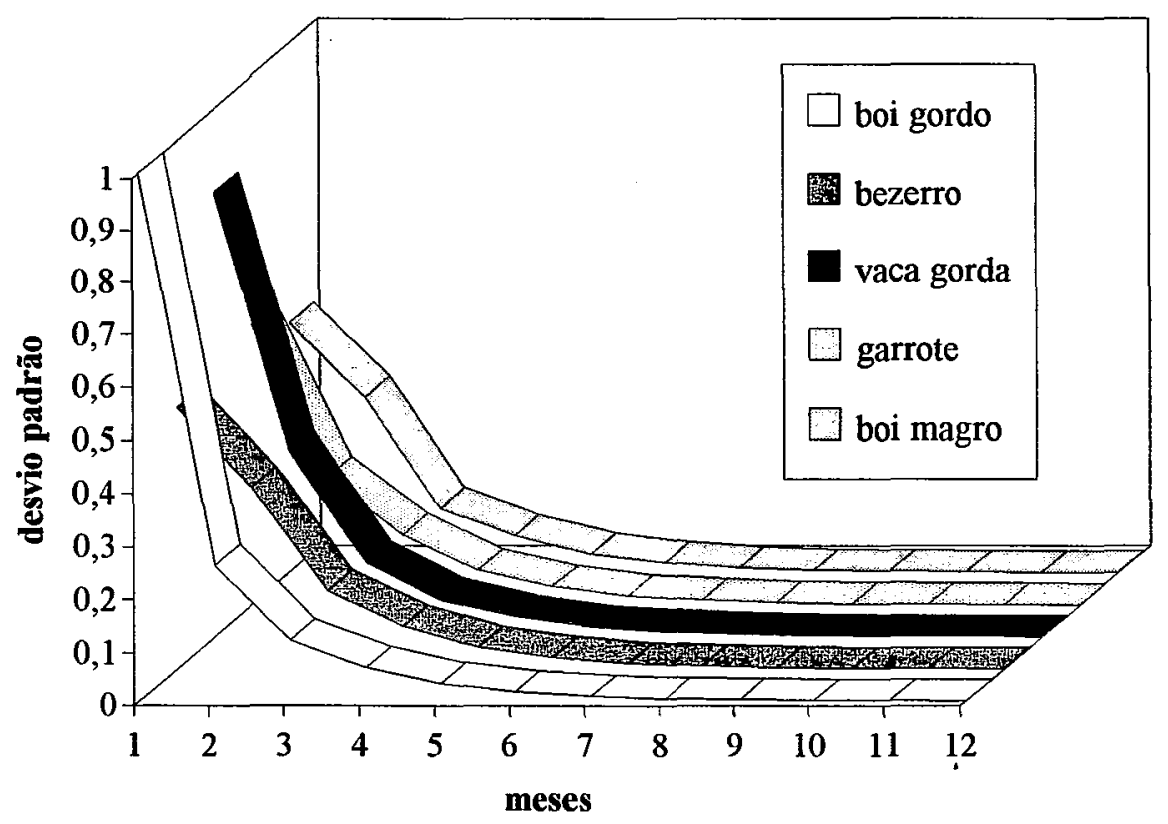

Figura 6.1.9 - Resposta-impulso quando há inovação na variável boi gordo no modelo VEC para o período de junho de 1970 a junho de 1982 (tabela A.1.2, apêndice).

Tabela 6.1.9 - Decomposição da variância para a variável boi gordo no modelo VEC para o período de junho de 1970 a junho de 1982

\begin{tabular}{crrrrr}
\hline passos & boi gordo & bezerro & vaca gorda & garrote & boi magro \\
\hline 1 & 100,0000 & 0,0000 & 0,0000 & 0,0000 & 0,0000 \\
2 & 86,1901 & 10,0609 & 0,3016 & 3,4464 & 0,0010 \\
3 & 83,3882 & 12,3290 & 0,2900 & 3,9874 & 0,0055 \\
4 & 82,7842 & 12,8292 & 0,2868 & 4,0943 & 0,0055 \\
5 & 82,6232 & 12,9582 & 0,2860 & 4,1272 & 0,0055 \\
6 & 82,5799 & 12,9935 & 0,2858 & 4,1353 & 0,0055 \\
7 & 82,5685 & 13,0027 & 0,2857 & 4,1375 & 0,0055 \\
8 & 82,5655 & 13,0052 & 0,2857 & 4,1381 & 0,0055 \\
9 & 82,5647 & 13,0059 & 0,2857 & 4,1383 & 0,0055 \\
10 & 82,5645 & 13,0060 & 0,2857 & 4,1383 & 0,0055 \\
11 & 82,5644 & 13,0061 & 0,2857 & 4,1383 & 0,0055 \\
12 & 82,5644 & 13,0061 & 0,2857 & 4,1383 & 0,0055 \\
\hline
\end{tabular}

Fonte: resultados da pesquisa. 


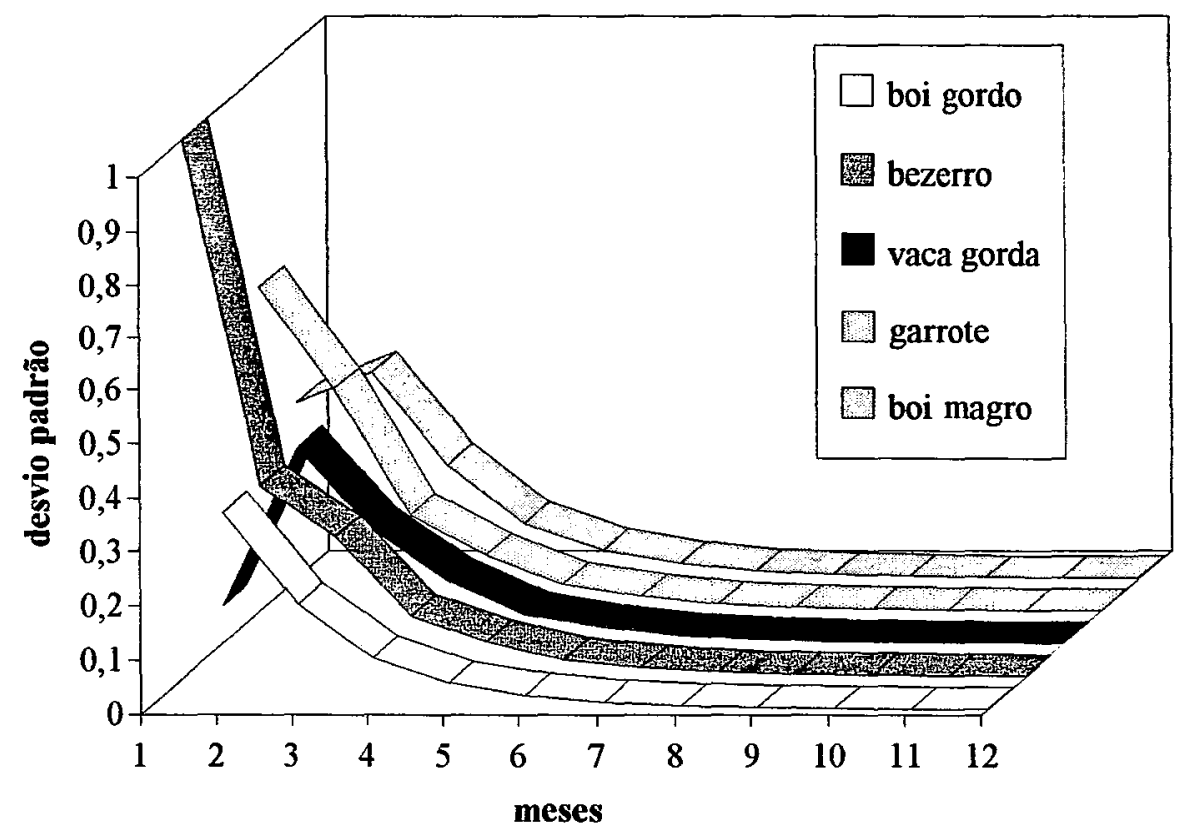

Figura 6.1.10 - Respostas aos impulsos quando há inovação na variável bezerro no modelo VEC para o período de junho de 1970 a junho de 1982 (tabela A.1.3, apêndice).

Tabela 6.1.10 - Decomposição da variância para a variável bezerro no modelo VEC para o período de junho de 1970 a junho de 1982

\begin{tabular}{rrrrrr}
\hline passos & boi gordo & bezerro & vaca gorda & garrote & boi magro \\
\hline 1 & 20,3671 & 79,6329 & 0,0000 & 0,0000 & 0,0000 \\
2 & 23,3365 & 69,2624 & 0,0129 & 7,3420 & 0,0462 \\
3 & 23,3423 & 69,2796 & 0,0208 & 7,2948 & 0,0624 \\
4 & 23,4128 & 69,0100 & 0,0213 & 7,4938 & 0,0621 \\
5 & 23,4246 & 68,9850 & 0,0214 & 7,5068 & 0,0622 \\
6 & 23,4290 & 68,9710 & 0,0214 & 7,5165 & 0,0621 \\
7 & 23,4299 & 68,9686 & 0,0214 & 7,5180 & 0,0621 \\
8 & 23,4302 & 68,9678 & 0,0214 & 7,5186 & 0,0621 \\
9 & 23,4303 & 68,9676 & 0,0214 & 7,5187 & 0,0621 \\
10 & 23,4303 & 68,9675 & 0,0214 & 7,5187 & 0,0621 \\
11 & 23,4303 & 68,9675 & 0,0214 & 7,5187 & 0,0621 \\
12 & 23,4303 & 68,9675 & 0,0214 & 7,5187 & 0,0621 \\
\hline
\end{tabular}

Fonte: resultados da pesquisa. 


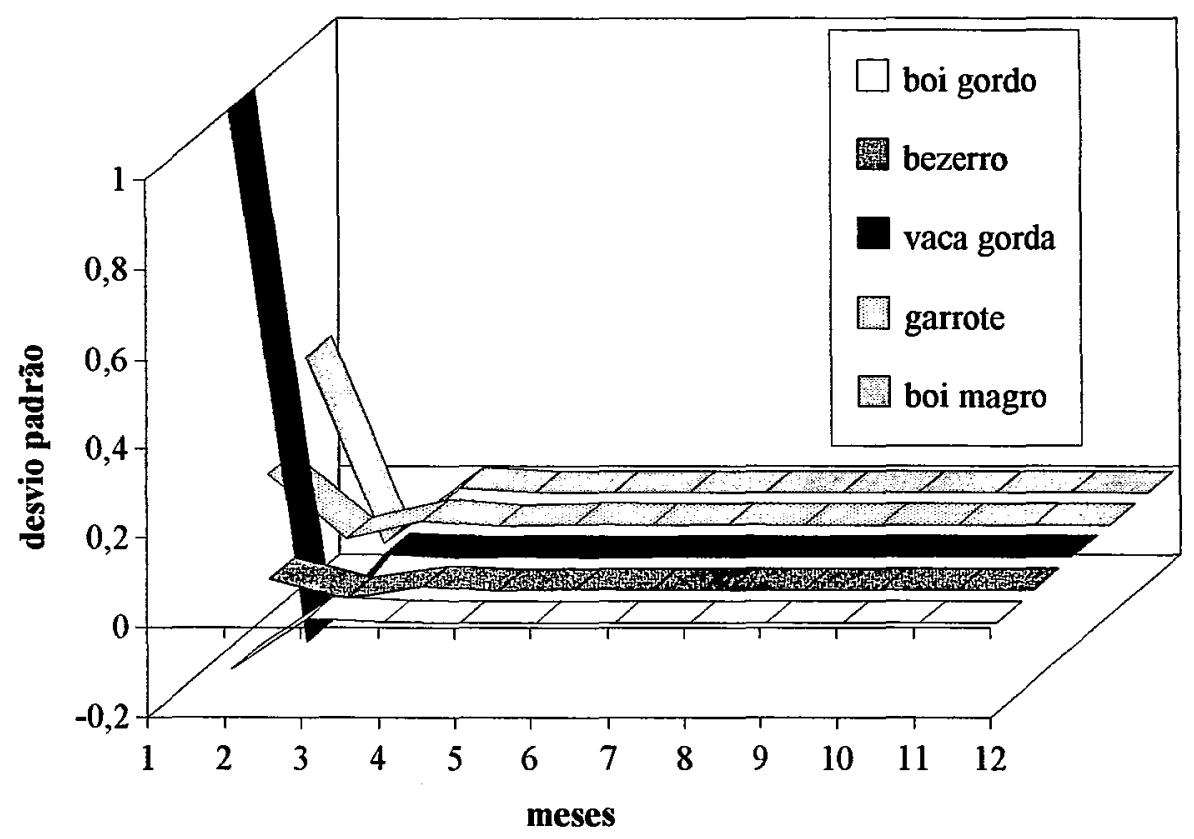

Figura 6.1.11 - Respostas aos impulsos quando há inovação na variável vaca gorda no modelo VEC para o período de junho de 1970 a junho de 1982 (tabela A.1.4, apêndice).

Tabela 6.1.11 - Decomposição da variância para a variável vaca gorda no modelo VEC para o período de junho de 1970 a junho de 1982

\begin{tabular}{rrrrrr}
\hline passos & boi gordo & bezerro & vaca gorda & garrote & boi magro \\
\hline 1 & 67,8066 & 0,4272 & 31,7662 & 0,0000 & 0,0000 \\
2 & 62,9261 & 9,7044 & 26,0913 & 1,2233 & 0,0549 \\
3 & 60,6493 & 12,1118 & 24,5662 & 2,6157 & 0,0569 \\
4 & 60,1625 & 12,8413 & 24,2334 & 2,7059 & 0,0570 \\
5 & 60,0504 & 12,9835 & 24,1465 & 2,7629 & 0,0568 \\
6 & 60,0184 & 13,0292 & 24,1233 & 2,7723 & 0,0568 \\
7 & 60,0102 & 13,0401 & 24,1172 & 2,7757 & 0,0568 \\
8 & 60,0080 & 13,0432 & 24,1156 & 2,7765 & 0,0568 \\
9 & 60,0074 & 13,0440 & 24,1151 & 2,7767 & 0,0568 \\
10 & 60,0073 & 13,0442 & 24,1150 & 2,7768 & 0,0568 \\
11 & 60,0072 & 13,0443 & 24,1150 & 2,7768 & 0,0568 \\
12 & 60,0072 & 13,0443 & 24,1150 & 2,7768 & 0,0568 \\
\hline
\end{tabular}

Fonte: resultados da pesquisa. 
96.

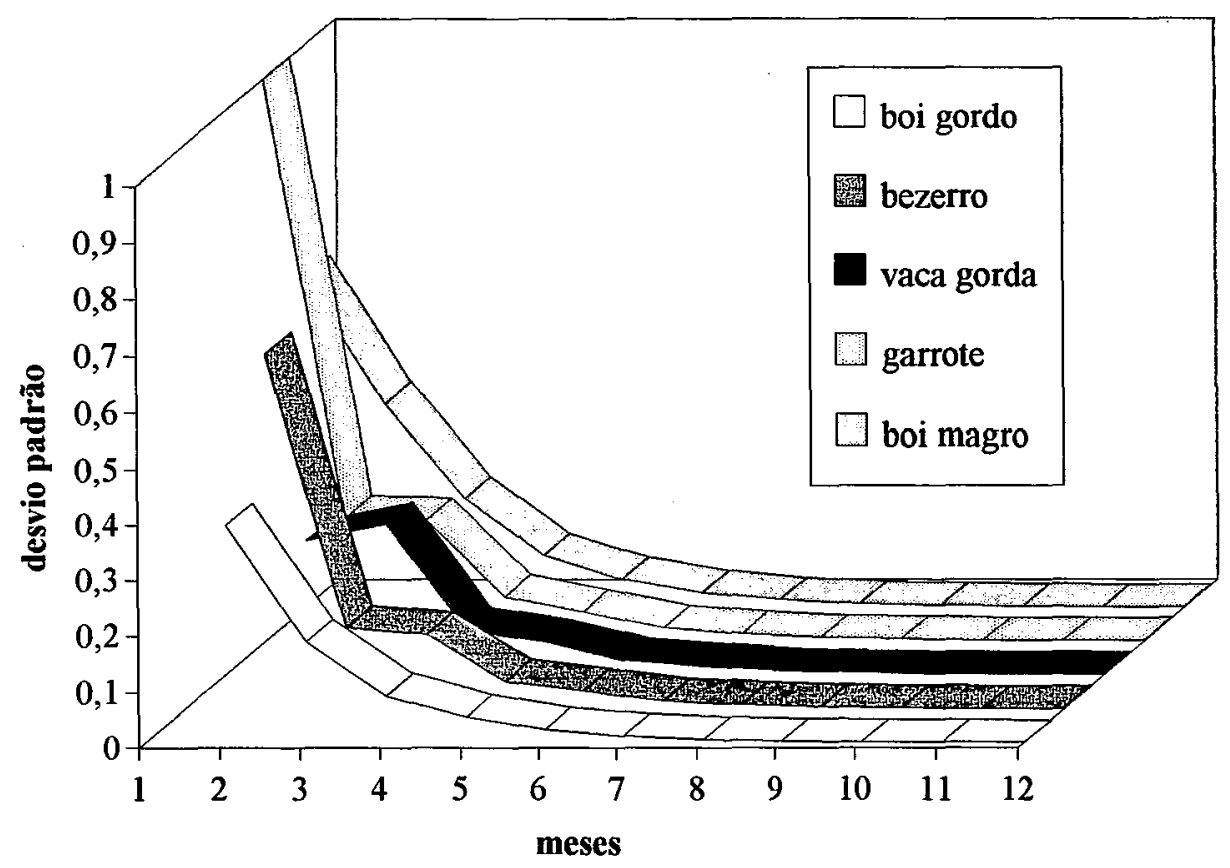

Figura 6.1.12 - Respostas aos impulsos quando há inovação na variável garrote no modelo VEC para o período de junho de 1970 a junho de 1982 (tabela A.1.5, apêndice).

Tabela 6.1.12 - Decomposição da variância para a variável garrote no modelo VEC para o período de junho de 1970 a junho de 1982

\begin{tabular}{rrrrrr}
\hline & boi gordo & bezerro & vaca gorda & garrote & boi magro \\
\hline 1 & 30,5222 & 38,1434 & 0,4782 & 30,8562 & 0,0000 \\
2 & 29,3274 & 44,3877 & 0,4109 & 25,8432 & 0,0308 \\
3 & 29,2995 & 44,6289 & 0,3922 & 25,6488 & 0,0305 \\
4 & 29,2596 & 44,8697 & 0,3875 & 25,4519 & 0,0313 \\
5 & 29,2550 & 44,9031 & 0,3861 & 25,4245 & 0,0312 \\
6 & 29,2530 & 44,9169 & 0,3858 & 25,4131 & 0,0312 \\
7 & 29,2526 & 44,9198 & 0,3857 & 25,4108 & 0,0312 \\
8 & 29,2525 & 44,9207 & 0,3857 & 25,4100 & 0,0312 \\
9 & 29,2524 & 44,9209 & 0,3857 & 25,4098 & 0,0312 \\
10 & 29,2524 & 44,9209 & 0,3857 & 25,4098 & 0,0312 \\
11 & 29,2524 & 44,9209 & 0,3857 & 25,4098 & 0,0312 \\
12 & 29,2524 & 44,9209 & 0,3857 & 25,4098 & 0,0312 \\
\hline
\end{tabular}

Fonte: resultados da pesquisa. 


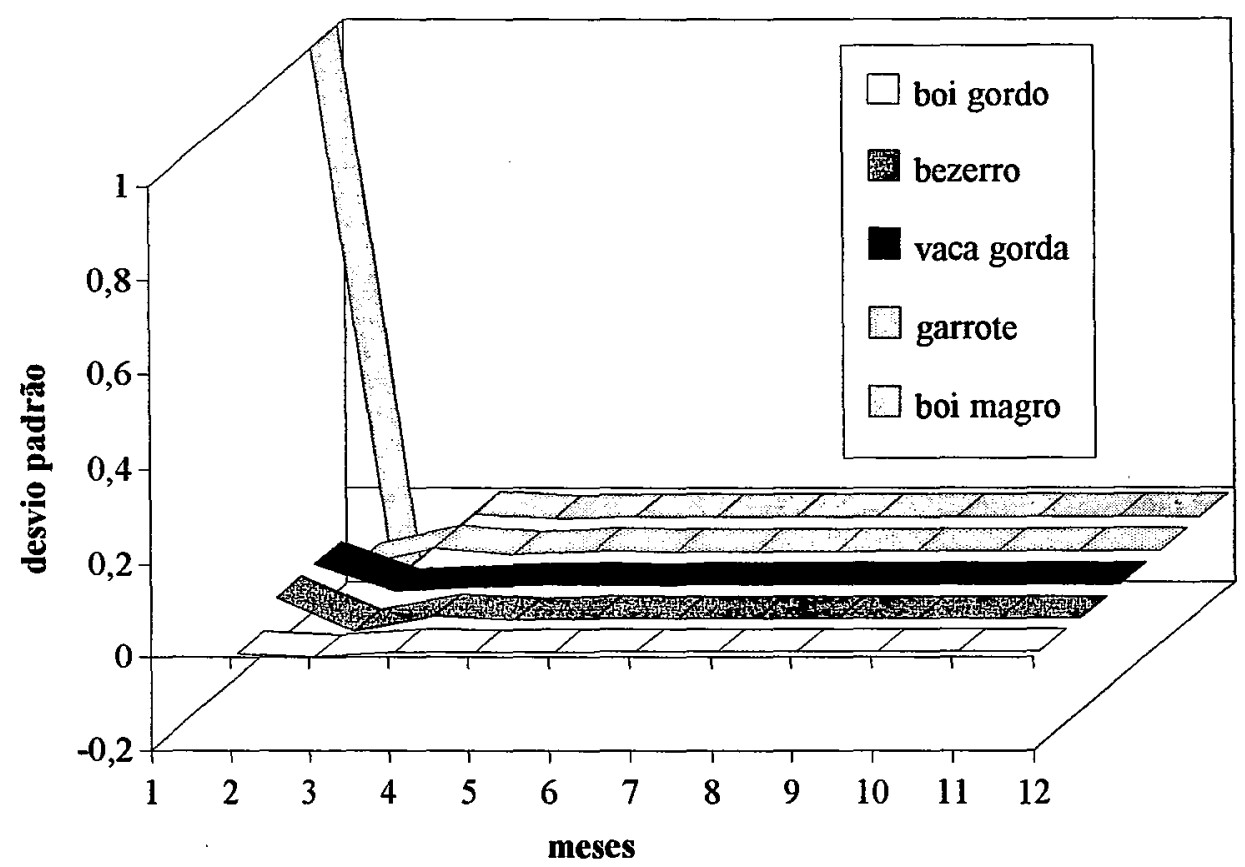

Figura 6.1.13 - Respostas aos impulsos quando há inovação na variável boi magro no modelo VEC para o período de junho de 1970 a junho de 1982 (tabela A.1.6, apêndice).

Tabela 6.1.13 - Decomposição da variância para a variável boi magro no modelo VEC para o período de junho de 1970 à junho de 1982

\begin{tabular}{crrrrr}
\hline passos & boi gordo & bezerro & vaca gorda & garrote & boi magro \\
\hline 1 & 27,2981 & 12,2872 & 3,8296 & 11,8859 & 44,6991 \\
2 & 29,8839 & 21,5176 & 3,2026 & 12,0660 & 33,3299 \\
3 & 29,4197 & 23,8437 & 3,0211 & 12,3011 & 31,4144 \\
4 & 29,4034 & 24,3344 & 2,9771 & 12,3279 & 30,9573 \\
5 & 29,3963 & 24,4630 & 2,9655 & 12,3384 & 30,8368 \\
6 & 29,3942 & 24,4977 & 2,9624 & 12,3408 & 30,8049 \\
7 & 29,3936 & 24,5068 & 2,9616 & 12,3415 & 30,7965 \\
8 & 29,3935 & 24,5092 & 2,9614 & 12,3417 & 30,7942 \\
9 & 29,3934 & 24,5099 & 2,9613 & 12,3417 & 30,7936 \\
10 & 29,3934 & 24,5101 & 2,9613 & 12,3417 & 30,7934 \\
11 & 29,3934 & 24,5101 & 2,9613 & 12,3417 & 30,7934 \\
12 & 29,3934 & 24,5101 & 2,9613 & 12,3417 & 30,7934 \\
\hline
\end{tabular}

Fonte: resultados da pesquisa. 
98.

\subsubsection{Análise dos resultados: junho de 1982 a maio de 1994}

As resposta aos impulsos obtidas quando há inovações em cada variável estão apresentadas nas figuras $6.1 .14,6.1 .15,6.1 .16,6.1 .17$ e 6.1.18. Os valores usados na confeç̧ão destas figuras estão tabulados no apêndice. As decomposições da variância para este período estão apresentadas nas tabelas 6.1.14, 6.1.15, 6.1.16, 6.1.17 e 6.1.18. Como foi visto inicialmente neste capítulo, o período aqui analisado, junho de 1982 a maio de 1994, corresponde ao período da série que o ciclo pecuário plurianual não é bem evidente. De um modo geral, o restabelecimento do equilíbrio após o choque é rápido. Tomando-se o choque na variável boi gordo na figura 6.1.14, a convergência ao nível zero se dá a partir do quarto passo. No que diz respeito à decomposição da variância, o preço do boi gordo é a variável fundamental exógena sendo responsável por mais de $60 \%$ da variação de todas as variáveis.

Ainda na figura 6.1.14, nota-se que as respostas aos impulsos no mercado da vaca gorda são muito semelhantes aos do boi gordo e o comportamento das variáveis preço do garrote e do preço do boi magro muito semelhantes aos do bezerro. Por outro lado, as variáveis preço do boi gordo e preço da vaca gorda sofrem um desvio padrão inicial em um nivel maior. Em seguida decrescem mais rapidamente que as outras chegando até a níveis negativos. $\mathrm{O}$ equilibrio em ambas as variáveis é restabelecido entre os passos quatro e cinco. Respostas aos impulsos negativas no terceiro passo, equivalem a taxas de crescimento negativa dos preços.

No caso da sua decomposição apresentada na tabela 6.1.14, aproximadamente $96 \%$ de sua variação é explicada pela própria variável preço do boi gordo. $\mathrm{Na}$ decomposição da variância vaca gorda 6.1.16, o preço do boi gordo é responsável por aproximadamente $91 \%$ da sua variação. 
O choque na variável preço do bezerro, apresentado na figura 6.1.15, praticamente não afeta as categorias boi gordo e vaca gorda. As respostas aos impulsos dos preços do boi gordo e da vaca gorda são pequenas, reforçando mais uma vez a existência de comportamento semelhantes entre os preços do boi gordo e da vaca gorda e entre os preços do bezerro e do garrote. Neste caso tanto o preço do boi gordo como o preço da vaca gorda são influenciados de maneira semelhante pelo preço do bezerro.

A decomposição da variância para a variável preço do bezerro, apresentada na tabela 6.1 .15 , revela que $o$ preço do boi gordo e o próprio preço do bezerro são responsáveis pela maior parte da sua variação. Observa-se que as demais categorias tem uma participação inferior a $1 \%$.

$\mathrm{Na}$ figura 6.1.16, as inovações ocorridas no mercado da vaca gorda afetam pouco as demais variáveis que têm respostas decrescentes até o terceiro passo, com exceção do bezerro. Este comportamento demonstra uma certa pertubação nos outros mercados quando ocorre alguma inovação no mercado da vaca gorda. Na tabela 6.1.16, do total de variação que ocorre no mercado da vaca gorda, aproximadamente $91 \%$ é devido ao preço do boi gordo, $5 \%$ à própria vaca gorda e $2 \%$ ao boi magro. Note que o bezerro e o garrote praticamente não afetam o mercado da vaca gorda.

No que diz respeito ao garrote, ocorre um fato interessante. Dado o choque na variável garrote, as demais categorias têm respostas negativas que atingem o equilíbrio entre o terceiro e quarto passo (figura 6.1.17). Observa-se, ainda, que nos mercados do boi gordo e da vaca gorda o restabelecimento do equilíbrio é um pouco mais rápido que nos demais. O preço do boi gordo explica aproximadamente $65 \%$ da variação no mercado do garrote, enquanto que o próprio preço do garrote é responsável por $17 \%$ e o preço do bezerro por $16,8 \%$ (tabela 6.1.17). As variações provenientes das categorias da 
vaca gorda e boi magro são inferiores a $1 \%$. Pela decomposição da variância percebe-se os preços do boi gordo e o bezerro têm influência considerável sobre o preço do garrote.

$\mathrm{Na}$ figura 6.1.18, observa-se mais uma vez que as respostas aos impulsos devido ao choque na variável boi magro são negativas e crescentes até restabelecer o equilíbrio entre o terceiro e quarto passos. Nos mercados do boi gordo e da vaca gorda o equilíbrio é restabelecido mais rapidamente que os demais. $\mathrm{Na}$ tabela 6.1 .18 , a decomposição da variância revela que o preço do boi gordo é responsável por aproximadamente $67 \%$ da variação do preço do boi magro, enquanto que o preço do bezerro e o próprio boi magro são responsáveis por $14 \%$ e $13 \%$, respectivamente. Os preços da vaca gorda e do garrote têm pouca importância como causa de variação para o boi magro.

Da mesma forma que ocorreu com o preço da vaca gorda e com o boi magro no periodo anterior, os preços do garrote, do boi magro e da vaca gorda têm um poder explicativo muito pequeno em relação às demais categorias para este este período. Notase que, neste período, o poder explicativo do boi gordo e do bezerro é bem maior em comparação ao período analisado anteriormente.

Não há explicações para as respostas a impulsos negativas quando ocorre inovações nos mercados do garrote e do boi magro. Tal fato chama atenção pelo início das respostas ocorrerem negativamente e crescerem até estabilizarem no nível próximo de zero. 


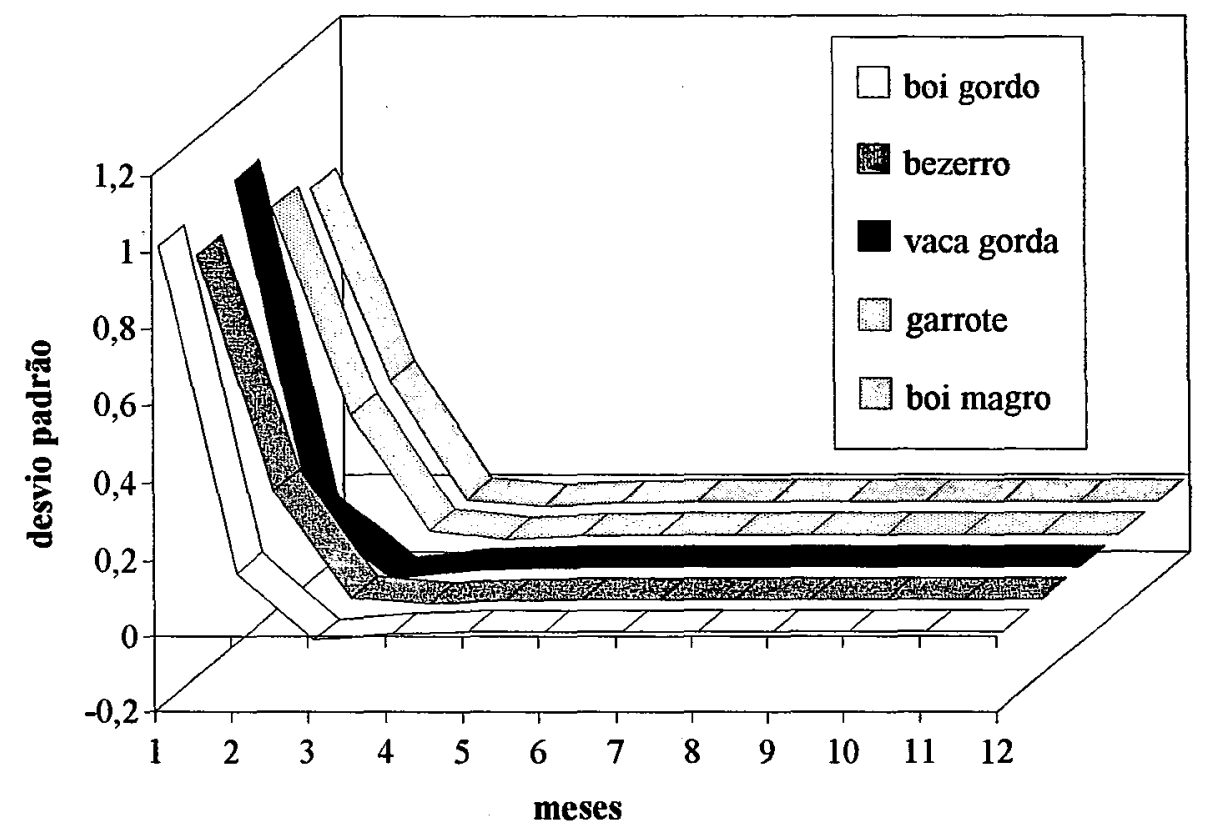

Figura 6.1.14 - Respostas aos impulsos quando há inovação na variável boi gordo no modelo VEC para o período de junho de 1982 a maio de 1994 (tabela A.1.7, apêndice).

Tabela 6.1.14 - Decomposição da variância para a variável boi gordo no modelo VEC para o período de junho de 1982 a maio de 1994

\begin{tabular}{crrrrr}
\hline passos & boi gordo & bezerro & vaca gorda & garrote & boi magro \\
\hline 1 & 100,0000 & 0,0000 & 0,0000 & 0,0000 & 0,0000 \\
2 & 96,4517 & 0,0026 & 0,0008 & 1,1393 & 2,4056 \\
3 & 96,4120 & 0,0240 & 0,0144 & 1,1389 & 2,4107 \\
4 & 96,4107 & 0,0241 & 0,0146 & 1,1401 & 2,4106 \\
5 & 96,4105 & 0,0241 & 0,0146 & 1,1401 & 2,4107 \\
6 & 96,4105 & 0,0241 & 0,0146 & 1,1401 & 2,4107 \\
7 & 96,4105 & 0,0241 & 0,0146 & 1,1401 & 2,4107 \\
8 & 96,4105 & 0,0241 & 0,0146 & 1,1401 & 2,4107 \\
9 & 96,4105 & 0,0241 & 0,0146 & 1,1401 & 2,4107 \\
10 & 96,4105 & 0,0241 & 0,0146 & 1,1401 & 2,4107 \\
11 & 96,4105 & 0,0241 & 0,0146 & 1,1401 & 2,4107 \\
12 & 96,4105 & 0,0241 & 0,0146 & 1,1401 & 2,4107 \\
\hline
\end{tabular}

Fonte: resultados da pesquisa. 


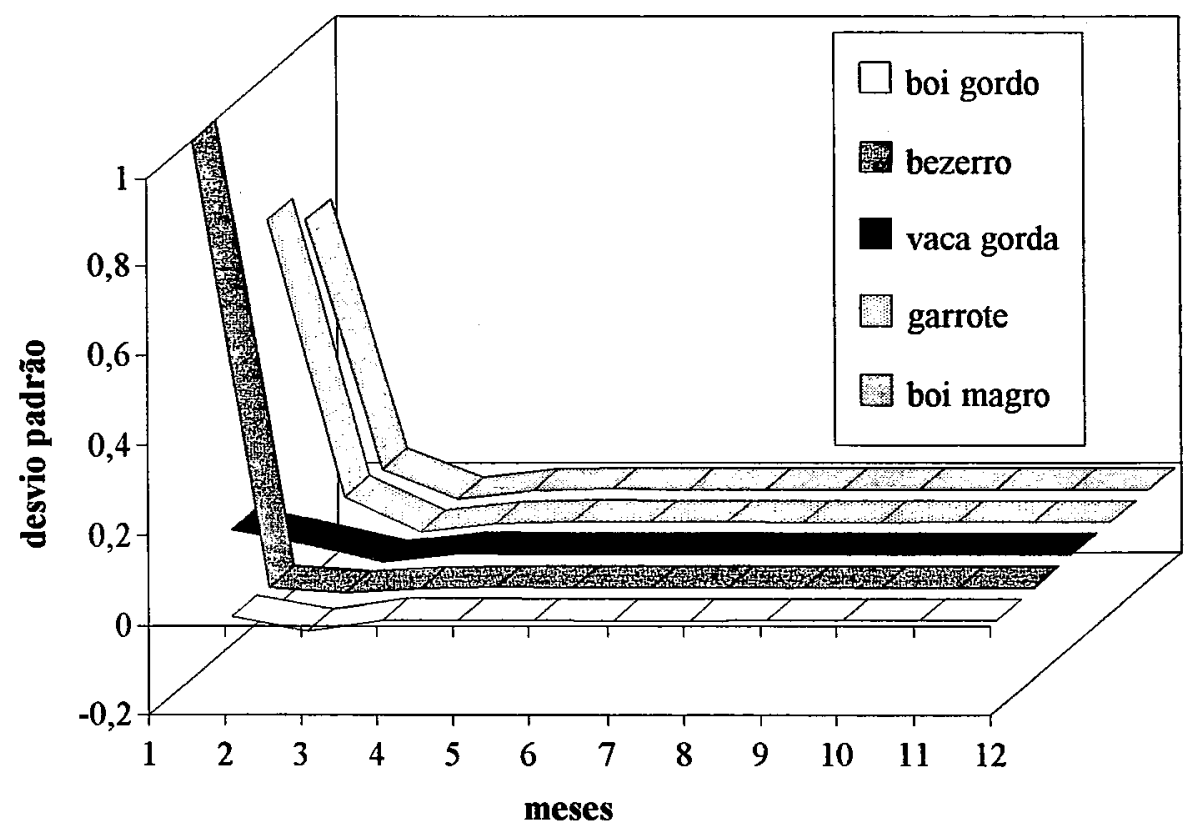

Figura 6.1.15 - Respostas aos impulsos quando há inovação na variável bezerro no modelo VEC para o período de junho de 1982 a maio de 1994 (tabela A.1.8, apêndice).

Tabela 6.1.15 - Decomposição da variância para a variável bezerro no modelo VEC para o período de junho de 1982 a maio de 1994

\begin{tabular}{crrrrr}
\hline passos & boi gordo & bezerro & vaca gorda & garrote & boi magro \\
\hline 1 & 63,5688 & 36,4312 & 0,0000 & 0,0000 & 0,0000 \\
2 & 64,8810 & 33,8273 & 0,1471 & 0,5042 & 0,6404 \\
3 & 64,8200 & 33,7984 & 0,1708 & 0,5246 & 0,6862 \\
4 & 64,8201 & 33,7941 & 0,1732 & 0,5251 & 0,6875 \\
5 & 64,8200 & 33,7940 & 0,1733 & 0,5252 & 0,6875 \\
6 & 64,8200 & 33,7940 & 0,1733 & 0,5252 & 0,6875 \\
7 & 64,8200 & 33,7940 & 0,1733 & 0,5252 & 0,6875 \\
8 & 64,8200 & 33,7940 & 0,1733 & 0,5252 & 0,6875 \\
9 & 64,8200 & 33,7940 & 0,1733 & 0,5252 & 0,6875 \\
10 & 64,8200 & 33,7940 & 0,1733 & 0,5252 & 0,6875 \\
11 & 64,8200 & 33,7940 & 0,1733 & 0,5252 & 0,6875 \\
12 & 64,8200 & 33,7940 & 0,1733 & 0,5252 & 0,6875 \\
\hline
\end{tabular}

Fonte: resultados da pesquisa. 


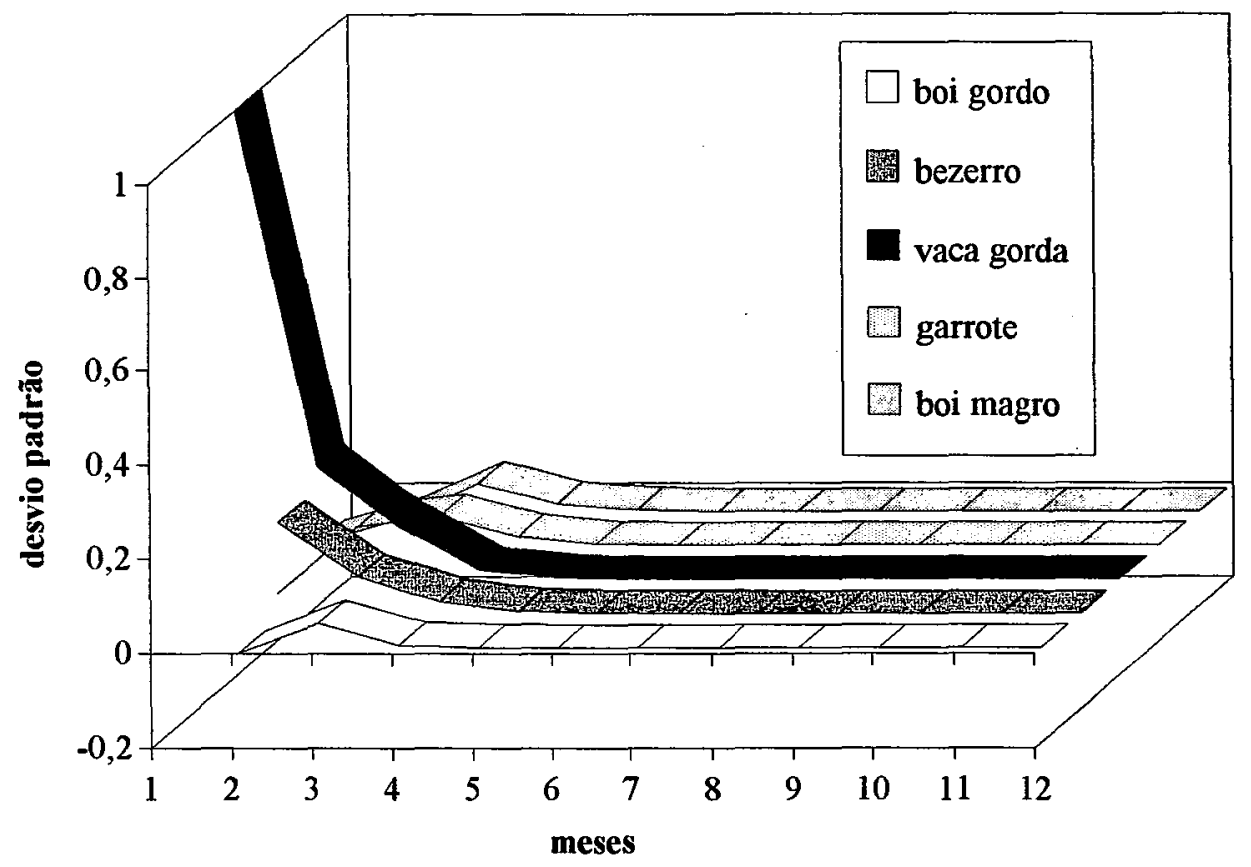

Figura 6.1.16 - Respostas aos impulsos quando há inovação na variável vaca gorda no modelo VEC para o período de junho de 1982 a maio de 1994 (tabela A.1.9, apêndice).

Tabela 6.1.16 - Decomposição da variância para a variável vaca gorda no modelo VEC para o período de junho de 1982 a maio de 1994

\begin{tabular}{|c|c|c|c|c|c|}
\hline & boi gordo & bezerro & vaca gorda & garrote & boi magro \\
\hline 1 & 94,9142 & 0,1304 & 4,9554 & 0,0000 & 0,0000 \\
\hline 2 & 92,0057 & 0,1439 & 4,9963 & 0,7862 & 2,0679 \\
\hline 3 & 91,9319 & 0,1548 & 5,0472 & 0,7852 & 2,0810 \\
\hline 4 & 91,9283 & 0,1550 & 5,0487 & 0,7870 & 2,0810 \\
\hline 5 & 91,9281 & 0,1551 & 5,0487 & 0,7871 & 2,0811 \\
\hline 6 & 91,9281 & 0,1551 & 5,0487 & 0,7871 & 2,0811 \\
\hline 7 & 91,9281 & 0,1551 & 5,0487 & 0,7871 & 2,0811 \\
\hline 8 & 91,9281 & 0,1551 & 5,0487 & 0,7871 & 2,0811 \\
\hline 9 & 91,9281 & 0,1551 & 5,0487 & 0,7871 & 2,0811 \\
\hline 10 & 91,9281 & 0,1551 & 5,0487 & 0,7871 & 2,0811 \\
\hline 11 & 91,9281 & 0,1551 & 5,0487 & 0,7871 & 2,0811 \\
\hline 12 & 91,9281 & 0,1551 & 5,0487 & 0,7871 & 2,0811 \\
\hline
\end{tabular}

Fonte: resultados da pesquisa. 


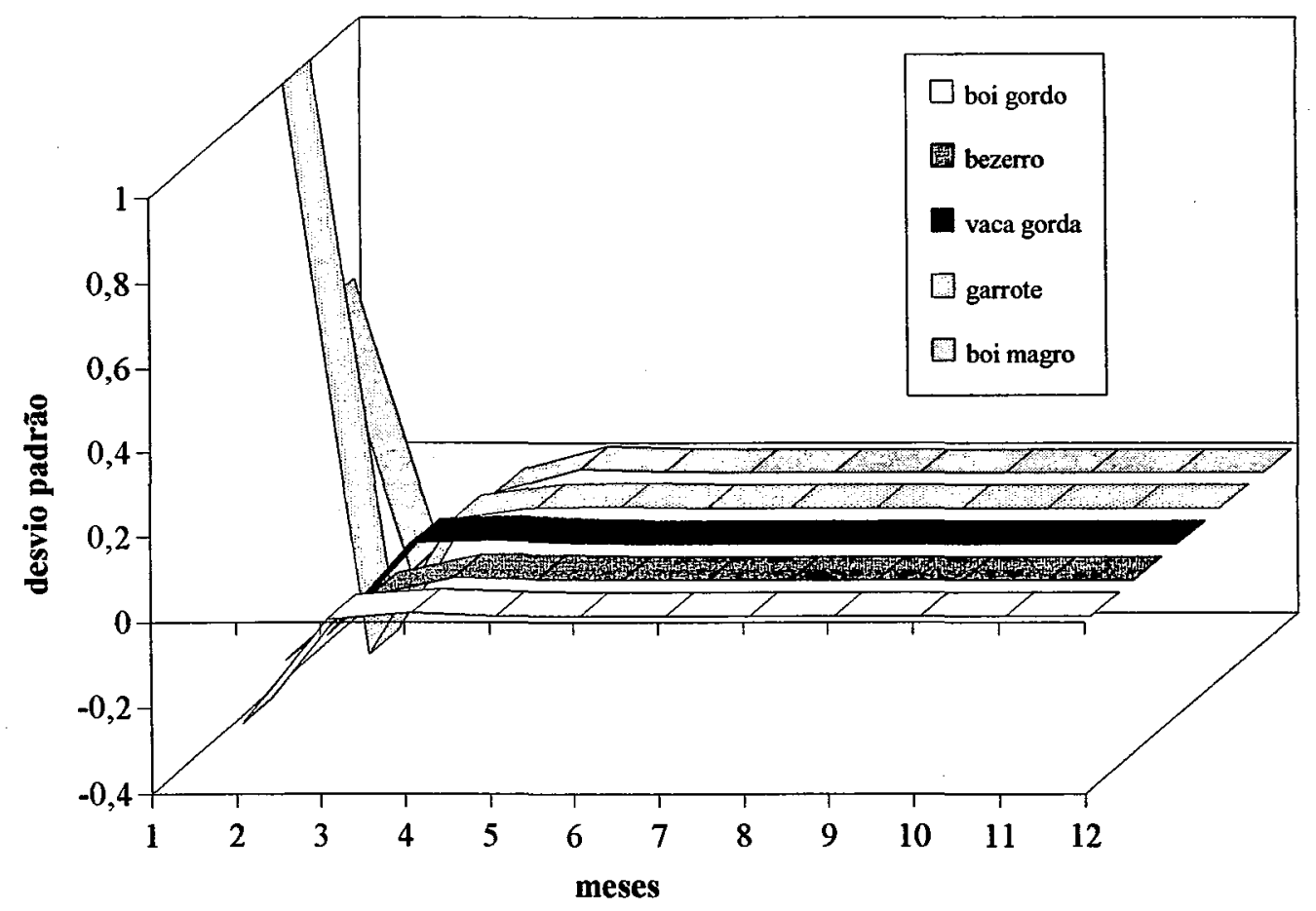

Figura 6.1.17 - Respostas aos impulsos quando há inovação na variável garrote no modelo VEC para o período de junho de 1982 a maio de 1994 (tabela A.1.10, apêndice).

Tabela 6.1.17 - Decomposição da variância para a variável garrote no modelo VEC para o período de junho de 1982 a maio de 1994

\begin{tabular}{rrrrrr}
\hline passos & boi gordo & bezerro & vaca gorda & garrote & boi magro \\
\hline 1 & 64,1376 & 18,6208 & 0,0503 & 17,1913 & 0,0000 \\
2 & 65,1840 & 16,8354 & 0,0522 & 17,2566 & 0,6718 \\
3 & 65,1140 & 16,8323 & 0,0682 & 17,2452 & 0,7403 \\
4 & 65,1153 & 16,8304 & 0,0697 & 17,2431 & 0,7414 \\
5 & 65,1152 & 16,8303 & 0,0698 & 17,2432 & 0,7415 \\
6 & 65,1152 & 16,8303 & 0,0698 & 17,2432 & 0,7415 \\
7 & 65,1152 & 16,8303 & 0,0698 & 17,2432 & 0,7415 \\
8 & 65,1152 & 16,8303 & 0,0698 & 17,2432 & 0,7415 \\
9 & 65,1152 & 16,8303 & 0,0698 & 17,2432 & 0,7415 \\
10 & 65,1152 & 16,8303 & 0,0698 & 17,2432 & 0,7415 \\
11 & 65,1152 & 16,8303 & 0,0698 & 17,2432 & 0,7415 \\
12 & 65,1152 & 16,8303 & 0,0698 & 17,2432 & 0,7415 \\
\hline
\end{tabular}

Fonte: resultados da pesquisa. 


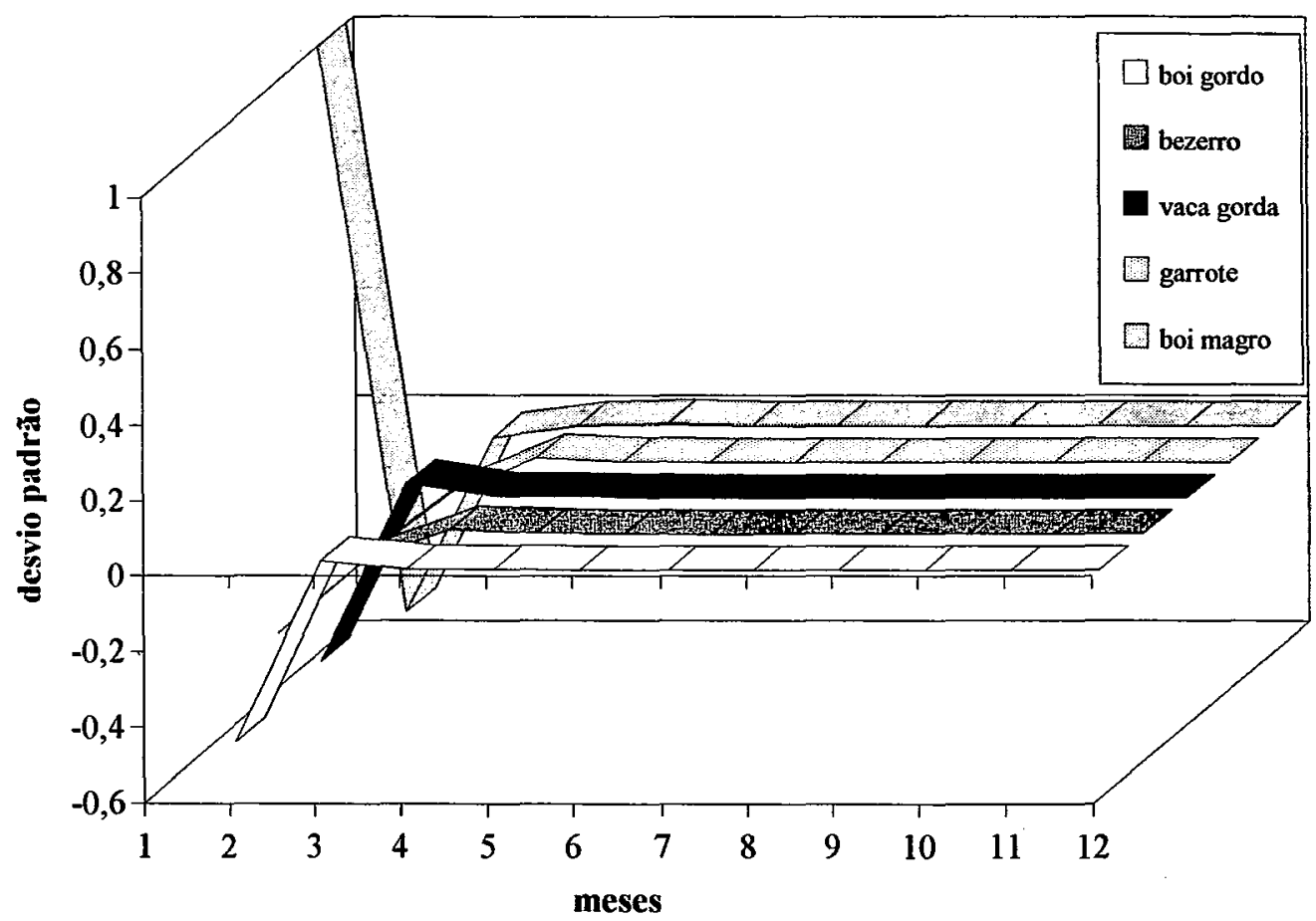

Figura 6.1.18 - Respostas aos impulsos quando há inovação na variável boi magro no modelo VEC para o período de junho de 1982 a maio de 1994 (tabela A.1.11, apêndice).

Tabela 6.1.18 - Decomposição da variância para a variável boi magro no modelo VEC para o período de junho de 1982 a maio de 1994

\begin{tabular}{rrrrrr}
\hline & boi gordo & bezerro & vaca gorda & garrote & boi magro \\
\hline 1 & 67,3631 & 16,8710 & 0,0243 & 3,2047 & 12,5369 \\
2 & 67,6296 & 14,8789 & 0,0225 & 3,7501 & 13,7189 \\
3 & 67,5732 & 14,8847 & 0,0392 & 3,7853 & 13,7176 \\
4 & 67,5746 & 14,8832 & 0,0403 & 3,7857 & 13,7161 \\
5 & 67,5745 & 14,8832 & 0,0404 & 3,7857 & 13,7162 \\
6 & 67,5745 & 14,8832 & 0,0404 & 3,7857 & 13,7162 \\
7 & 67,5745 & 14,8832 & 0,0404 & 3,7857 & 13,7162 \\
8 & 67,5745 & 14,8832 & 0,0404 & 3,7857 & 13,7162 \\
9 & 67,5745 & 14,8832 & 0,0404 & 3,7857 & 13,7162 \\
10 & 67,5745 & 14,8832 & 0,0404 & 3,7857 & 13,7162 \\
11 & 67,5745 & 14,8832 & 0,0404 & 3,7857 & 13,7162 \\
12 & 67,5745 & 14,8832 & 0,0404 & 3,7857 & 13,7162 \\
\hline
\end{tabular}

Fonte: resultados da pesquisa. 
106.

\subsubsection{Decomposição da variância para as fases do ciclo pecuário}

Para verificar se existe uma mudança no padrão quando se passa da fase ascendente para a fase descendente no ciclo pecuário, foi obtida a decomposição da variância para ambas as fases. Nas tabelas $6.1 .19,6.1 .20,6.1 .21,6.1 .22$ e 6.1 .23 estão as decomposições das variâncias correspondentes à fase ascendente do ciclo pecuário. As decomposições para a fase descendente do ciclo está apresentadas nas tabelas 6.1.24, $6.1 .25,6.1 .26,6.1 .27$ e 6.1 .28 .

Comparando a fase ascendente, correspondente ao período de junho de 1970 a novembro de 1973, com o período de junho de 1970 a junho de 1982 (tabelas 6.1.9, $6.1 .10,6.1 .11,6.1 .12$ e 6.1.13) que engloba o ciclo analisado, a parcela do boi gordo na variação de outras variáveis e da própria variável boi gordo é maior na fase ascendente do ciclo. Quando se compara a fase descendente do ciclo com o período mais abrangente, nota-se uma maior parcela do bezerro na variação das outras variáveis e de si própria. Nota-se, também, um leve aumento na importância das categorias vaca gorda, garrote e boi magro na variação dos mercados das outras categorias.

Finalmente, quando se faz a comparação da decomposição da variância entre ambas as fases, percebe-se que a influência do mercado do boi gordo sobre as demais na fase ascendente é maior e na fase descendente, menor. Para o caso do bezerro, cujo mercado parece ser tão dominante quanto o do boi gordo no período mais abrangente, tem um comportamento inverso ao do boi gordo. Ou seja, na fase ascendente, a influência do bezerro sobre as demais é menor enquanto que, na fase descendente, tornase maior. Parece que nas fases de preços ascendente o mercado do boi gordo é mais dinâmico e dá origem às mudanças de preço na cadeia produtiva. Na outra fase as 
iniciativas passam para o mercado do bezerro. Isso sugere que, no primeiro caso, a escassez da carne se manifesta inicialmente ao nível dos frigoríficos que compram o boi gordo, dando-se as elevações de preços que são, fortemente, transmitidas a outros segmentos. $\mathrm{Na}$ fase de preço descendente torna-se importante as mudanças de preços no mercado do bezerro refletindo queda na demanda para reposição.

Esta mudança pode ser associada, ainda, ao aspecto destacado por LATTIMORE (1974) e PLOUVIER MONTEMURRO(1979) de que a vaca possui a finalidade de gerar bezerros e de ser abatida. Ou seja, quando o criador decide-se por manter a vaca para aumentar o rebanho, há uma diminuição da oferta de animais para abate devido a expectativa de preços maiores para o boi gordo e a vaca gorda, correspondente a fase ascendente do ciclo. Quando o preço começa a diminuir o criador passa a abater parte de suas matrizes que deixam de gerar bezerros diminuindo a oferta de animais de reposição.

Tabela 6.1.19 - Decomposição da variância para a variável boi gordo no modelo VEC para o período de junho de 1970 a novembro de 1973

\begin{tabular}{cccccc}
\hline passos & boi gordo & bezerro & vaca gorda & garrote & boi magro \\
\hline 1 & 100,0000 & 0,0000 & 0,0000 & 0,0000 & 0,0000 \\
2 & 91,2767 & 5,6540 & 0,0078 & 1,2647 & 1,7968 \\
3 & 89,8826 & 6,1766 & 0,1199 & 1,3170 & 2,5040 \\
4 & 89,3232 & 6,5412 & 0,1239 & 1,3966 & 2,6151 \\
5 & 89,2156 & 6,6127 & 0,1266 & 1,3998 & 2,6452 \\
6 & 89,1685 & 6,6404 & 0,1268 & 1,4054 & 2,6589 \\
7 & 89,1556 & 6,6475 & 0,1274 & 1,4063 & 2,6633 \\
8 & 89,1510 & 6,6505 & 0,1274 & 1,4068 & 2,6643 \\
9 & 89,1498 & 6,6512 & 0,1274 & 1,4069 & 2,6647 \\
10 & 89,1493 & 6,6515 & 0,1274 & 1,4069 & 2,6648 \\
11 & 89,1492 & 6,6516 & 0,1274 & 1,4070 & 2,6649 \\
12 & 89,1491 & 6,6516 & 0,1274 & 1,4070 & 2,6649 \\
\hline
\end{tabular}

Fonte: resultados da pesquisa. 
Tabela 6.1.20 - Decomposição da variância para a variável bezerro no modelo VEC para o período de junho de 1970 a novembro de 1973

\begin{tabular}{rrrrrr}
\hline passos & boi gordo & bezerro & vaca gorda & garrote & boi magro \\
\hline 1 & 22,9641 & 77,0359 & 0,0000 & 0,0000 & 0,0000 \\
2 & 30,3658 & 66,7906 & 0,3304 & 0,3440 & 2,1692 \\
3 & 30,1365 & 65,6338 & 0,8330 & 0,4238 & 2,9729 \\
4 & 30,1750 & 65,5782 & 0,8298 & 0,4450 & 2,9720 \\
5 & 30,2845 & 65,4722 & 0,8312 & 0,4445 & 2,9676 \\
6 & 30,3038 & 65,4380 & 0,8313 & 0,4477 & 2,9791 \\
7 & 30,3067 & 65,4338 & 0,8319 & 0,4480 & 2,9797 \\
8 & 30,3087 & 65,4318 & 0,8319 & 0,4481 & 2,9795 \\
9 & 30,3095 & 65,4309 & 0,8319 & 0,4481 & 2,9796 \\
10 & 30,3096 & 65,4307 & 0,8319 & 0,4481 & 2,9797 \\
11 & 30,3097 & 65,4306 & 0,8319 & 0,4481 & 2,9797 \\
12 & 30,3097 & 65,4306 & 0,8319 & 0,4481 & 2,9797 \\
\hline
\end{tabular}

Fonte: resultados da pesquisa.

Tabela 6.1.21 - Decomposição da variância para a variável vaca gorda no modelo VEC para o periodo de junho de 1970 a novembro de 1973

\begin{tabular}{rrrrrr}
\hline passos & boi gordo & bezerro & vaca gorda & garrote & boi magro \\
\hline 1 & 16,3650 & 25,9690 & 57,6660 & 0,0000 & 0,0000 \\
2 & 46,4844 & 25,7821 & 25,6338 & 0,9003 & 1,1995 \\
3 & 50,0730 & 22,6850 & 22,7024 & 0,7969 & 3,7426 \\
4 & 49,9575 & 22,6272 & 22,1762 & 1,1511 & 4,0880 \\
5 & 50,1308 & 22,6244 & 22,0380 & 1,1444 & 4,0625 \\
6 & 50,2334 & 22,5934 & 21,9601 & 1,1498 & 4,0633 \\
7 & 50,2500 & 22,5810 & 21,9449 & 1,1506 & 4,0735 \\
8 & 50,2543 & 22,5810 & 21,9394 & 1,1516 & 4,0737 \\
9 & 50,2568 & 22,5803 & 21,9376 & 1,1516 & 4,0736 \\
10 & 50,2575 & 22,5800 & 21,9370 & 1,1517 & 4,0738 \\
11 & 50,2577 & 22,5800 & 21,9368 & 1,1517 & 4,0738 \\
12 & 50,2578 & 22,5800 & 21,9368 & 1,1517 & 4,0738 \\
\hline
\end{tabular}

Fonte: resultados da pesquisa.

Tabela 6.1.22 - Decomposição da variância para a variável garrote no modelo VEC para o período de junho de 1970 a novembro de 1973

\begin{tabular}{rrrrrr}
\hline passos & boi gordo & bezerro & vaca gorda & garrote & boi magro \\
\hline 1 & 42,7469 & 38,8586 & 1,4368 & 16,9577 & 0,0000 \\
2 & 45,2248 & 30,3693 & 2,1276 & 16,5781 & 5,7003 \\
3 & 44,1205 & 29,7141 & 3,6820 & 16,2082 & 6,2751 \\
4 & 43,9414 & 29,9729 & 3,7220 & 16,1257 & 6,2380 \\
5 & 44,0430 & 29,9048 & 3,7143 & 16,1039 & 6,2341 \\
6 & 44,0478 & 29,8907 & 3,7108 & 16,1041 & 6,2465 \\
7 & 44,0499 & 29,8890 & 3,7120 & 16,1027 & 6,2464 \\
8 & 44,0519 & 29,8886 & 3,7119 & 16,1017 & 6,2459 \\
9 & 44,0525 & 29,8881 & 3,7119 & 16,1014 & 6,2461 \\
10 & 44,0526 & 29,8881 & 3,7119 & 16,1014 & 6,2461 \\
11 & 44,0527 & 29,8880 & 3,7119 & 16,1013 & 6,2461 \\
12 & 44,0527 & 29,8880 & 3,7119 & 16,1013 & 6,2461 \\
\hline
\end{tabular}

Fonte: resultados da pesquisa. 
Tabela 6.1.23 - Decomposição da variância para a variável boi magro no modelo VEC para o período de junho de 1970 a novembro de 1973

\begin{tabular}{rrrrrr}
\hline passos & boi gordo & bezerro & vaca gorda & garrote & boi magro \\
\hline 1 & 31,4341 & 42,4503 & 0,8411 & 4,2291 & 21,0454 \\
2 & 48,1001 & 30,0415 & 2,5444 & 3,4257 & 15,8882 \\
3 & 47,0782 & 28,6274 & 3,4782 & 3,3934 & 17,4228 \\
4 & 46,9941 & 28,8576 & 3,4448 & 3,4539 & 17,2495 \\
5 & 47,1667 & 28,7794 & 3,4352 & 3,4407 & 17,1780 \\
6 & 47,1997 & 28,7471 & 3,4302 & 3,4437 & 17,1793 \\
7 & 47,2033 & 28,7436 & 3,4313 & 3,4436 & 17,1782 \\
8 & 47,2062 & 28,7431 & 3,4309 & 3,4436 & 17,1762 \\
9 & 47,2075 & 28,7424 & 3,4308 & 3,4435 & 17,1759 \\
10 & 47,2077 & 28,7422 & 3,4308 & 3,4435 & 17,1758 \\
11 & 47,2078 & 28,7422 & 3,4308 & 3,4435 & 17,1758 \\
12 & 47,2079 & 28,7422 & 3,4307 & 3,4435 & 17,1758 \\
\hline
\end{tabular}

Fonte: resultados da pesquisa.

Tabela 6.1.24 - Decomposição da variância para a variável boi gordo no modelo VEC para o período de novembro de 1973 a junho de 1977

\begin{tabular}{rrrrrr}
\hline passos & boi gordo & bezerro & vaca gorda & garrote & boi magro \\
\hline 1 & 100,0000 & 0,0000 & 0,0000 & 0,0000 & 0,0000 \\
2 & 72,5016 & 22,7556 & 0,0157 & 4,0729 & 0,6543 \\
3 & 69,9068 & 25,2704 & 0,0794 & 3,9525 & 0,7910 \\
4 & 69,4272 & 25,3967 & 0,1370 & 4,0314 & 1,0078 \\
5 & 69,3491 & 25,4605 & 0,1380 & 4,0268 & 1,0257 \\
6 & 69,3352 & 25,4577 & 0,1405 & 4,0289 & 1,0376 \\
7 & 69,3329 & 25,4595 & 0,1405 & 4,0288 & 1,0382 \\
8 & 69,3325 & 25,4594 & 0,1406 & 4,0289 & 1,0386 \\
9 & 69,3324 & 25,4594 & 0,1406 & 4,0289 & 1,0387 \\
10 & 69,3324 & 25,4594 & 0,1406 & 4,0289 & 1,0387 \\
11 & 69,3324 & 25,4594 & 0,1406 & 4,0289 & 1,0387 \\
12 & 69,3324 & 25,4594 & 0,1406 & 4,0289 & 1,0387 \\
\hline
\end{tabular}

Fonte: resultados da pesquisa.

Tabela 6.1.25 - Decomposição da variância para a variável bezerro no modelo VEC para o período de novembro de 1973 a junho de 1977

\begin{tabular}{rrrrrr}
\hline passos & boi gordo & bezerro & vaca gorda & garrote & boi magro \\
\hline 1 & 6,3202 & 93,6798 & 0,0000 & 0,0000 & 0,0000 \\
2 & 6,8640 & 82,6759 & 1,5054 & 4,6551 & 4,2996 \\
3 & 6,6256 & 83,0888 & 1,4557 & 4,5141 & 4,3158 \\
4 & 6,6777 & 82,5571 & 1,5362 & 4,6198 & 4,6092 \\
5 & 6,6708 & 82,5627 & 1,5347 & 4,6189 & 4,6129 \\
6 & 6,6736 & 82,5403 & 1,5379 & 4,6228 & 4,6254 \\
7 & 6,6734 & 82,5404 & 1,5378 & 4,6229 & 4,6254 \\
8 & 6,6735 & 82,5396 & 1,5380 & 4,6231 & 4,6258 \\
9 & 6,6735 & 82,5396 & 1,5380 & 4,6231 & 4,6258 \\
10 & 6,6735 & 82,5395 & 1,5380 & 4,6231 & 4,6258 \\
11 & 6,6735 & 82,5395 & 1,5380 & 4,6231 & 4,6258 \\
12 & 6,6735 & 82,5395 & 1,5380 & 4,6231 & 4,6258 \\
\hline
\end{tabular}

Fonte: resultados da pesquisa. 
Tabela 6.1.26 - Decomposição da variância para a variável vaca gorda no modelo VEC para o período de novembro de 1973 a junho de 1977

\begin{tabular}{rrrrrr}
\hline passos & boi gordo & bezerro & vaca gorda & garrote & boi magro \\
\hline 1 & 78,8256 & 2,9126 & 18,2619 & 0,0000 & 0,0000 \\
2 & 62,7947 & 19,2941 & 13,8200 & 3,5173 & 0,5738 \\
3 & 59,4601 & 23,2589 & 13,1048 & 3,4587 & 0,7174 \\
4 & 58,9645 & 23,5210 & 13,0465 & 3,5318 & 0,9363 \\
5 & 58,8765 & 23,6022 & 13,0294 & 3,5272 & 0,9646 \\
6 & 58,8626 & 23,6026 & 13,0282 & 3,5289 & 0,9777 \\
7 & 58,8602 & 23,6044 & 13,0277 & 3,5288 & 0,9788 \\
8 & 58,8598 & 23,6044 & 13,0277 & 3,5288 & 0,9793 \\
9 & 58,8597 & 23,6044 & 13,0277 & 3,5288 & 0,9794 \\
10 & 58,8597 & 23,6044 & 13,0277 & 3,5288 & 0,9794 \\
11 & 58,8597 & 23,6044 & 13,0277 & 3,5288 & 0,9794 \\
12 & 58,8597 & 23,6044 & 13,0277 & 3,5288 & 0,9794 \\
\hline
\end{tabular}

Fonte: resultados da pesquisa.

Tabela 6.1.27 - Decomposição da variância para a variável garrote no modelo VEC para o período de novembro de 1973 a junho de 1977

\begin{tabular}{rrrrrr}
\hline passos & boi gordo & bezerro & vaca gorda & garrote & boi magro \\
\hline 1 & 13,7592 & 33,5051 & 17,4472 & 35,2885 & 0,0000 \\
2 & 11,7100 & 43,0397 & 14,4157 & 29,1269 & 1,7076 \\
3 & 11,6804 & 42,2477 & 14,2074 & 29,5183 & 2,3462 \\
4 & 11,5854 & 42,7220 & 14,0810 & 29,2869 & 2,3247 \\
5 & 11,5943 & 42,6415 & 14,0837 & 29,2851 & 2,3955 \\
6 & 11,5917 & 42,6542 & 14,0800 & 29,2794 & 2,3947 \\
7 & 11,5923 & 42,6506 & 14,0800 & 29,2791 & 2,3980 \\
8 & 11,5922 & 42,6510 & 14,0799 & 29,2789 & 2,3980 \\
9 & 11,5922 & 42,6509 & 14,0799 & 29,2789 & 2,3981 \\
10 & 11,5922 & 42,6509 & 14,0799 & 29,2789 & 2,3981 \\
11 & 11,5922 & 42,6509 & 14,0799 & 29,2789 & 2,3981 \\
12 & 11,5922 & 42,6509 & 14,0799 & 29,2789 & 2,3981 \\
\hline
\end{tabular}

Fonte: resultados da pesquisa.

Tabela 6.1.28 - Decomposição da variância para a variável boi magro no modelo VEC para o período de novembro de 1973 a junho de 1977

\begin{tabular}{rrrrrr}
\hline passos & boi gordo & bezerro & vaca gorda & garrote & boi magro \\
\hline 1 & 3,0858 & 8,5497 & 9,4592 & 30,1568 & 48,7485 \\
2 & 3,8129 & 11,1256 & 8,9083 & 31,7090 & 44,4443 \\
3 & 4,4111 & 10,6183 & $\mathbf{8 , 9 4 5 5}$ & 32,0331 & 43,9920 \\
4 & 4,3985 & 11,2771 & $\mathbf{8 , 8 9 2 6}$ & 31,8713 & 43,5605 \\
5 & 4,4353 & 11,2513 & 8,9079 & 31,8651 & 43,5403 \\
6 & 4,4363 & 11,2793 & 8,9063 & 31,8586 & 43,5196 \\
7 & 4,4381 & 11,2787 & 8,9070 & 31,8579 & 43,5183 \\
8 & 4,4382 & 11,2798 & 8,9069 & 31,8577 & 43,5174 \\
9 & 4,4383 & 11,2798 & 8,9070 & 31,8576 & 43,5173 \\
10 & 4,4383 & 11,2799 & 8,9070 & 31,8576 & 43,5173 \\
11 & 4,4383 & 11,2799 & 8,9070 & 31,8576 & 43,5173 \\
12 & 4,4383 & 11,2799 & 8,9070 & 31,8576 & 43,5173 \\
\hline
\end{tabular}

Fonte: resultados da pesquisa. 


\subsubsection{Comparação entre os períodos analisados}

De acordo com a análise feita para ambos os períodos, junho de 1970 a junho de 1982 e junho de 1982 a maio de 1994, é bem evidente a importância do boi gordo e do bezerro no mercado de reposição. Na verdade, o boi gordo e o bezerro são as fontes fundamentais da variação dos seus próprios mercados e dos outros e pode-se dizer que as informações são usadas eficientemente nestes dois mercados.

Apesar do aumento do preço relativo do bezerro comentado no início deste capítulo, a importância do preço do bezerro cai expressivamente do primeiro para o segundo período. Este aumento do preço relativo estaria relacionado à especialização das fases do processo produtivo, principalmente a engorda, e ao maior uso dos leilões para a aquisição dos animais para a reposição. É importante observar que, de certa forma, a especialização das fases está intimamente relacionada ao uso dos leilões como canal de comercialização. Ou seja, o pecuarista, responsável pela engorda e acabamento final, precisa comprar o boi magro, garrote ou bezerro para repor o boi gordo que é vendido para o abate. O leilão agiliza a aquisição destes animais de reposição, pois centraliza parcialmente o mercado, facilitando a transação tanto para quem compra como para quem vende. Assim sendo, a especialização das fases estaria provocando uma provável diminuição da oferta de bezerro e, ao mesmo tempo, os leilões estariam possibilitando a extração do excedente do consumidor. Este aumento do preço relativo do bezerro pode estar associado a um menor ganho de produtividade do bezerro em relação ao boi gordo, cuja etapa tem um uso mais intensivo de tecnologia. Por outro lado, o melhor acesso às informações tem aumentado o fluxo de informações e o mercado do boi gordo tornou-se, de forma mais expressiva no segundo período, a principal fonte de variação das demais categorias. Verifica-se como a etapa final do processo produtivo é importante para as 
outras etapas direcionarem as suas atividades. Este melhor acesso às informações deve-se aos meios de comunicação bem como orgãos e instituições de pesquisas e até empresas privadas especializadas na coleta e distribuição de informações que promoveram o melhor fluxo de informações nos mercados agrícolas nos últimos dez anos.

Observando os resultados das tabelas A.2.1 a A.2.20, verifica-se como é importante definir a ordenação das variáveis no modelo VAR e no modeloVEC. Com a inversão das posições das variáveis preço do boi gordo e preço do bezerro, o preço do bezerro passa ser a principal fonte de variação entre os mercados e a sua importância aumenta expressivamente do primeiro para o segundo período analisado nesta pesquisa. Como foi comentado na seção anterior, as variáveis preço do boi gordo e preço do bezerro são muito semelhantes em termos de conteúdo de informação.

Ainda comparando o período de junho de 1982 a maio de 1994 com o período anterior, foi notado, através das respostas aos impulsos, que o restabelecimento do equilíbrio após as inovações parece ser mais rápida, ou seja, os mercados estão reagindo mais rapidamente a qualquer fato novo no processo produtivo. Esta maior rapidez na reação dos mercados pode ser observada na descaracterização do ciclo pecuário no período mais recente. $\mathrm{O}$ que pode explicar esta maior rapidez é o aumento do uso de tecnologia, apesar da tradicional resistência por parte da maioria dos pecuaristas na adoção de novas tecnologias. O confinamento, o cruzamento industrial e o manejo das pastagens são algumas das técnicas usadas para aumentar o rendimento por área e diminuir o ciclo de produção. A praticidade que o leilão proporciona na aquisição dos animais de reposição pode, também, estar contribuindo para esta reação mais rápida dos mercados às inovações bem como como a maior intensidade do fluxo de informações de mercado. 


\subsection{Leilóes: bezerros e garrotes}

Foram calculadas as médias e os desvios padrões dos preços semanais dos leilões para verificar a variabilidade dos preços por categoria, raça e sexo nas três praças consideradas nesta pesquisa. Os resultados destes cálculos encontram-se nas tabelas 6.2.1, 6.2.2 e 6.2.3.

Nas três praças os preços médios dos animais da raça nelore são mais altos que os preços médios dos animais mestiços, assim como o preço dos animais machos são também mais elevados que os animais fêmeas. A explicação quase trivial para ambos os fatos é o preço final. Ou seja, os animais nelores são mais valorizados que os mestiços que, na maioria, são cruzas de nelore com outras raças cujo uso geralmente não é para corte. Quanto a diferença devido ao sexo, as fềmeas tem um índice de aproveitamento da carcaça inferior ao do macho.

No que diz respeito a variabilidade dos preços médios, verificou-se, de um modo geral, a menor variabilidade em Araçatuba (tabela 6.2.1), onde o desvio padrão variou de 11,29\% a $18,03 \%$ em relação a média. A maior variabilidade foi constatada em Presidente Prudente (tabela 6.2.3). Nesta praça o desvio padrão variou de $24,23 \%$ a $42,02 \%$ em relação à média. Esta maior variabilidade em Presidente Prudente pode ser associada ao perfil tanto dos vendedores como dos compradores que, em boa parte, comportam-se como especuladores. Pela teoria do portfolio de Markowitz, o risco é proporcional à variância, ou seja, tanto o ganho como a perda potencial são maiores. Desta forma, um comprador ou vendedor avesso ao risco preferiria comercializar os seus animais em Araçatuba a comercializar em Presidente Prudente. Em Bauru, a variabilidade foi intermediária entre as outras duas praças (tabela 6.2.2). 0 desvio padrão variou de $13,02 \%$ a $28,79 \%$ em relação à media.

Quanto às médias dos preços para as diferentes categorias, raças e sexo, essas foram bem próximas nas três praças. Um detalhe interessante é quanto ao número de observações para as 
diferentes categorias, raças e sexo. Em Araçatuba, foram leiloados mais machos do que fềmeas, tanto entre bezerro e garrote como entre nelore e mestiço (tabela 6.2.1). Em Bauru, já houve uma predominância da raça nelore e uma leve predominância do animal macho (tabela 6.2.2). Em Presidente Prudente, ao contrário de Araçatuba, foram leiloados mais mestiços sendo que houve um predomínio do animal macho tanto entre bezerro e garrote como entre nelore e mestiço.

Tabela 6.2.1 - Média, desvio padrão e número de observações dos preços semanais, em dólar por unidade, dos leilões por categoria, raça, sexo em Araçatuba de maio de 1991 a dezembro de 1993.

média

desvio padrão

número de observações

Bezerro

nelore

macho

153,45

21,93

103

fêmea

105,16

15,30

51

mestiço

macho

112,53

17,89

111

fềmea

96,38

10,88

10

Garrote

nelore

macho

212,60

38,33

88

fềmea

137,22

23,14

28

mestiço

$169,05 \quad 24,58$

117

fềmea

125,11

21,07

19

Fonte:Dados da Pesquisa. 
Tabela 6.2.2 - Média, desvio padrão e número de observações dos preços semanais, em dólar por unidade, dos leilões por categoria, raça e sexo em Bauru de maio de 1991 a dezembro de 1993. média desvio padrão número de observações

Bezerro

nelore

$\begin{array}{cccr}\text { macho } & 152,28 & 19,83 & 109 \\ \text { fềmea } & 102,17 & 16,74 & 98 \\ \text { tiço } & & & \\ \text { macho } & 97,47 & 23,02 & 50 \\ \text { fềmea } & 80,91 & 14,77 & 23\end{array}$

Garrote

nelore macho $\quad 209,37 \quad 37,04 \quad 106$

fềmea $\quad 102,17 \quad 16,74 \quad 98$

mestiço

macho $\quad 156,02 \quad 44,92 \quad 85$

32,02

Fonte:Dados da Pesquisa.

Tabela 6.2.3 - Média, desvio padrão e número de observações dos preços semanais, em dólar por unidade, dos leilões por categoria, raça e sexo em Presidente Prudente de maio de 1991 a dezembro de 1993. média

Bezerro

nelore

macho

194,77

58,20

43

fềmea

127,28

55,01

mestiço

macho

175,06

42,42

124

fềmea

101,96

34,42

Garrote

nelore

macho

212,42

89,25

21

fềmea

141,38

41,93

19

mestiço

macho 200,69

59,73

103

fêmea

118,87

45,01

44

Fonte:Dados da Pesquisa. 
Como foi destacado anteriormente, as séries das médias dos leilões possuem muitas falhas e não são "bem comportadas", o que se verificou através da média e do desvio padrão destas séries. Não sendo possível defasar as séries para uma análise mais sofisticada, como a que foi usada para as séries mensais do CEPEA/FEALQ nas seções anteriores, utilizou-se apenas a análise de regressão linear múltipla sem o uso de variáveis defasadas. Ou seja, estimando regressões de cada variável contra as demais, foi possivel determinar o quanto cada uma das variáveis ajuda na explicação das demais. Para estimação das regressões, foram usadas apenas as semanas que tinham todos os dados nas três praças, totalizando 45 observações. $O$ coeficiente de determinação parcial assim como o teste $\mathrm{F}$ para a contribuição de cada variável estão apresentados na tabela 6.2.4. Os números dos graus de liberdade para o teste F são 1 e 37 . As defasagens das variáveis na decomposição da variância ou em um teste de causalidade de Granger servem, justamente, para determinar o sentido do fluxo de informações.

Existe um fluxo significativo, ao nivel de $10 \%$, entre as categorias bezerro mestiço de Presidente Prudente e Araçatuba. Ao nível de 5\%, existem relações significativas entre o bezerro mestiço de Presidente Prudente e o bezerro nelore de Bauru, e entre o bezerro e garrote nelore de Araçatuba. Ao nível de 1\%, há as relações entre o bezerro mestiço de Araçatuba e o bezerro nelore de Bauru e entre o bezerro e o garrote nelore de Bauru.

Quanto as variáveis garrote mestiço de Presidente Prudente e garrote mestiço de Araçatuba, nada contribuem na explicação das outras variáveis. 
Tabela 6.2.4 - Teste F da contribuição de cada variável e o coeficiente de determinação parcial, considerando todas as combinações quanto a variável dependente

\begin{tabular}{|c|c|c|c|c|c|c|c|c|}
\hline \multirow{3}{*}{$\begin{array}{l}\text { variável } \\
\text { depen- } \\
\text { dente }\end{array}$} & \multicolumn{8}{|c|}{ variáveis independentes } \\
\hline & $\begin{array}{c}\text { bezerro } \\
\text { mestiço } \\
\text { P.P. }\end{array}$ & $\begin{array}{c}\text { garrote } \\
\text { mestiço } \\
\text { P.P. }\end{array}$ & $\begin{array}{l}\text { bezerro } \\
\text { mestiço } \\
\text { Araçat. }^{2}\end{array}$ & $\begin{array}{l}\text { garrote } \\
\text { mestiço } \\
\text { Araçat. }^{2}\end{array}$ & $\begin{array}{c}\text { bezerro } \\
\text { nelore } \\
\text { Bauru }\end{array}$ & $\begin{array}{l}\text { garrote } \\
\text { nelore } \\
\text { Bauru }\end{array}$ & $\begin{array}{c}\text { bezerro } \\
\text { nelore } \\
\text { Araçat. }{ }^{2}\end{array}$ & $\begin{array}{c}\text { garrote } \\
\text { nelore } \\
\text { Araçat. }^{2}\end{array}$ \\
\hline & & & & $\begin{array}{r}\text { F cal } \\
\text { nivel de si } \\
\text { f. de detern }\end{array}$ & $\begin{array}{l}\text { lado } \\
\text { nificância } \\
\text { nação parci }\end{array}$ & & & \\
\hline $\begin{array}{c}\text { bezerro } \\
\text { mestiço } \\
\text { P.P.l }\end{array}$ & * & & & & & & & \\
\hline garrote & 1,23 & & & & & & & \\
\hline mestiço & N.S. ${ }^{3}$ & * & & & & & & \\
\hline P.P. 1 & $3,21 \mathrm{E}-02$ & & & & & & & \\
\hline bezerro & 3,37 & $3,38 \mathrm{E}-04$ & & & & & & \\
\hline mestiço & $10 \%$ & N.S. & * & & & & & \\
\hline Araçat. $^{2}$ & $8,35 \mathrm{E}-02$ & $9,14 \mathrm{E}-06$ & & & & & & \\
\hline garrote & 0,18 & 0,76 & 0,91 & & & & & \\
\hline mestiço & N.S. & N.S. & N.S. & * & & . & & \\
\hline Araçat. $^{2}$ & $4,77 \mathrm{E}-03$ & $2,01 \mathrm{E}-02$ & $2,41 \mathrm{E}-02$ & & & & & \\
\hline bezerro & 6,66 & 0,19 & 24,99 & 0,36 & & & & \\
\hline nelore & $5 \%$ & N.S. & $1 \%$ & N.S. & * & & & \\
\hline Bauru & 0,1526 & $5,16 \mathrm{E}-03$ & 0,4032 & $9,65 \mathrm{E}-03$ & & & & \\
\hline garrote & 0,95 & $2,76 \mathrm{E}-04$ & 0,62 & 0,38 & 8,41 & & & \\
\hline nelore & N.S. & N.S. & N.S. & N.S. & $1 \%$ & * & & \\
\hline Bauru & $2,50 \mathrm{E}-02$ & $7,45 \mathrm{E}-05$ & $1,65 \mathrm{E}-02$ & $1,03 E-02$ & 0,1851 & & & \\
\hline bezerro & 0,83 & 0,14 & 1,41 & 0,06 & 0,02 & 0,43 & & \\
\hline nelore & N.S. & N.S. & N.S. & N.S. & N.S. & N.S. & * & \\
\hline Araçat. $^{2}$ & $2,19 \mathrm{E}-02$ & $3,81 \mathrm{E}-03$ & $3,66 \mathrm{E}-02$ & $1,55 \mathrm{E}-03$ & 5,35E-04 & $1,16 \mathrm{E}-02$ & & \\
\hline garrote & 2,05 & $9,47 \mathrm{E}-04$ & 0,01 & 0,67 & 0,7 & 1,67 & 5,75 & \\
\hline nelore & N.S. & N.S. & N.S. & N.S. & N.S. & N.S. & $5 \%$ & * \\
\hline Araçat. $^{2}$ & $5,25 \mathrm{E}-02$ & $2,54 \mathrm{E}-05$ & $1,67 \mathrm{E}-04$ & $1,77 \mathrm{E}-02$ & $1,86 \mathrm{E}-02$ & $4,32 \mathrm{E}-02$ & 0,1345 & \\
\hline
\end{tabular}

Obs.: - Foi considerado significativo a $10 \%$ ou menos;

-Os números dos graus liberdade para o teste "F" são 1 e 37;

1 - Presidente Prudente;

2 - Araçatuba;

3 - não significativo à $10 \%$;

Fonte: resultados da pesquisa. 
É interessante notar que apenas na categoria bezerro existe um fluxo de informação significativo entre as três praças. Existe fluxo de informações significativo entre as categorias bezerro e garrote nelore de uma mesma praça em Bauru e Araçatuba.

O único resultado que parece ser um pouco estranho é a relação do bezerro mestiço de Presidente Prudente e Araçatuba com o bezerro nelore de Bauru serem significativas, enquanto que a relação entre Araçatuba e Bauru para as categorias bezerro e garrote nelore não serem.

Os resultado obtidos através das séries dos leilões não permitem rejeitar a hipótese da nulidade formulada inicialmente nesta pesquisa, ou seja, de que não existem mercados satélites e dominantes entre as três praças. Tal fato é explicado pelo fácil acesso às informações por parte dos agentes de comercializaçaão que atuam nesta três praças. Ou seja, qualquer fato novo em uma das três praças são conhecidas quase em tempo real pelos seus agentes de comercialização. Tal fato reflete como é grande o fluxo de informações de mercado que indiretamente deve-se a disponibilidade e às facilidades dos meios de comunicação. 


\section{CONCLUSÃO}

Os mercados da pecuária bovina de corte, bezerro, garrote, boi magro, boi gordo e vaca gorda, são, no conjunto, significativamente eficientes. Ou seja, os preços nestes mercados são cointegrados.

O preço do boi gordo ainda é o único mercado a influenciar sistematicamente os demais mercados da pecuária de corte. O preço do bezerro, que tem informações muito semelhantes ao do boi gordo, influencia bem menos as demais categorias, quando comparado com o preço do boi gordo. Os mercados do boi gordo e do bezerro são melhor estruturados, seja por possuirem maior quantidade de informação, ou seja, por possuirem um volume maior de comercialização. Adicionalmente, é importante destacar que o efeito do choque em uma das variáveis sobre as demais não é temporária como parece ser nas figuras apresentadas na discussão desta pesquisa. Pois, quando se trabalha com as variáveis em diferença, tem-se taxas de crescimento e não variações percentuais, e o efeito do choque é permanente quando se analisa as variáveis em nível.

No ciclo pecuário plurianual o padrão do fluxo de informações entre os mercados muda, principalmente, em relação ao boi gordo e ao bezerro. Ou seja, na fase ascendente do ciclo, o mercado do boi gordo domina os demais mercados como fonte da variação dos preços, enquanto que, na fase descendente, as outras categorias passam a influenciar muito mais os outros mercados quanto a variação dos preços. 
O prováveis motivos da mudança nas relações existentes entre os mercados da pecuária bovina de corte, verificadas no período de junho de 1970 a maio de 1994 , estariam relacionados à especialização do processo produtivo, ao significativo aumento do fluxo de informações de mercados decorrente do melhor acesso a estas informações através dos meios de comunicação convencionais, dos leilões, dos orgãos e instituições de pesquisas e de empresas privadas especializadas na coleta e distribuição de informações de mercados.

O mercado do garrote está relacionado ao do bezerro, assim como o mercado da vaca gorda está relacionado ao do boi gordo. O mercado do boi magro, por sua vez, está relacionado tanto ao do boi gordo como ao do bezerro. Ou seja, inovações do mercado do boi gordo assim como as do mercado do bezerro afetam o mercado do boi magro.

Em termos de política do governo para o setor, fica claro mais uma vez que qualquer ação do governo diretamente na oferta ou na demanda de carne bovina não é o melhor caminho. O problema está dentro do processo produtivo e as políticas governamentais devem ser direcionadas para que se aumente o uso de tecnologia e se dinamize as relações entre os mercados das fases intermediárias do processo produtivo. $\mathrm{O}$ uso mais intensivo de tecnologia pode ser conseguido através de estímulos que façam o pecuarista reduzir o ciclo de produção. Um maior investimento em pesquisas na pecuária bovina de corte pode ter uma ação indireta, mas efetiva, no que diz respeito a atenuação do efeito da entressafra na oferta de boi gordo.

Uma outra forma de tornar mais rápidas as respostas do processo produtivo da pecuária bovina de corte às variações de preços, é a dinamização do comércio de animais de reposição assim como os animais de abate. Esta maior dinâmica pode ser conseguida com um incremento ainda maior do fluxo de informações entre os agentes de 
comercialização, permitindo-se uma mudança mais rápida entre os criadores, recriadores e invernistas quanto a alocação de seus recursos.

No tocante aos leilões, os mercados das regiões de Presidente Prudente, Araçatuba e Bauru estão bem integrados no que diz respeito ao mercado do bezerro, sendo que não foi possivel, através dos dados de leilões, verificar o sentido do fluxo de informações entre estas regiões. Não existe relação dominante-satélite entre as três praças pesquisadas. 


\section{REFERÊNCIAS BIBLIOGRÁFICAS}

BACCHI, M.R.P. Previsão de preços de bovinos, suínos e frango com modelos de série temporais. Piracicaba, 1994. 166p. (Doutorado - Escola Superior de Agricultura Luiz de Queiroz / USP)

BAILEY, D.V. \& BRORSEN, B.W. Dynamics of regional fed cattle prices. Western Journal of Agricultural Economics, College Station, 10(1): 126-33, July 1985.

BARROS, G.S.C. Economia da comercialização produtos agrícolas. Piracicaba, FEALQ, 1987. 306p.

BARROS, G.S.C. Transmissão de preços pela central de abastecimento de São Paulo, Brasil. Revista Brasileira de Economia, Rio de Janeiro, 44(1):5-20, jan./mar. 1990.

BLISKA, F.M.M. Transmissão de preços de carne bovina entre níveis de mercado: uma aplicação do modelo de auto-regressão vetorial. Piracicaba, 1989. 209p. (Mestrado - Escola Superior de Agricultura Luiz Queiroz / USP).

BOX, G.E.P. \& JENKINS, G.M. Time series analysis forecasting and control. Oakland, Holden-Day, 1976. 575p. 
BRANDÃO, A.S.P. Moeda e preços relativos: evidência empírica. Revista de Econometria, Rio de Janeiro, 5(2):33-80, nov. 1985.

BUCCOLA, S.T. Pricing efficiency in centralized and noncentralized markets. American Journal of Agricultural Economics, Lexington, 67(3): 583-90, Aug. 1985.

CENSO AGROPECUÁRIO - 1985, Rio de Janeiro, (21):68-71,81,87,798-809, 1991.

CENSO AGROPECUÁRIO - 1985, Rio de Janeiro, (1): 66-71,81,87,310, 1991.

COORDENADORIA DE ASSISTÊNCIA TÉCNICA INTEGRAL. Caracterização da bovinocultura de corte no estado de São Paulo. Campinas, 1985. 84p. (CATI. Documento Técnico, 58).

DIAS, G. L. S. Avaliação do política econômica para pecuária de corte no Brasil. São Paulo, 1972. 118 p. (Doutorado - Faculdade de Economia e Administração / USP)

DICKEY, D.A. \& FULLER, W.A. Distribution of the estimators for autoregressive time series with a unit root. Journal of the American Statistical Association, Alexandria, 74(366):427-31, June 1979.

DICKEY, D.A. \& FULLER, W.A. Likelihood ratio statistics for autoregressive time series with a unit root. Econometrica, Evanston, 49(4):1057-72, July 1981.

DOAN, T.A. Rats v.4.0; user's manual. Evaston, Estima, 1992.

DOLADO, J.J.; JENKINSON, T.; SOSVILLA-RIVERO, S. Cointegration and unit roots. Journal of Economic Surveys, Oxford, 4(3):249-73, 1990. 
ENGLE, R.F. \& GRANGER, C.W.J. Co-integration and error correction: representation, estimation and testing. Econometrica, Evanston, 55(2):251-76, Mar. 1987.

ENGLE, R.F. \& YOO, S. Forecasting and testing in cointegrated systems. Journal of Econometrics, New York, 35:143-59, 1987.

FULLER, W.A. Introduction to statistical time series. New York, John Wiley, 1976.

GARBADE, K.D. \& SILBER, W.L. Dominant and satellite markets: a study of duallytraded securities. The Review of Economics and Statistics, Cambridge, 61(3): 455-60, Aug. 1979

GOODWIN, B.K. \& SCHROEDER, T.C. Cointegration tests and Spatial price linkages in regional cattle markets. American Journal of Agricultural Economics, Lexington, 73(2):452-64, May 1991.

GRANGER, C.W.J. Investigating causal relations by econometric models and crossspectral methods. Econometrica, Evanston, 37:424-38, 1969.

GRANGER, C.W.J. Development in the study of cointegrated economic variables. Oxford Bullettin of Economics and Statistics, Oxford, 48(3):213-28, Aug. 1986.

GUIMARÃES, V.D.A. Comercialização e transmissão de preços de carne de frango no estado de São Paulo. Piracicaba, 1990. 119p. (Mestrado - Escola Superior de Agricultura Luiz de Queiroz / USP) 
HADDAD, C.M. A carne bovina da fonte de produção ao consumidor: problemas e propostas de soluções. In: PEIXOTO, A.M.; MOURA, J.C.; FARIA, V.P., ed. Bovinocultura de corte. 2. ed. Piracicaba, FEALQ, 1993. p.513-31. (Atualização em Zootecnia, 8).

HAMILTON, J.D. Time series analysis. Princeton, Princeton University Press, 1994. 799p.

HAKKIO, C.G. \& MORRIS, C.S. Vector autoregressions; a user's guide. Kansas, Federal Reserve Bank of Kansas City, 1982 82p. (Research Working Paper,84-10).

HARRIS, M.\& RAVIV, A. A theory of monopoly schemes with demand uncertainty. American Economic Review, Menasha, 71(3): 347-65, June 1981.

HENDRY, D.F. Econometric modelling with cointegrated variables: a overview. Oxford Bulletin of Economics and Statistics, Oxford, 48(3):201-12, Aug. 1986.

HOFFMANN,R. \& VEIRA, S. Análise de regressão, uma introdução à econometria. 2. ed. São Paulo, HUCITEC, 1983. 379p.

IGREJA, A.C.M. Evolução da pecuária bovina de corte no estado de São Paulo no periodo de 1969-1984. Piracicaba, 1987. 197p. (Mestrado - Escola Superior de Agricultura Luiz de Queiroz / USP)

JOHANSEN, S. Statistical analysis of cointegration vectors. Journal of Economic Dynamics and Control, New York, 12(2/3):231-54, June/Sept. 1988. 
JOHANSEN, S. Estimation and hypotesis testing of cointegration vectors in gaussian vector autoregressive models. Econometrica, Evanston, 59(6):1551-80, Nov. 1991.

JOHANSEN, S.; JUSELIUS, L. Maximum likelihood estimation and inference on cointegration with aplications to the demand for money. Oxford Bulletin of Economics and Statistics, Oxford, 52(2):169-210, 1990.

JUDGE, G.G.; GRIFFITHS, W.E.; HILL, R.C.; LÜTKEPOHL, H. LEE, T.C. The theory and pratice of econometrics. 2. ed. New York, John Wiley, 1985. 1019p.

JUDGE, G.G.; GRIFFITHS, W.E.; HILL, R.C.; LÜTKEPOHL, H.; LEE, T.C. Introduction to the theory and pratice of econometrics. 2 ed. New York, John Wiley, 1987. 1024p.

KASSOUF, A. L. Previsão de preços na pecuária de corte do Estado de São Paulo. Piracicaba, 1988. 102p. (Mestrado - Escola Superior de Agricultura Luiz de Queiroz / USP).

KOONTZ, S.R.; GARCIA, P.; HUDSON, M.A. Dominant-satellite relationships between live cattle cash and futures markets. The Journal of Futures Markets, New York, 10(2): 123-36, 1990.

LATTIMORE, R.G. An econometric study of the brazilian beef sector. W. Lafayette, 1974. 177p. (Ph.D. - Purdue University). 
LIMA, E.C.R.; LOPES, H.F.; MOREIRA, A.R.B.; PEREIRA, P.L.V. Tendências estocásticas do produto efeito de flutuações da produtividade e da taxa de juros real. In: ENCONTRO BRASILEIRO DE ECONOMETRIA. 15. , Belo Horizonte, 1993. Belo Horizonte, Sociedade Brasileira de Econometria, 1993. p.697-719.

LOOMES, G. Experimental economics. In: HEY, J. D. Current issues in microeconomics. Hampshire, MacMillan, 1989. p.163-73.

LÜTKEPOHL, H. Introduction to multiple time series analysis. Berlin, SpringerVerlag, 1991. 545p.

MACHADO FILHO, C.A.P. Leilão de animais no Brasil. Revista de Administração, São Paulo, 29(1):76-82, jan./mar. 1994.

MILGROM, P.R. \& WEBER, R.J. A theory of auctions and competitive bidding. Econometrica, Evanston, 50(5): 1089-22, Sept. 1982.

MARQUES, P.V. \& AGUIAR, D.R.D. Comercialização de produtos agrícolas. São Paulo, EDUSP, 1993. 295 p. (Coleção Campi, 13).

McAFEE, R.P. \& McMILLAN, J. Auctions and bidding. Journal of Economic Literature, Menasha, 25(2): 699-38, June 1987.

MASCOLO, J.L. Um estudo econométrico da pecuária de corte no Brasil. Revista Brasileira de Economia, Rio de Janeiro, 33(1):65-105, jan./mar. 1979.

O MERCADO de carne bovina: um guia para a análise. Suma Agrícola, Rio de Janeiro (203): 5-10, jan. 1987. 
MORETTIN, P.A. \& TOLOI, C.M.C. Previsão de séries temporais. 2. ed. São Paulo, Atual, 1986. $439 \mathrm{p}$.

MUELLER, C.C. O ciclo do gado e as tentativas governamentais de controle do preço da carne. Estudos Econômicos, São Paulo, 17(3): 435-56, set./dez. 1987.

OLIVEIRA, J. A. F. G. Condicionalidades do crescimento da pecuária bovina de corte nos anos 80. Rio de Janeiro, IPEA, 1991. 15p. (IPEA. Texto para Discussão, 221).

PANTON, D.B. A semi-strong form evaluation of the efficiency of the hog futures market: comment. American Journal of Agricultural Economics, Lexington, 62(3):584, Aug. 1980.

PEIXOTO, A.M. Fatores que interferem no crescimento do gado de corte até a desmama. In: PEIXOTO, A.M.; MOURA, J.C.; FARIA, V.P., ed. Bovinocultura de corte. 2. ed. Piracicaba, FEALQ, 1993. p.129-58. (Série Atualização em Zootecnia, 8).

PEREIRA, P.V. Cointegração e suas representações: uma resenha. Revista de Econometria, Rio de Janeiro, 11(2):185-216, nov. 1991.

PLOUVIER MONTEMURRO, L.E. Fatores condicionantes do comportamento do setor pecuário no Uruguai. Piracicaba, 1979. 153p. (Mestrado -Escola Superior de Agricultura Luiz Queiroz / USP). 
PORTUGAL, M.S. Um modelo de correção de erros para a demanda por importações brasileiras. Pesquisa e Planejamento Econômico, Rio de Janeiro, 22(3):501-40, dez. 1992.

SANTANA, A.C. \& BRANDT, S.A. Encadeamento de preços na pecuária de corte: uma aplicação do modelo de correção de erro. Revista de Economia e Sociologia Rural, Brasília, 29 (2): 135-49, abr./jun. 1991.

SARKER, R. A maximum likelihood cointegration analysis of canadian lumber exports. Canadian Journal of Agricultural Economics, Ottawa, 41(1): 97-110, Mar. 1993.

SCHERER, F.M. Industrial market structure and economic performance. Chicago, Rand McNally College Publishing, 1970.

SCHROEDER, T.C. \& GOODWIN, B.K. Regional fed cattle price dynamics. Western Journal of Agricultural Economics, College Station, 15(1): 111-22, July 1990.

SIMS, C.A. Macroeconomics and reality. Econometrica, Evanston, 48(1):1-48, Jan. 1980.

SPREEN, T.; SHONKWILER, J.S. Causal relationships in the fed cattle market. Southern Journal of Agricultural Economics, Lexington, 13:149-153, July 1981.

TOLEDO, Y.I.M. \& SANTIAGO, M.M.D. Análise do comportamento de preços na pecuária bovina, estado de São Paulo, 1970-83. Informações Econômicas, São Paulo, 14(6): 21-8, jun. 1984. 
130.

VAN TASSELL, L.W. \& BESSLER, D.A. Dynamic price adjustments between commercial and purebred cattle markets. Southern Journal of Agricultural Economics, Lexington, 20: 137-43, Dec. 1988.

VICKREY, W. Counterspeculation, auctions and competitive sealed tenders. Journal of Finance, New York, 16: 8-37, 1961.

WILLIAMS, C.H. \& BEWLEY, R.A. Price arbitrage between Queensland cattle auctions. Australian Journal of Agricultural Economics, Armidale, 37(1): 33-55, Apr. 1993.

ZIMMER, A.H. Pastagens para bovinos de corte. In: PEIXOTO, A.M.; MOURA, J.C.; FARIA, V.P., ed. Bovinocultura de corte. 2. ed. Piracicaba, FEALQ, 1993. p.231-67. (Atualização em Zootecnia, 8). 
Apêndice 
Tabela A.1.1 - Valores críticos para a estatística tal-tal do teste ADF

\begin{tabular}{ccccc}
\hline graus de liberdade & \multicolumn{4}{c}{ Probabilidade de um valor menor } \\
\cline { 2 - 5 } & 0,01 & 0,025 & 0,05 & 0,10 \\
\hline 25 & $-4,38$ & $-3,95$ & $-3,60$ & $-3,24$ \\
50 & $-4,15$ & $-3,80$ & $-3,50$ & $-3,18$ \\
100 & $-4,04$ & $-3,73$ & $-3,45$ & $-3,15$ \\
250 & $-3,99$ & $-3,69$ & $-3,43$ & $-3,13$ \\
500 & $-3,98$ & $-3,68$ & $-3,42$ & $-3,13$ \\
$\propto$ & $-3,96$ & $-3,66$ & $-3,41$ & $-3,12$ \\
\hline
\end{tabular}

Fonte: FULLER, W.A. Introduction to statistical time series. New York: John Wiley \& Sons, 1976, p.373.

Tabela A.1.2 - Resposta-impulso quando há inovação na variável boi gordo no modelo VEC para o período de junhode 1970 a junho de 1982

\begin{tabular}{crrrrr}
\hline passos & boi gordo & bezerro & vaca gorda & garrote & boi magro \\
\hline 1 & $1,0000 \mathrm{E}+00$ & $4,9105 \mathrm{E}-01$ & $8,4321 \mathrm{E}-01$ & $5,2680 \mathrm{E}-01$ & $4,6937 \mathrm{E}-01$ \\
2 & $2,5489 \mathrm{E}-01$ & $3,4028 \mathrm{E}-01$ & $3,4798 \mathrm{E}-01$ & $2,3805 \mathrm{E}-01$ & $3,3007 \mathrm{E}-01$ \\
3 & $1,1415 \mathrm{E}-01$ & $1,4548 \mathrm{E}-01$ & $1,4039 \mathrm{E}-01$ & $1,3231 \mathrm{E}-01$ & $1,2107 \mathrm{E}-01$ \\
4 & $6,2737 \mathrm{E}-02$ & $8,0650 \mathrm{E}-02$ & $6,9066 \mathrm{E}-02$ & $6,5131 \mathrm{E}-02$ & $6,9925 \mathrm{E}-02$ \\
5 & $3,2778 \mathrm{E}-02$ & $4,0327 \mathrm{E}-02$ & $3,8489 \mathrm{E}-02$ & $3,4458 \mathrm{E}-02$ & $3,5748 \mathrm{E}-02$ \\
6 & $1,6693 \mathrm{E}-02$ & $2,1202 \mathrm{E}-02$ & $1,9196 \mathrm{E}-02$ & $1,7508 \mathrm{E}-02$ & $1,8371 \mathrm{E}-02$ \\
7 & $8,6357 \mathrm{E}-03$ & $1,0786 \mathrm{E}-02$ & $1,0022 \mathrm{E}-02$ & $9,1064 \mathrm{E}-03$ & $9,4770 \mathrm{E}-03$ \\
8 & $4,4483 \mathrm{E}-03$ & $5,6083 \mathrm{E}-03$ & $5,1307 \mathrm{E}-03$ & $4,6685 \mathrm{E}-03$ & $4,8863 \mathrm{E}-03$ \\
9 & $2,2945 \mathrm{E}-03$ & $2,8760 \mathrm{E}-03$ & $2,6578 \mathrm{E}-03$ & $2,4153 \mathrm{E}-03$ & $2,5191 \mathrm{E}-03$ \\
10 & $1,1824 \mathrm{E}-03$ & $1,4876 \mathrm{E}-03$ & $1,3659 \mathrm{E}-03$ & $1,2424 \mathrm{E}-03$ & $1,2986 \mathrm{E}-03$ \\
11 & $6,0973 \mathrm{E}-04$ & $7,6532 \mathrm{E}-04$ & $7,0555 \mathrm{E}-04$ & $6,4141 \mathrm{E}-04$ & $6,6951 \mathrm{E}-04$ \\
12 & $3,1429 \mathrm{E}-04$ & $3,9507 \mathrm{E}-04$ & $3,6329 \mathrm{E}-04$ & $3,3038 \mathrm{E}-04$ & $3,4514 \mathrm{E}-04$ \\
\hline
\end{tabular}

Fonte: resultados da pesquisa.

Tabela A.1.3 - Resposta-impulso quando há inovação na variável bezerro no modelo VEC para o período de junho de 1970 a junho de 1982

\begin{tabular}{rrrrrr}
\hline passos & boi gordo & bezerro & vaca gorda & garrote & boi magro \\
\hline 1 & $0,0000 \mathrm{E}+00$ & $1,0000 \mathrm{E}+00$ & $6,8927 \mathrm{E}-02$ & $6,0651 \mathrm{E}-01$ & $3,2432 \mathrm{E}-01$ \\
2 & $3,6312 \mathrm{E}-01$ & $3,5157 \mathrm{E}-01$ & $3,6243 \mathrm{E}-01$ & $4,1065 \mathrm{E}-01$ & $3,8247 \mathrm{E}-01$ \\
3 & $1,9287 \mathrm{E}-01$ & $2,5812 \mathrm{E}-01$ & $2,1052 \mathrm{E}-01$ & $1,7808 \mathrm{E}-01$ & $2,1019 \mathrm{E}-01$ \\
4 & $9,3751 \mathrm{E}-02$ & $1,1015 \mathrm{E}-01$ & $1,1616 \mathrm{E}-01$ & $1,0366 \mathrm{E}-01$ & $1,0267 \mathrm{E}-01$ \\
5 & $4,8133 \mathrm{E}-02$ & $6,3542 \mathrm{E}-02$ & $5,3421 \mathrm{E}-02$ & $4,9548 \mathrm{E}-02$ & $5,3121 \mathrm{E}-02$ \\
6 & $2,5149 \mathrm{E}-02$ & $3,0590 \mathrm{E}-02$ & $2,9707 \mathrm{E}-02$ & $2,6793 \mathrm{E}-02$ & $2,7534 \mathrm{E}-02$ \\
7 & $1,2872 \mathrm{E}-02$ & $1,6487 \mathrm{E}-02$ & $1,4687 \mathrm{E}-02$ & $1,3409 \mathrm{E}-02$ & $1,4157 \mathrm{E}-02$ \\
8 & $6,6592 \mathrm{E}-03$ & $\mathbf{8 , 2 6 4 8 E}-03$ & $7,7669 \mathrm{E}-03$ & $7,0442 \mathrm{E}-03$ & $7,3059 \mathrm{E}-03$ \\
9 & $3,4260 \mathrm{E}-03$ & $4,3371 \mathrm{E}-03$ & $3,9400 \mathrm{E}-03$ & $3,5887 \mathrm{E}-03$ & $3,7643 \mathrm{E}-03$ \\
10 & $1,7686 \mathrm{E}-03$ & $2,2111 \mathrm{E}-03$ & $2,0523 \mathrm{E}-03$ & $1,8641 \mathrm{E}-03$ & $1,9414 \mathrm{E}-03$ \\
11 & $9,1098 \mathrm{E}-04$ & $1,1480 \mathrm{E}-03$ & $1,0512 \mathrm{E}-03$ & $9,5646 \mathrm{E}-04$ & $1,0006 \mathrm{E}-03$ \\
12 & $4,6991 \mathrm{E}-04$ & $5,8921 \mathrm{E}-04$ & $5,4415 \mathrm{E}-04$ & $4,9457 \mathrm{E}-04$ & $5,1594 \mathrm{E}-04$ \\
\hline
\end{tabular}

Fonte: resultados da pesquisa. 
Tabela A.1.4 - Resposta-impulso quando há inovação na variável vaca gorda no modelo VEC para o período de junho de 1970 a junho de 1982

\begin{tabular}{rrrrrr}
\hline passos & boi gordo & bezerro & vaca gorda & garrote & boi magro \\
\hline 1 & $0,0000 \mathrm{E}+00$ & $0,0000 \mathrm{E}+00$ & $1,0000 \mathrm{E}+00$ & $1,1425 \mathrm{E}-01$ & $3,0461 \mathrm{E}-01$ \\
2 & $-1,0577 \mathrm{E}-01$ & $2,4307 \mathrm{E}-02$ & $-1,8917 \mathrm{E}-01$ & $-3,1707 \mathrm{E}-02$ & $-1,1466 \mathrm{E}-01$ \\
3 & $8,1882 \mathrm{E}-03$ & $-2,0490 \mathrm{E}-02$ & $5,9666 \mathrm{E}-03$ & $8,8065 \mathrm{E}-03$ & $9,5409 \mathrm{E}-03$ \\
4 & $6,0321 \mathrm{E}-04$ & $6,4755 \mathrm{E}-03$ & $-1,4522 \mathrm{E}-03$ & $-3,9124 \mathrm{E}-03$ & $-4,5430 \mathrm{E}-05$ \\
5 & $-3,6917 \mathrm{E}-04$ & $-2,4267 \mathrm{E}-03$ & $1,1809 \mathrm{E}-03$ & $9,4936 \mathrm{E}-04$ & $-3,5146 \mathrm{E}-04$ \\
6 & $-1,7298 \mathrm{E}-04$ & $5,3334 \mathrm{E}-04$ & $-7,5598 \mathrm{E}-04$ & $-5,0500 \mathrm{E}-04$ & $-1,5248 \mathrm{E}-04$ \\
7 & $-3,0875 \mathrm{E}-05$ & $-2,9400 \mathrm{E}-04$ & $1,3132 \mathrm{E}-04$ & $6,3497 \mathrm{E}-05$ & $-5,1449 \mathrm{E}-05$ \\
8 & $-3,7897 \mathrm{E}-05$ & $3,4512 \mathrm{E}-05$ & $-9,6304 \mathrm{E}-05$ & $-7,2309 \mathrm{E}-05$ & $-3,6039 \mathrm{E}-05$ \\
9 & $-1,3274 \mathrm{E}-05$ & $-4,3122 \mathrm{E}-05$ & $1,8439 \mathrm{E}-06$ & $-3,1030 \mathrm{E}-06$ & $-1,6329 \mathrm{E}-05$ \\
10 & $-8,7465 \mathrm{E}-06$ & $-2,3868 \mathrm{E}-06$ & $-1,5762 \mathrm{E}-05$ & $-1,2731 \mathrm{E}-05$ & $-9,0305 \mathrm{E}-06$ \\
11 & $-3,8834 \mathrm{E}-06$ & $-7,6837 \mathrm{E}-06$ & $-2,6497 \mathrm{E}-06$ & $-2,9392 \mathrm{E}-06$ & $-4,4540 \mathrm{E}-06$ \\
12 & $-2,2093 \mathrm{E}-06$ & $-1,8620 \mathrm{E}-06$ & $-3,1532 \mathrm{E}-06$ & $-2,6947 \mathrm{E}-06$ & $-2,3641 \mathrm{E}-06$ \\
\hline
\end{tabular}

Fonte: resultados da pesquisa.

Tabela A.1.5 - Resposta-impulso quando há inovação na variável garrote no modelo VEC para o periodo de junho de 1970 a junho de 1982

\begin{tabular}{rrrrrr}
\hline & \multicolumn{1}{c}{ boi gordo } & \multicolumn{1}{c}{ bezerro } & vaca gorda & \multicolumn{1}{l}{ garrote } & boi magro \\
\hline 1 & $0,0000 \mathrm{E}+00$ & $0,0000 \mathrm{E}+00$ & $0,0000 \mathrm{E}+00$ & $1,0000 \mathrm{E}+00$ & $5,8474 \mathrm{E}-01$ \\
2 & $3,8960 \mathrm{E}-01$ & $6,3265 \mathrm{E}-01$ & $2,4012 \mathrm{E}-01$ & $2,2283 \mathrm{E}-01$ & $3,6324 \mathrm{E}-01$ \\
3 & $1,7873 \mathrm{E}-01$ & $1,4459 \mathrm{E}-01$ & $2,7071 \mathrm{E}-01$ & $2,1844 \mathrm{E}-01$ & $1,9673 \mathrm{E}-01$ \\
4 & $8,3655 \mathrm{E}-02$ & $1,3269 \mathrm{E}-01$ & $7,9852 \mathrm{E}-02$ & $7,8817 \mathrm{E}-02$ & $9,3314 \mathrm{E}-02$ \\
5 & $4,5815 \mathrm{E}-02$ & $4,8946 \mathrm{E}-02$ & $5,8270 \mathrm{E}-02$ & $5,1608 \mathrm{E}-02$ & $4,9822 \mathrm{E}-02$ \\
6 & $2,3005 \mathrm{E}-02$ & $3,1656 \mathrm{E}-02$ & $2,4810 \mathrm{E}-02$ & $2,3021 \mathrm{E}-02$ & $2,5426 \mathrm{E}-02$ \\
7 & $1,2044 \mathrm{E}-02$ & $1,4229 \mathrm{E}-02$ & $1,4524 \mathrm{E}-02$ & $1,3039 \mathrm{E}-02$ & $1,3168 \mathrm{E}-02$ \\
8 & $6,1445 \mathrm{E}-03$ & $8,0146 \mathrm{E}-03$ & $6,9113 \mathrm{E}-03$ & $6,3406 \mathrm{E}-03$ & $6,7672 \mathrm{E}-03$ \\
9 & $3,1896 \mathrm{E}-03$ & $3,9110 \mathrm{E}-03$ & $3,7514 \mathrm{E}-03$ & $3,3929 \mathrm{E}-03$ & $3,4961 \mathrm{E}-03$ \\
10 & $1,6372 \mathrm{E}-03$ & $2,0881 \mathrm{E}-03$ & $1,8728 \mathrm{E}-03$ & $1,7088 \mathrm{E}-03$ & $1,8000 \mathrm{E}-03$ \\
11 & $8,4636 \mathrm{E}-04$ & $1,0531 \mathrm{E}-03$ & $9,8539 \mathrm{E}-04$ & $8,9408 \mathrm{E}-04$ & $9,2872 \mathrm{E}-04$ \\
12 & $4,3558 \mathrm{E}-04$ & $5,5054 \mathrm{E}-04$ & $5,0153 \mathrm{E}-04$ & $4,5666 \mathrm{E}-04$ & $4,7854 \mathrm{E}-04$ \\
\hline
\end{tabular}

Fonte: resultados da pesquisa.

Tabela A.1.6 - Resposta-impulso quando há inovação na variável boi magro no modelo VEC para o período de junho de 1970 a junho de 1982

\begin{tabular}{rrrrrr}
\hline & boi gordo & bezerro & vaca gorda & garrote & boi magro \\
\hline 1 & $0,0000 \mathrm{E}+00$ & $0,0000 \mathrm{E}+00$ & $0,0000 \mathrm{E}+00$ & $0,0000 \mathrm{E}+00$ & $1,0000 \mathrm{E}+00$ \\
2 & $-5,9345 \mathrm{E}-03$ & $4,4267 \mathrm{E}-02$ & $4,4871 \mathrm{E}-02$ & $-3,1189 \mathrm{E}-02$ & $-1,3406 \mathrm{E}-01$ \\
3 & $-1,2730 \mathrm{E}-02$ & $-2,9039 \mathrm{E}-02$ & $-1,4261 \mathrm{E}-02$ & $6,5508 \mathrm{E}-03$ & $4,9110 \mathrm{E}-03$ \\
4 & $-6,9305 \mathrm{E}-04$ & $5,0102 \mathrm{E}-03$ & $-5,6324 \mathrm{E}-03$ & $-6,3332 \mathrm{E}-03$ & $-3,1661 \mathrm{E}-03$ \\
5 & $-1,0217 \mathrm{E}-03$ & $-3,8307 \mathrm{E}-03$ & $7,5326 \mathrm{E}-04$ & $2,2338 \mathrm{E}-04$ & $-9,6452 \mathrm{E}-04$ \\
6 & $-6,5431 \mathrm{E}-04$ & $8,7621 \mathrm{E}-05$ & $-1,3598 \mathrm{E}-03$ & $-1,0502 \mathrm{E}-03$ & $-6,9136 \mathrm{E}-04$ \\
7 & $-2,6554 \mathrm{E}-04$ & $-6,3143 \mathrm{E}-04$ & $-1,1656 \mathrm{E}-04$ & $-1,5999 \mathrm{E}-04$ & $-3,0747 \mathrm{E}-04$ \\
8 & $-1,5907 \mathrm{E}-04$ & $-1,0352 \mathrm{E}-04$ & $-2,4646 \mathrm{E}-04$ & $-2,0698 \mathrm{E}-04$ & $-1,6886 \mathrm{E}-04$ \\
9 & $-7,5160 \mathrm{E}-05$ & $-1,2579 \mathrm{E}-04$ & $-6,6338 \mathrm{E}-05$ & $-6,6099 \mathrm{E}-05$ & $-8,4552 \mathrm{E}-05$ \\
10 & $-4,1010 \mathrm{E}-05$ & $-4,1287 \mathrm{E}-05$ & $-5,4143 \mathrm{E}-05$ & $-4,7305 \mathrm{E}-05$ & $-4,4353 \mathrm{E}-05$ \\
11 & $-2,0389 \mathrm{E}-05$ & $-2,8950 \mathrm{E}-05$ & $-2,1393 \mathrm{E}-05$ & $-2,0081 \mathrm{E}-05$ & $-2,2615 \mathrm{E}-05$ \\
12 & $-1,0758 \mathrm{E}-05$ & $-1,2430 \mathrm{E}-05$ & $-1,3151 \mathrm{E}-05$ & $-1,1754 \mathrm{E}-05$ & $-1,1740 \mathrm{E}-05$ \\
\hline
\end{tabular}

Fonte: resultados da pesquisa. 
Tabela A.1.7 - Resposta-impulso quando há inovação na variável boi gordo no modelo VEC para o período de junho de 1982 a maio de 1994

\begin{tabular}{crrrrr}
\hline passos & boi gordo & bezerro & vaca gorda & garrote & boi magro \\
\hline 1 & $1,0000 \mathrm{E}+00$ & $8,9100 \mathrm{E}-01$ & $1,0065 \mathrm{E}+00$ & $8,4828 \mathrm{E}-01$ & $8,1445 \mathrm{E}-01$ \\
2 & $1,5325 \mathrm{E}-01$ & $2,8064 \mathrm{E}-01$ & $1,2920 \mathrm{E}-01$ & $3,0774 \mathrm{E}-01$ & $3,0954 \mathrm{E}-01$ \\
3 & $-2,3464 \mathrm{E}-02$ & $5,1640 \mathrm{E}-03$ & $-2,9209 \mathrm{E}-02$ & $1,0703 \mathrm{E}-02$ & $4,3564 \mathrm{E}-03$ \\
4 & $-7,4081 \mathrm{E}-03$ & $-1,0855 \mathrm{E}-02$ & $-7,7476 \mathrm{E}-03$ & $-1,0852 \mathrm{E}-02$ & $-9,9999 \mathrm{E}-03$ \\
5 & $-4,1911 \mathrm{E}-04$ & $-1,5819 \mathrm{E}-03$ & $-3,9301 \mathrm{E}-04$ & $-1,7514 \mathrm{E}-03$ & $-1,7288 \mathrm{E}-03$ \\
6 & $2,5875 \mathrm{E}-04$ & $1,1907 \mathrm{E}-04$ & $2,4581 \mathrm{E}-04$ & $1,1232 \mathrm{E}-04$ & $1,5759 \mathrm{E}-04$ \\
7 & $3,4847 \mathrm{E}-05$ & $7,0047 \mathrm{E}-05$ & $2,4303 \mathrm{E}-05$ & $7,7267 \mathrm{E}-05$ & $6,9581 \mathrm{E}-05$ \\
8 & $-3,1412 \mathrm{E}-06$ & $1,2242 \mathrm{E}-06$ & $-5,7618 \mathrm{E}-06$ & $3,2493 \mathrm{E}-06$ & $3,7249 \mathrm{E}-06$ \\
9 & $-2,2723 \mathrm{E}-06$ & $-2,6304 \mathrm{E}-06$ & $-2,6903 \mathrm{E}-06$ & $-2,5017 \mathrm{E}-06$ & $-2,6658 \mathrm{E}-06$ \\
10 & $-1,1935 \mathrm{E}-07$ & $-5,6745 \mathrm{E}-07$ & $-1,8237 \mathrm{E}-07$ & $-5,7637 \mathrm{E}-07$ & $-4,8185 \mathrm{E}-07$ \\
11 & $3,8973 \mathrm{E}-08$ & $1,6923 \mathrm{E}-09$ & $1,9043 \mathrm{E}-08$ & $4,0512 \mathrm{E}-09$ & $2,6848 \mathrm{E}-09$ \\
12 & $1,1211 \mathrm{E}-08$ & $1,0818 \mathrm{E}-08$ & $4,7184 \mathrm{E}-09$ & $1,4133 \mathrm{E}-08$ & $1,6316 \mathrm{E}-08$ \\
\hline
\end{tabular}

Fonte: resultados da pesquisa.

Tabela A.1.8 - Resposta-impulso quando há inovação na variável bezerro no modelo VEC para o período de junho de 1982 a maio de 1994

\begin{tabular}{crrrrr}
\hline passos & \multicolumn{1}{c}{ boi gordo } & \multicolumn{1}{l}{ bezerro } & \multicolumn{1}{c}{ vaca gorda } & \multicolumn{1}{c}{ garrote } & \multicolumn{1}{c}{ boi magro } \\
\hline 1 & $0,0000 \mathrm{E}+00$ & $1,0000 \mathrm{E}+00$ & $5,5315 \mathrm{E}-02$ & $6,7763 \mathrm{E}-01$ & $6,0428 \mathrm{E}-01$ \\
2 & $7,7761 \mathrm{E}-03$ & $-4,5150 \mathrm{E}-04$ & $2,1934 \mathrm{E}-02$ & $5,5426 \mathrm{E}-02$ & $4,4098 \mathrm{E}-02$ \\
3 & $-2,2369 \mathrm{E}-02$ & $-1,0882 \mathrm{E}-02$ & $-1,6516 \mathrm{E}-02$ & $-2,1834 \mathrm{E}-02$ & $-2,1439 \mathrm{E}-02$ \\
4 & $9,1529 \mathrm{E}-04$ & $-2,3414 \mathrm{E}-03$ & $2,5501 \mathrm{E}-03$ & $-1,9883 \mathrm{E}-03$ & $-2,2006 \mathrm{E}-03$ \\
5 & $5,3920 \mathrm{E}-04$ & $8,8480 \mathrm{E}-04$ & $8,9463 \mathrm{E}-04$ & $5,2363 \mathrm{E}-04$ & $5,8581 \mathrm{E}-04$ \\
6 & $1,2751 \mathrm{E}-04$ & $2,4884 \mathrm{E}-04$ & $1,9679 \mathrm{E}-04$ & $2,6274 \mathrm{E}-04$ & $2,2270 \mathrm{E}-04$ \\
7 & $-3,5244 \mathrm{E}-06$ & $3,1039 \mathrm{E}-05$ & $1,3519 \mathrm{E}-05$ & $2,2019 \mathrm{E}-05$ & $2,1697 \mathrm{E}-05$ \\
8 & $-2,9367 \mathrm{E}-06$ & $3,5160 \mathrm{E}-07$ & $1,6582 \mathrm{E}-06$ & $-6,7031 \mathrm{E}-07$ & $-2,3916 \mathrm{E}-06$ \\
9 & $1,7842 \mathrm{E}-07$ & $4,0812 \mathrm{E}-07$ & $1,3872 \mathrm{E}-06$ & $-2,3236 \mathrm{E}-07$ & $-1,1471 \mathrm{E}-07$ \\
10 & $1,9292 \mathrm{E}-07$ & $4,0274 \mathrm{E}-07$ & $4,7375 \mathrm{E}-07$ & $3,0542 \mathrm{E}-07$ & $2,2541 \mathrm{E}-07$ \\
11 & $5,1355 \mathrm{E}-08$ & $1,1867 \mathrm{E}-07$ & $1,1641 \mathrm{E}-07$ & $9,3849 \mathrm{E}-08$ & $9,1708 \mathrm{E}-08$ \\
12 & $2,6920 \mathrm{E}-09$ & $2,2923 \mathrm{E}-08$ & $1,8194 \mathrm{E}-08$ & $1,8035 \mathrm{E}-08$ & $1,2983 \mathrm{E}-08$ \\
\hline
\end{tabular}

Fonte: resultados da pesquisa.

Tabela A.1.9 - Resposta-impulso quando há inovação na variável vaca gorda no modelo VEC para o período de junho de 1982 a maio de 1994

\begin{tabular}{rrrrrr}
\hline & boi gordo & bezerro & vaca gorda & garrote & boi magro \\
\hline 1 & $0,0000 \mathrm{E}+00$ & $0,0000 \mathrm{E}+00$ & $1,0000 \mathrm{E}+00$ & $-1,0330 \mathrm{E}-01$ & $-6,7211 \mathrm{E}-02$ \\
2 & $-1,2638 \mathrm{E}-02$ & $1,9340 \mathrm{E}-01$ & $2,3931 \mathrm{E}-01$ & $4,0718 \mathrm{E}-02$ & $-1,5982 \mathrm{E}-02$ \\
3 & $5,2225 \mathrm{E}-02$ & $7,7843 \mathrm{E}-02$ & $1,1186 \mathrm{E}-01$ & $6,1587 \mathrm{E}-02$ & $5,9595 \mathrm{E}-02$ \\
4 & $6,4720 \mathrm{E}-03$ & $2,5083 \mathrm{E}-02$ & $2,0263 \mathrm{E}-02$ & $1,9148 \mathrm{E}-02$ & $1,5561 \mathrm{E}-02$ \\
5 & $1,0980 \mathrm{E}-03$ & $4,2485 \mathrm{E}-03$ & $4,4517 \mathrm{E}-03$ & $3,2704 \mathrm{E}-03$ & $2,8549 \mathrm{E}-03$ \\
6 & $3,4039 \mathrm{E}-05$ & $8,3047 \mathrm{E}-04$ & $8,6839 \mathrm{E}-04$ & $4,8965 \mathrm{E}-04$ & $3,2065 \mathrm{E}-04$ \\
7 & $6,3963 \mathrm{E}-05$ & $1,9826 \mathrm{E}-04$ & $2,7049 \mathrm{E}-04$ & $1,2279 \mathrm{E}-04$ & $1,0158 \mathrm{E}-04$ \\
8 & $1,9096 \mathrm{E}-05$ & $6,2736 \mathrm{E}-05$ & $6,8840 \mathrm{E}-05$ & $4,3062 \mathrm{E}-05$ & $3,4295 \mathrm{E}-05$ \\
9 & $5,2390 \mathrm{E}-06$ & $1,5897 \mathrm{E}-05$ & $1,7188 \mathrm{E}-05$ & $1,1643 \mathrm{E}-05$ & $9,9961 \mathrm{E}-06$ \\
10 & $8,3240 \mathrm{E}-07$ & $3,6669 \mathrm{E}-06$ & $3,7254 \mathrm{E}-06$ & $2,5923 \mathrm{E}-06$ & $2,0596 \mathrm{E}-06$ \\
11 & $1,9577 \mathrm{E}-07$ & $7,9807 \mathrm{E}-07$ & $9,0469 \mathrm{E}-07$ & $5,3808 \mathrm{E}-07$ & $4,3794 \mathrm{E}-07$ \\
12 & $4,9234 \mathrm{E}-08$ & $1,9735 \mathrm{E}-07$ & $2,2233 \mathrm{E}-07$ & $1,3156 \mathrm{E}-07$ & $1,0314 \mathrm{E}-07$ \\
\hline
\end{tabular}

Fonte: resultados da pesquisa. 
Tabela A.1.10 - Resposta-impulso quando há inovação na variável garrote no modelo VEC para o período de junho de 1982 a maio de 1994

\begin{tabular}{rrrrrr}
\hline & boi gordo & bezerro & vaca gorda & garrote & boi magro \\
\hline 1 & $0,0000 \mathrm{E}+00$ & $0,0000 \mathrm{E}+00$ & $0,0000 \mathrm{E}+00$ & $1,0000 \mathrm{E}+00$ & $4,0450 \mathrm{E}-01$ \\
2 & $-2,5036 \mathrm{E}-01$ & $-1,8752 \mathrm{E}-01$ & $-2,1359 \mathrm{E}-01$ & $-3,4304 \mathrm{E}-01$ & $-2,3374 \mathrm{E}-01$ \\
3 & $-6,3010 \mathrm{E}-03$ & $-3,8141 \mathrm{E}-02$ & $4,1167 \mathrm{E}-03$ & $-2,4979 \mathrm{E}-02$ & $-4,7290 \mathrm{E}-02$ \\
4 & $\mathbf{8 , 2 4 0 3 \mathrm { E } - 0 3}$ & $6,0469 \mathrm{E}-03$ & $1,0651 \mathrm{E}-02$ & $1,5368 \mathrm{E}-03$ & $7,0828 \mathrm{E}-03$ \\
5 & $9,1032 \mathrm{E}-04$ & $2,7838 \mathrm{E}-03$ & $1,2134 \mathrm{E}-03$ & $3,2469 \mathrm{E}-03$ & $1,9402 \mathrm{E}-03$ \\
6 & $6,6780 \mathrm{E}-05$ & $1,9245 \mathrm{E}-04$ & $1,5298 \mathrm{E}-04$ & $1,1712 \mathrm{E}-04$ & $3,1846 \mathrm{E}-04$ \\
7 & $-7,4240 \mathrm{E}-05$ & $-1,4341 \mathrm{E}-05$ & $-5,0701 \mathrm{E}-05$ & $-1,3056 \mathrm{E}-05$ & $-6,8033 \mathrm{E}-05$ \\
8 & $4,6586 \mathrm{E}-06$ & $-8,2456 \mathrm{E}-06$ & $1,2169 \mathrm{E}-05$ & $-1,3388 \mathrm{E}-05$ & $-2,9586 \mathrm{E}-06$ \\
9 & $4,6694 \mathrm{E}-07$ & $3,2056 \mathrm{E}-06$ & $2,0383 \mathrm{E}-06$ & $2,6670 \mathrm{E}-06$ & $3,8819 \mathrm{E}-07$ \\
10 & $7,6012 \mathrm{E}-07$ & $7,7883 \mathrm{E}-07$ & $1,1250 \mathrm{E}-06$ & $6,4344 \mathrm{E}-07$ & $1,0151 \mathrm{E}-06$ \\
11 & $-4,7959 \mathrm{E}-08$ & $1,8982 \mathrm{E}-07$ & $3,1309 \mathrm{E}-08$ & $1,6849 \mathrm{E}-07$ & $5,6905 \mathrm{E}-08$ \\
12 & $7,9549 \mathrm{E}-09$ & $5,2067 \mathrm{E}-09$ & $2,9974 \mathrm{E}-08$ & $-2,5977 \mathrm{E}-09$ & $1,2376 \mathrm{E}-08$ \\
\hline
\end{tabular}

Fonte: resultados da pesquisa.

Tabela A.1.11 - Resposta-impulso quando há inovação na variável boi magro no modelo VEC para o período de junho de 1982 a maio de 1994

\begin{tabular}{rrrrrr}
\hline & boi gordo & bezerro & vaca gorda & garrote & boi magro \\
\hline 1 & $0,0000 \mathrm{E}+00$ & $0,0000 \mathrm{E}+00$ & $0,0000 \mathrm{E}+00$ & $0,0000 \mathrm{E}+00$ & $1,0000 \mathrm{E}+00$ \\
2 & $-4,5473 \mathrm{E}-01$ & $-2,6414 \mathrm{E}-01$ & $-4,3298 \mathrm{E}-01$ & $-2,6073 \mathrm{E}-01$ & $-4,9741 \mathrm{E}-01$ \\
3 & $2,5131 \mathrm{E}-02$ & $-7,1157 \mathrm{E}-02$ & $3,8605 \mathrm{E}-02$ & $-8,3794 \mathrm{E}-02$ & $-3,0802 \mathrm{E}-02$ \\
4 & $2,5785 \mathrm{E}-03$ & $1,2165 \mathrm{E}-02$ & $4,3342 \mathrm{E}-03$ & $1,1064 \mathrm{E}-02$ & $1,4200 \mathrm{E}-03$ \\
5 & $3,2872 \mathrm{E}-03$ & $2,4966 \mathrm{E}-03$ & $3,5875 \mathrm{E}-03$ & $2,5502 \mathrm{E}-03$ & $4,4031 \mathrm{E}-03$ \\
6 & $-4,2193 \mathrm{E}-04$ & $4,4413 \mathrm{E}-04$ & $-3,8476 \mathrm{E}-04$ & $4,5616 \mathrm{E}-04$ & $-7,6705 \mathrm{E}-06$ \\
7 & $-2,6133 \mathrm{E}-06$ & $-9,8387 \mathrm{E}-05$ & $2,1511 \mathrm{E}-05$ & $-1,0416 \mathrm{E}-04$ & $-2,3188 \mathrm{E}-05$ \\
8 & $-1,6993 \mathrm{E}-05$ & $-2,5579 \mathrm{E}-06$ & $-1,0967 \mathrm{E}-05$ & $-7,0557 \mathrm{E}-06$ & $-2,3797 \mathrm{E}-05$ \\
9 & $5,2843 \mathrm{E}-06$ & $8,6835 \mathrm{E}-07$ & $6,8508 \mathrm{E}-06$ & $3,1681 \mathrm{E}-07$ & $3,7808 \mathrm{E}-06$ \\
10 & $-2,0820 \mathrm{E}-08$ & $1,4280 \mathrm{E}-06$ & $2,4016 \mathrm{E}-07$ & $1,3139 \mathrm{E}-06$ & $5,3113 \mathrm{E}-07$ \\
11 & $1,2391 \mathrm{E}-07$ & $8,1579 \mathrm{E}-08$ & $1,9404 \mathrm{E}-07$ & $7,5068 \mathrm{E}-08$ & $1,9852 \mathrm{E}-07$ \\
12 & $-3,6391 \mathrm{E}-08$ & $1,7119 \mathrm{E}-08$ & $-1,9395 \mathrm{E}-08$ & $8,9448 \mathrm{E}-09$ & $-2,3531 \mathrm{E}-08$ \\
\hline
\end{tabular}

Fonte: resultados da pesquisa. 
Tabela A.2.1 - Resposta-impulso quando há inovação na variável bezerro no modelo VEC para o período de junho de 1970 a junho de 1982

\begin{tabular}{rrrrrr}
\hline & bezerro & boi gordo & garrote & vaca gorda & boi magro \\
\hline 1 & $1,0000 \mathrm{E}+0$ & $4,1476 \mathrm{E}-01$ & $7,0148 \mathrm{E}-01$ & $4,0462 \mathrm{E}-01$ & $4,5294 \mathrm{E}-01$ \\
2 & $4,2110 \mathrm{E}-01$ & $3,9488 \mathrm{E}-01$ & $4,2575 \mathrm{E}-01$ & $4,3294 \mathrm{E}-01$ & $4,4147 \mathrm{E}-01$ \\
3 & $2,6589 \mathrm{E}-01$ & $2,0093 \mathrm{E}-01$ & $1,9668 \mathrm{E}-01$ & $2,2587 \mathrm{E}-01$ & $2,1760 \mathrm{E}-01$ \\
4 & $1,2117 \mathrm{E}-01$ & $1,0068 \mathrm{E}-01$ & $1,0956 \mathrm{E}-01$ & $1,2115 \mathrm{E}-01$ & $1,1076 \mathrm{E}-01$ \\
5 & $6,7327 \mathrm{E}-02$ & $5,1925 \mathrm{E}-02$ & $5,3748 \mathrm{E}-02$ & $5,8504 \mathrm{E}-02$ & $5,7129 \mathrm{E}-02$ \\
6 & $3,3154 \mathrm{E}-02$ & $2,6950 \mathrm{E}-02$ & $2,8598 \mathrm{E}-02$ & $3,1619 \mathrm{E}-02$ & $2,9546 \mathrm{E}-02$ \\
7 & $1,7603 \mathrm{E}-02$ & $1,3832 \mathrm{E}-02$ & $1,4455 \mathrm{E}-02$ & $1,5853 \mathrm{E}-02$ & $1,5205 \mathrm{E}-02$ \\
8 & $8,9076 \mathrm{E}-03$ & $7,1479 \mathrm{E}-03$ & $7,5458 \mathrm{E}-03$ & $\mathbf{8 , 3 1 3 0 \mathrm { E } - 0 3}$ & $7,8445 \mathrm{E}-03$ \\
9 & $4,6467 \mathrm{E}-03$ & $3,6798 \mathrm{E}-03$ & $3,8596 \mathrm{E}-03$ & $4,2399 \mathrm{E}-03$ & $4,0425 \mathrm{E}-03$ \\
10 & $2,3778 \mathrm{E}-03$ & $1,8988 \mathrm{E}-03$ & $1,9997 \mathrm{E}-03$ & $2,2008 \mathrm{E}-03$ & $2,0846 \mathrm{E}-03$ \\
11 & $1,2316 \mathrm{E}-03$ & $9,7834 \mathrm{E}-04$ & $1,0277 \mathrm{E}-03$ & $1,1297 \mathrm{E}-03$ & $1,0745 \mathrm{E}-03$ \\
12 & $6,3306 \mathrm{E}-04$ & $5,0455 \mathrm{E}-04$ & $5,3086 \mathrm{E}-04$ & $5,8400 \mathrm{E}-04$ & $5,5401 \mathrm{E}-04$ \\
\hline
\end{tabular}

Fonte: resultados da pesquisa.

Tabela A.2.2 - Resposta-impulso quando há inovação na variável boi gordo no modelo VEC para o período de junho de 1970 a junho de 1982

\begin{tabular}{rrrrrr}
\hline & bezerro & boi gordo & garrote & vaca gorda & boi magro \\
\hline 1 & $0,0000 \mathrm{E}+0$ & $1,0000 \mathrm{E}+0$ & $2,2897 \mathrm{E}-01$ & $8,0936 \mathrm{E}-01$ & $3,1012 \mathrm{E}-01$ \\
2 & $1,6764 \mathrm{E}-01$ & $7,6576 \mathrm{E}-02$ & $3,6403 \mathrm{E}-02$ & $1,7000 \mathrm{E}-01$ & $1,4226 \mathrm{E}-01$ \\
3 & $1,8727 \mathrm{E}-02$ & $1,9446 \mathrm{E}-02$ & $4,4866 \mathrm{E}-02$ & $3,7018 \mathrm{E}-02$ & $1,7853 \mathrm{E}-02$ \\
4 & $2,6559 \mathrm{E}-02$ & $1,6700 \mathrm{E}-02$ & $1,4229 \mathrm{E}-02$ & $1,2023 \mathrm{E}-02$ & $1,9506 \mathrm{E}-02$ \\
5 & $9,1239 \mathrm{E}-03$ & $9,1421 \mathrm{E}-03$ & $1,0127 \mathrm{E}-02$ & $1,2257 \mathrm{E}-02$ & $9,6623 \mathrm{E}-03$ \\
6 & $6,1809 \mathrm{E}-03$ & $4,3432 \mathrm{E}-03$ & $4,3511 \mathrm{E}-03$ & $4,6081 \mathrm{E}-03$ & $4,8500 \mathrm{E}-03$ \\
7 & $2,6905 \mathrm{E}-03$ & $2,3147 \mathrm{E}-03$ & $2,5218 \mathrm{E}-03$ & $2,8103 \mathrm{E}-03$ & $2,5249 \mathrm{E}-03$ \\
8 & $1,5498 \mathrm{E}-03$ & $1,1783 \mathrm{E}-03$ & $1,2094 \mathrm{E}-03$ & $1,3168 \mathrm{E}-03$ & $1,2987 \mathrm{E}-03$ \\
9 & $7,4624 \mathrm{E}-04$ & $6,1214 \mathrm{E}-04$ & $6,5305 \mathrm{E}-04$ & $7,2301 \mathrm{E}-04$ & $6,7064 \mathrm{E}-04$ \\
10 & $4,0182 \mathrm{E}-04$ & $3,1391 \mathrm{E}-04$ & $3,2705 \mathrm{E}-04$ & $3,5810 \mathrm{E}-04$ & $3,4522 \mathrm{E}-04$ \\
11 & $2,0159 \mathrm{E}-04$ & $1,6239 \mathrm{E}-04$ & $1,7174 \mathrm{E}-04$ & $1,8937 \mathrm{E}-04$ & $1,7816 \mathrm{E}-04$ \\
12 & $1,0574 \mathrm{E}-04$ & $8,3538 \mathrm{E}-05$ & $8,7518 \mathrm{E}-05$ & $9,6087 \mathrm{E}-05$ & $9,1788 \mathrm{E}-05$ \\
\hline
\end{tabular}

Fonte: resultados da pesquisa.

Tabela A.2.3- Resposta-impulso quando há inovação na variável garrote no modelo VEC para o período de junho de 1982 a maio de 1994

\begin{tabular}{rrrrrr}
\hline & bezerro & boi gordo & garrote & vaca gorda & boi magro \\
\hline 1 & $0,0000 \mathrm{E}+0$ & $0,0000 \mathrm{E}+0$ & $1,0000 \mathrm{E}+0$ & $1,3357 \mathrm{E}-01$ & $6,1650 \mathrm{E}-01$ \\
2 & $6,2625 \mathrm{E}-01$ & $3,6953 \mathrm{E}-01$ & $2,1520 \mathrm{E}-01$ & $2,1119 \mathrm{E}-01$ & $3,4238 \mathrm{E}-01$ \\
3 & $1,3965 \mathrm{E}-01$ & $1,7709 \mathrm{E}-01$ & $2,1629 \mathrm{E}-01$ & $2,6738 \mathrm{E}-01$ & $1,9500 \mathrm{E}-01$ \\
4 & $1,3153 \mathrm{E}-01$ & $8,2459 \mathrm{E}-02$ & $7,7092 \mathrm{E}-02$ & $7,8440 \mathrm{E}-02$ & $9,1884 \mathrm{E}-02$ \\
5 & $4,7875 \mathrm{E}-02$ & $4,5066 \mathrm{E}-02$ & $5,0947 \mathrm{E}-02$ & $5,7539 \mathrm{E}-02$ & $4,9015 \mathrm{E}-02$ \\
6 & $3,1244 \mathrm{E}-02$ & $2,2631 \mathrm{E}-02$ & $2,2602 \mathrm{E}-02$ & $2,4330 \mathrm{E}-02$ & $2,5018 \mathrm{E}-02$ \\
7 & $1,3973 \mathrm{E}-02$ & $1,1856 \mathrm{E}-02$ & $1,2848 \mathrm{E}-02$ & $1,4320 \mathrm{E}-02$ & $1,2960 \mathrm{E}-02$ \\
8 & $7,8969 \mathrm{E}-03$ & $6,0457 \mathrm{E}-03$ & $6,2342 \mathrm{E}-03$ & $6,7930 \mathrm{E}-03$ & $6,6591 \mathrm{E}-03$ \\
9 & $3,8456 \mathrm{E}-03$ & $3,1392 \mathrm{E}-03$ & $3,3407 \mathrm{E}-03$ & $3,6944 \mathrm{E}-03$ & $3,4406 \mathrm{E}-03$ \\
10 & $2,0560 \mathrm{E}-03$ & $1,6111 \mathrm{E}-03$ & $1,6810 \mathrm{E}-03$ & $1,8421 \mathrm{E}-03$ & $1,7713 \mathrm{E}-03$ \\
11 & $1,0360 \mathrm{E}-03$ & $8,3292 \mathrm{E}-04$ & $8,8005 \mathrm{E}-04$ & $9,7000 \mathrm{E}-04$ & $9,1395 \mathrm{E}-04$ \\
12 & $5,4189 \mathrm{E}-04$ & $4,2864 \mathrm{E}-04$ & $4,4933 \mathrm{E}-04$ & $4,9346 \mathrm{E}-04$ & $4,7092 \mathrm{E}-04$ \\
\hline
\end{tabular}

Fonte: resultados da pesquisa. 
Tabela A.2.4 - Resposta-impulso quando há inovação na variável vaca gorda no modelo VEC para o período de junho de 1970 a junho de 1982

\begin{tabular}{rrrrrr}
\hline & bezerro & boi gordo & garrote & vaca gorda & boi magro \\
\hline 1 & $0,0000 \mathrm{E}+00$ & $0,0000 \mathrm{E}+00$ & $0,0000 \mathrm{E}+00$ & $1,0000 \mathrm{E}+00$ & $2,3781 \mathrm{E}-01$ \\
2 & $-4,7972 \mathrm{E}-02$ & $-1,5028 \mathrm{E}-01$ & $-5,7165 \mathrm{E}-02$ & $-2,1661 \mathrm{E}-01$ & $-1,5615 \mathrm{E}-01$ \\
3 & $-3,7009 \mathrm{E}-02$ & $-1,2231 \mathrm{E}-02$ & $-1,6150 \mathrm{E}-02$ & $-2,4961 \mathrm{E}-02$ & $-1,2934 \mathrm{E}-02$ \\
4 & $-8,6835 \mathrm{E}-03$ & $-8,9541 \mathrm{E}-03$ & $-1,2917 \mathrm{E}-02$ & $-1,0575 \mathrm{E}-02$ & $-1,0706 \mathrm{E}-02$ \\
5 & $-8,0186 \mathrm{E}-03$ & $-5,6034 \mathrm{E}-03$ & $-4,9466 \mathrm{E}-03$ & $-5,4763 \mathrm{E}-03$ & $-6,0435 \mathrm{E}-03$ \\
6 & $-3,0832 \mathrm{E}-03$ & $-2,8012 \mathrm{E}-03$ & $-3,1351 \mathrm{E}-03$ & $-3,5904 \mathrm{E}-03$ & $-3,0573 \mathrm{E}-03$ \\
7 & $-1,9196 \mathrm{E}-03$ & $-1,4068 \mathrm{E}-03$ & $-1,4261 \mathrm{E}-03$ & $-1,5280 \mathrm{E}-03$ & $-1,5558 \mathrm{E}-03$ \\
8 & $-8,8112 \mathrm{E}-04$ & $-7,3988 \mathrm{E}-04$ & $-7,9670 \mathrm{E}-04$ & $-8,8590 \mathrm{E}-04$ & $-8,0916 \mathrm{E}-04$ \\
9 & $-4,8994 \mathrm{E}-04$ & $-3,7768 \mathrm{E}-04$ & $-3,9073 \mathrm{E}-04$ & $-4,2674 \mathrm{E}-04$ & $-4,1574 \mathrm{E}-04$ \\
10 & $-2,4095 \mathrm{E}-04$ & $-1,9579 \mathrm{E}-04$ & $-2,0795 \mathrm{E}-04$ & $-2,2972 \mathrm{E}-04$ & $-2,1467 \mathrm{E}-04$ \\
11 & $-1,2800 \mathrm{E}-04$ & $-1,0058 \mathrm{E}-04$ & $-1,0508 \mathrm{E}-04$ & $-1,1523 \mathrm{E}-04$ & $-1,1056 \mathrm{E}-04$ \\
12 & $-6,4759 \mathrm{E}-05$ & $-5,1973 \mathrm{E}-05$ & $-5,4866 \mathrm{E}-05$ & $-6,0452 \mathrm{E}-05$ & $-5,7036 \mathrm{E}-05$ \\
\hline
\end{tabular}

Fonte: resultados da pesquisa.

Tabela A.2.5. - Resposta-impulso quando há inovação na variável boi magro no modelo VEC para o período de junho de 1970 a junho de 1982

\begin{tabular}{rrrrrr}
\hline & bezerro & boi gordo & garrote & vaca gorda & boi magro \\
\hline 1 & $0,0000 \mathrm{E}+00$ & $0,0000 \mathrm{E}+00$ & $0,0000 \mathrm{E}+00$ & $0,0000 \mathrm{E}+00$ & $1,0000 \mathrm{E}+00$ \\
2 & $4,4267 \mathrm{E}-02$ & $-5,9345 \mathrm{E}-03$ & $-3,1189 \mathrm{E}-02$ & $4,4871 \mathrm{E}-02$ & $-1,3406 \mathrm{E}-01$ \\
3 & $-2,9039 \mathrm{E}-02$ & $-1,2730 \mathrm{E}-02$ & $6,5508 \mathrm{E}-03$ & $-1,4261 \mathrm{E}-02$ & $4,9110 \mathrm{E}-03$ \\
4 & $5,0102 \mathrm{E}-03$ & $-6,9305 \mathrm{E}-04$ & $-6,3332 \mathrm{E}-03$ & $-5,6324 \mathrm{E}-03$ & $-3,1661 \mathrm{E}-03$ \\
5 & $-3,8307 \mathrm{E}-03$ & $-1,0217 \mathrm{E}-03$ & $2,2338 \mathrm{E}-04$ & $7,5326 \mathrm{E}-04$ & $-9,6452 \mathrm{E}-04$ \\
6 & $8,7621 \mathrm{E}-05$ & $-6,5431 \mathrm{E}-04$ & $-1,0502 \mathrm{E}-03$ & $-1,3598 \mathrm{E}-03$ & $-6,9136 \mathrm{E}-04$ \\
7 & $-6,3143 \mathrm{E}-04$ & $-2,6554 \mathrm{E}-04$ & $-1,5999 \mathrm{E}-04$ & $-1,1656 \mathrm{E}-04$ & $-3,0747 \mathrm{E}-04$ \\
8 & $-1,0352 \mathrm{E}-04$ & $-1,5907 \mathrm{E}-04$ & $-2,0698 \mathrm{E}-04$ & $-2,4646 \mathrm{E}-04$ & $-1,6886 \mathrm{E}-04$ \\
9 & $-1,2579 \mathrm{E}-04$ & $-7,5160 \mathrm{E}-05$ & $-6,6099 \mathrm{E}-05$ & $-6,6338 \mathrm{E}-05$ & $-8,4552 \mathrm{E}-05$ \\
10 & $-4,1287 \mathrm{E}-05$ & $-4,1010 \mathrm{E}-05$ & $-4,7305 \mathrm{E}-05$ & $-5,4143 \mathrm{E}-05$ & $-4,4353 \mathrm{E}-05$ \\
11 & $-2,8950 \mathrm{E}-05$ & $-2,0389 \mathrm{E}-05$ & $-2,0081 \mathrm{E}-05$ & $-2,1393 \mathrm{E}-05$ & $-2,2615 \mathrm{E}-05$ \\
12 & $-1,2430 \mathrm{E}-05$ & $-1,0758 \mathrm{E}-05$ & $-1,1754 \mathrm{E}-05$ & $-1,3151 \mathrm{E}-05$ & $-1,1740 \mathrm{E}-05$ \\
\hline
\end{tabular}

Fonte: resultados da pesquisa.

Tabela A.2.6 - Decomposicão da variância para a variável bezerro no modelo VEC para o período de junho de 1970 a junho de 1982

\begin{tabular}{rrrrrr}
\hline & bezerro & boi gordo & garrote & vaca gorda & boi magro \\
\hline 1 & 100,0000 & 0,0000 & 0,0000 & 0,0000 & 0,0000 \\
2 & 91,1358 & 1,4632 & 7,3055 & 0,0494 & 0,0462 \\
3 & 91,2231 & 1,3988 & 7,2413 & 0,0743 & 0,0624 \\
4 & 91,0092 & 1,4135 & 7,4403 & 0,0748 & 0,0621 \\
5 & 90,9973 & 1,4123 & 7,4524 & 0,0758 & 0,0622 \\
6 & 90,9872 & 1,4128 & 7,4619 & 0,0759 & 0,0621 \\
7 & 90,9858 & 1,4127 & 7,4634 & 0,0760 & 0,0621 \\
8 & 90,9852 & 1,4128 & 7,4639 & 0,0760 & 0,0621 \\
9 & 90,9851 & 1,4128 & 7,4640 & 0,0760 & 0,0621 \\
10 & 90,9850 & 1,4128 & 7,4641 & 0,0760 & 0,0621 \\
11 & 90,9850 & 1,4128 & 7,4641 & 0,0760 & 0,0621 \\
12 & 90,9850 & 1,4128 & 7,4641 & 0,0760 & 0,0621 \\
\hline
\end{tabular}

Fonte: resultados da pesquisa. 
Tabela A.2.7 - Decomposição da variância para a variável boi gordo no modelo VEC para o período de junho de 1970 a junho de 1982

\begin{tabular}{rrrrrr}
\hline & bezerro & boi gordo & garrote & vaca gorda & boi magro \\
\hline 1 & 20,3671 & 79,6329 & 0,0000 & 0,0000 & 0,0000 \\
2 & 31,4244 & 64,8265 & 3,1485 & 0,5995 & 0,0010 \\
3 & 33,7329 & 61,9843 & 3,7005 & 0,5768 & 0,0055 \\
4 & 34,2849 & 61,3285 & 3,8086 & 0,5726 & 0,0055 \\
5 & 34,4278 & 61,1535 & 3,8415 & 0,5717 & 0,0055 \\
6 & 34,4665 & 61,1069 & 3,8497 & 0,5714 & 0,0055 \\
7 & 34,4766 & 61,0946 & 3,8519 & 0,5714 & 0,0055 \\
8 & 34,4793 & 61,0913 & 3,8525 & 0,5713 & 0,0055 \\
9 & 34,4801 & 61,0905 & 3,8527 & 0,5713 & 0,0055 \\
10 & 34,4803 & 61,0902 & 3,8527 & 0,5713 & 0,0055 \\
11 & 34,4803 & 61,0902 & 3,8527 & 0,5713 & 0,0055 \\
12 & 34,4803 & 61,0902 & 3,8527 & 0,5713 & 0,0055 \\
\hline
\end{tabular}

Fonte: resultados da pesquisa.

Tabela A.2.8 - Decomposição da variância para a variável garrote no modelo VEC para o período de junho de 1970 a junho de 1982

\begin{tabular}{rrrrrr}
\hline & bezerro & boi gordo & garrote & vaca gorda & boi magro \\
\hline 1 & 64,0738 & 4,5918 & 31,3344 & 0,0000 & 0,0000 \\
2 & 69,9586 & 3,7565 & 26,1601 & 0,0941 & 0,0308 \\
3 & 70,2288 & 3,6996 & 25,9446 & 0,0964 & 0,0305 \\
4 & 70,4655 & 3,6638 & 25,7397 & 0,0996 & 0,0313 \\
5 & 70,5004 & 3,6578 & 25,7107 & 0,1000 & 0,0312 \\
6 & 70,5143 & 3,6556 & 25,6988 & 0,1001 & 0,0312 \\
7 & 70,5172 & 3,6551 & 25,6963 & 0,1002 & 0,0312 \\
8 & 70,5181 & 3,6550 & 25,6955 & 0,1002 & 0,0312 \\
9 & 70,5184 & 3,6549 & 25,6953 & 0,1002 & 0,0312 \\
10 & 70,5184 & 3,6549 & 25,6953 & 0,1002 & 0,0312 \\
11 & 70,5184 & 3,6549 & 25,6953 & 0,1002 & 0,0312 \\
12 & 70,5184 & 3,6549 & 25,6953 & 0,1002 & 0,0312 \\
\hline
\end{tabular}

Fonte: resultados da pesquisa.

Tabela A.2.9 - Decomposição da variância para a variável vaca gorda no modelo VEC para o período de junho de 1970 a junho de 1982

\begin{tabular}{rrrrrr}
\hline & bezerro & boi gordo & garrote & vaca gorda & boi magro \\
\hline 1 & 18,4853 & 49,7485 & 0,4848 & 31,2815 & 0,0000 \\
2 & 31,4407 & 41,1898 & 1,3454 & 25,9693 & 0,0549 \\
3 & 33,9026 & 38,8586 & 2,7169 & 24,4651 & 0,0569 \\
4 & 34,6637 & 38,3401 & 2,8032 & 24,1361 & 0,0570 \\
5 & 34,8229 & 38,2109 & 2,8592 & 24,0502 & 0,0568 \\
6 & 34,8722 & 38,1754 & 2,8682 & 24,0274 & 0,0568 \\
7 & 34,8842 & 38,1661 & 2,8716 & 24,0214 & 0,0568 \\
8 & 34,8876 & 38,1637 & 2,8723 & 24,0198 & 0,0568 \\
9 & 34,8884 & 38,1630 & 2,8725 & 24,0193 & 0,0568 \\
10 & 34,8886 & 38,1628 & 2,8726 & 24,0192 & 0,0568 \\
11 & 34,8887 & 38,1628 & 2,8726 & 24,0192 & 0,0568 \\
12 & 34,8887 & 38,1628 & 2,8726 & 24,0192 & 0,0568 \\
\hline
\end{tabular}

Fonte: resultados da pesquisa. 
Tabela A.2.10 - Decomposição da variância para a variável boi magro no modelo VEC para o período de junho de 1970 a junho de 1982

\begin{tabular}{rrrrrr}
\hline & bezerro & boi gordo & garrote & vaca gorda & boi magro \\
\hline 1 & 30,0959 & 9,4894 & 13,4171 & 2,2985 & 44,6991 \\
2 & 42,9879 & 8,4136 & 12,8590 & 2,4095 & 33,3299 \\
3 & 45,3118 & 7,9516 & 13,0464 & 2,2757 & 31,4144 \\
4 & 45,8764 & 7,8614 & 13,0592 & 2,2457 & 30,9573 \\
5 & 46,0223 & 7,8370 & 13,0659 & 2,2380 & 30,8368 \\
6 & 46,0614 & 7,8305 & 13,0673 & 2,2359 & 30,8049 \\
7 & 46,0717 & 7,8288 & 13,0677 & 2,2354 & 30,7965 \\
8 & 46,0744 & 7,8283 & 13,0678 & 2,2352 & 30,7942 \\
9 & 46,0752 & 7,8282 & 13,0679 & 2,2352 & 30,7936 \\
10 & 46,0753 & 7,8281 & 13,0679 & 2,2352 & 30,7934 \\
11 & 46,0754 & 7,8281 & 13,0679 & 2,2352 & 30,7934 \\
12 & 46,0754 & 7,8281 & 13,0679 & 2,2352 & 30,7934 \\
\hline
\end{tabular}

Fonte: resultados da pesquisa.

Tabela A.2.11 - Resposta aos impulsos quando há inovação na variável bezerro no modelo VEC para o período de junho de 1982 a maio de 1994

\begin{tabular}{|c|c|c|c|c|c|}
\hline & bezerro & boi gordo & garrote & vaca gorda & boi magro \\
\hline 1 & $1,0000 \mathrm{E}+00$ & $7,1346 \mathrm{E}-01$ & $8,5208 \mathrm{E}-01$ & $7,3825 E-01$ & $8,0122 \mathrm{E}-01$ \\
\hline 2 & $2,0006 \mathrm{E}-01$ & $1,1217 \mathrm{E}-01$ & $2,3975 \mathrm{E}-01$ & $1,0017 \mathrm{E}-01$ & $2,3691 \mathrm{E}-01$ \\
\hline 3 & $-2,7998 \mathrm{E}-04$ & $-2,4890 \mathrm{E}-02$ & $-3,1810 \mathrm{E}-04$ & $-2,6856 \mathrm{E}-02$ & $-4,7025 \mathrm{E}-03$ \\
\hline 4 & $-8,5977 \mathrm{E}-03$ & $-4,9519 \mathrm{E}-03$ & $-8,4668 \mathrm{E}-03$ & $-4,5986 \mathrm{E}-03$ & $-7,9363 \mathrm{E}-03$ \\
\hline 5 & $-8,0630 \mathrm{E}-04$ & $-1,0258 \mathrm{E}-04$ & $-1,0588 \mathrm{E}-03$ & $4,5529 \mathrm{E}-05$ & $-1,0200 \mathrm{E}-03$ \\
\hline 6 & $1,7561 \mathrm{E}-04$ & $2,3106 \mathrm{E}-04$ & $1,7586 \mathrm{E}-04$ & $2,4707 \mathrm{E}-04$ & $1,9357 \mathrm{E}-04$ \\
\hline 7 & $6,1283 \mathrm{E}-05$ & $2,3578 \mathrm{E}-05$ & $6,3149 \mathrm{E}-05$ & $2,2264 \mathrm{E}-05$ & $5,7547 \mathrm{E}-05$ \\
\hline 8 & $1,0015 \mathrm{E}-06$ & $-3,3110 \mathrm{E}-06$ & $2,0741 E-06$ & $-3,5067 \mathrm{E}-06$ & $1,7863 \mathrm{E}-06$ \\
\hline 9 & $-1,7280 \mathrm{E}-06$ & $-1,5562 \mathrm{E}-06$ & $-1,8695 \mathrm{E}-06$ & $-1,4140 \mathrm{E}-06$ & $-1,9437 \mathrm{E}-06$ \\
\hline 10 & $-2,5813 \mathrm{E}-07$ & $-1,4868 \mathrm{E}-08$ & $-2,9995 \mathrm{E}-07$ & $4,2480 \mathrm{E}-08$ & $-2,6166 \mathrm{E}-07$ \\
\hline 11 & $4,4439 \mathrm{E}-08$ & $4,6515 \mathrm{E}-08$ & $3,7081 \mathrm{E}-08$ & $5,5995 \mathrm{E}-08$ & $3,5326 \mathrm{E}-08$ \\
\hline 12 & $1,6070 \mathrm{E}-08$ & $8,9795 \mathrm{E}-09$ & $1,6654 \mathrm{E}-08$ & $9,9946 \mathrm{E}-09$ & $1,6371 \mathrm{E}-08$ \\
\hline
\end{tabular}

Fonte: resultados da pesquisa.

Tabela A.2.12 - Resposta aos impulsos quando há inovação na variável boi gordo no modelo VEC para o período de junho de 1982 a maio de 1994

\begin{tabular}{rrrrrr}
\hline & bezerro & boi gordo & garrote & vaca gorda & boi magro \\
\hline 1 & $0,0000 \mathrm{E}+00$ & $1,0000 \mathrm{E}+00$ & $2,4451 \mathrm{E}-01$ & $9,5722 \mathrm{E}-01$ & $2,7605 \mathrm{E}-01$ \\
2 & $2,8104 \mathrm{E}-01$ & $1,4632 \mathrm{E}-01$ & $2,5836 \mathrm{E}-01$ & $1,0966 \mathrm{E}-01$ & $2,7025 \mathrm{E}-01$ \\
3 & $1,4860 \mathrm{E}-02$ & $-3,5339 \mathrm{E}-03$ & $3,0157 \mathrm{E}-02$ & $-1,4493 \mathrm{E}-02$ & $2,3459 \mathrm{E}-02$ \\
4 & $\mathbf{- 8 , 7 6 8 9 \mathrm { E } - 0 3}$ & $-8,2236 \mathrm{E}-03$ & $-9,0805 \mathrm{E}-03$ & $-1,0020 \mathrm{E}-02$ & $-8,0392 \mathrm{E}-03$ \\
5 & $-2,3703 \mathrm{E}-03$ & $-8,9954 \mathrm{E}-04$ & $-2,2179 \mathrm{E}-03$ & $-1,1901 \mathrm{E}-03$ & $-2,2508 \mathrm{E}-03$ \\
6 & $-1,0265 \mathrm{E}-04$ & $1,4514 \mathrm{E}-04$ & $-1,2177 \mathrm{E}-04$ & $7,0472 \mathrm{E}-05$ & $-4,0832 \mathrm{E}-05$ \\
7 & $4,2391 \mathrm{E}-05$ & $3,7987 \mathrm{E}-05$ & $5,7647 \mathrm{E}-05$ & $1,2258 \mathrm{E}-05$ & $5,0248 \mathrm{E}-05$ \\
8 & $9,1088 \mathrm{E}-07$ & $-5,2465 \mathrm{E}-07$ & $3,8466 \mathrm{E}-06$ & $-7,2393 \mathrm{E}-06$ & $5,8557 \mathrm{E}-06$ \\
9 & $-2,9940 \mathrm{E}-06$ & $-2,4312 \mathrm{E}-06$ & $-2,2946 \mathrm{E}-06$ & $-3,9263 \mathrm{E}-06$ & $-2,5636 \mathrm{E}-06$ \\
10 & $-9,2628 \mathrm{E}-07$ & $-2,9123 \mathrm{E}-07$ & $-8,4851 \mathrm{E}-07$ & $-6,0447 \mathrm{E}-07$ & $-6,8269 \mathrm{E}-07$ \\
11 & $-1,0404 \mathrm{E}-07$ & $-6,7836 \mathrm{E}-09$ & $-7,9568 \mathrm{E}-08$ & $-8,4675 \mathrm{E}-08$ & $-7,9027 \mathrm{E}-08$ \\
12 & $-9,6063 \mathrm{E}-09$ & $8,8128 \mathrm{E}-09$ & $-1,9361 \mathrm{E}-09$ & $-1,1492 \mathrm{E}-08$ & $4,7483 \mathrm{E}-09$ \\
\hline
\end{tabular}

Fonte: resultados da pesquisa. 
140.

Tabela A.2.13 - Resposta aos impulsos quando há inovação na variável garrote no modelo VEC para o período de junho de 1982 a maio de 1994

\begin{tabular}{rrrrrr}
\hline & bezerro & boi gordo & garrote & vaca gorda & boi magro \\
\hline 1 & $0,0000 \mathrm{E}+00$ & $0,0000 \mathrm{E}+00$ & $1,0000 \mathrm{E}+00$ & $-2,8245 \mathrm{E}-02$ & $4,0522 \mathrm{E}-01$ \\
2 & $-1,9243 \mathrm{E}-01$ & $-2,4927 \mathrm{E}-01$ & $-3,4319 \mathrm{E}-01$ & $-2,1973 \mathrm{E}-01$ & $-2,3261 \mathrm{E}-01$ \\
3 & $-4,0229 \mathrm{E}-02$ & $-7,7577 \mathrm{E}-03$ & $-2,6646 \mathrm{E}-02$ & $9,4510 \mathrm{E}-04$ & $-4,8835 \mathrm{E}-02$ \\
4 & $5,3208 \mathrm{E}-03$ & $8,0334 \mathrm{E}-03$ & $9,9148 \mathrm{E}-04$ & $1,0048 \mathrm{E}-02$ & $6,6226 \mathrm{E}-03$ \\
5 & $2,6557 \mathrm{E}-03$ & $8,7665 \mathrm{E}-04$ & $3,1451 \mathrm{E}-03$ & $1,0841 \mathrm{E}-03$ & $1,8539 \mathrm{E}-03$ \\
6 & $1,6843 \mathrm{E}-04$ & $6,5624 \mathrm{E}-05$ & $1,0294 \mathrm{E}-04$ & $1,2801 \mathrm{E}-04$ & $3,0848 \mathrm{E}-04$ \\
7 & $-1,9899 \mathrm{E}-05$ & $-7,5831 \mathrm{E}-05$ & $-1,6486 \mathrm{E}-05$ & $-5,8193 \mathrm{E}-05$ & $-7,0704 \mathrm{E}-05$ \\
8 & $-9,9936 \mathrm{E}-06$ & $4,1057 \mathrm{E}-06$ & $-1,4565 \mathrm{E}-05$ & $1,0190 \mathrm{E}-05$ & $-3,9187 \mathrm{E}-06$ \\
9 & $2,7472 \mathrm{E}-06$ & $3,1761 \mathrm{E}-07$ & $2,3303 \mathrm{E}-06$ & $1,5469 \mathrm{E}-06$ & $1,0472 \mathrm{E}-07$ \\
10 & $6,7299 \mathrm{E}-07$ & $7,3439 \mathrm{E}-07$ & $5,6834 \mathrm{E}-07$ & $1,0164 \mathrm{E}-06$ & $9,5395 \mathrm{E}-07$ \\
11 & $1,6673 \mathrm{E}-07$ & $-5,3348 \mathrm{E}-08$ & $1,5281 \mathrm{E}-07$ & $5,6644 \mathrm{E}-09$ & $4,4369 \mathrm{E}-08$ \\
12 & $-3,8251 \mathrm{E}-10$ & $6,5411 \mathrm{E}-09$ & $-6,3061 \mathrm{E}-09$ & $2,3607 \mathrm{E}-08$ & $9,4264 \mathrm{E}-09$ \\
\hline
\end{tabular}

Fonte: resultados da pesquisa.

Tabela A.2.14 - Resposta aos impulsos quando há inovação na variável vaca gorda no modelo VEC para o período de junho de 1982 a maio de 1994

\begin{tabular}{rrrrrr}
\hline & bezerro & boi gordo & garrote & vaca gorda & boi magro \\
\hline 1 & $0,0000 \mathrm{E}+0$ & $0,0000 \mathrm{E}+00$ & $0,0000 \mathrm{E}+0$ & $1,0000 \mathrm{E}+00$ & $-2,5427 \mathrm{E}-02$ \\
2 & $1,7403 \mathrm{E}-01$ & $-3,8501 \mathrm{E}-02$ & $5,2817 \mathrm{E}-03$ & $2,1724 \mathrm{E}-01$ & $-4,0128 \mathrm{E}-02$ \\
3 & $7,3903 \mathrm{E}-02$ & $5,1574 \mathrm{E}-02$ & $5,9007 \mathrm{E}-02$ & $1,1229 \mathrm{E}-01$ & $5,4710 \mathrm{E}-02$ \\
4 & $2,5707 \mathrm{E}-02$ & $7,3232 \mathrm{E}-03$ & $1,9307 \mathrm{E}-02$ & $2,1364 \mathrm{E}-02$ & $1,6293 \mathrm{E}-02$ \\
5 & $4,5360 \mathrm{E}-03$ & $1,1920 \mathrm{E}-03$ & $3,6058 \mathrm{E}-03$ & $4,5770 \mathrm{E}-03$ & $3,0554 \mathrm{E}-03$ \\
6 & $8,5035 \mathrm{E}-04$ & $4,0937 \mathrm{E}-05$ & $5,0175 \mathrm{E}-04$ & $8,8419 \mathrm{E}-04$ & $3,5355 \mathrm{E}-04$ \\
7 & $1,9677 \mathrm{E}-04$ & $5,6293 \mathrm{E}-05$ & $1,2144 \mathrm{E}-04$ & $2,6525 \mathrm{E}-04$ & $9,4550 \mathrm{E}-05$ \\
8 & $6,1885 \mathrm{E}-05$ & $1,9577 \mathrm{E}-05$ & $4,1679 \mathrm{E}-05$ & $7,0097 \mathrm{E}-05$ & $3,3990 \mathrm{E}-05$ \\
9 & $1,6228 \mathrm{E}-05$ & $5,2872 \mathrm{E}-06$ & $1,1918 \mathrm{E}-05$ & $1,7398 \mathrm{E}-05$ & $1,0036 \mathrm{E}-05$ \\
10 & $3,7474 \mathrm{E}-06$ & $9,1092 \mathrm{E}-07$ & $2,6588 \mathrm{E}-06$ & $3,8416 \mathrm{E}-06$ & $2,1644 \mathrm{E}-06$ \\
11 & $8,1767 \mathrm{E}-07$ & $1,9081 \mathrm{E}-07$ & $5,5549 \mathrm{E}-07$ & $9,0793 \mathrm{E}-07$ & $4,4382 \mathrm{E}-07$ \\
12 & $1,9789 \mathrm{E}-07$ & $5,0056 \mathrm{E}-08$ & $1,3129 \mathrm{E}-07$ & $2,2543 \mathrm{E}-07$ & $1,0442 \mathrm{E}-07$ \\
\hline
\end{tabular}

Fonte: resultados da pesquisa.

Tabela A.2.15 - Resposta aos impulsos quando há inovação na variável boi magro no modelo VEC para o período de junho de 1982 a maio de 1994

\begin{tabular}{rrrrrr}
\hline & bezerro & boi gordo & garrote & vaca gorda & boi magro \\
\hline 1 & $0,0000 \mathrm{E}+00$ & $0,0000 \mathrm{E}+00$ & $0,0000 \mathrm{E}+00$ & $0,0000 \mathrm{E}+00$ & $1,0000 \mathrm{E}+00$ \\
2 & $-2,6414 \mathrm{E}-01$ & $-4,5473 \mathrm{E}-01$ & $-2,6073 \mathrm{E}-01$ & $-4,3298 \mathrm{E}-01$ & $-4,9741 \mathrm{E}-01$ \\
3 & $-7,1157 \mathrm{E}-02$ & $2,5131 \mathrm{E}-02$ & $-8,3794 \mathrm{E}-02$ & $3,8605 \mathrm{E}-02$ & $-3,0802 \mathrm{E}-02$ \\
4 & $1,2165 \mathrm{E}-02$ & $2,5785 \mathrm{E}-03$ & $1,1064 \mathrm{E}-02$ & $4,3342 \mathrm{E}-03$ & $1,4200 \mathrm{E}-03$ \\
5 & $2,4966 \mathrm{E}-03$ & $3,2872 \mathrm{E}-03$ & $2,5502 \mathrm{E}-03$ & $3,5875 \mathrm{E}-03$ & $4,4031 \mathrm{E}-03$ \\
6 & $4,4413 \mathrm{E}-04$ & $-4,2193 \mathrm{E}-04$ & $4,5616 \mathrm{E}-04$ & $-3,8476 \mathrm{E}-04$ & $-7,6705 \mathrm{E}-06$ \\
7 & $-9,8387 \mathrm{E}-05$ & $-2,6133 \mathrm{E}-06$ & $-1,0416 \mathrm{E}-04$ & $2,1511 \mathrm{E}-05$ & $-2,3188 \mathrm{E}-05$ \\
8 & $-2,5579 \mathrm{E}-06$ & $-1,6993 \mathrm{E}-05$ & $-7,0557 \mathrm{E}-06$ & $-1,0967 \mathrm{E}-05$ & $-2,3797 \mathrm{E}-05$ \\
9 & $8,6835 \mathrm{E}-07$ & $5,2843 \mathrm{E}-06$ & $3,1681 \mathrm{E}-07$ & $6,8508 \mathrm{E}-06$ & $3,7808 \mathrm{E}-06$ \\
10 & $1,4280 \mathrm{E}-06$ & $-2,0820 \mathrm{E}-08$ & $1,3139 \mathrm{E}-06$ & $2,4016 \mathrm{E}-07$ & $5,3113 \mathrm{E}-07$ \\
11 & $8,1579 \mathrm{E}-08$ & $1,2391 \mathrm{E}-07$ & $7,5068 \mathrm{E}-08$ & $1,9404 \mathrm{E}-07$ & $1,9852 \mathrm{E}-07$ \\
12 & $1,7119 \mathrm{E}-08$ & $-3,6391 \mathrm{E}-08$ & $8,9448 \mathrm{E}-09$ & $-1,9395 \mathrm{E}-08$ & $-2,3531 \mathrm{E}-08$ \\
\hline
\end{tabular}

Fonte: resultados da pesquisa. 
Tabela A.2.16 - Decomposição da variância para a variável bezerro no modelo VEC para o período de junho de 1982 a junho de 1994

\begin{tabular}{rrrrrr}
\hline & bezerro & boi gordo & garrote & vaca gorda & boi magro \\
\hline 1 & 100,0000 & 0,0000 & 0,0000 & 0,0000 & 0,0000 \\
2 & 96,5688 & 2,1394 & 0,5326 & 0,1188 & 0,6404 \\
3 & 96,4751 & 2,1433 & 0,5553 & 0,1400 & 0,6862 \\
4 & 96,4691 & 2,1451 & 0,5557 & 0,1426 & 0,6875 \\
5 & 96,4688 & 2,1453 & 0,5558 & 0,1427 & 0,6875 \\
6 & 96,4688 & 2,1453 & 0,5558 & 0,1427 & 0,6875 \\
7 & 96,4688 & 2,1453 & 0,5558 & 0,1427 & 0,6875 \\
8 & 96,4688 & 2,1453 & 0,5558 & 0,1427 & 0,6875 \\
9 & 96,4688 & 2,1453 & 0,5558 & 0,1427 & 0,6875 \\
10 & 96,4688 & 2,1453 & 0,5558 & 0,1427 & 0,6875 \\
11 & 96,4688 & 2,1453 & 0,5558 & 0,1427 & 0,6875 \\
12 & 96,4688 & 2,1453 & 0,5558 & 0,1427 & 0,6875 \\
\hline
\end{tabular}

Fonte: resultados da pesquisa.

Tabela A.2.17 - Decomposição da variância para a variável boi gordo no modelo VEC para o período de junho de 1982 a junho de 1994

\begin{tabular}{rrrrrr}
\hline & bezerro & boi gordo & garrote & vaca gorda & boi magro \\
\hline 1 & 63,5688 & 36,4312 & 0,0000 & 0,0000 & 0,0000 \\
2 & 61,3871 & 35,0672 & 1,1327 & 0,0074 & 2,4056 \\
3 & 61,4016 & 35,0344 & 1,1327 & 0,0206 & 2,4107 \\
4 & 61,4004 & 35,0343 & 1,1338 & 0,0208 & 2,4106 \\
5 & 61,4003 & 35,0343 & 1,1338 & 0,0208 & 2,4107 \\
6 & 61,4003 & 35,0343 & 1,1338 & 0,0208 & 2,4107 \\
7 & 61,4003 & 35,0343 & 1,1338 & 0,0208 & 2,4107 \\
8 & 61,4003 & 35,0343 & 1,1338 & 0,0208 & 2,4107 \\
9 & 61,4003 & 35,0343 & 1,1338 & 0,0208 & 2,4107 \\
10 & 61,4003 & 35,0343 & 1,1338 & 0,0208 & 2,4107 \\
11 & 61,4003 & 35,0343 & 1,1338 & 0,0208 & 2,4107 \\
12 & 61,4003 & 35,0343 & 1,1338 & 0,0208 & 2,4107 \\
\hline
\end{tabular}

Fonte: resultados da pesquisa.

Tabela A.2.18 - Decomposição da variância para a variável garrote no modelo VEC para o período de junho de 1982 a junho de 1994

\begin{tabular}{rrrrrr}
\hline & bezerro & boi gordo & garrote & vaca gorda & boi magro \\
\hline 1 & $\mathbf{8 0 , 8 1 7 0}$ & 1,9414 & 17,2416 & 0,0000 & 0,0000 \\
2 & $\mathbf{7 8 , 3 2 9 2}$ & 3,6902 & 17,3086 & $\mathbf{0 , 0 0 0 1}$ & $\mathbf{0 , 6 7 1 8}$ \\
3 & $\mathbf{7 8 , 2 3 4 0}$ & 3,7122 & 17,2986 & $\mathbf{0 , 0 1 4 8}$ & 0,7403 \\
4 & $\mathbf{7 8 , 2 3 1 5}$ & 3,7142 & 17,2965 & $\mathbf{0 , 0 1 6 4}$ & $\mathbf{0 , 7 4 1 4}$ \\
5 & $\mathbf{7 8 , 2 3 1 2}$ & 3,7143 & 17,2965 & 0,0164 & $\mathbf{0 , 7 4 1 5}$ \\
6 & $\mathbf{7 8 , 2 3 1 2}$ & 3,7143 & 17,2965 & 0,0164 & $\mathbf{0 , 7 4 1 5}$ \\
7 & $\mathbf{7 8 , 2 3 1 2}$ & 3,7143 & 17,2965 & 0,0164 & 0,7415 \\
8 & $\mathbf{7 8 , 2 3 1 2}$ & 3,7143 & 17,2965 & 0,0164 & $\mathbf{0 , 7 4 1 5}$ \\
9 & $\mathbf{7 8 , 2 3 1 2}$ & 3,7143 & 17,2965 & 0,0164 & $\mathbf{0 , 7 4 1 5}$ \\
10 & $\mathbf{7 8 , 2 3 1 2}$ & 3,7143 & 17,2965 & 0,0164 & 0,7415 \\
11 & $\mathbf{7 8 , 2 3 1 2}$ & 3,7143 & 17,2965 & 0,0164 & 0,7415 \\
12 & $\mathbf{7 8 , 2 3 1 2}$ & 3,7143 & 17,2965 & 0,0164 & 0,7415 \\
\hline
\end{tabular}

Fonte: resultados da pesquisa. 
Tabela A.2.19 - Decomposição da variância para a variável vaca gorda no modelo VEC para o período de junho de 1982 a junho de 1994

\begin{tabular}{rrrrrr}
\hline & bezerro & boi gordo & garrote & vaca gorda & boi magro \\
\hline 1 & 63,7697 & 31,2749 & 0,0145 & 4,9409 & 0,0000 \\
2 & 61,9332 & 30,2165 & 0,8482 & 4,9343 & 2,0679 \\
3 & 61,9126 & 30,1741 & 0,8468 & 4,9855 & 2,0810 \\
4 & 61,9090 & 30,1744 & 0,8485 & 4,9872 & 2,0810 \\
5 & 61,9088 & 30,1743 & 0,8485 & 4,9873 & 2,0811 \\
6 & 61,9088 & 30,1743 & 0,8485 & 4,9873 & 2,0811 \\
7 & 61,9088 & 30,1743 & 0,8485 & 4,9873 & 2,0811 \\
8 & 61,9088 & 30,1743 & 0,8485 & 4,9873 & 2,0811 \\
9 & 61,9088 & 30,1743 & 0,8485 & 4,9873 & 2,0811 \\
10 & 61,9088 & 30,1743 & 0,8485 & 4,9873 & 2,0811 \\
11 & 61,9088 & 30,1743 & 0,8485 & 4,9873 & 2,0811 \\
12 & 61,9088 & 30,1743 & 0,8485 & 4,9873 & 2,0811 \\
\hline
\end{tabular}

Fonte: resultados da pesquisa.

Tabela A.2.20 - Decomposição da variância para a variável boi magro no modelo VEC para o período de junho de 1982 a junho de 1994

\begin{tabular}{rrrrrr}
\hline & bezerro & boi gordo & garrote & vaca gorda & boi magro \\
\hline 1 & 81,4150 & 2,8192 & 3,2255 & 0,0035 & 12,5369 \\
2 & 77,6651 & 4,8434 & 3,7620 & 0,0106 & 13,7189 \\
3 & 77,6009 & 4,8571 & 3,7998 & 0,0246 & 13,7176 \\
4 & 77,5992 & 4,8586 & 3,8001 & 0,0259 & 13,7161 \\
5 & 77,5989 & 4,8588 & 3,8002 & 0,0259 & 13,7162 \\
6 & 77,5989 & 4,8588 & 3,8002 & 0,0259 & 13,7162 \\
7 & 77,5989 & 4,8588 & 3,8002 & 0,0259 & 13,7162 \\
8 & 77,5989 & 4,8588 & 3,8002 & 0,0259 & 13,7162 \\
9 & 77,5989 & 4,8588 & 3,8002 & 0,0259 & 13,7162 \\
10 & 77,5989 & 4,8588 & 3,8002 & 0,0259 & 13,7162 \\
11 & 77,5989 & 4,8588 & 3,8002 & 0,0259 & 13,7162 \\
12 & 77,5989 & 4,8588 & 3,8002 & 0,0259 & 13,7162 \\
\hline
\end{tabular}

Fonte: resultados da pesquisa. 